2004 Volume 9

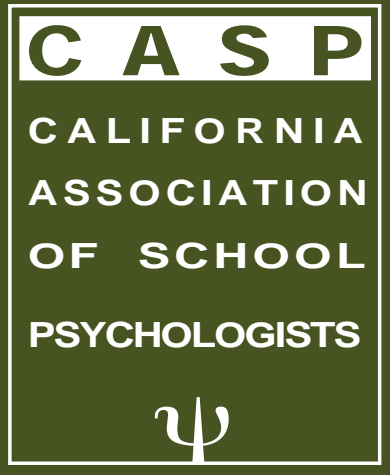

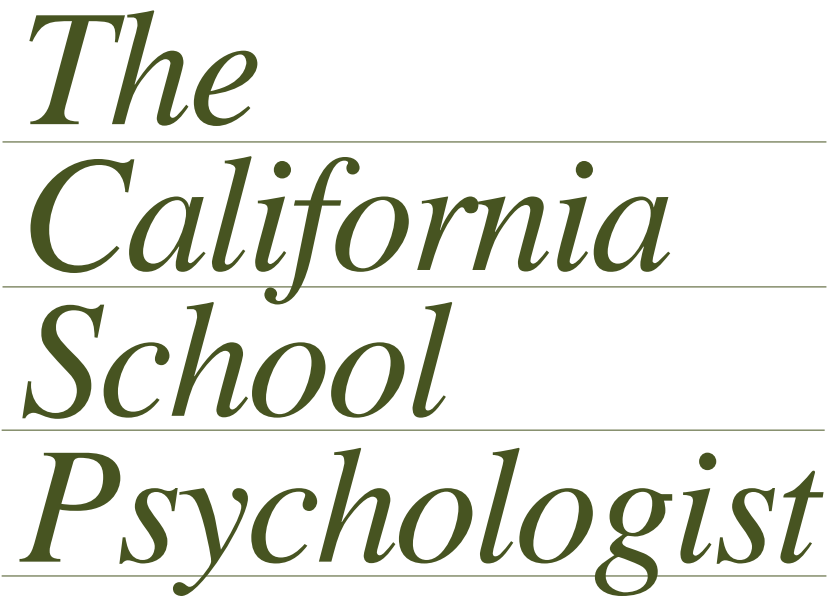

Includes a Special Topic Section:

Strength-Based Assessment, Youth Development, and School Success 


\title{
The California School Psychologist
}

\author{
EDITOR \\ Shane R. Jimerson \\ University of California, Santa Barbara

$\begin{array}{ccc}\text { Brent Duncan } & \text { ASSOCIATE EDITORS } & \text { Michael Furlong } \\ \text { Humboldt State University } & \text { University of California, Santa Barbara }\end{array}$

EDITORIAL ADVISORY BOARD

John Brady
Chapman University
Stephen Brock
California State University, Sacramento
Susan Bryner
Clovis Unified School District
Valerie Cook-Morales
San Diego State University
Leslie Cooley
California State University, Sacramento
Barbara D'Incau
University of California, Santa Barbara
Jean Elbert
California State University, Northridge

Gabrielle Anderson
University of California, Santa Barbara
Rebecca Bell
University of California, Berkeley

John Brady

Chapman University

ia State University, Sacramento

Clovis Unified School District

Valerie Cook-Morales

an Diego State University

Terry Gutkin
San Franciso State University
Kristi Hagans-Murillo
California State University, Long Beach
Meri Harding Storino
Sonoma State University
Carolyn Hartsough
University of California, Berkeley
Michael Hass
Chapman University
Bonnie Ho
California State University, Hayward
Lee Huff

Huntington Beach Unified High School District

Colette Ingraham

San Diego State University

\section{STUDENT EDITORIAL PANEL}

Amber Kaufman
University of California, Santa Barbara
Stacy L. O'Farrell
University of California, Santa Barbara

\author{
Brian Leung \\ Loyola Marymount University \\ Kristin Powers \\ California State University, Long Beach \\ Jonathan Sandoval \\ University of California, Davis \\ Jill Sharkey \\ University of California, Santa Barbara \\ Michael Vanderwood \\ University of California, Riverside \\ Linda Webster \\ University of the Pacific \\ Marilyn Wilson \\ California State University, Fresno
}

\section{CASP BOARD OF DIRECTORS 2003-2004}

President
Bobbie Kohrt
President-Elect
Stephen Brock
Past President
Lynne B. Aung
cretary/Treasurer
Irene Elliott
iate Representative
Patrick Crain

Region I Representative

Melinda Susan

Region II Representative

Connie Hilton

Region III Representative Paul Carlson

Region IV Representative Janet Murdock

Region V Representative Doug Siembieda
Region VI Representative Denise Zuckerman

Region VII Representative Art Reifman

Region VIII Representative Patricia McGovern

Region IX Representative Elena Alvarez

Region X Representative Catherine Christo

Design, Layout, and Formatting of The California School Psychologist 2004, Volume 9 completed by Shane R. Jimerson, Michael J. Furlong, Sarah W. Pletcher, and Amber M. Kaufman at

The Center for School-Based Youth Development, at the University of California, Santa Barbara

Copyright by CASP, 2004 Produced annually by the California Association of School Psychologists. Articles herein printed are the expressions of the author(s) and are neither statements of policy nor endorsements of CASP. Submission of manuscripts for review and consideration for publication in the The California School Psychologist journal are to be mailed directly to the Editor. See Guidelines for Authors on the back cover of this volume for more information. Individuals (other than members) with an annual subscription to CASP Today do not receive The California School Psychologist as part of their subscription. Individual copies of The California School Psychologist are available for $\$ 20.00$.

ISSN: 1087-3414

\section{CASP OFFICE}

Suzanne Fisher, Executive Director

1400 K Street, Suite 311, Sacramento, CA 95814

Phone (916) 444-1595 Fax (916) 444-1597 www.casponline.org 


\section{The California School Psychologist}

\begin{tabular}{|c|c|c|}
\hline \multicolumn{3}{|c|}{ 2004, Volume 9} \\
\hline \multicolumn{3}{|c|}{ CONTENTS } \\
\hline \multicolumn{3}{|c|}{ Editorial } \\
\hline Shane R. Jimerson & $\begin{array}{l}\text { The California School Psychologist Provides Valuable } \\
\text { Information Regarding Strength-Based Assessment, } \\
\text { Youth Development, and School Success }\end{array}$ & 3 \\
\hline \multicolumn{3}{|c|}{ Special Topic Articles } \\
\hline $\begin{array}{l}\text { Shane R. Jimerson } \\
\text { Jill D. Sharkey } \\
\text { Vanessa Nyborg } \\
\text { Michael J. Furlong }\end{array}$ & $\begin{array}{l}\text { Strength-Based Assessment and School Psychology: } \\
\text { A Summary and Synthesis }\end{array}$ & 9 \\
\hline $\begin{array}{l}\text { Jacquelyn A. Buckley } \\
\text { Michael H. Epstein }\end{array}$ & $\begin{array}{l}\text { The Behavioral and Emotional Rating Scale-2 (BERS-2): } \\
\text { Providing a Comprehensive Approach to Strength-Based } \\
\text { Assessment }\end{array}$ & 21 \\
\hline $\begin{array}{l}\text { Carien Lubbe } \\
\text { Irma Eloff }\end{array}$ & $\begin{array}{l}\text { Asset-Based Assessment in Educational Psychology: } \\
\text { Capturing Perceptions During a Paradigm Shift }\end{array}$ & 29 \\
\hline $\begin{array}{l}\text { Amanda B. Nickerson } \\
\text { Amy M. Brosof } \\
\text { Valerie B. Shapiro }\end{array}$ & $\begin{array}{l}\text { Predicting Positive Outcomes for Students With } \\
\text { Emotional Disturbance }\end{array}$ & 39 \\
\hline $\begin{array}{l}\text { Paul A. LeBuffe } \\
\text { Valerie B. Shapiro }\end{array}$ & $\begin{array}{l}\text { Lending "Strength" to the Assessment of Preschool } \\
\text { Social-Emotional Health }\end{array}$ & 51 \\
\hline $\begin{array}{l}\text { Oanh K. Tran } \\
\text { Michael J. Furlong }\end{array}$ & $\begin{array}{l}\text { Personal Strengths and Assets Among Adolescents: } \\
\text { A Comparison of Smokers and Nonsmokers }\end{array}$ & 63 \\
\hline $\begin{array}{l}\text { Margaret Libby } \\
\text { Maureen Sedonaen } \\
\text { Jim Kooler }\end{array}$ & $\begin{array}{l}\text { From Deficits to Development: } \\
\text { A Case Study of the Journey of Friday Night Live }\end{array}$ & 79 \\
\hline Joel H. Brown & Resilience: From Program to Process & 89 \\
\hline $\begin{array}{l}\text { Shane R. Jimerson } \\
\text { Jill D. Sharkey } \\
\text { Michael J. Furlong } \\
\text { Kathryn M. O’Brien }\end{array}$ & $\begin{array}{l}\text { Using the Santa Barbara Assets and Risks Assessment } \\
\text { to Examine the Ecology of Youths Experiencing Behavior } \\
\text { Problems }\end{array}$ & 99 \\
\hline $\begin{array}{l}\text { Merith Cosden } \\
\text { Frances Panteleakos } \\
\text { Lisa Gutierrez } \\
\text { Sivan Barazan } \\
\text { Elisa Gottheil }\end{array}$ & $\begin{array}{l}\text { Strength-Based Assessment of Adolescents Who Abuse } \\
\text { Drugs: Implications for Helping High-Risk Youth }\end{array}$ & 115 \\
\hline $\begin{array}{l}\text { E. Scott Huebner } \\
\text { Rich Gilman }\end{array}$ & $\begin{array}{l}\text { Perceived Quality of Life: A Neglected Component of } \\
\text { Assessments and Intervention Plans for Students in } \\
\text { School Settings }\end{array}$ & 127 \\
\hline \multicolumn{3}{|c|}{ General Articles } \\
\hline $\begin{array}{l}\text { Aimee P. Miltich } \\
\text { Mary Helen Hunt } \\
\text { Joel Meyers }\end{array}$ & $\begin{array}{l}\text { Dropout and Violence Needs Assessment: A Follow-up } \\
\text { Study }\end{array}$ & 135 \\
\hline $\begin{array}{l}\text { Kristin M. Powers } \\
\text { Kristi S. Hagans-Murillo } \\
\text { Alberto F. Restori }\end{array}$ & $\begin{array}{l}\text { Twenty-five Years after Larry P.: The California Response } \\
\text { to Overrepresentation of African Americans in Special } \\
\text { Education }\end{array}$ & 145 \\
\hline
\end{tabular}




\title{
The California School Psychologist Provides Valuable Information Regarding Strength-Based Assessment, Youth Development, and School Success
}

\author{
Shane R. Jimerson \\ University of California, Santa Barbara
}

\begin{abstract}
This issue of The California School Psychologist includes important information regarding strengthbased assessment in facilitating youth development and school success. This collection of articles provides valuable insights that will inform contemporary school psychologists working in the schools, as well as contribute to the foundation and future direction of scholarship in the field of school psychology. Previous articles published in The California School Psychologist, including those in the recent volume addressing school engagement, are available on-line at www.education.ucsb.edu/schoolpsychology.

This volume includes the special topic section on Strength-Based Assessment, Youth Development, and School Success. The Center for School-Based Youth Development at the University of California, Santa Barbara (UCSB) is sponsoring this special section of The California School Psychologist. Resources for this initiative were made possible through a Gevirtz Graduate School of Education - Funds for Excellence Grant from Don and Marilyn Gevirtz. It is the mission of the UCSB Center for School-Based Youth Development to enhance school engagement for all students through strength-based assessment and targeted interventions designed to promote social and cognitive competence. This mission is facilitated through research and development and by increasing the cadre of educators who are knowledgeable about and support a comprehensive and coordinated approach to student support services. Drs. Furlong, Jimerson, Morrison, and Cosden are the UCSB faculty collaborating to establish the Center for School-Based Youth Development. For additional information about the Center, you may visit its website at www.education.ucsb.edu/school-psychology.

Recent trends in scholarship reflect an increasing awareness and emphasis on the connections between strength-based assessment, youth development, and school success. The emerging literature addressing facilitating student strengths and promoting developmental assets highlights the importance of further understanding strength-based assessment. Strength-based assessment is an emerging topic of professional and scholarly interest that warrants further consideration and scrutiny, partially in response to the pervasive use of deficit or problem-oriented assessment strategies and also as a potential mechanism to enhance our understanding of youth development, and promote school success. There are an assortment of powerful influences on developmental trajectories and educational success (e.g., school dropout, violence prevention, and promoting the well-being of students). It is important that school psychologists better understand whether or not incorporating assessments that yield information regarding both the problems and assets that a given youth possesses or has experienced may inform intervention strategies to enhance developmental and educational outcomes. Amidst an era emphasizing "standards and accountability" in education, it is particularly important to consider the dynamic interplay between socio-emotional, behavioral, and cognitive development as they influence academic success and learning. Promoting the social and cognitive competence of all stu-
\end{abstract}


dents is essential in facilitating the academic success of students in schools. This issue of The California School Psychologist journal provides information addressing five broad areas of scholarship: (a) an overview of conceptual considerations regarding strength-based assessment, (b) a review of literature related to strength-based assessment, (c) empirical articles related to strength-based assessment, (d) application articles demonstrating the uses and implications of strength-based assessment strategies for practitioners, and (e) an emphasis on incorporating this information into preparing future professionals.

This volume of The California School Psychologist offers numerous articles that address important aspects of strength-based assessment, youth development, and school success, including: a summary of strength-based assessment as related to the field of school psychology, empirical articles examining various measures that include strength-based dimensions, studies that investigate the association of assets and behaviors among students, reviews of conceptual underpinnings and paradigm shifts, and overviews of programs that incorporated strength-based assessment and aimed at promoting positive youth development. Two additional articles that are included in this volume provide information regarding a dropout and needs assessment, and a particularly thought provoking article addressing how the overrepresentation of African Americans receiving special education services has been navigated in California. The following highlights from each article provide an overview of the topics addressed in this volume.

The first article (Jimerson, Sharkey, Nyborg, \& Furlong, 2004) highlights the increasing interest in positive psychology, and an emerging shift away from the traditional deficit-based model of mental health towards a framework that emphasizes social-emotional strengths. The authors indicate that the building of strengths and an emphasis on the prevention of problems are at the forefront of positive psychology and are likely to be equally important in the field of school psychology. Building upon a review of the extant literature, this article addresses four questions: (a) What is strength-based assessment? (b) Why use strength-based assessment in school psychology? (c) What are examples of strengthbased assessments? and (d) What are the limitations and needs for further research related to strengthbased assessment? The authors discuss the implications for both research and practice.

The second article (Buckley \& Epstein, 2004) emphasizes that few instruments are available to school psychologists that allow for systematic and comprehensive evaluation of a student's emotional and behavioral strengths. The authors discuss the Behavioral and Emotional Ratings Scale (BERS), which was developed in response to the need for a valid and reliable instrument for assessing and evaluating strengths. This article provides valuable information on the restandardized BERS with two additional scales: a parent rating scale and a youth self-report scale. This article discusses: (a) strengthbased assessment in school psychological practice, (b) the development of the BERS-2, and (c) the use of the BERS-2 in school psychological practice.

The third article (Lubbe \& Eloff, 2004) provides a unique international perspective regarding the emerging trend toward a philosophy of assessment that is asset-based and strength focused. This article reports the results from a study that explored perceptions about asset-based assessment in Educational Psychology in South Africa (Educational Psychology in South Africa, as well as other parts of the world, is the term used to describe professionals in the field of School Psychology in the United States). The authors conclude that the results of this study reveal that educational psychologists perceive asset-based assessment as involving: (a) a focus on assets, (b) individual and community level assessment, (c) collaboration skills, and (d) self-reflective skills. The authors conclude that the first three themes are congruent with asset-based conceptual foundations, however, the fourth theme is currently underrepresented in asset-based literature and thus requires further research. 
The fourth article (Nickerson, Brosof, \& Shapiro, 2004) reports on a study of changes in skills for 84 students with emotional disturbance (ED) over a one-year time period in a private special education school, revealing variables that predicted positive outcomes for these students. The authors report that students exhibited improved peer relationships and emotional maturity, and demonstrated several strengths. Results also indicated that the students with ED were unlikely to experience success in less restrictive educational settings. Problem severity, school behavior, and skills for inclusion each predicted positive outcomes, however, none of the variables predicted placement in less restrictive educational settings. The authors highlight the importance of using strength-based approaches, in addition to using empirically supported interventions,

The fifth article (LeBuffe \& Shapiro, 2004) examines the advantages of a strength-based perspective relative to the a pathology-based approach to assessment. The authors suggest theoretical advantages to strength-based assessment, including greater compatibility with early prevention efforts and increased acceptance by multiple stakeholders. The Devereux Early Childhood Assessment (DECA) is discussed as a measure of within-child protective factors in preschoolers, and used to empirically validate the utility of strength-based assessment. The authors report that the DECA discriminates between groups of preschoolers with and without emotional and behavior problems and the DECA assessment of protective factors predicted behavioral concerns as well as a standardized assessment of risk. The authors suggest that a strength-based perspective and the resilience model have great utility for universal use with preschool populations.

The sixth article (Tran \& Furlong, 2004) reports on a study that examined protective factors and personal strengths in 386 adolescents as part of a high school Tobacco Use Prevention Education (TUPE) program funded by the California Department of Education. Results indicated a significant relationship between gender, smoking status, and personal strengths with smokers having lower levels of personal strengths. The authors suggest that cessation programs consider smoking within the context of youths' personal assets and their social support network. The authors also encourage school support services professionals to contribute to prevention efforts by attending to smoking behavior and its correlates when they are involved in assessments, consultation, or direct counseling with students.

The seventh article (Libby, Sedonaen, \& Kooler, 2004) describes the efforts and outcomes of the Youth Leadership Institute and the California Friday Night Live Partnership (a statewide prevention program serving over 800,000 youths). This collaborative initiative set out to transform its statewide network of local prevention programs by shifting from a problem, or deficit, orientation to an approach that links effective and innovative prevention strategies with positive youth development research and best practice. The authors describe the research that informed the shift and the collaboration that brought it about. Results from the project indicate that youth participants experience many of the supports and opportunities that research has linked to positive developmental outcomes.

The eighth article (Brown, 2004) explores school engagement from a resilience perspective. Despite a 40-year research legacy, only recently have practitioners/researchers engaged in the explicit, prospective facilitation of resilience in school settings. Based on supporting theory and evidence, a process-based model is advanced to promote the explicit, prospective facilitation of resilience in school settings. The author suggests that Resilience Education (ReSed) is conducted by balancing a global youth development orientation with the specificity of supporting protective factor development. The author refers to preliminary evidence suggesting high satisfaction and internalization of the model by workshop participants. The author also suggests that ReSed offers a promising model of how "resilience" occurs, not solely as an outcome, but as a moment-to-moment learning and development process. 
The ninth article (Jimerson, Sharkey, Furlong, \& O'Brien, 2004) provides a review of important factors and considerations among youths displaying behavior problems and also reports the results of a study that examined the predictive validity of the Santa Barbara Assets and Risks Assessment (SB ARA) with 566 European American and Mexican American high-risk adolescents. The authors suggest that the results of this study provide evidence that the SB ARA has adequate predictive validity of recidivism. The authors highlight that the SB ARA provided prediction of recidivism, 12 months following assessment, for both females and males, revealing a different set of indicators by gender. The authors propose that the SB ARA is appropriate to use with males and females, and provides valuable information in understanding youths displaying behavior problems.

The tenth article (Cosden, Panteleakos, Gutierrez, Barazan, \& Gottheil, 2004) describes the use of two strength-based assessment procedures with adolescents who have serious drug problems. The youths in this study were participants in a drug treatment court, that allowed them to remain at home and to attend their neighborhood schools. This paper examines different methods of using strengthbased assessments. In Study 1, assessments are used to identify students' competencies and determine which of these factors were related to youth outcomes. In Study 2, a case study is presented in which strength-based assessments are used at the individual level to develop specific treatment plans. The authors also discuss the current state of the field, and future challenges for effective utilization of the strength-based approach to assessment and intervention.

The eleventh article (Huebner \& Gilman, 2004) explores the relevance and contribution of the construct of quality of life to assessments and intervention plans for children and youth in school settings. The authors review theory, measurement, and research related to perceived quality of life (PQOL) and suggest that PQOL information contributes incremental validity above and beyond traditional deficit-based information. The authors also suggest that the use of PQOL in assessments, treatment planning, and monitoring of the well-being of students in school settings warrants further consideration to provide more comprehensive assessment-intervention activities.

The twelfth article (Miltich, Hunt, \& Meyers, 2004) investigated a needs assessment survey designed to measure perceptions of causes of dropout and school violence and related interventions. The needs assessment was conceptualized as a first step to be taken by schools to facilitate program planning, school-based implementation and acceptability of programs designed to prevent school violence and dropout. The results compare survey administration in Michigan with an original sample in Georgia. The authors suggest that the results supported the five-factor model proposed in the initial research (e.g., School Connectedness, Causes of Disruptive of Violent Behavior, Causes of School Disengagement/Dropout, Interventions for Violence, and Interventions for Dropout). The authors discuss implications for future use of adapted versions of this needs assessment survey in developing effective preventive interventions.

The thirteenth article (Powers, Hagans-Murillo, \& Restori, 2004) reviews major laws, regulations, court cases, policies and practices related to intelligence testing of African American students in California. The authors examine the California Department of Education (CDE) ban on intelligence testing of African American students for the purpose of determining special education eligibility [enforced by Special Education Hearing Officers (SEHO) and Coordinated Compliance Reviewers (CCR)]. Although the CDE bases its restrictions on the results of the Larry P. case, the authors contend that (a) the CDE policy runs counter to the ruling and intent of the Larry P. case, (b) overrepresentation of African Americans in special education programs continues despite the use of alternative assessment methods to measure intelligence, and (c) overrepresentation of African Americans in special education is not the result of intelligence test bias, rather, more endemic socio-political inequalities. The authors also discuss three critical questions to be considered in future responses to the Larry P. court case. 
The collection of articles in this volume provide a wealth of information that may be used by educational professionals working with children, families, and colleagues to enhance the academic success and promote positive developmental trajectories of students. The use of strength-based assessment warrants further consideration by both practitioners and scholars. There is the potential for tremendous contributions for facilitating the development of youths. The authors of the manuscripts in this volume offer numerous insights and review the extant literature that is necessary to advance our understanding of strength-based assessment. In addition, it is anticipated that the manuscript addressing policies and practices related to intelligence testing of African American students in California will serve as a catalyst for further discussion and scholarship related to this particularly important topic. The California School Psychologist provides valuable information regarding strength-based assessment, youth development, and school success.

\section{REFERENCES}

Brown, J. H. (2004). Resilience: From program to process. The California School Psychologist, 9, 89-98.

Buckley, J. A., \& Epstein, M. H. (2004). The Behavioral and Emotional Rating Scale - 2 (BERS-2): Providing a comprehensive approach to strength-based assessment. The California School Psychologist, 9, 21-27.

Cosden, M., Panteleakos, F., Gutierrez, L., Barazan, S., \& Gottheil, E. (2004). Strength-based assessment of adolescents who abuse drugs: Implications for helping high-risk youth. The California School Psychologist, 9, 115-126.

Huebner. E., \& Gilman, S. (2004). Perceived quality of life: A neglected component of assessment and intervention plans for students in school settings. The California School Psychologist, 9, 127-134.

Jimerson, S. R., Sharkey, J. D., Furlong, M. J., \& O'Brien, K. M. (2004). Using the Santa Barbara Assets and Risks Assessment to examine the ecology of students experiencing behavior problems. The California School Psychologist, 9, 99-113.

Jimerson, S. R., Sharkey, J. D., Nyborg, V., \& Furlong, M. J. (2004). Strength-based assessment and school psychology: A summary and synthesis. The California School Psychologist, 9, 9-19.

LeBuffe, P. A., \& Shapiro, V. A. (2004). Lending "strength" to the assessment of preschool social-emotional health. The California School Psychologist, 9, 51-61.

Libby, M., Sedonaen, M., \& Kooler, J. (2004). From deficits to development: A case study of the journey of Friday Night Live. The California School Psychologist, 9, 79-87.

Lubbe, C., \& Eloff, I. (2004). Asset-based assessment in educational psychology: Capturing perceptions during a paradigm shift. The California School Psychologist, 9, 29-38.

Miltich, A. P., Hunt, M. H., \& Meyers, J. (2004). Dropout and violence needs assessment: A follow-up study. The California School Psychologist, 9, 135-144.

Nickerson, A. B., Brosof, A. M., \& Shapiro, V. B. (2004). Predicting positive outcomes for students with emotional disturbance. The California School Psychologist, 9, 39-49.

Powers, K. M., Hagans-Murillo, K. S., \& Restori, A. F. (2004). Twenty-five years after Larry P.: The California response to overrepresentation of African Americans in special education. The California School Psychologist, 9, 145-158.

Tran, O. K., \& Furlong, M. J. (2004). Personal strengths and assets among adolescents: A comparison of smokers and nonsmokers. The California School Psychologist, 9, 63-77. 
The California School Psychologist, 2004, Vol. 9 


\title{
Strength-Based Assessment and School Psychology: A Summary and Synthesis
}

\author{
Shane R. Jimerson, Jill D. Sharkey, Vanessa Nyborg, Michael J. Furlong \\ University of California, Santa Barbara
}

\begin{abstract}
During the past decade there has been an increasing interest in positive psychology, which promotes a shift away from the traditional deficit-based model of mental health to a framework that emphasizes social-emotional strengths. The building of strengths and an emphasis on the prevention of problems are at the forefront of positive psychology and equally important in the field of school psychology. Based on a review of the extant literature, this article addresses four important questions: (a) What is strength-based assessment? (b) Why use strength-based assessment in school psychology? (c) What are examples of strength-based assessments? and (d) What are the limitations and needs for further research related to strength-based assessment? Implications for both research and practice are emphasized throughout.
\end{abstract}

Key Words: Strength-Based, Assessment, School, Deficits, Assets, Strengths

Modern psychology has been co-opted by the disease model. We've become too preoccupied with repairing damage when our focus should be on building strength and resilience, especially in children. (Seligman, 2003)

In the new millennium, school psychologists have increasingly recognized alternatives to a deficit-based perspective regarding assessment, practice, and research that emerged from the historical disease model of human functioning pervasive in the field of psychology (Buckley, Storino, \& Saarni, 2003; Rhee, Furlong, Turner, \& Harari, 2001; Terjesen, Jacofsky, Froh, \& DiGiuseppe, 2004). The recent zeitgeist in the field of psychology includes an emphasis on positive psychology (Huebner \& Gilman, 2003; Seligman \& Csikszentmihalyi, 2000; Seligman, Reivich, Jaycox, \& Gillham, 1995) and the perspective that wellness is more than the absence of disease symptoms. Positive psychology advocates a change from a preoccupation with solely repairing the worst things in life to also building the best qualities in life (Seligman, 2002). Thus, the building of strengths and an emphasis on the prevention of problems are at the forefront of positive psychology (Seligman \& Peterson, 2000). Likewise, the emerging emphasis on promoting "developmental assets" has focused on the strengths of youths, families, and communities (Scales \& Leffert, 1999). Scales and Leffert (1999) describe developmental assets as "the positive relationships, opportunities, competencies, values, and self-perceptions that youth need to succeed" (p. 1). School psychologists have long endorsed strength-based perspectives (e.g., Lambert, 1964), and during the past decade, there has been a growing recognition and an emphasis to embrace this perspective that is promoted among some school psychology practitioners and researchers (Baker, Dilly, Aupperlee, \& Patil, 2003; Chafouleas \& Bray, 2004; Doll \& Lyon, 1998; Miller, 1998; Nettles, Mucherah, \& Jones, 2000; Rhee et al., 2001; Robertson, Harding, \& Morrison, 1998; Smokowski, Reynolds, \& Bezruczko, 1999; Terjesen et al., 2004).

Wieck, Rapp, Sullivan, and Kisthardt (1989) coined the term "strengths perspective" as a framework to view youths and families with greater emphasis on their strengths and competencies. The use of this approach is increasing in many disciplines and practices (Rapp, 1997; Seligman, 2002; Seligman

Funding for the development of this manuscript was provided in part by the Don and Marilyn Gevirtz Funds for Excellence initiative. Address correspondence to Shane R. Jimerson; University of California, Santa Barbara; Gevirtz Graduate School of Education; Center for School-Based Youth Development; 2208 Phelps Hall; Santa Barbara, CA 93106-9490. E-mail: jimerson@education.ucsb.edu. 
\& Csikszentmihalyi, 2000). For example, a strength-based approach has been evident in the mental health field (e.g., constructive therapies; Hoyt, 1996), medical field (e.g., wellness vs. illness), community-level advocacy (e.g., asset-based storehouses vs. wastelands; Kretzman \& McNight, 1993), and prevention and education research (e.g., resilience and hardiness; see reviews by Anthony, 1987; Butler, 1997; Cowan, Cowan, \& Schultz, 1996; Gore \& Eckenrode, 1994; Kaplan, 1999; Masten, Best, \& Garmezy, 1990; Mrazek \& Haggerty, 1994; Rutter, 1990). The purpose of this article is to explore the following questions: (a) What is strength-based assessment? (b) Why use strength-based assessment in school psychology? (c) What are examples of strength-based assessments? and (d) What are the limitations and needs for further research related to strength-based assessment?

\section{What is Strength-Based Assessment?}

Developmental trajectories cannot be fully understood without an integrated focus on pathology and competence (Masten \& Coatsworth, 1995) and research has shown that youths' strengths are as important to consider as their weaknesses in understanding potential for succeeding in all areas of functioning (Garmezy, 1993; Kirby \& Fraser, 1997). Whereas not all children who experience significant risk ultimately experience negative outcomes, most children who have a variety of strengths experience healthy outcomes (e.g., Masten, Hubbard, Gest, Tellegen, Garmezy, \& Ramirez, 1999). However, much of the practice of identifying students' needs is based on a deficit model, which focuses on problems such as processing deficits, poor achievement, and social-emotional difficulties in order to prescribe intervention programs. The availability of many psychometrically sound instruments to assess mental illness and disability sustains this deficit focus (Epstein, 1999). Though psychologists, social workers, and counselors have developed informal approaches for strength-based assessment, the empirical validation of assessments examining youth strengths is in its early stages.

Subtle but significant differences between various terms associated with resiliency need to be carefully defined in order to clarify various phenomena under study. Terms such as "risk factors," "protective factors," "assets," and "resilience" all represent distinct mechanisms that are often associated with particular models proposed to explain resilience. A risk factor is any influence in a youth's life, whether biological, behavioral, environmental, sociocultural, or demographic, that increases the probability of a negative outcome. On the other hand, a protective factor is defined as any influence in a youth's life that decreases the probability of a negative outcome (Kirby \& Fraser, 1997). Stress is a condition resulting from an individual's perceived inability to meet life demands that threatens the ability of the individual to function successfully (Masten et al., 1999). Asset, resource, or promotive factors increase positive developmental outcomes and decrease negative developmental outcomes regardless of adversity or risk (Leffert, Benson, Scales, Sharma, Drake, \& Blyth, 1998; Sameroff \& Fiese, 2000). A buffer is a factor that is only associated with a positive outcome in the presence of risk (Gore \& Eckenrode, 1994). Resilience represents successful adaptation in the face of adversity (Masten et al., 1999). The development of so many similar yet distinct terms is a result of the many theoretical models developed to explain the phenomenon of resiliency.

As the development and application of strength-based instruments and assessment strategies continues, MacDonald and Validivieso (2000) offer a framework for categorizing factors related to desirable outcomes in a youth's life: (a) Aspects of identity-self-confidence, connection, commitment to others, self-worth, mastery and future orientation, belonging and membership, responsibility, spirituality, and self-awareness. (b) Areas of ability — physical health, mental health, intellectual, employment, civic, as well as social and cultural abilities. (c) Developmental opportunities-for exploration, 
expression and creativity, adult roles and responsibilities such as group membership, contribution and service, and employment. (d) Emotional, motivational, strategic supports—nurturance and friendship, high expectations, standards and boundaries, options assessment and planning, and access to resources.

Many different models explaining the relative influences of risk and protective factors have been proposed; however, as a relatively new concept, little research has been conducted to critically examine existing models. According to an Additive Model or Compensatory Model, risk and protective factors are cumulative in nature, with each additional risk factor increasing the odds of a negative outcome and each additional protective factor decreasing the odds of a negative outcome (Garmezy, 1993). Under this model, the number of risk and protective factors is more important than the specific type of factor. An alternative, the Interactive Model or Risk-Protective Model, states that protective factors only come into play in the presence of risk factors. Under this model, positive parenting practices, for example, have their maximum impact only in the presence of a stressful experience such as poverty or divorce. Thus, protective factors may only buffer, interrupt, or prevent the effect of risk factors (Rutter, 2000). More recent conceptualizations of resilience have combined elements of the Additive and the Interactive models. The Protective-Protective Model proposes that it is both the presence and number of protective factors that is significant in reducing risk (Hollister-Wagner, Foshee, \& Jackson, 2001). On the other hand, the Challenge Model posits that moderate levels of risk promote successful adaptation to stress, whereas low levels do not promote enough stress for action and high levels are overwhelming (O'Leary, 1998). O'Leary comments that it is the successful overcoming of challenge that results in the attainment of resilience, and in some cases, thriving.

At least four distinct but related conceptual models emerge from the literature to detail the specific influence of positive factors on outcome. First, psychologists have long had an interest in the support and promotion of psychological well-being (Lucas, Diener, \& Suh, 1996). This model examines one's global sense of quality of life and is related to school psychology in psychological states such as happiness. Promoting happiness is one way to reduce the likelihood of negative outcomes for children. Huebner, in particular, has developed the Multidimensional Student Life Satisfaction Survey based upon this strength-based model (Gilman \& Huebner, 2003; McCullough \& Huebner, 2003). A second way that strength-based assessment has been conceptualized is as of an examination of positive traits, for example, intellectual functioning and athleticism are traits that can be developed and utilized to enhance a student's well-being. Such a model falls within the body of work related to the assessment constructs such as social-emotional intelligence (e.g., Ciarrochi, Chan, \& Bajgar, 2001) and self-efficacy (e.g., Muris, 2001). As such, it examines the positive traits of individual youths and the development of their character; that is, these have been called "character strengths" and are valued regardless of their relationship to negative developmental outcomes. For example, when asked, adolescents indicate that leadership, practical intelligence, wisdom, social intelligence, love of learning, spirituality, and the capacity to love and be loved are traits that they value (Steen, Kachorek, \& Peterson, 2003). Third, some strength-based assessment approaches have focused on those within-youth traits that help them to manage and cope with risks and life challenges (e.g., Ewart, Jorgensen, Suchday, Chen, \& Matthews, 2002). A fourth way in which strength-based assessment has been considered is as protective factor-those factors outside the individual child such as family functioning, peer relationships, and community factors that can also provide a buffer to risk. Bonnie Benard offers such a model (Brown, D'Emidio-Caston, \& Benard, 2000) and it provides the conceptual basis for the Resilience Youth Development Module of the California Healthy Kids Survey (see www.wested.org/pub/docs/ chks_samplereports.html\#resilience). 


\section{Why use a Strength-Based Approach in Assessment in School Psychology?}

The profession of psychology is oriented toward the study of human behavior and cognition with the goal of improving the human experience. Historically, however, psychologists have focused on the study of abnormal development and psychopathology while ignoring the study of what factors improve academic, cognitive, and social functioning (Terjesen et al., 2004). Though in its infancy, the strengths movement has been a catalyst for the development of assessment and intervention practices based on positive youth development. Using a strength-based focus in work with youth, school psychologists can better meet the standards of their profession by fostering youths' "capacity-building" to cope with life challenges.

Although strengths are emphasized as an important component of Individualized Education Plan (IEP) processes, school psychologists continue to focus on deficits as mandated by federal and state regulations to assess areas of disability and deficits, with no comparable requirement to assess student strengths (Rhee et al., 2001). Focusing on deficits may allow school psychologists to diagnose disabilities, but such practice does not inform intervention and treatment approaches. In contrast, it is argued that identifying areas of strength to capitalize upon, such as fostering motivation or nurturing confidence, may promote addressing underlying problems as opposed to simply altering observable behaviors (Terjesen et al., 2004). Further, when using strength-based assessments, school psychologists recognize the importance of ecological and contextual variables, which may lead to a deeper, and arguably, a more appropriate understanding of youths and their resources. Unique information may be gleaned from a closer inspection of a youth's strengths that, in turn, facilitates comprehensive intervention planning (Rhee et al., 2001).

Strength-based assessment can promote a positive arena for school psychologists, teachers, and families to monitor student performance and communicate with success. The endorsement of strengths can empower children and families to take responsibility and navigate their own life experiences (Rhee et al., 2001). In addition, school personnel benefit personally from implementing such an approach through increased optimism, hope, and motivation for change that comes from examining strengths and competencies rather than feeling overwhelmed and hopeless by a focus on multiple problems (Clark, 1999; Constantine, Benard, \& Diaz, 1999).

A strength-based approach to assessment enhances the practice of school-based consultation, collaboration, and intervention. As reflected in state standards, school psychologists have a responsibility to provide developmental support and opportunities to boost functioning in students (Rhee et al., 2001). As Rhee and colleagues point out, The National Association of School Psychologists (NASP) Training Standard 2.7-Prevention, Crisis Intervention, and Mental Health states that "school psychologists provide or contribute to prevention and intervention programs that promote mental health and physical well-being of students." Additionally, California Commission on Teacher Credentialing-Pupil Personnel-School Psychology Specialization Standard 21-Wellness Promotion, Crisis Intervention, and Counseling, maintains that "candidates are prepared to help design, implement and evaluate wellness, prevention, intervention, and other mental health programs" (Rhee et al., 2001).

One particularly appealing application of the strength-based approach is in the identification of keystone variables, which when targeted for intervention are likely to have a broad impact on the positive functioning of a student after consideration of their particular constellation of behavior (Barnett, Bauer, Ehrhardt, Lentz, \& Stollar, 1996). Specifically, Barnett and colleagues define keystone variables as pivotal in deflecting a constellation of behavior toward the positive, resulting in associated benefits from personal, peer, and adult viewpoints, and providing foundational skills for future development. Though relatively simple to identify and teach, keystone variables have a profound impact on 
changing the trajectory of ongoing problems while preventing the development of future difficulties. Examples of keystone variables include foundational skills (e.g., study skills and social skills) and environmental conditions (e.g., parental communication and adult mentoring).

\section{What are Examples of Strength-Based Assessments?}

As psychologists have begun to examine aspects of positive psychology more critically, various instruments have been developed for research and clinical practice. Epstein and Sharma (1998) define strength-based assessment as:

...the measurement of those emotional and behavioral skills, competencies, and characteristics that create a sense of personal accomplishment; contribute to satisfying relationships with family members, peers, and adults; enhance one's ability to deal with adversity and stress; and promote one's personal, social, and academic development. (p. 3)

A variety of instruments are available to objectively assess variables related to strengths and resiliency among youth. Brief overviews of selected strength-oriented assessments are provided in the following table as an introduction to a sampling of such measures.

\section{What are Limitations and Needs Related to Strength-Based Assessment?}

Strength-based assessment and intervention practices are based on strength building, rather than deficiency focused and, when included in a multidimensional assessment, allow for a more "balanced" approach to viewing youth development. Moreover, employing this approach to assessment enhances the practice of school-based consultation, collaboration, and intervention. Despite the intuitive benefits of seeking enriched information about the strengths of children, it is acknowledged that there is little empirical data examining available strength oriented measures (e.g., BERS and CHKS) in promoting positive youth development. Only recently have studies began to more rigorously examine these "strength-based" instruments' ability to reliably assess positive indicators and predict positive youth outcomes (Scales et al., 2000). Furthermore, as school psychologists expand their use of strengthbased assessment resources, it is essential that they base practice on more than ideological preferences; thus, further research is necessary to clarify and delineate the value of assessing strengths and the models, paradigms, or theories that drive their use.

Though longitudinal studies have examined the relative influences of measured risk and protective factors on targeted developmental outcomes, there is limited research examining the relative merits and limitations of a strength-based approach to assessment in the school context. Further research investigating the value-added of considering strengths, in addition to risk factors is essential. Likewise, often the focus of related research has examined the value of predicting problems; however, a strength-based approach suggests that it is desirable to examine positive outcomes as well. While positive psychology has appealed to many scholars and professionals, there is limited empirical investigation that delineates the merits of this perspective in working with children or families. Further research explicating how strengths can be used to facilitate positive youth development is important. That is, to enhance school psychology assessment practices, evidence is needed that a strength-based assessment that considers a balance of student needs and skills, provides more comprehensive and meaningful information than traditional deficit-focused models. Ultimately, strength-based assessments must be more than a set of loosely arranged principles or assessment practices, and organized by models that lead to better understanding of all students.

As school psychologists expand their application of strength-based perspectives, it is important that they maintain an open mind about what these approaches encompass. The work of Daleiden, 
Table 1.

A Sample of Strength-Based Measures

\begin{tabular}{|c|c|c|}
\hline Measure & Strength-Based Subscales & Reliability \\
\hline $\begin{array}{l}\text { Behavioral } \\
\text { Assessment Scale } \\
\text { (BASC) } \\
\text { (Reynolds \& } \\
\text { Kamphaus, 1992) }\end{array}$ & $\begin{array}{l}\text { Respondent: Parent, Teacher, } \\
\text { Self } \\
\text { Parent and Teacher forms: } \\
\text { Adaptive scale, included } \\
\text { items that measure } \\
\text { Adaptability, Leadership, } \\
\text { Social Skills, and Study } \\
\text { Skills } \\
\text { Self-report form: Adaptive } \\
\text { scale includes items that } \\
\text { measure Relations with } \\
\text { Parents, Interpersonal } \\
\text { Relations, Self-Esteem, and } \\
\text { Self-Reliance }\end{array}$ & $\begin{array}{l}\text { Internal consistency } \\
\text { alpha coefficients } \\
\text { ranged from } .80 \text { to } \\
.90\end{array}$ \\
\hline
\end{tabular}

Behavioral and

Emotional Rating

Scale (BERS)

(Epstein \& Sharma, 1998)

\section{California Healthy \\ Kids Survey- \\ Resilience Youth \\ Development \\ Module (RYDM) \\ (Constantine et al., 1999)}

\section{Respondent: Primary Caregiver, Self (BERS-2)}

All forms: Interpersonal Strengths, Affective Strength, Family Involvement, School Functioning, Intrapersonal Strengths
Internal consistency alpha coefficients $=$ .98

Test-retest $=.99$ Interrater reliability ranged from .83 to .98

\section{Respondent: Self}

Externally-situated strengths (e.g., the presence of caring relationships, high expectations, and opportunities to participate in
Concurrent Validity

Correlations between the BASC Teacher form and the TRF competence subscales ranged from .52 to .82

Correlations between the BASC Parent form and the Child Behavior Checklist (CBCL) competence subscales ranged from .40 to .68

Correlations between the BASC Self form and the Youth Self Report competence subscales ranged from .15 to .39

Correlations between BERS subscales and the Teacher Report Form (TRF) competence subscales ranged from .29 to .73

Correlations between BERS and the SSRS Social Skills correlations ranged from .46 to .73 and Academic Competence ranged from .50 to .72 meaningful activities) and

Internally-situated strengths (e.g., social competence, autonomy, sense of meaning, and purpose)
Correlations between RYDM and the Multidimensional Life Satisfaction Scale ranged from .43 to .66

Correlations between RYDM and the Extended Life Orientation Test were .56
Internal consistency alpha coefficients ranged from .55 to .88

The exception to this was the Meaningful Participation in the Community subscale, which had "low reliability and new items were [subsequently] written to be assessed in the next phase of the field test" (Constantine et al., 1999, p. 7). 
Table 1 continued.

A Sample of Strength-Based Measures

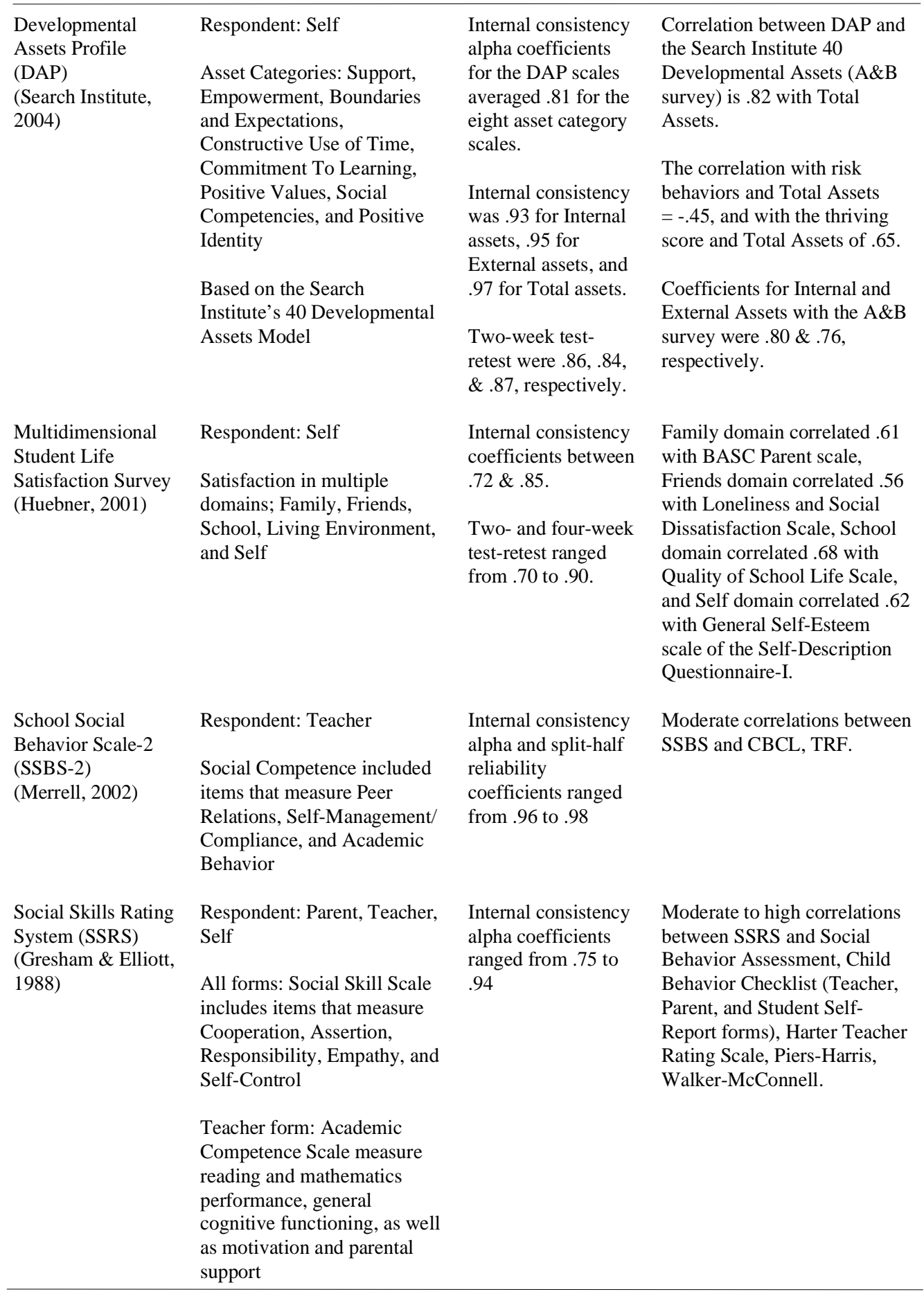


Vasey, and Williams (1996), for example, suggests that counting "good" things or "positive" psychological experiences is insufficient to understand the emotional status of a youth. For example, some research (e.g., Eisenberg et al., 1996) has found that excessively high levels of positive emotions are associated with developmental problems. An intriguing possibility for strength-based assessment is that it may also include examination of the regulation of both negative and positive emotions. As such, it will encourage school psychologists to de-emphasize assessments that search for symptoms and focus more on how youths manage their social and emotional worlds. An example of a recently developed instrument that takes such an integrated strength approached is the How I Feel scale (Walden, Harris, \& Catron, 2003), which examines positive and negative emotional experiences as well as emotional control.

There is a need to propose and understand how strengths influence behavior and development. Some investigations provide intriguing ideas about how this can be done. Research related to the States of Mind model provides an example of a current theory that holds promise to show how strengthbased approaches can be integrated with more traditional symptoms-based assessment models. States of Mind research has examined how the balance of individual's inner thoughts (e.g., ideas and affective experiences) is related to mental well being. What has been found is that psychological well being is not defined by the mere absence of negative cognitions or emotional experiences, but by maintaining a proper balance between them. When the ratio of positive to negative thoughts $(\mathrm{P} / \mathrm{P}+\mathrm{N})$ persistently falls outside of the .56 to .68 range (researchers refer to .62 as a "set point"), then an individual is at increased risk of experiencing some mental disorder. Too many negative thoughts are associated with various forms of psychopathology, whereas too many positive thoughts are associated with excessive optimism and mania. Daleiden et al. (1996) extended this research to include children and adolescents and found that this model was applicable to them also. This research emphasizes the presence of an internal psychological modulating process, not a static counting of negative or positive conditions.

In addition to offering a way to focus on youths' emotional management, strength-based assessment also focuses attention on positive outcomes for youth. This is another area in which strengthbased approaches can make a potentially useful contribution, by better identifying key measures for positive development. Within the field of education, this should be a familiar objective because schools are devoted to developing positive academic achievement. Similarly, students need to develop personal and social-emotional competence. Current efforts by the Search Institute surveys and the CHKS Resilience Youth Development Module, based in positive youth development and strength-based rationales, serve the valuable purpose of refocusing attention to desired developmental outcomes. Within school psychology, Huebner's Multidimensional Student Life Satisfaction Survey (e.g., McCullough $\&$ Huebner, 2003) provides a way to examine general well being within the contexts of family, friends, school, living environment, and self.

\section{Conclusion: From Discussion to Practice}

As school psychologists expand their awareness of strength-based assessment tools and practices, there are a number of entry points they will want to consider. Strength-based assessment can begin at the level of taking steps to increase awareness of personal strengths as a motivation to reorient assessment and the IEP process away from a search for deficits and negative symptoms. This may include adding a section to psychological reports under headings such as "Student Personal and Social Resources" or by beginning IEP meetings by asking teachers and parents to comment about what the student does well or how they are likable. It would then be reasonable to begin the process of incorpo- 
rating at least one existing strength-based assessment instrument regularly into social-emotional competence assessment plans. Even if the referral questions focus on behavioral difficulties or depression, it may be helpful to also assess what is going well for the student or to compile examples of times when the student had positive experiences or managed their emotions well. Beyond focusing on individual students, strength-based assessment also considers how a student's social contexts act as supportive resources. From this perspective, school psychologists can also work with their school sites to consider using the CHKS Resilience Youth Development Module, the Developmental Assets Profile and related assessments to conduct environmental scans to better understand the strength profiles of students and the positive youth development capacity of the school. The CHKS is mandated for use in all California schools every two years (grades 7, 9, and 11). Becoming involved with the collection of these surveys and working with school committees to examine what the students have to say about sources of social support at school complements school psychologists' efforts to consider individual student strengths. Finally, as progress in the development and application of strength-based assessment continues, school psychologists will benefit by seeking out professional development to expand understanding of positive psychology and strength-based assessment and to consider how these perspectives can be incorporated into assessment, consultation, and counseling services.

\section{REFERENCES}

Anthony, E. J. (1987). Risk, vulnerability, and resilience: An overview. In E. J. Anthony \& B. Cohler (Eds.), The invulnerable child (pp. 3-48). New York: Guilford.

Baker, J. A., Dilly, L. J., Aupperlee, J. L., \& Patil, S. A. (2003). The developmental context of school satisfaction: Schools as psychologically healthy environments. School Psychology Quarterly, 18, 206-221.

Barnett, D. W., Bauer, A. M., Ehrhardt, K. E., Lentz, F. E., \& Stollar, S. A. (1996). Keystone targets for change: Planning for widespread positive consequences. School Psychology Quarterly, 11, 95-117.

Brown, J. H., D'Emidio-Caston, M., \& Benard, B. (2000). Resilience education. Thousand Oaks, CA: Corwin Press.

Buckley, M., Storino, M., \& Saarni, C. (2003). Promoting emotional competence in children and adolescents: Implications for school psychologists. School Psychology Quarterly, 18, 177-191.

Butler, K. (1997). The anatomy of resilience. The Family Therapy Networker, 21, 22-31.

Chafouleas, S. M., \& Bray, M. A. (2004). Introducing positive psychology: Finding a place within school psychology. Psychology in the Schools, 16, 1-5.

Clark, M. D. (1999). Strength-based practice: The ABC's of working with adolescents who don't want to work with you. Retrieved February 27, 2001, from http://www.drugs.indiana.edu/prevention/assets/asset2.html

Constantine, N., Benard, B., \& Diaz, M. (1999). Measuring protective factors and resilience traits in youth: The Healthy Kids Resilience assessment. Paper presented at the Seventh Annual Meeting of the Society for Prevention Research, New Orleans, LA.

Cowan, P., Cowan, C. P., \& Schultz, M. (1996). Thinking about risk and resilience in families. In E. M. Hetherington \& E. Blechman (Eds.), Stress, coping and resilience in children and families (pp. 155-172). Mahwah, NJ: Lawrence Erlbaum.

Ciarrochi, J., Chan, A. Y. C., \& Bajgar, J. (2001). Measuring emotional intelligence in adolescents. Personality \& Individual Differences. 31, 1105-1119.

Daleiden, E. L., Vasey, M. W., \& Williams, L. L. (1996). Assessing children's state of mind: A multitrait, multimethod study. Psychological Assessment, 8, 125-134.

Doll, B., \& Lyon, M. A. (1998). Risk and resilience: Implications for the delivery of educational and mental health services in schools. School Psychology Review, 27, 348-363.

Eisenberg, N., Fabes, R. A., Guthrie, I. K., Murphy, B., Maszk, P., Holgren, R., \& Suh, K. (1996). The relations of regulation and emotionality to problem behavior in elementary school children. Development and Psychopathology, 8, 141-162.

Epstein, M. H. (1999). The development and validation of a scale to assess the emotional and behavioral strengths of children and adolescents. Remedial \& Special Education, 20, 258-263.

Ewart, C. K., Jorgensen, R. S., Suchday, S., Chen, E., \& Matthews, K. A. (2002). Measuring stress resilience and coping in vulnerable youth: The social competence interview. Psychological Assessment, 14, 339-352.

Epstein, M. H., \& Sharma, J. (1998). Behavioral and Emotional Rating Scale: A strength-based approach to assessment. Austin, TX: PRO-ED. 
Garmezy, N. (1993). Children in poverty: Resilience despite risk. Psychiatry, 56, 127-136.

Gilman, R., \& Huebner, S. (2003). A review of life satisfaction research with children and adolescents. School Psychology Quarterly. 18, 192-205.

Gore, S., \& Eckenrode, J. (1994). Context and process in research on risk and resilience. In R. Haggerty, L. Sherrod, N. Garmezy, \& M. Rutter (Eds.), Stress, risk, and resilience in children and adolescents: Processes, mechanisms, and interventions (pp. 19-63). New York: Cambridge University Press.

Gresham, F. M., \& Elliott, S. N. (1988). Teachers' social validity ratings of social skills: Comparisons between mildly handicapped and nonhandicapped children. Journal of Psychoeducational Assessment, 6, 225-234.

Hollister-Wagner, G. H., Foshee, V., \& Jackson, C. (2001). Adolescent aggression: Models of resiliency. Journal of Applied Social Psychology, 31, 445-466.

Hoyt, M. (1996). Constructive therapies Vol. 2. New York: Guilford.

Huebner, E. S., \& Gilman, R. (2003). Toward a focus on positive psychology in school psychology. School Psychology Quarterly, 18(2), 99-102.

Kaplan, H. (1999). Toward an understanding of resilience: A critical review of definitions and models. In M. Glantz \& J. Johnson (Eds.), Resilience and development: Positive life adaptations. New York: Plenum.

Kirby, L. D., \& Fraser, M. W. (1997). Risk and resilience in childhood: An ecological perspective. In M. W. Fraser (Ed.), Risk and resilience in childhood: An ecological perspective (pp. 10-33). Washington, DC: NASW Press.

Kretzman, J. P., \& McNight, J. L. (1993). Building communities from the inside out. Evanston, IL: Northwestern University, Center for Urban Affairs and Policy Research.

Lambert, N. M. (1964). The protection and promotion of mental health in schools. (Public Health Service Publication No. 1226. 4003342015). Washington DC: U.S. Dept. of Health, Education, and Welfare, Public Health Service, National Institutes of Health, National Institute of Mental Health.

Leffert, N., Benson, P. L., Scales, P. C., Sharma, A. R., Drake, D. R., \& Blyth, D. A. (1998). Developmental assets: Measurement and prediction of risk behaviors among adolescents. Applied Developmental Science, 2(4), 209230.

Lucas, R. E., Diener, E., \& Suh, E. (1996). Discriminant validity of well being measures. Journal of Personality and Social Psychology, 71, 616-628.

MacDonald, G. B., \& Validivieso, R. (2000). Measuring deficits and assets: How we track youth development now, and how we should track it. Washington, DC: Academy for Educational Development, Center for Youth Development and Policy Research.

Masten, A. S., Best, K., \& Garmezy, N. (1990). Resilience and development: Contributions from the study of children who overcame adversity. Development and Psychopathology, 2, 425-444.

Masten, A. S., \& Coatsworth, D. (1995). Competence, resilience, and psychopathology. In D. Cicchetti \& D. Cohen (Eds.), Developmental psychopathology, Volume 2: Risk, disorder, and adaptation (pp. 715-752). New York: Wiley.

Masten, A. S., Hubbard, J. J., Gest, S. D., Tellegen, A., Garmezy, N., \& Ramirez, M. (1999). Competence in the context of adversity: Pathways to resilience and maladaption from childhood to late adolescence. Development and Psychopathology, 11, 143-169.

McCullough, G., \& Huebner, E. S. (2003). Life satisfaction reports of adolescents with learning disabilities and normally achieving adolescents. Journal of Psychoeducational Assessment, 21, 311-324.

Merrell, K. M. (2002). School Social Behavior Scales, second edition: User's guide. Eugene, OR: AssessmentIntervention Resources.

Mrazek, P. J., \& Haggerty, R. (Eds.). (1994). Reducing risks for mental disorders: Frontiers for preventive intervention research. Washington, DC: National Academy Press.

Muris, P. (2001). A brief questionnaire for measuring self-efficacy in youth. Journal of Psychopathology and Behavioral Assessment, 23, 145-149.

Nettles, S. M., Mucherah, W., \& Jones, D. S. (2000). Understanding resilience: The role of social resources. Journal of Education for Students Placed at Risk, 5, 47.

O'Leary, V. E. (1998). Strength in the face of adversity: Individual and social thriving. Journal of Social Issues, 54(2), 425-446.

Rapp, C. A. (1997). Preface. In D. Saleeby (Ed.), The strengths perspective in social work practice. New York: Longman.

Reynolds, C. R., \& Kamphaus, R. W. (1992). Behavior Assessment System for Children (BASC). Circle Pines, $\mathrm{MN}$ : American Guidance Services.

Rhee, S., Furlong, M., Turner, J., \& Harari, I. (2001). Integrating strength-based perspectives in psychoeducational evaluations. The California School Psychologist, 6, 5-17.

Robertson, L. M., Harding, M. S., \& Morrison, G. M. (1998). A comparison of risk and resilience indicators among Latino/a students: Differences between students identified as at-risk, learning disabled, speech impaired and not at-risk. Education \& Treatment of Children, 21, 333-353. 
Rutter, M. (1990). Psychosocial resilience and protective mechanisms. In J. Rolf, A. S. Masten, D. Cicchetti, K. H. Nuechterlein, \& S. Weintraub (Eds.), Risk and protective factors in the development of psychopathology (pp. 181-214). New York: Cambridge University Press.

Rutter, M. (2000). Resilience reconsidered: Conceptual considerations, empirical findings, and policy implications. In J. P. Shonkoff \& S. J. Meisels (Eds.), Handbook of early childhood intervention (pp. 651-682). New York: Cambridge University Press.

Sameroff, A. J., \& Fiese, B. (2000). Transactional regulation: The developmental ecology of early intervention. In J. P. Shonkoff \& S. J. Meisels (Eds.), Early intervention: A handbook of theory, practice, and analysis ( $2^{\text {nd }}$ ed., pp. 135-159). New York: Cambridge University Press.

Scales, P. C., \& Leffert, N. (1999). Developmental assets: A synthesis of the scientific research on adolescent development. Minneapolis, MN: Search Institute.

Scales, P. C., Benson, P. L., Leffert, N., \& Blyth, D. A. (2000). Contribution of developmental assets to the prediction of thriving among adolescents. Applied Developmental Science, 4, 27-46.

Seligman, M. E. P. (2002). Positive psychology, positive prevention, and positive therapy. In C. R. Snyder \& S. J. Lopez (Eds.), Handbook of positive psychology (pp. 3-9). New York: Oxford University Press.

Seligman, M. E. P. (2003). Quote from the APA Positive Psychology website. Retrieved December 20, 2003, from http://www.apa.org/releases/positivepsy.html

Seligman, M. E. P., \& Csikszentmihalyi, M. (2000). Positive psychology: An introduction [Special Issue]. American Psychologist, 55, 5-14.

Seligman, M. E. P., \& Peterson, C. (2000). Positive clinical psychology. Retrieved December 20, 2003, from http://www.psych.upen.edu/seligman/posclinpsychchap.html

Seligman, M. E. P., Reivich, K., Jaycox, L., \& Gillham, J. (1995). The optimistic child. New York: Houghton Mifflin.

Smokowski, P. R., Reynolds, A. J., \& Bezruczko, N. (1999). Resilience and protective factors in adolescence: An autobiographical perspective from disadvantaged youth. Journal of School Psychology, 37, 425-448.

Steen, T. A., Kachorek, L. V., \& Peterson, C. (2003). Character strengths among youth. Journal of Youth \& Adolescence, 32, 5-16.

Terjesen, M. D., Jacofsky, M., Froh, J., \& DiGiuseppe, R. (2004). Integrating positive psychology into schools: Implications for practice. Psychology in the Schools, 4l(1), 163-172.

Walden, T. A., Harris, V. S., \& Catron, T. F. (2003). How I Feel: A self-report measure of emotional arousal regulation for children. Psychological Assessment, 15, 399-412.

Wieck, A., Rapp, C., Sullivan, W. P., \& Kisthardt, S. (1989). A strengths perspective for social work practice. Social Work, 34, 350-354. 
he California School Psychologist, Vol. 9, pp. 21-27, 2004

Copyright 2004 California Association of School Psychologists

\title{
The Behavioral and Emotional Rating Scale-2 (BERS-2): Providing a Comprehensive Approach to Strength-Based Assessment
}

\author{
Jacquelyn A. Buckley, Michael H. Epstein \\ University of Nebraska-Lincoln
}

\begin{abstract}
Identification of strengths is considered an important part of school psychological practice. However, few instruments are available to school psychologists that allow for systematic and comprehensive evaluation of a student's emotional and behavioral strengths. School psychologists must be provided with psychometrically sound instruments that will measure students' emotional and behavioral skills and competencies. The Behavioral and Emotional Ratings Scale (BERS) was developed in response to the need for a valid and reliable instrument for assessing and evaluating strengths, but it became evident that the single instrument was not comprehensive. The BERS has now been restandardized to create two additional scales: a parent rating scale and a youth selfreport scale. The Behavioral and Emotional Rating Scale-2 ${ }^{\text {nd }}$ Edition (BERS-2) scales now provide school psychologists with a comprehensive set of standardized instruments to assess children's emotional and behavioral strengths. The purpose of this article is threefold: (a) to provide a brief overview of strength-based assessment in school psychological practice, (b) to discuss the development of the BERS-2, and (c) to discuss the use of the BERS-2 in school psychological practice.
\end{abstract}

Key Words: Strengths, BERS, Assessment, Students

Assessing the emotional and behavioral needs of students is a challenging task for school psychologists. The multidimensional nature of behavior (e.g., contextual influences, varying perspective of informants) as well as the type of assessment used influence the perception of a student's behavior (Freidman, Leone, \& Freidman, 1999). For school psychologists, behavioral rating scales are one of the most widely used methods of assessing emotional and behavioral needs of students (Wilson \& Reschly, 1996). School psychologists routinely collect rating scale information from several informants to capture multiple perspectives of behavior across settings. Although information is also typically collected through direct observation of behavior and interviews, behavioral ratings have an influential impact on assessment results. Therefore, the way in which a student's behavior is characterized is largely influenced by the rating scales used.

Currently many behavior rating scales are primarily deficit-based, meaning the psychologist is limited to collecting information about deficits, problems, or pathologies. The Child Behavior Checklist (CBCL; Achenbach, 1991) for example, a widely used scale in research and practice, allows for the reporting of problematic behavior with scant regard to what the child can do well. Other measures have included questions or subscales designed to capture a child's positive behaviors (e.g., the Adaptive scales from the Behavior Assessment System for Children; Reyolds \& Kamphaus, 1992) but the strengths measured are limited in number and scope. Although the documentation of deficits is essential for special education eligibility requirements, current mental health and education initiatives have encouraged the documentation of strengths and resources in children's mental health assessment, treatment and service delivery (Epstein, 1999; Van Den Berg \& Grealish, 1996). Strength-based assessment advocates argue for incorporating strength measures into assessments of social and emotional

Address correspondence to Michael H. Epstein; Center for At-Risk Children's Services; 202 Barkley Center; University of Nebraska-Lincoln; Lincoln, NE 68583-0732. This research was supported in part by grants from the Center for Mental Health Services and U.S. Department of Education, Office of Special Education Programs. Opinions expressed do not necessarily reflect the position of the funding agencies and no endorsement should be inferred. 
disorders in children because child strengths are seen as an important component of clinical decision making (Oswald, Cohen, Best, Jenson, \& Lyons, 2001). A strength-based assessment paradigm recognizes that children with even the most challenging behaviors have strengths that can be built on to develop a treatment or intervention approach (Epstein, 1999; Provence, Erikson, Vater, \& Palmeri, 1995). This is not to suggest that the assessment of deficits be eliminated, but rather that assessment of deficits and strengths can provide a more comprehensive, balanced, and holistic view of a child. For example, the documentation of a student's strengths and weaknesses is routine practice for school psychologists conducting psychoeducational evaluations and for students' Individualized Education Programs (IEP).

Although documenting what a child can do well is not new to school psychological practice, standardized resources available to professionals to formally document strengths has been limited. The development of strength-based assessment tools is still in its infancy, but the Behavioral and Emotional Rating Scale (BERS; Epstein \& Sharma, 1998) has emerged as a widely used standardized instrument designed solely to assess children's emotional and behavioral strengths. The BERS was developed in response to the paradigm shift away from a deficit-only focus to the enhancement of students' strengths. More practically, it was developed in response to the need for an instrument dedicated to the assessment of students' strengths and competencies. Items on the BERS were created from existing research literature about behavioral and emotional skills and included input from parents and professionals (e.g., teachers, mental health workers) to develop items that were representative of the skills reported in the literature (Epstein \& Sharma, 1998). The 52-item BERS was designed to be completed by adults (e.g., teachers, caregivers) who rate the behaviors of children ages 5-18. Reliability (Epstein, Cullinan, Harniss, \& Ryser, 1999) and validity (Epstein, 1999; Epstein, Cullinan, Ryser, \& Pearson, 2002) studies have demonstrated that the BERS possesses sound psychometric properties.

The research on the psychometric properties of the BERS indicated that it has adequate reliability and validity as a behavioral strength measure. However, it became apparent that the instrument was not comprehensive in two important ways: (a) the original BERS did not differentiate between parent and teacher respondents, so there was a need to establish separate norms for parent and teacher respondent groups, and (b) the BERS did not allow for a child/adolescent to report on his/her own perceived strengths and competencies. Below is an overview of the revised BERS scales and a discussion of how school psychologists can use the scales to provide a comprehensive behavioral assessment.

\section{BERS-2: Parent, Teacher, and Youth Rating Scales}

To address the problems with the original BERS, the scale was renormed in 2001-2002 and included a large, nationally representative sample of parents/caregivers and children and adolescents. The original BERS items were rewritten to reflect a parent and youth perspective respectively and the new versions of the scale were named the BERS-2: Parent Rating Scale (Epstein, 2004) and the BERS2: Youth Rating Scale (Epstein, 2004). The original BERS scale was restandardized for use by teachers and renamed the BERS 2: Teacher Rating Scale (Epstein, 2004). An overview of the scales, including the norms and factor structure follows.

Norms. Ratings were collected on a nationally representative sample of 927 persons for the BERS2 Parent Rating Scale and 1,301 youth for the Youth Rating Scale. Parents of students with disabilities comprised $17 \%$ of the Parent Rating Scale sample and $16 \%$ of the Youth Ratings Scale sample were students with disabilities. All students with disabilities were school-system identified and receiving special education services. Data with regard to geographic region, gender, race, ethnicity, family income, rural or urban residence, and disability status were collected on the two samples. The percentages for these characteristics were then compared to those reported in the Statistical Abstract of the 
United States (U.S. Bureau of the Census, 2001). The comparison demonstrated that the national samples were representative of children nationwide (Epstein, 2004).

Instruments. The BERS-2 scales were modeled after the original BERS scales, and therefore the same 52 items included in the BERS were included in the scales for both parents and teachers. The Parent Rating Scale and the Teacher Rating Scale are designed to be completed in approximately 10 minutes by parents and teachers, respectively, who read each statement and mark the rating that reflects how much a given characteristic is representative of the child. The items are rated on a 4-point Likert scale that ranges from 0 (not at all like the child) to 3 (very much like the child). The scales are composed of an overall Strength Index that provides a single summary score of strengths and five subscales: Interpersonal Strength, Family Involvement, Intrapersonal Strength, School Functioning, and Affective Strength. The five subscales have a mean standard score of 10 and a standard deviation of 3. The sum of the subscale standard scores is converted into the Strength Index that has a mean of 100 and standard deviation of 15 . All scales are written at a fifth-grade reading level.

The scale also contains eight open-ended questions that allow parents and teachers to note a child's specific academic, social, athletic, family, and community strengths. New to the Parent Rating Scale is the inclusion of a brief five-question subscale (Career Strengths) that measures the career and vocational strengths of the rated child.

The BERS-2 Youth Rating Scale, intended for youth ages 11-18, is identical to the parent and teacher scales except the youth self-report included minor wording changes to reflect a student perspective. For example, "asks for help" was changed to "I ask for help when I need it." The 5-item career subscale was also included in the youth version. Most youth can complete the 57 items in approximately 10 minutes.

Factor structure. The overall strength index consists of five factors: Interpersonal Strength, Family Involvement, Intrapersonal Strength, School Functioning, and Affective Strength. The Interpersonal Strength subscale consists of 15 items that identify a child's ability to interact with others in social situations (e.g., accepts criticism, accepts responsibility for own actions). The Family Involvement subscale contains 10 items that measure a child's relationship with his or her family (e.g., trusts a significant person in his or her life, participates in family activities). The Intrapersonal Strength subscale is composed of 11 items that focus on how a child perceives his or her competence and accomplishment (e.g., identifies personal strengths, talks about the positive aspects of life). The School Functioning scale consists of 9 items that address a child's competence and performance in classroom and school tasks (e.g., completes school tasks on time, attends school regularly). Finally, the Affective Strength subscale is made up of 7 items that measure a child's ability to give and receive affection from others (e.g., shows concern for the feelings of others, expresses affection for others).

Confirmatory factor analysis research (Buckley, Ryser, Reid, \& Epstein, 2004) indicated that the same factor structure that existed for the original BERS exists with the Parent Rating Scale and Youth Rating Scale. Four indexes of model fit were computed in testing this model with the BERS-2 Parent and Youth Rating Scales: Bentler's (1990) comparative fit index (CFI), Tucker and Lewis's (1973) index of fit (TLI), and Bentler and Bonnett's (1980) normed fit index (NFI) and Browne and Cudek's (1993) root mean square error of approximation (RMSEA). The CFI, TLI, and NFI values should be at or above .95 to indicate a good fitting model (Hu \& Bentler, 1999), and a RMSEA of less than .11 indicates a reasonable fit, and about .05 or less indicates a close fit of the model (Browne \& Cudek, 1993). The results indicate that three of the four indices supported the fit of the model to the data, with the CFI equal to .993 and .995 , the TLI equal to .986 and .979 , the NFI equal to .995 and .993 , and the RMSEA equal to .148 and .120 for the Parent and Youth Rating Scales, respectively. CFA research that tests for second order factors to confirm the utility of the strength index is needed. In addition, al- 
though three of the fit estimates suggested that the five-factor model was a good fit for the data, the RMSEA did not reflect this. Additional studies are necessary to replicate and further understand these findings. Further support for the factor structure includes a similar confirmatory factor analysis conducted on the original BERS completed by over 1,400 parents of children with emotional disturbance which reported the identical factor structure (Liao, Holden, \& Epstein, 2002).

Reliability. Adequate reliability has been established for the BERS-2. For example, the subscales have strong internal consistency with average coefficients ranging from .84 to .92 for the Teacher Rating Scale, .84 to .93 for the Parent Rating Scale, and .79 to .88 for the Youth Rating Scale. The strength quotient also has strong internal consistency with coefficients ranging from .95 to .97 (Epstein, 2004). Stability of the BERS-2 ratings has also been established; across the scales, short-term testretest (i.e., 6 weeks) coefficients ranged from .84 to .98 , and long-term test-retest (i.e., 6 months) coefficients ranged from .53 to .79 . The addition of a youth self-report prompted studies of crossinformant reliability. A study of the agreement between the parent and youth version of the scale resulted in coefficients for the subscales and the overall strength quotient ranging from .50 to .63, indicating highly acceptable levels of cross informant agreement (Synhorst, Buckley, Reid, Epstein, \& Ryser, 2004). Research into the agreement between other raters (e.g., teacher and parent) is also warranted but those studies are not yet reported. Please refer to the BERS-2 manual for additional information concerning the reliability of the instruments.

Validity. The BERS-2 manual provides information indicating that adequate validity has been established for the BERS-2. First, the manual provides a description of the selection of subscale content and format to show that the construct measured by the BERS-2 is consistent with current knowledge about student strengths, competencies, and resiliency. Combined with factor analysis results, this indicates that the BERS-2 has established content-description validity (Epstein, 2004). The ability of the BERS-2 to discriminate students with and without emotional disturbance (EBD) was examined. As expected, the range of average performances across all three rating scales for an EBD subgroup was significantly lower, almost one standard deviation lower across the subscales and strength index (Epstein, 2004). A previous BERS study (Reid, Epstein, Pastor, \& Ryser, 2000) also indicted that the instrument could discriminate among students with behavior disorders, learning disabilities and without disabilities.

In addition, previous studies examined criterion validity and determined that the instrument correlated positively with other scales or subscales measuring strengths or positive behaviors such as the adaptive scale from the Systematic Screening for Behavior Disorders (SSBD; Walker \& Severson, 1992; Harniss, Epstein, Ryser, \& Pearson, 1999). The instrument also correlated negatively with scales measuring deficits or problems scales such as the Scale Assessing Emotional Disturbance (SAED; Epstein \& Cullinan, 1998; Epstein, Nordness, Nelson, \& Hertzog, 2002).

Additional validity information for the BERS-2 can be obtained from the manual. Further study is warranted on the relationship of the BERS-2 to other criterion measures (e.g., sociometrics, academic progress). Overall, professionals are also encouraged to study the test using different samples and measures, and share their findings with the test author. The additional research data will help further clarify the validity of the BERS-2 and provide guidance for future revisions of the test.

\section{Implications for School Psychologists}

The creation of the BERS-2 rating scales is an important advancement in strength-based assessment and intervention. The scales are quick and easy to administer, possess a logical factor structure, have nationally representative norms, and possess adequate reliability and validity. The BERS- 2 rating scales allow school psychologists to collect strength-based information from multiple perspectives, 

attention to the positive and what the student does well will focus the IEP team on the strengths of the student and how to improve student competencies. Goals identified should match the needs and strengths of the child and family.

Monitoring and outcomes. Because strength-based assessment focuses attention on strengths and competencies, progress monitoring and assessment of outcomes should focus on improvements in these areas as well as improvement in problem behavior areas. When the goal of interventions is to enhance a student's functioning and competencies, the BERS- 2 scale can be used to document changes in those strengths and competencies. Administering the BERS-2 at pre-treatment and at regular intervals (e.g., every 6 months) would be helpful in detailing the strengths of children as they progress through specialized programs. The importance of intervention accountability cannot be overstated, and the BERS- 2 can be used in combination with other measures (e.g., goal attainment scaling, other norm-referenced measures) to demonstrate the effectiveness of interventions. Documentation helps not only with intervention accountability, but can also assist with further intervention modification or planning. Administrators and policy makers would likely be interested in programs that can document improvement in students' emotional and behavioral strengths and competencies.

For an example of the use of the original BERS scales in educational practices, readers are encouraged to read an article by Epstein, Randolph, and Epstein (2000) that depicts a case study illustrating the use of the original BERS in transition planning. Additional papers illustrating the use of the BERS2 scales in practices would provide a worthwhile contribution to the literature on the use of strengthbased assessment.

\section{CONCLUSION}

This article provided an overview of the Behavioral and Emotional Rating Scale $-2^{\text {nd }}$ Edition (BERS-2), and discussed the use of the BERS-2 in school psychological practice. As the mental health and education fields embrace a strength-based paradigm, school psychologists can become leaders in the field by advocating for comprehensive behavioral assessments that include multiple perspectives of a child's strengths. Although the development of strength-based tools is still in its infancy, the creation of the BERS-2 Rating Scales represent an important advancement in the development of strength-based instruments. The BERS-2 rating scales are tools that can assist in identifying strengths and competencies to aid in understanding and building upon existing behavioral strengths to influence the positive development of students. Additional research is still needed into the psychometric properties of the BERS-2 as well as the use of the scales in school psychological practice. However, the existence of strength-based scales helps school psychologists to become more focused on what children do well and promote positive behavioral and emotional youth development.

\section{REFERENCES}

Achenbach, T. M. (1991). Manual for the child behavior checklist/4-18 and 1991 profile. Burlington, VT: University of Vermont, Department of Psychiatry.

Bentler, P. M. (1990). Comparative fit indexes in structural models. Psychological Bulletin, 107, 238-246.

Bentler, P. M., \& Bonett, D. G. (1980). Significance tests and goodness of fit in the analysis of covariance structures. Psychological Bulletin, 88, 588-606.

Browne, M. W., \& Cudek, R. (1993). Alternative ways of assessing model fit. In K. A. Bollen \& J. S. Long (Eds.), Testing structural equation models (pp. 445-455). Newbury Park, CA: Sage.

Buckley, J. A., Ryser, G., Reid, R., \& Epstein, M. H. (2004). Confirmatory factor analysis of the Behavioral and Emotional Rating Scale-2 (BERS-2) Parent and Youth Rating Scales. Manuscript submitted for publication.

Epstein, M. H. (1999). The development and validation of a scale to assess the emotional and behavioral strengths of children and adolescents. Remedial and Special Education, 20, 258-262. 
Epstein, M. H. (2004). Behavioral and Emotional Rating Scale-2 ${ }^{\text {nd }}$ Edition: A strengths-based approach to assessment. Austin, TX: PRO-ED.

Epstein, M. H., \& Cullinan, D. (1998). Scale for Assessing Emotional Disturbance. Austin, TX: PRO-ED.

Epstein, M. H., Cullinan, D., Harniss, M. K., \& Ryser, G. (1999). The scale for assessing emotional disturbance: Test-retest and interrater reliability. Behavioral Disorders, 24, 222-230.

Epstein, M. H., Cullinan, D., Ryser, G., \& Pearson, N. (2002). Development of a scale to assess emotional disturbance. Behavioral Disorders, 28, 5-22.

Epstein, M. H., Nordness, P. D., Nelson, J. R., \& Hertzog, M. (2002). Convergent validity of the Behavioral and Emotional Rating Scale with primary grade students. Topics in Early Childhood Special Education, 23, 114121.

Epstein, M. H., Randolph, S., \& Epstein, A. A. (2000). Using strength-based assessment in transition planning. Teaching Exceptional Children, 32, 50-54.

Epstein, M. H., \& Sharma, J. (1998). Behavioral and Emotional Rating Scale: A strengths-based approach to assessment. Austin, TX: PRO-ED.

Freidman, K. A., Leone, P. E., \& Freidman, P. (1999). Strengths-based assessment of children with SED: Consistency of reporting by teachers and parents. Journal of Child and Family Studies, 8, 169-180.

Harniss, M. K., Epstein, M. H., Ryser, G., \& Pearson, N. (1999). The Behavioral and Emotional Rating Scale: Convergent validity. Journal of Psychoeducational Assessment, 17, 4-14.

Hu, E., \& Bentler, P. M. (1999). Cutoff criteria for fit indexes in covariance structure analysis: Conventional criteria versus new alternatives. Structural Equation Modeling, 6, 1-55.

Liao, Q., Holden, E. W., \& Epstein, M. H. (2002). Confirmatory Factor Analysis of the Behavioral and Emotional Rating Scale (BERS). In C. Newman, C. Liberton, K. Kutash, \& R. M. Friedman (Eds.), The $15^{\text {th }}$ annual research conference proceedings, a system of care for children's mental health: Expanding the research base (pp. 467-470). Tampa, FL: University of South Florida, The Louis de la Parte Florida Mental Health Institute, Research and Training Center for Children's Mental Health.

Oswald, D. P., Cohen, R., Best, A. M., Jenson, C. E., \& Lyons, J. S. (2001). Child strengths and the level of care for children with emotional and behavioral disorders. Journal of Emotional and Behavioral Disorders, 9, $192-$ 199.

Powell, D. S., Batsche, C. J., Ferro, J., Fox, L., \& Dunlap, G. (1997). A strength-based approach in support of multi-risk families: Principles and issues. Topics in Early Childhood Special Education, 17, 1-26.

Provence, S., Erikson, J., Vater, S., \& Palmeri, S. (1995). Infant-Toddler Development Assessment. IDA. Chicago: Riverside Publishing.

Reid, R., Epstein, M. H., Pastor, D. A., Ryser, G. R. (2000). Strengths-based assessment differences across students with LD and EBD. Remedial and Special Education, 21, 346-355.

Reynolds, C. R., \& Kamphaus, R. W. (1992). Behavior Assessment System for Children (BASC). Circle Pines, MN: American Guidance Service.

Synhorst, L. L., Buckley, J. A., Reid, R., Epstein, M. H., \& Ryser, G. (2004). Cross informant reliability of the Behavioral and Emotional Rating Scale-2 ${ }^{\text {nd }}$ edition (BERS-2). Manuscript submitted for publication.

Tucker, L. R., \& Lewis, C. (1973). A reliability coefficient for maximum likelihood factor analysis. Psychometrika, $38,1-10$.

U. S. Bureau of the Census. (2001). The statistical abstract of the United States. Washington, DC: Author.

Van Den Berg, J., \& Grealish, E. (1996). Individualized services and supports through the wraparound process: Philosophy and procedures. Journal of Child \& Family Studies, 5, 7-22.

Walker, H., \& Severson, H. (1990). Systematic Screening for Behavior Disorders (SSBD). Longmont, CO: Sopris West.

Wilson, M. S., \& Reschly, D. J. (1996). Assessment in school psychology training and practice. School Psychology Review, 25, 9-23. 
he California School Psychologist, Vol. 9, pp. 29-38, 2004 Copyright 2004 California Association of School Psychologists

\title{
Asset-Based Assessment In Educational Psychology: Capturing Perceptions During a Paradigm Shift
}

\author{
Carien Lubbe, Irma Eloff \\ University of Pretoria
}

\begin{abstract}
Several trends are compelling educational psychologists towards a philosophy of assessment that is asset-based and strength focused. This article shares the results from a study that explored perceptions about asset-based assessment in Educational Psychology in South Africa. Three focus groups were held and four main themes emerged from the transcribed data. Results indicate that educational psychologists perceive asset-based assessment as involving: (a) a focus on assets, (b) individual and community level assessment, (c) collaboration skills, and (d) self-reflective skills. The first three themes are congruent with asset-based theories, but the fourth theme is currently under-represented in asset-based literature and therefore in need of further research.
\end{abstract}

Key Words: Assets, Educational Psychology, Assessment, Strengths, Skills

The dominance of the deficit model and paradigm in Educational Psychology ${ }^{1}$, with its focus on needs and problems, has recently led to the development of counter models in different pockets of the science and practice of Educational Psychology (Ammerman \& Parks, 1998; Eloff \& Ebersöhn, 2002; Hernandez, 1998; Kretzmann \& McKnight, 1993; Lockett, 2000; McDonald, 1997; Mokwena, 1997; Page-Adams \& Sherraden, 1997; Rudolph \& Epstein, 2000; Sharpe \& Greany, 2000; Sharratt, 1995). Themes such as resilience (Hiew, 2002; LaFramboise, 2002; Ow, 2002; Satiadarma, 2002; Takahashi, 2002), asset-based approaches (Eloff \& Ebersöhn, 2001; Kretzmann \& McKnight, 1993) and a focus on the fortogenic perspective in psychology are evident (Wissing \& Van Eeden, 2002). Research on resiliency has shifted attention to children that succeed and thrive under extenuating circumstances, along with other constructs conceptualizing aspects of psychological health, strengths and wellness and their origins (fortogenesis). This move away from the deficit paradigm, toward a paradigm that focuses on the counter constructs, strengths, resources and capacities of people, points toward an asset-based approach. In terms of assessment, this transition implies a culture of dynamic assessment that includes the broader social systems in the assessment process, which creates coherence, stresses collaboration and values partnerships.

The research and practice of asset-based assessment is now emerging in the field of Educational Psychology. Questions that remain unanswered are vast: How do we conduct asset-based assessment? Who could and should be doing asset-based assessment? What are the consequences of asset-based assessment? How does asset-based assessment fit within broader educational, psychological and sociological domains? These questions highlight how much is yet to be understood about asset-based assessment and this realization can be overwhelming, because traditionally, educational psychologists do not work in an asset-based manner. However, this realization can also be inspiring as it provides a new emphasis on assessment and can facilitate a more holistic conceptualization of an individual or family (Rhee, Furlong, Turner, \& Harari, 2001).

${ }^{1}$ Educational Psychology: It is the science that concerns itself with theories and practices in psychology and education and the intersections between psychology and education. Educational psychologists assess, diagnose and intervene in order to facilitate the psychological adjustment and development of children and adolescents within the contexts of family, school, social or peer groups and communities.

Address correspondence to Irma Eloff; Department of Educational Psychology; Faculty of Education; University of Pretoria; PRETORIA, South Africa 0002. E-mail: irma.eloff@up.ac.za. 
In largely uncharted territory such as the field of asset-based assessment (specifically in Educational Psychology), these emerging questions leave the options of exploring the terrain from any number of vantage points. Therefore, a study was undertaken to explore the perceptions of professionals about asset-based assessment. This led to the research question: What are perceptions of asset-based assessment in Educational Psychology? The rationale is that the perceptions of professionals can have a significant impact on the ways in which asset-based assessment is taught, practiced, and implemented. It may also provide valuable insights into asset-based assessment itself.

The purpose of this article is to share the results from a study that explored the perceptions of professionals about asset-based assessment and to compare results with asset-based theory in order to enhance an understanding of asset-based assessment. Through an analysis of practitioners and scholars' "voices," insight and understanding can be gained to advance knowledge of how the asset-based approach can be utilized in assessment.

\section{Contextualization of the study}

This study was conducted within the South African context. Since 1994, the country has undergone crucial changes on different domains including, the development of a new constitution, anthem, flag, set of labor laws, and curriculum for the education system. This transformation inevitably impacted the role of Educational Psychology, especially in developing new methods of service delivery. Over the past few years it has become clear that the traditional role of the educational psychologist to render an individually-based service, whether in private practice consulting with schools, or based at a school or similar agency, seemed not to have an effective and sustainable impact (Ammerman \& Parks, 1998; Mokwena, 1997). In order to address the vast socioeconomic and socio-psychological disparities and inequalities in the needs of the people, educational psychologists have had to focus more on communities, on establishing networks and partnerships, and to collaborate with the relevant stakeholders.

\section{Theoretical Framework}

In this study, we utilize the theoretical framework provided by Kretzmann and McKnight (1993) on the asset-based approach. This approach is based on the perspective of working from what is present in a given family or community, focusing on the assets of individuals, non-governmental organizations (NGOs), associations and institutions. These assets refer on an individual level to the talents, gifts and skills that a person has to offer and on a broader level to the resources, talents and skills within a community. This approach by no means negates problems or needs, but rather strengthens the resources within a system to establish sustainable intervention. Articulating this community-based approach for school-based practices, it becomes evident that the psychologist can facilitate the identification and mobilization of each individual person's or family's assets. Assessing in an asset-based manner implies more than the traditional focus on the strengths and weaknesses of a child, or assessing in an ecosystemic framework, as it reflects the fundamental nature of thinking in terms of capacities, instead of deficits (Ebersöhn \& Eloff, 2003).

\section{METHOD}

\section{Participants}

Educational psychologists, Educational Psychology master's degree students and a stakeholder from the disability sector who is a registered educational psychologist were purposefully selected. The 
selection criteria for the participants were based on: (a) involvement in the field of Educational Psychology and (b) knowledge and background regarding the asset-based approach. The minimum participants that were present at a given time were 9 and the maximum 11. Morse (1994) stated that the optimum number of participants for a focus group is between 5 to 12 members. Larger groups become more difficult to moderate and may frustrate the participants themselves as they have less time to adequately express their views. All of the participants were female and of the same ethnicity (Caucasian). The participants in this study were invited to participate in the study via telephone calls and email correspondence.

\section{Measures}

The focus group interviews were tape- and video-recorded and then transcribed by a research assistant. The researchers then verified the transcriptions by comparing the transcribed data with the video- and audio-recordings of the data.

\section{Procedures}

Focus groups as well as field notes were used to collect data. Field notes were made by two researchers during the focus groups and collated with the data from the transcriptions. Three focus groups were held over a period of three consecutive weeks. Each focus group lasted approximately one hour. The rationale for using focus groups is that it serves as a primary mean of collecting qualitative data to explore new research areas from the participants' own perspectives. It generates a discussion of similarities and differences among the participants so that contrary opinions can be explored and new areas of inquiry be generated (Morgan, 1997; Morse, 1994). Experiences and perspectives can be shared that would not have been accessible without the group's interaction.

The focus groups were held in a secure, quiet room with audio- and video-recording facilities. Every participant was seated on a low, comfortable chair and empty chairs were removed before the session commenced. Chairs were arranged in a circle with empty space in the middle. A facilitator was appointed for the focus groups. The role of the facilitator entailed a word of welcome to the participants, explanation of the study and facilitation during the focus group. The facilitation involved asking the focus group question, summarizing the comments and contributions at some points in the focus group, monitoring the time and closing the focus group session. Responses from participants were spontaneous and random. The question that was posed to the group was "What is asset-based assessment in Educational Psychology?"

\section{Analyses}

The transcribed data from the focus groups were analyzed by incorporating two techniques. "Thematic qualitative analysis" as described by Hayes (2000) and "Themes and coding qualitative data" as described by Strauss (in Neuman, 2000) were integrated for the purposes of data analysis in order to generate the themes that are identified in this study.

Thematic analysis is qualitative analysis that involves sorting information into themes; that is, recurring ideas or topics in a particular set of data (Hayes, 2000). Coding of data involves raw data that are organized into conceptual categories and themes (Neuman, 2000). Advantages of these techniques are that a large mass of data becomes manageable and relevant parts can be quickly retrieved. It frees the researcher from becoming entangled in the details of raw data and higher level thinking about the data is thus encouraged. The limitations of this method are that it can be a long and tedious process and that the researcher can become biased and selective (Hayes, 2000; Neuman, 2000). 
The first step entailed preparing the data for analysis, by transcribing the focus group discussions. Then each line of the focus group data was systematically read through to identify constructs or items of information that link or belong with each other. Initial labels were assigned to these emerging themes or proto-themes. A preliminary concept or label was written, examined, and initially defined for each of the themes. A list of these themes was then made, followed by an open coding-process and categorization.

A "second pass" through data entailed separately and carefully re-examining each categorized theme to find the relevant statements or supporting data for each specific theme. During this re-examination process, questions about the consequences, conditions and interactions, strategies and processes were kept in mind to refine the themes and definitions. Connections between the concepts and evidence were reinforced. Final themes were named, defined and each line of data was integrated into these final themes. Finally, the relevant illustrative data for reporting on the themes were selected, which could highlight and illustrate each theme optimally.

\section{RESULTS}

The main themes on perceptions about asset-based assessment that were identified during this study are: (a) focusing on assets, (b) individual and/or community assessment, (c) collaboration skills, and (d) self-reflective skills. These themes are components that are relevant for the assessor, not the assessed, as these themes are representative of the perceptions of educational psychologists and students in Educational Psychology doing asset-based assessment.

The following section illustrates each of the identified themes by including examples from the raw data. These raw data or direct quotes are numbered according to the specific participant who made a comment (each participant was assigned a number, e.g., P1 or P9).

\section{Theme 1: Focusing On Assets}

Throughout the focus groups the term "assets" came up as a key concept in assessment. Even though this term was part of the question that was posed to the participants, the data indicated that the participants created asset-based assessment discursively by using this term continuously. The professionals explored their understanding thereof, giving synonyms and/or practical examples to explain and explore the new concept of "assets."

P1: "Asset-based listening, asset-based interviewing, asset-based empathy... you should actually listen for green lights" P1: “Asset-analysis” P2: "Wouldn't that be your ecograms, ecomaps and genograms?" P3: "We also have systemic models...we have models with which we can assess the processes and the areas of strengths" P3: "You must be able to draw up a capacity inventory or an asset-map of the context" P1: "assimilate all the knowledge to put it together in a framework of an asset profile of this child."

At times the shift between the needs or deficit-based and asset-based approaches was debated, or the needs-based approach was used to explain what asset-based assessment must nót be. P7: "The way in which you look at a child, looking at strengths, assets, uhm, not what is the problem...that is crucial." P3: "It's not going to be a deficit model where we go in to see this is wrong and that is wrong." P8: "Most of the psychological assessment instruments we have is, um, needs based." P6: "The strengths and gifts are not taken into account."

\section{Theme 2: Individual and/or Community Assessments}

The participants discussed the tension between individual assessments versus community assessments, stemming from the challenge to address different levels of assessment to enhance the impact of intervention. 
P4: "We talk about two levels now; a generic kind of intervention program for a whole lot of communities... and then about individually tailored assessments, more focused program for specific needs to be addressed, where you look at that individuals' assets... support, to help that individual, either groups or individual." P3: "Now we are going to a whole context and assessing a whole context and situation." P1: "It's first to be pro-active within an environment and then after you've assessed all the assets, you've assessed all the resources, processes, you can then determine further assessment might be necessary for individual purposes."

Again the discussion focused on practicalities to explore and explain their perceptions. P4: "What about program development, because you are going to need to develop programs." P3: "That's suitable for the context in which you are working.... Work with existing programs and adapting it to make it more suitable." P1: "The capacity inventory... to have a framework like that to go into a community and assess the assets, resources, processes."

\section{Theme 3: Collaboration Skills}

The participants suggested that collaboration was an integral part of asset-based assessment. They shared that team work, role-release, lifelong learning as well as working in an indigenous manner were of importance. Some of the participants suggested that this collaboration could lead to empowerment and capacity building.

P1: “...to go to um, an institute and telling them...listen, I have these skills, I want to collaborate with you, I want to go into a community...have initiative.” P1: I think something else which links up with collaboration ... is that of teamwork." P4: "Something that links with teamwork is ... the skills to work multiculturally." P3: "The appreciation of diversity." P4: "To benefit from each other, benefit to learn." P6: "And linking with that is actually guiding others to believe in themselves" P2: "Letting go of your own role." P3: "There's definitely people who have a value of collaborating with each other, not only as a skill, but they value the collaborative style of professional conduct." P7: "That's why the empowerment is so important, and to use the resources available so that they, the community can actually go on... um without becoming dependant on the professional."

\section{Theme 4: Self-reflective Skills}

The participants seemed to regard self-reflective skills, such as self-awareness, self-monitoring, as well as insight and understanding of the client as of extreme importance. They associated these skills as a continuous process in asset-based assessment.

P4: "Being aware of your own value system, self-awareness, um, know where you come from so that you understand and respect and so forth, self-awareness, cause if you don't know yourself and know how you think and feel about communication and prejudice.” P1: “...for you to work comfortably, to be able to communicate, observe, have empathy for people different, diverse from what you know." P3: "I think if we think of the Hypocratical principle of first, do no harm, this whole principle of self-awareness and reflection becomes very important, because you can be doing harm without even realising it, and that is what you want addressed, so that they don't unknowingly do harm." P5: "Add meta-cognitive skills... to really monitor the process and keep monitoring yourself with making another plan, adjusting it." P4: "And I think with that goes honesty, honesty about your own weaknesses and honesty toward the people you are working with..." P5: "Transparency and openness." P4: "Antibias is very important." P3: "I think so, cause it links up with the value of non-discrimination." 


\section{DISCUSSION}

The four themes will now be compared to literature on the asset-based approach, with the purpose of exploring implications for asset-based assessment.

\section{Focusing on Assets}

The notion that the participants perceived a focus on assets as part of asset-based assessment came as almost no surprise. Available literature on the asset-based approach describes and explores the concept of "assets." As this concept is the core of the meaning that is associated with this approach, it is essential to take a closer look at what is meant by "focusing on assets." Kretzmann and McKnight (1993) explained "assets" as the talents, gifts, and skills of individuals, that which is present, the capacities of the individuals, associations and institutions. Hein (1999) also supported this when she argued for seeing and valuing youth as a resource and to capitalize on their fresh approach, talents, and energy. Sharpe and Greany (2000) referred to physical assets for example schools, playgrounds, and human assets. For Roehlkepartain and Leffert (2000), developmental assets are key factors that contribute to the development of children's full potential. From the focus group data assets are described as "green lights," available resources, capacities, areas of strength and gifts of individuals. This correlates with the asset-based literature, as well as with the strength-based approach. "Strengths" can be described as emotional and behavioral skills, competencies, and characteristics that create a sense of personal accomplishment and contribute to satisfying relationships (Rhee et al., 2001; Rudolph \& Epstein, 2000). Seligman (2002) stated clearly that if we are to understand wellbeing, we also have to understand personal strengths.

For the educational psychologist working within a framework of focussing on assets, all the relevant role players must become involved in identifying the capacities, competencies, resources, and areas of strength. Due to most current standardized instruments being deficit-based, a dynamic process of assessment and intervention seems most valuable. This entails identifying relevant role-players, establishing a trusting and working relationship and maintaining these relationships in the assessment process to receive ongoing input and feedback. The needs and problems faced by a particular family, school and/or community are not negated, but the process of assessment and intervention will develop from focusing on what is available, i.e. the assets.

When defined, this theme "focusing on assets," will therefore indicate an inclination in the educational psychologist conducting the assessment for the positive constructs, the strengths and the capacities.

\section{Individual and/or Community Assessments}

Educational psychologists are urged by current socioeconomic scenarios to broaden their perspective of viewing the individual as having the problem. The interrelation between individual and community assessment and intervention, the realization that it is neither single dimensional nor leveled, but an interrelated process, ought to be carefully weighed and considered. Educational psychologists will probably find themselves moving along a continuum between individual tailored assessments and broader based community assessments and interventions. Sharratt (1995) argued that there are few resources left for a professional practice in South Africa, oriented toward one-to-one interventions on an individual basis. An applications-only, individually focused profession is unlikely to be viable in the future of South Africa. Community-based intervention offers a process for implementing change with respect to shared decision making with parents, teachers, and other community members. This may increase the awareness of community members of community resources related to psychological care (Buysse, Wesley, \& Skinner, 1999). 
It is important for educational psychologists to realize that assessments need to be tailored according to the contextual factors that play a role, such as, culture, language, and familiarity with assessment concepts. Terre Blanche and Durrheim (1999) argue that if psychology as a profession is truly interested in empowerment, the reform of testing practices should be one of its priorities. Existing programs or techniques can be adopted in a scientific manner to enhance its suitability for a specific context, as done by Herbst and Huysamen (2000) who adopted existing evaluating instruments to develop new developmental scales for environmentally disadvantaged preschool children. The success of adapting programs, methods and techniques will largely depend on the effective collaboration between professionals from all disciplines.

In light of this study, the theme "individual and community assessments" can be defined as broad, systemic assessment that assesses both the individual and the surrounding community. As Baltes, Glück, and Kunzmann (2002, p. 341) suggest, conceptions of individual and collective wellbeing are tied together and it involves the insight that one cannot exists without the other.

\section{Collaboration Skills}

Enablement, capacity building and collaborating with significant caretakers in working partnerships are the essence of asset-based assessment (Mokwena, 1997; Page-Adams \& Sherraden, 1997). In partnership with parents, other caretakers and teachers, the assets of the family or community can be identified, then mobilized and expand in order to help them optimally cope in their daily lives (i.e., emotional health for life). As Stone-McCown (2003, p. 85) states, "with multiple resources people can create stronger relationships woven with the strands of trust, optimism, accountability and care." Another factor mentioned in the focus groups, was to work in a transdisciplinary manner. This links with the collaboration skills of teamwork, conflict resolution and role release. Embracing professionals from other disciplines in acknowledging their roles and capacities, and merging and mobilizing the experience and knowledge of all the stakeholders involved is essential in achieving collaboration.

Another point to consider is the notion of Indigenous Psychology, mentioned in the focus group. There are strong arguments in psychology that current psychological practices are carried out from a westernized, Eurocentric paradigm and that the rich tradition of African/South African psychological theory also needs to be incorporated for professionals to work within an indigenous framework. Indigenization implies that existing theories and constructs can be utilized, but in order to enhance the suitability in working with a specific community, it should be adapted, modified and/or refined (Freeman, 1991; Moll, 2002; Stead \& Watson, 1999).

The asset-based rationale for assessment and intervention is to work with what we have, to think in terms of capacities, collaboration, partnerships, empowerment and enablement (Kretzmann \& McKnight, 1993; Mokwena, 1997). To achieve this, the educational psychologist will have to move away from traditionalist thinking and create new and creative pathways for assessment and intervention.

Parents and other caretakers are increasingly seen as partners in the assessment process. The fields of Education and Psychology are moving away from the notion that the professional is the only expert that can assess and optimally know the child. Research increasingly indicates that by involving the parents/ caretakers the whole community becomes involved, with the secondary effects of capacity building and empowerment (Feikama, Segalavich, \& Jeffries, 1997; Lockett, 2000; Webster-Stratton, 1997). Dinnebeil, Hale, and Rule (1999) emphasize this point by stating that effective services are provided in the context of a collaborative relationship between family members and the professionals, that parents are viewed as the key decision makers and regarded as partners in the service delivery. The characteristics of these partnerships include high levels of mutual acceptance, respect, openness, trust, and shared responsibility. This implies that the role of the educational psychologist will change from 
the traditional view of assessing and intervening (Sharatt, 1995) to that of facilitating, consulting, networking, and collaboration.

A final operational definition stemming from the focus groups was that collaboration means the sharing of ideas in a joint decision-making and problem-solving process directed toward a common goal. An atmosphere of mutual respect and support, trust, and open communication enhances this process to enable all stakeholders involved.

\section{Self-reflective Skills}

From the results it can be seen that a psychologist's self-reflectiveness is of extreme importance. These self-reflective skills and self-awareness correlate with multicultural values and the skills and knowledge needed for working with people with diversities or different abilities. Egan (1998) stated that the awareness of the helper's own cultural values and biases together with an understanding of the worldview of the client can help counselors to take special care to be sensitive to differences. Although reflection as a skill is well known in psychological circles (Baldwin, 2002; Upton, 1999) it has not yet been this strongly associated with the asset-based approach. Sharpe and Greany (2000) are so far the only authors that link reflection with the asset-based approach and mention that in assessments, constant self-reflection is necessary, and mutual respect and trust need to exist between the assessor and the community.

The importance for assessment is that self-reflection must become part of the assessment process, that one's self-awareness is an integral component and cannot just be seen as an added on skill. This links directly to the asset-based principle of working with what is present in the given situation. The strong emphasis on self-reflective skills as a category/theme in this study, opens up yet another new opportunity for research and for practitioners to explore. Self-reflective skills, according to the focus group data, entail the ability to be aware of your true self, your own value system, your own biases, strengths, respecting different viewpoints, true understanding of a fellow human being, and working in the true spirit of enhancing people's gifts, capacities, experiences, knowledge and insights.

\section{CONCLUSION}

This study focused on perceptions about asset-based assessment, which is an under-examined area in Educational Psychology. Research on how assessment from an asset-based perspective translates into the theory and practice of Educational Psychology has been limited and fragmented. Perceptions of professionals were explored and four main themes, focusing on important components of the assessor, were identified. These perceptions enhance our understanding of the ways in which practitioners and scholars view asset-based assessment.

\section{REFERENCES}

Ammerman, A., \& Parks, C. (1998). Preparing students for more effective community interventions: Assets assessment. Family and Community Health, 21, 32-43.

Baldwin, C. M. (2002). Teaching self-reflection and meta-cognition. ETC: A Review of General Semantics, 59, 71-82.

Baltes, P. B., Glück, J., \& Kunzmann, U. (2002). Wisdom: Its structure and function in regulating successful life span development. In C. R. Snyder \& S. J. Lopez (Eds.), Handbook of positive psychology (pp. 327-350). Oxford, England: Oxford University Press.

Buysse, V., Wesley, P. W., \& Skinner, D. (1999). Community development approaches for early intervention. Topics in Early Childhood Special Education, 19, 236-243.

Dinnebeil, L. A., Hale, L., \& Rule, S. (1999). Early intervention program practices that support collaboration. Topics in Early Childhood Special Education, 19, 225-235.

Ebersöhn, L., \& Eloff, I. (2003). Lifeskills and assets. Pretoria, South Africa: Van Schaik. 
Egan, G. (1998). The skilled helper: A problem-management approach to helping (6 ${ }^{\text {th }}$ ed.). Pacific Grove, CA: Brooks/Cole.

Eloff, I., \& Ebersöhn, L. (2001). The implications of the asset-based approach for early intervention. Perspectives in Education, 19, 147-157.

Feikama, R. J., Segalavich, J. H., \& Jeffries, S. H. (1997). From child development to community development: One agency's journey. Family in Society: The Journal of Contemporary Human Services, 78, 185-195.

Freeman, M. (1991). Mental health for all-moving beyond rhetoric. South African Journal of Psychology, 21, 141-146.

Fullan, M. (2002). Leading in a culture of change. Presentation at the University of Pretoria, Senate Hall, Groenkloof campus, February 2002.

Goldrick, M., \& Gerson, R. (1985). Genograms in family assessment. New York: Norton.

Hayes, N. (2000). Doing psychological research. London: Open University Press.

Hein, K. (1999). Young people as assets: A foundation view. Social Policy, 30, 20-30.

Herbst, I., \& Huysamen, G. K. (2000). The constructions and validation of developmental scales for environmentally disadvantaged preschool children. South African Journal of Psychology, 30, 19-24.

Hernandez, E. (1998). Assets and obstacles in community leadership. Journal of Community Psychology, 26, 269280.

Hiew, C. (2002). Stress and resilience in Canadian school aged children. Paper presented at the International Conference of Applied Psychology, Singapore, July 2002.

Kretzmann, J. P. (2000). Co-producing health: Professionals and communities build on assets. Health Forum Journal, 43, 42.

Kretzmann, J. P., \& McKnight, J. L. (1993). Building communities from the inside out: A path toward finding and mobilizing a community's assets. Chicago: ACTA.

LaFramboise, T. (2002). Resilience in Native American teenagers. Paper presented at University of Pretoria, Senate Hall, Groenkloof campus, August 2002.

Lockett, A. (2000). A contextual orientation to assessment. In S. Wolfendale (Ed.), Special needs in the early years: Snapshots of practice (pp. 178-205). London: Routledge Falmer.

McDonald, L. (1997). Building on the strengths and assets of families and communities. Families in Society, 78, 115-116.

Mokwena, K. (1997). Empowerment as a tool for community health development. CHASA Journal of Comprehensive Health, 8, 66-70.

Moll, I. (2002). African psychology: Myth or reality. South African Journal of Psychology, 32, 9-16.

Morgan, D. L. (1997). Focus groups as qualitative research ( $2^{\text {nd }}$ ed.). Thousand Oaks, CA: Sage.

Morse, J. M. (Ed.). (1994). Critical issues in qualitative research methods. Thousand Oaks, CA: Sage.

Neuman, W. L. (2000). Social research methods, qualitative and quantitative approaches. Boston: Allyn \& Bacon.

Ow, R. (2002). Stress and resilience in Singaporean youth. Paper presented at the International Conference of Applied Psychology, Singapore, July 2002.

Page-Adams, D., \& Sherraden, M. (1997). Asset building as a community revitalization strategy. Social Work, 42, 423-429.

Patton, M. (2002). Evaluation. Presentation at the University of Pretoria, Senate Hall, Groenkloof campus, April 2002.

Rhee, S., Furlong, M. J., Turner, J. A., \& Harari, I. (2001). Integrating strength-based perspectives in psychoeducational evaluations. The California School Psychologist, 6, 5-17.

Roehlkepartain, J. L., \& Leffert, N. (2000). What young children need to succeed. Minneapolis, MN: Free Spirit Publishing.

Rudolph, S. M., \& Epstein, M. H. (2000). Empowering children and families through strength-based assessment. Reclaiming Children and Youth, 8(4), 207-209. Retrieved January 28, 2004, from http://www.air.org/cecp/ interact/expertonline/strength/empower/2.htm.

Satiadarma, M. (2002). Stress and resilience in Indonesian street children. Paper presented at the International Conference of Applied Psychology, Singapore, July 2002.

Sharpe, P. A., \& Greany, M. L. (2000). Assets-orientated community assessment. Public Health Reports, 115, 205-214.

Sharratt, P. (1995). Is educational psychology alive and well in the new South Africa? South African Journal of Psychology, 25, 211-216.

Seligman, M. E. P. (2002). Authentic happiness. New York: Random House.

Stead, G. B., \& Watson, M. B. (1999). Indigenisation of career psychology in South Africa. In G. B. Stead \& M. B. Watson (Eds.), Career psychology in the South African context (pp. 214-225). Pretoria, South Africa: Van Schaik.

Stone-McCown, K. (2003). From theory to practice: a personal history of Self-Science. Perspectives in Education, $21(4), 83-85$. 
Takahashi, K. (2002). Stress and resilience in Japanese school-aged children. Paper presented at the International Conference of Applied Psychology, Singapore, July 2002.

Terre Blanche, M., \& Durrheim, K. (Eds.). (1999). Research in practice, applied methods for the social sciences. Cape Town, South Africa: UCT Press.

Upton, D. (1999). Encouraging counsellor reflection. British Journal of Guidance and Counselling, 27, 191-204.

Webster-Stratton, C. (1997). From parent training to community building. Family in Society: The Journal of Contemporary Human Services, 78, 156-171.

Wissing, M. P., \& Van Eeden, C. (2002). Empirical clarification of the nature of psychological well-being. South African Journal of Psychology, 32, 32-44. 
The California School Psychologist, Vol. 9, pp. 39-49, 2004 Copyright 2004 California Association of School Psychologists

\title{
Predicting Positive Outcomes for Students With Emotional Disturbance
}

\author{
Amanda B. Nickerson \\ University at Albany, State University of New York \\ Amy M. Brosof \\ Devereux Day School \\ Valerie B. Shapiro \\ Devereux Institute for Clinical Training and Research
}

\begin{abstract}
This longitudinal study assessed changes in skills for students with emotional disturbance (ED) over a one-year time period in a private special education school and examined variables that predicted positive outcomes for these students. At Time 1, teachers rated 84 students with ED using standardized behavior rating scales to assess problem severity and skills for predicting inclusion. Information was also obtained about students' school behavior from the school's behavioral level system. One year later (Time 2), the educational placement of 83 of the 84 students was categorized as being either equal/more restrictive or being less restrictive, and teachers completed rating scales assessing skills for inclusion and emotional/behavioral strengths of 54 students still enrolled in the special education school. Students exhibited improved peer relationships and emotional maturity, and demonstrated several strengths. Scores indicated that the students with ED were unlikely to experience success in less restrictive educational settings. Although none of the variables predicted placement in less restrictive educational settings, problem severity, school behavior, and skills for inclusion each predicted the other positive outcomes. The importance of using strength-based approaches, in addition to empirically supported interventions, is highlighted.
\end{abstract}

Key words: Strengths, Emotional Disturbance, Educational Placement

Educating students with emotional disturbance (ED) has resulted in bleak outcomes (Meadows, Neel, Scott, \& Parker, 1994; Reddy, 2001). The profound impact of social, emotional, and behavioral problems on students' educational, familial, social, vocational, and interpersonal functioning has been emphasized in the literature (Quinn \& McDougal, 1998). Historically, assessment and intervention for youths with ED has focused on deficits, but recent ideology has centered on the importance of positive psychology and strength-based approaches (Huebner \& Gilman, 2003; Rhee, Furlong, Turner, \& Harari, 2001). The purpose of this longitudinal study was to assess changes in skills theorized to be related to successful inclusion over a one-year time period for students attending a special education school. The study also examined the extent to which problem severity, school behavior, and skills for predicting inclusion predicted a variety of positive outcomes for students with ED.

Half of students with ED drop out of school, which is the highest dropout rate among children with disabilities (U.S. Department of Education, 2002). In addition, students with ED who attend school are more likely to be placed in restrictive educational settings (Reddy, 2001). Although educating students with disabilities in the least restrictive educational environment has been a priority from both legislative and professional standpoints, children with ED are often unsuccessful in the general education setting and present educators with many challenges, such as poor work habits, social skills

Address correspondence to Amanda Nickerson; Department of Educational and Counseling Psychology; ED 232; University at Albany-State University of New York, Albany, NY 12222. E-mail: anickerson@uamail.albany.edu. The authors express their sincere appreciation to the teachers who participated in this study. We also thank Sarah Colby for her editorial assistance. 
deficits, and behavioral extremes such as aggression or withdrawal (Meadows et al., 1994). Schoolbased best practices include competent assessment, behavioral or cognitive-behavioral interventions, academic instruction, crisis management, and interdisciplinary collaboration (Quinn \& McDougal, 1998). However, assessment of ED is often problematic, particularly with regard to the federal definition's exclusion of children only with social maladjustment, which can be difficult to distinguish from ED (Forness, 1992). In addition, school personnel are often unprepared for the challenging behaviors exhibited by students with ED (Cheney \& Barringer, 1995).

Given these sobering statistics, it is not surprising that deficit-based approaches to youth functioning and outcomes have been institutionalized in school psychology training and practice. However, a shift toward positive psychology and strength-based perspectives has begun to occur (Huebner \& Gilman, 2003; Rhee et al., 2001). In order to gain a comprehensive understanding of mental health, it is necessary to understand the factors that contribute to positive outcomes as well as those that contribute to psychopathology (Huebner \& Gilman, 2003) and to better integrate the constructs of competence and psychopathology (Masten \& Curtis, 2000).

Perhaps the most well articulated aspect of a strength-based approach in school psychology has been strength-based assessment. This has been defined as "the measurement of those emotional and behavioral skills, competencies, and characteristics that create a sense of personal accomplishment; contribute to satisfying relationship with family members, peers, and adults; enhance one's ability to deal with adversity and stress; and promote one's personal, social, and academic development" (Epstein \& Sharma, 1998, p. 3). Although formal, norm-based assessment of strengths has been argued to be of great utility, there is a need for closer psychometric scrutiny of strength-based measures (Epstein, Dakan, Oswald, \& Yoe, 2001).

\section{Predictors of Positive Outcomes}

There has been a growing interest in factors related to child well-being and resilience, or competence despite exposure to significant stressors. Variables such as temperament, internal locus of control, extraversion, close peer relationships, and adult support systems outside the family predict resilience and well-being (Doll \& Lyon, 1998; Huebner, 1991, 1997). There is evidence to suggest that children who are transitioned from special education to general education settings before sixth grade (Schneider \& Byrne, 1984), and students who have effective work habits, positive peer relationships, and coping skills (Fad \& Ryser, 1993) are more likely to be successful in less restrictive educational settings than children who are transitioned after sixth grade and those who do not possess these skills. However, students with ED are largely under-represented in the aforementioned studies. Significant attention has been given to problem reductions for students with ED, but far less is known about the strengths developed in special education programs (Epstein \& Sharma, 1998). Both strengths and severity of psychopathology are related to children's discharge to less restrictive placements from residential treatment centers (Lyons, Uziel-Miller, Reyes, \& Sokol, 2000; Oswald, Cohen, Best, Jenson, \& Lyons, 2001), though school-based studies are needed to examine strengths that develop in special education programs and the extent to which individual skills and problem severity predict placement in less restrictive educational environments.

The Scales for Predicting Successful Inclusion (SPSI; Gilliam \& McConnell, 1997) was developed to evaluate student adjustment and assist educators in making placement decisions. Although the SPSI has adequate psychometric properties, there is a lack of research using the instrument to predict outcomes for students with ED (Worth, 2000). Because these students are often expected to adopt the standards of behaviors expected in less restrictive environments, validating the SPSI for use with this population is important. The SPSI has been shown to distinguish between ED students with more and 
less severe behaviors, but longitudinal studies are needed to assess the instrument's ability to assess change following intervention and to predict placement in less restrictive settings (Nickerson \& Brosof, 2003).

This study addressed these research needs by examining strengths and skills of students with ED and assessing factors that predict positive outcomes. Goals of this study were to (a) compare skills related to successful inclusion across a one-year time period for students with ED attending a private special education school; (b) assess the skills for inclusion and strengths of these students; and (c) determine the extent to which school behavior, problem severity, and skills predict several positive outcomes for students with ED, such as restrictiveness of educational environment, readiness for inclusion, and emotional and behavioral strengths.

\section{METHOD}

\section{Participants}

Time 1. Participants at Time 1 consisted of 84 students classified with ED according to state and federal guidelines. The students attended a private special education school in the suburb of a large mid-Atlantic city. The school offers individualized instruction, behavioral interventions, social skills training, assessment, consultation, individual and group counseling, and interdisciplinary collaboration. Ninety-two percent of the sample was male and $8 \%$ was female. The students ranged in age from $9-18$, with a mean age of $14.19(S D=2.27)$. Eighty-seven percent of the sample was Caucasian, $11 \%$ was African-American, $1 \%$ was Asian, and the remaining $1 \%$ was from multi-racial backgrounds.

Time 2. Participants at Time 2 included 83 of the 84 students from Time 1 for whom data were collected on educational placement. One student moved out of state and the researchers were unable to obtain information about the placement. In addition, ratings of skills and strengths were collected for the 54 students who were still enrolled in the special education school. These students ranged in age from 11-18, with a mean age of $14.98(S D=2.16)$. Eighty-three percent of this sample was Caucasian, $13 \%$ African-American, and the remaining $4 \%$ was distributed evenly across Asian and multi-racial backgrounds.

\section{Measures}

Skills for inclusion. The Scales for Predicting Successful Inclusion (SPSI; Gilliam \& McConnell, 1997) is a 60-item standardized rating scale that includes four subscales: Work Habits, Coping Skills, Peer Relationships, Emotional Maturity, and a Successful Inclusion Quotient (SIQ). Teachers rate the student's behavior on a 9-point Likert-type scale broken down into three broadband categories (1-3 = below average, 4-6 = average, 7-9 = above average). The SIQ has a mean of 100 and a standard deviation of 15 , and the subscales have a mean of 10 and a standard deviation of 3 . The standardization sample consisted of 1,715 school-age children, which was divided into two norm groups: (a) students without disabilities and (b) students with disabilities. Both groups represented demographic characteristics of the U.S. school population.

According to the test manual (Gilliam \& McConnell, 1997), internal reliability coefficients for the subscales are above .95 for students with and without known disabilities. Over a one-week time period, inter-rater reliability coefficients ranged from .82-.94 for students with disabilities. SPSI subscales correlated inversely with the Connors' Teacher Rating Scales and positively with the Adjustment Scales for Children and Adolescents. The SPSI successfully distinguished between students with a variety of disabilities and those without, as well as students who were successful in school and those who were unsuccessful. 
Problem severity. The Devereux Behavior Rating Scale-School Form (DBRS-SF; Naglieri, LeBuffe, $\&$ Pfeiffer, 1993) is a 40-item behavior rating scale comprised of a Total Scale and four subscales reflecting the federal definition's domains of emotional disturbance: Interpersonal Problems, Inappropriate Behaviors/Feelings, Depression, and Physical Symptoms/Fears. Each item is rated on a scale from 0 to 4 ( 0 =never, $1=$ rarely, $2=$ occasionally, $3=$ frequently, $4=$ very frequently). The Total Scale has a mean of 100 and a standard deviation of 15, and subscales have a mean of 10 and a standard deviation of 3 . The standardization sample consisted of 3,153 children and adolescents between the ages of 5-18.

Internal reliability coefficients for the Total Scale range from .92-.97 and the median internal reliability coefficients for the subscales range from .82-.85. Test-retest reliability coefficients range from $.53-.84$ for the subscales and .69-.85 for the Total Scale. Subscale inter-rater reliability coefficients range from .36-.60 and Total Scale reliability coefficients range from .40-.53. Several studies examining the criterion-related of the $D B R S-S F$ have found overall classification accuracy rates of $75.3 \%$ for the $5-12$ year-old sample and $77.5 \%$ for the $13-18$ year-old sample.

School behavior. A behavioral level system is the primary means by which the school collects data on students' school behavior. All students entering the school begin on Level 2, and work their way up through levels 3, 4, and 5 as they achieve behavioral success. During each period, students complete a point sheet where they record whether or not they have achieved each of the following goals: (a) follow directions the first time, (b) complete work within assigned time, (c) keep hands and feet to self, (d) remain on task, and (e) use positive comments and language. Teachers also record whether or not the students have achieved each of the goals and students can earn up to one bonus point each period if their self-assessment matches the teacher's assessment of their behavior. The teacher point total is used to determine whether the student meets the point requirement to "earn" the day. A student must earn a specified number of days to move up a level (e.g., students must obtain specified number of points for 10 days on level 2, 15 days on level 3, and 20 days on level 4, and 10 days on level 5).

Educational environment. Information was obtained about each student's educational environment, which was coded " 0 " for equally or more restrictive (e.g., special education school, residential treatment center, or juvenile detention facility) or "1" for less restrictive (e.g., home school district, vocational school, graduated) compared to the previous year.

Emotional and behavioral strengths. The Behavioral and Emotional Rating Scale (BERS; Epstein \& Sharma, 1998) was designed to measure the emotional and behavioral strengths of children. The scale's 52 items comprise five areas of childhood strengths, derived through factor analysis: Interpersonal Strength, Family Involvement, Intrapersonal Strength, School Functioning, and Affective Strength. Combining the five subscale standard scores derives the Strength Quotient. Items are rated on a Likerttype scale ranging from 0 to $3(0=$ not at all like the child, $1=$ not much like the child, $2=$ like the child, 3 = very much like the child). The Strength Quotient has a mean of 100 and a standard deviation of 15 and the subscales have a mean of 10 and a standard deviation of 3. The standardization sample for the $B E R S$ consisted of a nationally representative sample of 2,176 students ranging in age from 5-18 years. In addition, 861 students ranging in age from 5-18 diagnosed with an emotional or behavioral disorder comprised a separate normative group.

The internal consistency for the Strength Quotient ranged from .95-.97 for disabled children and $.96-.99$ for nondisabled children. One study found a test-retest reliability of .99 and inter-rater reliability coefficients of .98 for the Strength Quotient and .83 and higher for the subscales (Epstein, Harniss, Pearson, \& Ryser, 1999). The concurrent validity of the BERS has been demonstrated with other rating scales (Harniss, Epstein, Ryser, \& Pearson, 1999) and the BERS differentiates between emotionally or behaviorally disabled children and nondisabled children (Epstein \& Sharma, 1998). 


\section{Procedure}

Time 1 data were collected in Spring 2002. The SPSI was designed to be completed by teachers, so the other rating scales were also administered to teachers to ensure consistency. All 11 certified special education teachers in the school were asked to read instructions and complete the SPSI and the $D B R S-S F$ for students in their homerooms, as the homeroom teacher served as the primary instructor for students and the liaison between home and school. Information about each student's behavioral level during the week preceding the completion of the rating scales was obtained. Because the behavioral level system is structured according to a graduated system, the number of days earned was divided by the total number of days needed for advancement, yielding equal proportions for each behavioral level. The lowest possible level was level 2, day 1 (2.0), and the highest level was level 5, day 10 (6.0). Time 2 data were collected one year later in Spring 2003. Information about the child's educational placement was obtained from school staff. All 10 certified special education teachers in the school completed the SPSI and BERS on their homeroom students, resulting in 10 students having the same teacher rate their behavior for Time 1 and Time 2. The BERS replaced the DBRS-SF at Time 2 to measure positive outcomes for the students. Standard scores were obtained by using norms for the standardization sample, as opposed to clinical norms, to facilitate comparisons across measures.

\section{RESULTS}

\section{Changes in Skills for Inclusion}

To assess changes in students' skills for inclusion from Time 1 to Time 2, a series of paired $t$-tests were conducted on the SIQ and all subscales of the SPSI. Because five separate $t$-tests were conducted, a Bonferroni correction was used to minimize Type I errors, resulting in an alpha level of .01. As shown in Table 1, scores in all areas increased from Time 1 to Time 2, with Peer Relationships and Emotional Maturity showing significant increases. Despite these changes, Time 2 SIQ and SPSI subscale means indicated that students were "unlikely" or "very unlikely" to exhibit skills necessary for successful adjustment in inclusive settings according to descriptive classifications in the SPSI test manual (Gilliam \& McConnell, 1997).

The emotional and behavioral strengths of the students with ED were assessed at Time 2 with the BERS. The overall mean on the Strength Quotient of $87.50(S D=12.28)$ fell within the "below average" range (Epstein \& Sharma, 1998). However, many strengths across subscales fell into the qualitative "average" range compared to the normative sample: Interpersonal Strength $(M=8.00, S D=2.19)$, Family Involvement $(M=8.50, S D=2.13)$, Intrapersonal Strength $(M=8.78, S D=2.60)$, School Functioning $(M=8.04, S D=2.64)$, and Affective Strength $(M=8.69, S D=2.39)$.

\section{Predictors of Positive Outcomes}

As shown in Table 2, the predictor variables of less problem severity and better school behavior, as measured by the Time 1 DBRS-SF Total Scale and behavioral level, respectively, correlated significantly with the Time 2 criterion variables of skills for inclusion and emotional and behavioral strengths. In addition, Emotional Maturity was significantly correlated with both criterion variables, and Inappropriate Behaviors/Feelings was correlated in a significant, inverse direction with both criterion variables. Time 1 Coping Skills and the SIQ correlated significantly with the Time 2 SIQ. In addition, Interpersonal Problems correlated inversely with the Time 2 SIQ. Depression at Time 1 was negatively correlated with emotional and behavioral strengths at Time 2. In addition, the criterion variables (SIQ and BERS Strength Quotient) correlated significantly, $r=.73, p<.001$. 
Table 1.

Time 1 and Time 2 Scales for Predicting Successful Inclusion Ratings $(n=54)$

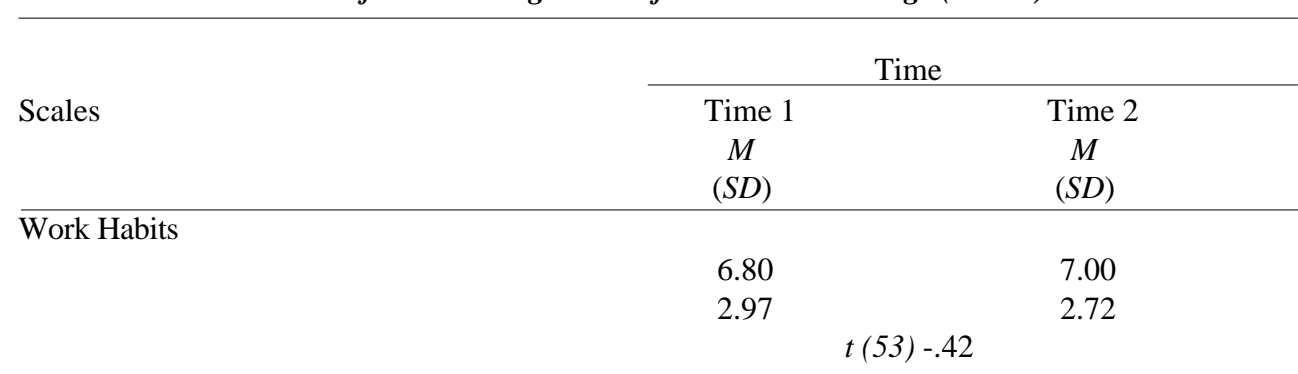

Coping Skills

$\begin{array}{lll}5.46 & & 6.11 \\ 3.06 & & 3.04 \\ & t(53)-1.41 & \end{array}$

Peer Relationships

$\begin{array}{lll}5.06 & & 6.44 \\ 3.21 & & 3.27 \\ & t(53)-2.84^{*} & \end{array}$

Emotional Maturity

$\begin{array}{lrr}5.04 & & 6.39 \\ 2.96 & & 3.33 \\ & t(53) 3.01 * & \end{array}$

Successful Inclusion Quotient

$\begin{array}{lll}70.67 & & 76.59 \\ 17.88 & & 17.53 \\ & t(53)-2.15 & \end{array}$

Note. Subscale standard score $M=10, S D=3$; Successful Inclusion Quotient standard score $M=100$, $S D=15$. $* p<.01$.

Sixty-three students $(76 \%)$ were in educational placements at Time 2 of equal or greater restrictiveness than those at Time 1 . The majority (57) remained in the same special education school, 1 student was transferred to another special education school, 4 were hospitalized or in juvenile detention facilities, and 1 student dropped out. Of the 20 students who were in less restrictive educational placements at Time 2, 16 returned to their public school districts and 4 graduated from high school. To examine variables that predicted educational placement, logistic regression analyses were conducted. Younger age, less severe problems, possession of skills for inclusion, and positive school behavior have all been theorized to be important for placement in less restrictive educational settings. Therefore, predictor variables included age, total scale scores on the DBRS-SF and SPSI, and behavioral level. The criterion variable was educational placement at Time 2, dichotomized as the same or more restrictive (coded 0 ) or less restrictive (coded 1) than the previous year. The logistic regression model was not significant, $\chi^{2}(4)=4.75, p=.32$, indicating that the variance in educational placement was not explained by the model. 
Table 2.

Correlations Between Time 1 Predictor Variables and Time 2 Criterion Variables

Time 1 Predictor Variables

Time 2 Criterion Variables

\begin{tabular}{lcc}
\cline { 2 - 3 } & $\begin{array}{c}\text { SPSI } \\
\text { Successful Inclusion Quotient }\end{array}$ & $\begin{array}{c}\text { BERS } \\
\text { Strength Quotient }\end{array}$ \\
\hline Work Habits & .22 & .21 \\
Coping Skills & $.35^{* *}$ & .19 \\
Peer Relationships & .23 & .25 \\
Emotional Maturity & $.40^{* *}$ & $.28^{*}$ \\
Successful Inclusion Quotient & $.34^{*}$ & .26 \\
Interpersonal Problems & $-.31^{*}$ & -.23 \\
Inappropriate Behaviors/Feelings & $-.42^{* *}$ & $-.34^{*}$ \\
Depression & -.22 & $-.43^{* *}$ \\
Physical Symptoms/Fears & -.09 & -.21 \\
DBRS-SF Total Scale & $-.38^{* *}$ & $-.47^{* *}$ \\
Behavioral Level & $.35^{* *}$ & $.34^{*}$ \\
\hline
\end{tabular}

Note. SPSI = Scales for Predicting Successful Inclusion; BERS = Behavioral and Emotional Rating Scale; DBRS-SF = Devereux Behavior Rating Scale-School Form.

$* p<.01 . * *<.001$.

A simultaneous multiple regression analysis was conducted for the 54 students for whom Time 2 SPSI data were collected to assess the extent to which age and functioning at Time 1, assessed by the $S P S I, D B R S-S F$, and behavioral level system, predicted ratings on the SPSI SIQ. Simultaneous regression was selected to assess the extent to which each variable contributed unique variance to students' readiness for inclusion. The regression model was significant, $F(4,53)=4.70, p<.01$, Adjusted $R^{2}=$ .22. A closer inspection of the data indicated that the only variable that significantly predicted $S P S I$ scores at Time 2 was the DBRS-SF Total Scale from Time $1, B=-.32, t=-1.99, p<.05$. To assess which specific problems predicted the SIQ at Time 2, a separate regression model was conducted with DBRS$S F$ subscales serving as predictor variables, $F(4,53)=2.68, p<.05$, Adjusted $R^{2}=.11$. The only variable that contributed unique variance to the SIQ at Time 2 was the $D B R S-S F$ Inappropriate Behavior/Feelings subscale, $B=-.39, t=-2.07, p<.05$. A series of exploratory standardized multiple regression analyses were conducted with each subscale of the SPSI serving as a separate criterion variable. 
School behavior, as measured by the behavioral level system, predicted Time 2 Work Habits, $F(3,53)$ $=5.72, p<.01$, Adjusted $R^{2}=.21, \beta=.42, t=2.76, p<.01$, and Coping Skills, $F(3,53)=4.50, p<.01$, Adjusted $R^{2}=.17, \beta=.30, t=1.90, p<.06$. Time 1 SIQ predicted Time 2 Peer Relationships, $F(3,53)$ $=3.02, p<.05$, Adjusted $R^{2}=.10, \beta=.30, t=2.21, p<.05$, and Emotional Maturity, $F(3,53)=4.91$, $p<.01$, Adjusted $R^{2}=.18, \beta=.29, t=2.24, p<.05$.

The multiple regression analysis using Time 1 behavioral level, SIQ, and the DBRS-SF Total Scale as predictor variables and the BERS Strength Quotient, was also significant, $F(3,53)=5.23$, $p<.01$, Adjusted $R^{2}=.19$. Similar to the findings for the Time 2 SIQ, the only variable that significantly predicted emotional and behavioral strengths at Time 2 was the Time 1 DBRS-SF Total Scale Score, $B=-.44, t=-2.70, p<.01$. A follow-up simultaneous regression analysis revealed that the $D B R S-S F$ Depression subscale was the only variable that uniquely predicted the Time 2 BERS Strength Quotient, $F(4,53)=3.45, p<.01$, Adjusted $R^{2}=.16, \beta=-.36, t=-2.43, p<.05$. Exploratory analyses using each Time 2 BERS subscale as a separate criterion variable indicated that behavioral level predicted School Functioning, $F(3,53)=3.22, p<.05$, Adjusted $R^{2}=.11, \beta=.36, t=2.21, p<.05$ and problem severity, measured by the $D B R S-S F$, predicted Interpersonal Strengths, $F(3,53)=5.38$, $p<.01$, Adjusted $R^{2}=.20, \beta=-.33, t=-2.14, p<.05$.

\section{DISCUSSION}

Results of this study add to our limited knowledge about strengths exhibited by students with ED, changes in skills over a one-year time period in a special education setting, and variables that predict positive outcomes for these students. Students with ED showed improved emotional maturity and peer relationships over the course of a one-year time period in the special education school. In addition, teachers rated the students as having a number of strengths at Time 2, including intrapersonal and affective strengths, school functioning, family involvement, and interpersonal strengths. Although this may suggest that the "best practice" services provided in the school (e.g., behavioral interventions, interdisciplinary collaboration) led to improved skills, this determination cannot be made definitively due to the non-experimental nature of the design. Although the students' skills improved over time, their scores on the SPSI suggested that success in inclusive settings would be unlikely, which is consistent with the known pervasive nature of the problems for students with ED (Quinn \& McDougal, 1998).

None of the variables predicted the restrictiveness of educational placement for the students. Therefore, the predictive validity of the SPSI with this sample was not supported, which is consistent with Worth's (2000) hypothesis that the SPSI may be more reliable and valid for students with physical and learning disabilities than for those with ED. Because the variables under investigation in this study were limited to student skills and behaviors, important teacher and school variables that may have accounted for much of the variance in restrictiveness of educational placement were not examined. Inclusion of students with ED into general education settings appears to require intensive training of school personnel, consultative support, and specific interventions (Shapiro, Miller, Sawka, Gardill, \& Handler, 1999).

Problem severity was a significant predictor of students' skills for inclusion in Year 2. Specifically, students with lower scores on the Inappropriate Behaviors/Feelings subscale of the DBRS-SF, which assessed externalizing behaviors (e.g., difficulty controlling anger, verbal and physical disruptive behaviors), were more likely to exhibit skills for inclusion and emotional and behavioral strengths. Aggression and anger have been associated with a wide range of social, academic, and health-related outcomes (Smith \& Furlong, 1998) and results of this study underscore their potential role in prevent- 
ing children from increasing skills and maximizing strengths. The presence of these externalizing behaviors also highlights the difficulty in distinguishing emotional disturbance from social maladjustment.

School behavior, as assessed by the behavioral level system, predicted work habits, coping skills, and school functioning, suggesting the importance of day-to-day school behavior for successful outcomes. These results also provide evidence for the use of the level system as one of many possible predictors of future school performance for students. In addition, the SIQ predicted scores on two Year-2 SPSI subscales. Although the SPSI did not predict students' placement at Time 2, the fact that the total scale predicted subscale scores one year later is a positive indicator of the measure's stability.

Depression predicted students' emotional and behavioral strengths at Time 2. Although externalizing behaviors have greater long-term predictive significance for competence, internalizing problems may have greater significance in terms of future adaptation than once thought (Masten \& Curtis, 2000). Results from this study suggest that depression may inhibit children's emotional and behavioral strengths, particularly in terms of interpersonal strengths.

\section{Limitations}

Because this study was conducted with a small sample consisting primarily of Caucasian students from a single private education school, results cannot be generalized to other populations. Special education teachers completed all the ratings, so it is possible that expectancy effects influenced the results. It would be useful to validate the teachers' ratings by obtaining ratings from parents and students, especially because some measures, such as the $D B R S-S F$, have low inter-rater reliability coefficients. In addition, few students were exited from the school, which may have diminished the ability of the measures to find differences. Both the small sample size and measurement issues may have contributed to nonsignificant findings. In addition, using restrictiveness of educational placement as an outcome criterion was limiting because it did not provide information about the student's functioning within the environment. As mentioned previously, a limitation of this study was that it focused exclusively on student strength, skills, and behaviors, as opposed to important contextual variables (e.g., placement options).

\section{Future Research}

Although the strength-based approach is, in some ways, in its empirical infancy, the growing recognition of its importance and the potential for research that may enhance the lives of children and families is exciting. Future studies should assess positive outcomes for students with ED using information gathered from multiple informants, such as special education teachers, parents, students, and general education teachers from the inclusive setting. Research is also needed to examine changes in emotional and behavioral strengths of children with ED over time and the specific types of programs and interventions that lead to these positive changes, which could be measured by administering the same measures pre- and post-intervention. Longitudinal studies that examine the dynamic interplay between problem severity, strengths, academic skills, and adaptive functioning in less restrictive educational environments are also needed to further explore the complex relationship between these constructs.

\section{Implications for Practice}

Students in this private education school showed improvements in emotional maturity and peer relationships over a one-year time period and exhibited many strengths, yet still were unlikely to be 
successful in inclusive settings. In addition, both externalizing and internalizing problems were predictive of skills and strengths. It is critical for school psychologists to use comprehensive assessment, prevention, and intervention approaches that enhance strengths and skills. Strength-based approaches should not negate the need for treatment of emotional and behavioral problems, rather, recognizing and nurturing existing skills and strengths should augment the use of empirically-based interventions.

\section{REFERENCES}

Cheney, D., \& Barringer, C. (1995). Teacher competence, student diversity, and staff training for the inclusion of middle school students with emotional and behavioral disorders. Journal of Emotional and Behavioral Disorders, 3, 174-182.

Doll, B., \& Lyon, M. A. (1998). Risk and resilience: Implications for the delivery of educational and mental health services in schools. School Psychology Review, 27, 348-363.

Epstein, M. H., \& Sharma, J. M. (1998). Behavioral and Emotional Rating Scale: Examiner's manual. Austin, TX: Pro-Ed.

Epstein, M. H., Dakan, E., Oswald, D. P., \& Yoe, J. T. (2001). Using strengths-based data to evaluate children's mental health programs. In M. Hernandez \& S. Hodges (Eds.), Developing outcome strategies in children's mental health (pp. 153-166). Baltimore, MD: Brooks.

Epstein, M., Harniss, M. K., Pearson, N., \& Ryser, G. (1999). The Behavioral and Emotional Rating Scale: Testretest and inter-rater reliability. Human Sciences Press, 8, 319-327.

Fad, K. S., \& Ryser, G. R. (1993). Social/behavioral variables related to success in general education. Remedial and Special Education, 14, 25-35.

Forness, S. R. (1992). Legalism versus professionalism in diagnosing SED in the public schools. School Psychology Review, 21, 29-34.

Gilliam, J. E., \& McConnell, K. S. (1997). Scales for Predicting Successful Inclusion: Examiner's manual. Austin, TX: Pro-Ed.

Harniss, M. K., Epstein, M. H., Ryser, G., \& Pearson, N. (1999). The Behavioral and Emotional Rating Scale: Convergent validity. Journal of Psychoeducational Assessment, 17, 4-14.

Huebner, E. S. (1991). Correlates of life satisfaction in children. School Psychology Quarterly, 6, $103-111$.

Huebner, E. S. (1997). Life satisfaction and happiness. In G. G. Bear, K. M. Minke, \& A. Thomas (Eds.), Children's needs II: Development, problems, and alternatives (pp. 271-278). Bethesda, MD: National Association of School Psychologists.

Huebner, E. S., \& Gilman, R. (2003). Toward a focus on positive psychology in school psychology. School Psychology Quarterly, 18, 99-102.

Lyons, J. S., Uziel-Miller, N. D., Reyes, F., \& Sokol, P. T. (2000). Strengths of children and adolescents in residential settings: Prevalence and associations with psychopathology and discharge placement. Journal of the American Academy of Child and Adolescent Psychiatry, 39, 176-181.

Masten, A. S., \& Curtis, W. J. (2000). Integrating competence and psychopathology: Pathway toward a comprehensive science of adaptation in development. Development and Psychopathology, 12, 529-550.

Meadows, N. B., Neel, R. S., Scott, C. M., \& Parker, G. (1994). Academic performance, social competence, and mainstream accommodations: A look at mainstreamed students with serious behavioral disorders. Behavioral Disorders, 19, 170-180.

Naglieri, J. A., LeBuffe, P. A., \& Pfeiffer, S. I. (1993). The Devereux Behavior Rating Scale-School Form. San Antonio, TX: The Psychological Corporation.

Nickerson, A. B., \& Brosof, A. M. (2003). Identifying skills and behaviors for successful inclusion of students with emotional or behavioral disorders. Behavioral Disorders, 28, 401-409.

Oswald, D. P., Cohen, R., Best, A. M., Jenson, C. E., \& Lyons, J. S. (2001). Child strengths and the level of care for children with emotional and behavioral disorders. Journal of Emotional and Behavioral Disorders, 9, 192199.

Quinn, K. P., \& McDougal, J. L. (1998). A mile wide and a mile deep: Comprehensive interventions for children and youth with emotional and behavioral disorders and their families. School Psychology Review, 27, 191203.

Reddy, L. A. (2001). Serious emotional disturbance in children and adolescents: Current status and future directions. Behavior Therapy, 32, 667-691.

Rhee, S., Furlong, M. J., Turner, J. A., \& Harari, I. (2001). Integrating strength-based perspectives in psychoeducational evaluations. The California School Psychologist, 6, 5-17. 
Schneider, B. H., \& Byrne, B. M. (1984). Predictors of successful transition from self-contained special education to regular class settings. Psychology in the Schools, 21, 375-380.

Shapiro, E. S., Miller, D. N., Sawka, K., Gardill, M. C., \& Handler, M. W. (1999). Facilitating the inclusion of students with emotional and behavioral disorders into general education classrooms. Journal of Emotional and Behavioral Disorders, 7, 83-93.

Smith, D. C., \& Furlong, M. J. (1998). Introduction to the special issue: Addressing youth anger and aggression in school settings. Psychology in the Schools, 35, 201-203.

U.S. Department of Education. (2002). Twenty-fourth annual report to congress on the implementation of the Individuals with Disabilities Education Act. Jessup, MD: Author.

Worth, S. (2000). Review of the Scales for Predicting Successful Inclusion. Journal of Psychoeducational Assessment, 18, 394-398. 


\title{
Lending "Strength" to the Assessment of Preschool Social-Emotional Health
}

\author{
Paul A. LeBuffe, Valerie B. Shapiro \\ Institute of Clinical Training and Research \\ Devereux Foundation
}

\begin{abstract}
This paper compares the advantages of a strength-based perspective to the long-standing pathology-based approach to assessment. Theoretical advantages to strength-based assessment, such as greater compatibility with early prevention efforts and increased acceptance by multiple stakeholders, are suggested. The Devereux Early Childhood Assessment (DECA), a reliable measure of within-child protective factors in preschoolers, is used to empirically validate the utility of strength-based assessment. The authors found the DECA to discriminate between groups of preschoolers with and without emotional and behavior problems, the DECA Total Protective Factor Scale to predict group membership just as well as the DECA Behavioral Concerns Screener, and the $D E C A$ assessment of protective factors to predict behavioral concerns as well as a standardized assessment of risk. These empirical findings, combined with the presented theoretical rationale, indicate that a strength-based perspective and the resilience model have great utility for universal use with preschool populations.
\end{abstract}

Key words: Strengths, Resilience, Preschool, Social-Emotional, Assessment, DECA

Strength-based assessment and intervention is a comparatively new approach in child psychology, especially in contrast to the more established pathology-oriented models of childhood psychopathology. As a consequence, the literature discussing the relative advantages and challenges of strengthbased approaches is sparse and often anecdotal. After five years of implementing a strength-based assessment and intervention program for at-risk preschoolers, the Devereux Early Childhood Initiative can now further explain the merit of the strength-based perspective. This article shares some of the compelling theoretical reasons that one could use to advocate for a strengths orientation. Though many of these assertions have not yet been studied empirically, this article will present contrasted group data that clearly show the utility of strength-based assessment. This article is written in hope that the findings will encourage researchers and practitioners to put additional assumptions about the strengths perspective through a similar evaluative process.

\section{THEORETICAL ADVANTAGES OF STRENGTH-BASED ASSESSMENT}

\section{An Advantage of Timing}

The most notable advantage of a strength-based approach is that it lends itself far more readily to primary prevention and wellness-promotion than a pathology-focused model. Rather than waiting for challenging or symptomatic behaviors to occur, a strength-based model can assess the absence or relative weakness of any necessary skill, competency, or attribute so that an intervention designed to strengthen these characteristics can be implemented prior to the emergence of problematic behaviors. When done effectively, this can result in either the avoidance of symptomatic behaviors completely or at least in their reduced severity, longevity, or pervasiveness. As Walker et al. (1996) explain so well, this rational for the strength perspective has already been embraced by more medically oriented sectors of the human service field. For example, the Department of Public Health makes recommenda-

Address correspondence to Valerie Shapiro; Institute of Clinical Training and Research; Devereux Foundation; P.O. Box 638; Villanova, PA 19085. E-mail: vshapiro@devereux.org. 
tions to exercise and learn stress management techniques in order to prevent or moderate the risk of coronary trouble, even before any sign of coronary trouble is evident. Such a sound medical approach is no longer questioned, and neither should be the role of primary prevention in psychology.

Even after problematic behaviors have occurred, a strength-based approach to intervention has distinct advantages over pathology-focused strategies. Often conceptualized within a functional behavioral framework, these strategies strive to provide children with pro-social ways of meeting their needs, and in effect, render counterproductive and negative behaviors useless. Fraser, Richman, and Galinsky (1999) reviewed the finding that cumulative protective factors can reduce problem behavior over time. This implies that a strength-based approach may also be extremely influential as an intervention tool after symptoms have developed, making a strength-based approach useful at all stages of a child's development.

\section{An Advantage from Every Perspective}

A strengths-oriented functional approach to treatment offers advantages to all parties involved in the treatment of the client (e.g., the client, parent, educator, etc.). From the perspective of the client, strength-based approaches can add competencies (e.g., friendship skills and problem solving skills), which promote individual social and emotional health. These new strengths, because they are often automatically rewarded, may also generalize more easily and naturally to non-treatment settings. This contrasts with approaches designed at reducing problem behaviors that attempt to manage antecedent conditions or post-behavior consequences in ways that are difficult to generalize to new settings. Strength-based approaches also avoid the negative correlates of response reduction measures, such as an increased arousal or frustration, or a student becoming inured to punishment. Furthermore, because focusing on developing a child's strengths typically enhances his or her sense of empowerment and self-esteem, such approaches may be more motivating than consequential strategies, resulting in greater treatment compliance and less attrition.

From a parent/guardian perspective, a strengths orientation can lead to greater collaboration between the caregiver and the treatment professionals. Walker et al. (1996) position collaboration as the key to reversing severe delinquent behavior. Collaboration is more likely with a strength-based approach due to the common desire of caregivers and professionals not to label young children with a permanent pathology. In addition, pathology-focused strategies can induce shame or guilt for a parent when meeting with a professional, interfering with effective collaboration. Parents often sense that they are being blamed for their child's problem behaviors and may also be loathe to discuss their difficulties in implementing contingency management strategies. Though professionals should continue to validate the emotional distress that parents may feel as a result of their child's challenging behaviors or symptoms, it may encourage the resilience of parents to additionally speak about their child in a positive light.

A strengths-oriented, primary prevention program is often met with greater acceptance and enthusiasm by parents and teachers than a deficit or pathology oriented model. Both parents and teachers see their mission as providing children with the skills necessary for success at home, in school, and for life. Consequently, a strength-fostering program is consistent with their self-perceived role and feels comfortable for them to implement. Conversely, many parents and teachers of young children seem less comfortable focusing on a child's misbehavior and implementing problem-focused strategies. A positive, strengths promotion approach may also facilitate attachment between the child and the parent, leading to greater advocacy and collaboration.

In order for a strength-based assessment approach to be viewed as advantageous from the perspective of a school administrator or psychologist, it must be shown to be an effective, psychometrically sound method. Additionally, it must accurately identify those children who may be at increased 
risk for negative developmental outcomes due to relatively weak or inadequate strengths in key areas that could be targeted through a primary prevention program. To be most useful, this assessment should be theory-based, easy to administer and interpret, and lead to strategies to help develop the inchoate child characteristics.

Unfortunately, few empirically sound, well-developed measures of important child strengths exist. There are some instruments such as the Behavioral and Emotional Rating Scale (Epstein \& Sharma, 1998) and the Child and Adolescent Needs and Strengths (Lyons, 1999) that have now begun to fill this gap, but are not to be widely used at the preschool level as a universal measure. The Institute of Clinical Training and Research of the Devereux Foundation developed a measure of preschool children's strengths that are related to healthy social and emotional development. This assessment is called the Devereux Early Childhood Assessment (DECA).

\section{THE DEVEREUX EARLY CHILDHOOD ASSESSMENT}

The Devereux Early Childhood Assessment (LeBuffe \& Naglieri, 1999) is a nationally normed behavior rating scale evaluating within-child protective factors in preschool children aged two to five. Completed by parents, family caregivers, or early childhood professionals (i.e., preschool teachers and child care providers), the DECA evaluates the frequency of 27 positive behaviors (i.e., strengths) exhibited by preschoolers. Typical items include "have confidence in his/her abilities," "act good-natured or easygoing," and "ask adults to play with or read to her/him." These items were derived from the childhood resilience literature and through focus groups conducted with parents and early childhood professionals. The DECA also contains a 10-item behavioral concerns screener. The standardized scores that the $D E C A$ provides are $T$-scores and percentiles.

The three primary purposes of the DECA are to (a) identify children who are low on the protective factors so that targeted classroom and home-based strategies can be implemented to strengthen these abilities, (b) generate classroom profiles indicating the relative strengths of all children so that classroom design and instructional strategies can facilitate the healthy social and emotional growth of all children, and (c) screen for children who may be exhibiting behavioral concerns so that these can be addressed before they become entrenched and possibly develop into behavioral disorders.

\section{A Standardized Assessment}

The DECA was normed on a sample of 2,000 children from 28 states that accurately reflected the diversity of preschool children in the country. Half of the children in the sample were rated by a parent or other family caregiver. The other half were rated by a preschool teacher or childcare center staff. Fifty-one percent of the children rated were boys and $49 \%$ girls. One quarter of the children in the sample were from poor families (defined as either receiving public assistance or subsidized child care), which matches the prevalence of poverty among young children. The sample was stratified based on the demographic characteristics used by the U.S. Census Bureau including, race, Hispanic ethnicity, and region of residence. The most recent data available from the U.S. Department of the Census (1996) was used to identify appropriate percentages for these variables.

\section{Reliable Scale Structure}

Exploratory factor analysis of the standardization items yielded a comprehensible series of scales that were consistent with published descriptive longitudinal research on protective factors (e.g., Werner $\&$ Smith, 1982). A three-factor solution fit the data best. Based on an inspection of the item content of the three factors, the scales were labeled: Initiative - which measures the child's ability to use independent thought and action to meet his or her needs; Self Control - which assesses the child's ability to 
experience a range of feelings and express them using the words and actions that American society considers appropriate; and Attachment - a measure of a mutual, strong, and long-lasting relationship between a child and significant adult(s). The factor analytic results are presented in Table 1.

Table 1.

Varimax Rotated Factor Analysis Results for the DECA Protective Factor Scales

\begin{tabular}{|c|c|c|c|}
\hline & Factor 1 & Factor 2 & Facto 3 \\
\hline 19. Try or ask to try new things or activities & .65 & & \\
\hline 20. Start or organize play with other children & .63 & & \\
\hline 36. Make decisions for herself/himself & .63 & & \\
\hline 3. Choose to do a task that was challenging for her/him & .62 & & \\
\hline 16. Try different ways to solve a problem & .59 & .40 & \\
\hline 12. Keep trying when unsuccessful (act persistent) & .56 & & \\
\hline 28. Say positive things about the future (act optimistic) & .54 & & \\
\hline 24. Focus his/her attention or concentrate on a task or activity & .52 & & \\
\hline 32. Ask other children to play with her/him & .51 & & \\
\hline 2. Do things for himself/herself & .48 & & \\
\hline \multicolumn{4}{|l|}{ 7. Participate actively in make-believe play with others (dress-up, etc.).46 } \\
\hline 21. Show patience & & 74 & \\
\hline 13. Handle frustration well & & .72 & \\
\hline 5. Control her/his anger & & .71 & \\
\hline 4. Listen to or respect others & & .62 & .37 \\
\hline 33. Cooperate with others & & .59 & \\
\hline 30. Accept another choice when her/his first choice was unavailable & & .56 & \\
\hline 34. Calm herself/himself down when upset & & .54 & \\
\hline 25. Share with other children & & .52 & \\
\hline 10. Show affection for familiar adults & & & 69 \\
\hline 17. Act happy or excited when parent/guardian returned & & & 60 \\
\hline 1. Act in a way that made adults smile or show interest in her/him & & & .60 \\
\hline 29. Trust familiar adults and believe what they say & & & .58 \\
\hline 37. Show an interest in what children/adults are doing & & & .55 \\
\hline 22. Ask adults to play with or read to her/him & & & .55 \\
\hline 6. Respond positively to adult comforting when upset & & & .52 \\
\hline 31. Seek help from children/adults when necessary & & & .48 \\
\hline
\end{tabular}

Note: Only loadings above .34 , which accounts for $10 \%$ or more of the item variance, are reported.

The $D E C A$ is a highly reliable instrument. Each of the alpha coefficients for the protective factor scales meets or exceeds the .80 "desirable standard" established by Bracken (1987) for internal consistency estimates.

\section{A Valid Instrument}

An important and interesting question regarding the DECA was to what degree the assessment of a child's strengths would provide useful information for identifying children who may be at risk for social and emotional difficulties. In order to determine whether strength-based assessments could be a valid tool when used to assess these developmental trajectories and to inform intervention strategies for preschool children, three studies of the DECA were conducted. The purpose of these three studies 
was to explore the accuracy of the interpretations based on DECA test scores. According to the Standards for Educational and Psychological Testing published by the American Psychological Association in 1999, such studies demonstrating the degree to which "evidence and theory support the interpretation of test scores" (p. 9) is fundamental to establishing the validity of strength-based measurement.

\section{STUDY ONE: \\ CONTRASTED GROUPS CRITERION VALIDITY}

Criterion validity measures the degree to which the scores on the assessment instrument predict either (a) an individual's performance on an outcome or criterion measure or (b) the status or group membership of an individual. Protective factors buffer children against stress and adversity (Masten \& Garmezy, 1991), hence it follows that children with high protective factors should have better developmental outcomes than those that lack similar strengths. As one important outcome for preschool children is social and emotional health, it is predicted that children with high scores on the $D E C A$ Protective Factor Scales should have greater social and emotional health than children with low scores on these scales.

\section{Method}

To test this hypothesis, $D E C A$ ratings were obtained from the family members of children in 39 different programs across 18 states, and categorized into two groups of preschool children. The problem-identified sample $(n=95)$ had known emotional and behavioral problems as determined by their meeting at least one of the following criteria: (a) a program or plan had been developed to manage their behavioral problems, (b) they had been referred to a professional for emotional/behavioral problems, (c) they were currently being treated by a mental health professional, (d) they had been asked to leave a child care/preschool program due to their behavior, and/or (e) they had been given a psychiatric diagnosis. The comparison group was a group of typical preschool children labeled the community sample $(n=300)$. From the community sample, a matched sample of 86 children was selected for comparison with the identified sample. Matching variables included age, gender, race, and Hispanic ethnicity. Table 2 provides descriptive information on the samples that shows that the two groups were demographically similar.

Table 2.

Sample Characteristics for the Criterion Validity Study

\begin{tabular}{|c|c|c|c|c|c|}
\hline & & \multicolumn{2}{|c|}{$\begin{array}{l}\text { Identified Sample } \\
\qquad(n=95)\end{array}$} & \multicolumn{2}{|c|}{$\begin{array}{c}\text { Community Sample } \\
\qquad(n=86)\end{array}$} \\
\hline & & $n$ & $\%$ & $n$ & $\%$ \\
\hline Age & Mean $(S D)$ & \multicolumn{2}{|c|}{$4.6(.9)$} & \multicolumn{2}{|c|}{$4.6(.9)$} \\
\hline \multirow[t]{2}{*}{ Gender } & Boys & 63 & 66 & 58 & 67 \\
\hline & Girls & 32 & 34 & 28 & 33 \\
\hline \multirow[t]{5}{*}{ Race } & Asian/Pacific Islander & 2 & 2 & 3 & 3 \\
\hline & Black & 25 & 27 & 28 & 33 \\
\hline & Native American & 1 & 1 & 0 & 0 \\
\hline & White & 57 & 60 & 50 & 58 \\
\hline & Other & 9 & 10 & 5 & 6 \\
\hline \multicolumn{2}{|c|}{ Hispanic Ethnicity } & 9 & 10 & 4 & 5 \\
\hline
\end{tabular}




\section{Results}

The contrasted groups approach to assessing criterion validity examines scale score differences between groups of individuals who differ on an important variable. Multivariate Analysis of Variance (MANOVA) procedures were used to contrast Initiative, Self-control, and Attachment Scale T-scores for the identified and community samples. Independent $t$-tests were used to compare both the Total Protective Factors and Behavioral Concerns Scale scores for the two groups.

Table 3 presents the results of this study and documents that there were large and significant differences between the mean scores of the identified and community samples on all five DECA scales. The mean standard score differences and other results reported in Table 3 clearly show that the ratings of the two groups differed significantly despite the similarity in demographic characteristics. All scale comparisons were significant $(p<.01)$.

Table 3.

Mean Scores, Standard Deviations, and Difference Statistics for Contrast Groups Validity Study

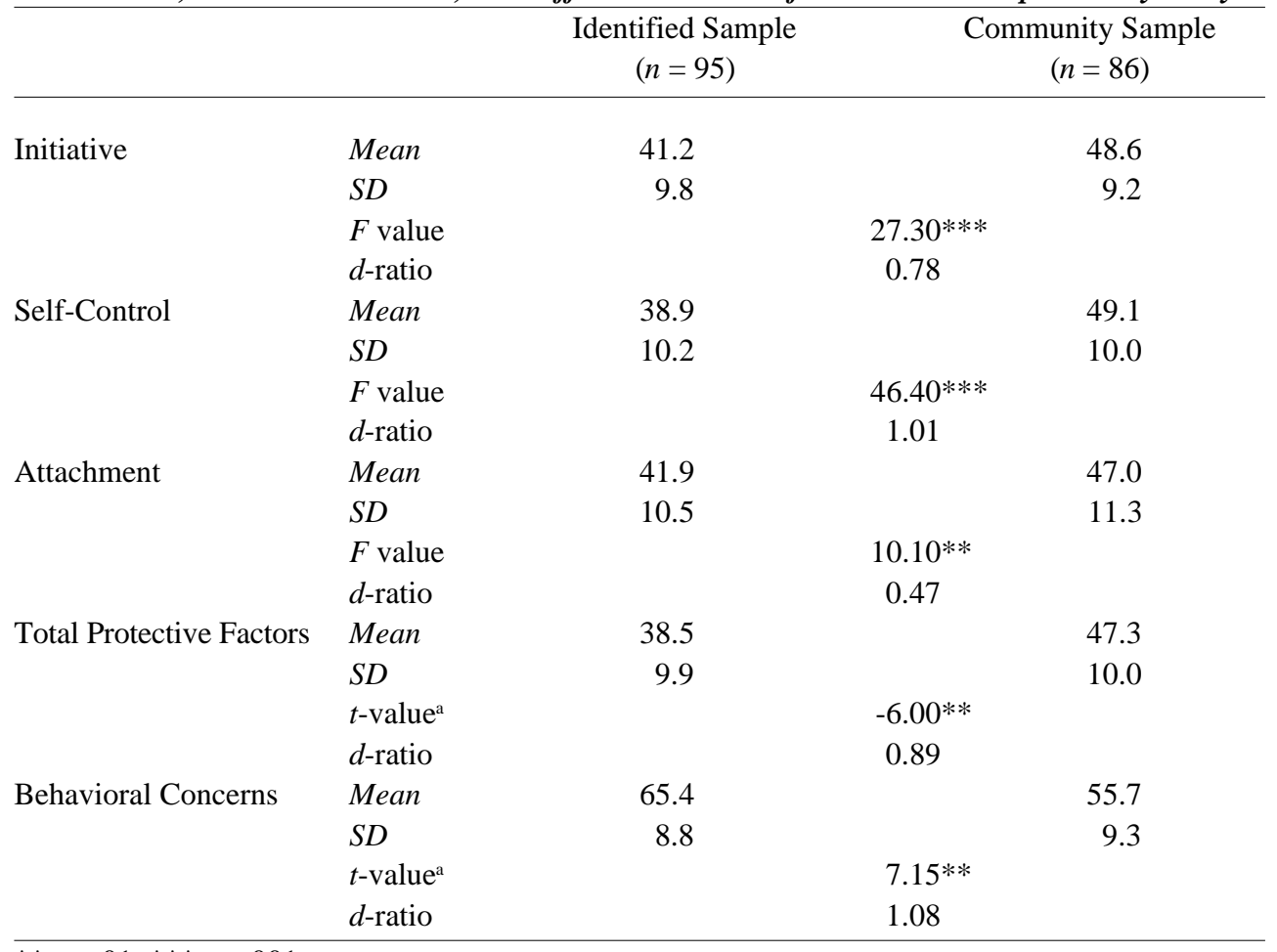

$* * p<.01 * * * p<.001$

${ }^{\mathrm{a}} t$-test for independent means

In addition to being statistically significant, the means of the two groups on each scale differed by approximately half a standard deviation or more ( $d$-ratios range from .47 to 1.08 ). The $d$-ratio is a measure of the size of difference between the mean scores expressed in standard deviation units. According to commonly accepted guidelines for interpreting $d$-ratios (Cohen, 1988), $d$-ratios of .2, .5, and .8 are interpreted as small, medium, and large, respectively. Therefore, the effect sizes in Table 3 would be characterized as small verging on medium (Attachment), medium verging on large (Initia- 
tive), and large (Self-control, Total Protective Factors, and Behavioral Concerns). These results provide evidence of the validity of a strength-based assessment such as the DECA in discriminating between groups of preschoolers with and without emotional and behavioral problems.

\section{STUDY TWO: INDIVIDUAL PREDICTION CRITERION VALIDITY}

Knowing that the DECA discriminates between groups of preschoolers, the next step was to determine whether a strength-based assessment scale score could accurately predict group membership for individual study participants. The extent to which both the Total Protective Factor Scale scores and the Behavioral Concerns Scale scores accurately predicted membership in either the identified or community sample was investigated.

\section{Method}

Using the ratings collected for the contrasted group study detailed above, individuals were reorganized into two new groups. Those individuals with a $T$-score of less than or equal to 40 on the Total Protective Factors Scale were predicted to be members of the identified sample; those with scores above 40 were predicted to be members of the community sample. For the Behavioral Concerns Scale, individuals with a $T$-score of greater than or equal to 60 were predicted to be members of the identified sample; those with scores below 60 were predicted to be members of the community sample. $T$-Scores of 40 and below suggest poor Protective Factor scores and $T$-Scores of 60 and above on the Behavioral Concerns Scale indicate potential behavior problems. These cut scores were chosen to be consistent with the interpretation guidelines presented in the DECA manual.

\section{Results}

The accuracy of these predictions was compared to actual group membership and the results are shown in Table 4. The Total Protective Factors Scale score correctly predicted group membership for $69 \%$ of the children in this study. Chi-square analysis results, $\chi^{2}=26.49, d f=1, p<.001$, indicate that the Total Protective Factors Scale scores were significantly related to group membership. The Behavioral Concerns Scale score correctly predicted group membership for $71 \%$ of the children in this study. Chi-square analysis results, $\chi^{2}=34.16, d f=1, p<.001$, indicate that the Behavioral Concerns Scale scores were significantly related to group membership. It should be noted that the Total Protective Factor Scale was nearly as efficient in predicting which children had emotional and behavioral problems as the Behavioral Concerns Scale (69\% vs. $71 \%)$.

Table 4.

Actual and Predicted Group Membership for the Individual Prediction Criterion Validity Study

\begin{tabular}{|c|c|c|c|c|}
\hline \multirow{2}{*}{$\begin{array}{l}\text { Actual Group Membership } \\
\text { Predicted Group Membership }\end{array}$} & \multicolumn{2}{|c|}{$\frac{\text { Identified Sample }}{(n=95)}$} & \multicolumn{2}{|c|}{$\frac{\text { Community Sample }}{(n=86)}$} \\
\hline & $n$ & $\%$ & $n$ & $\%$ \\
\hline \multicolumn{5}{|l|}{ Total Protective Factors } \\
\hline $\mathrm{TPF}<40$ & 64 & 67 & 25 & 29 \\
\hline $\mathrm{TPF}>40$ & 31 & 33 & 61 & 71 \\
\hline \multicolumn{5}{|l|}{ Behavioral Concerns } \\
\hline $\mathrm{BCS}>60$ & 74 & 78 & 30 & 35 \\
\hline $\mathrm{BCS}<60$ & 21 & 22 & 56 & 65 \\
\hline
\end{tabular}




\section{STUDY THREE: CONSTRUCT VALIDITY}

Though the criterion validity clearly demonstrates the ability for a strength-based instrument to distinguish between healthy and unhealthy mental health outcomes, it remains unclear whether a strengthbased approach is preferable to a risk-based approach for the purpose of identifying high-risk children for early prevention purposes. Construct-related validity ascertains the degree to which the assessment instrument measures the theoretical construct or trait of interest. In the case of the DECA, constructrelated validity concerns to what extent the DECA scale scores truly relate to resilience versus some other characteristic of preschool children.

Protective factors have been defined as "characteristics that are thought to moderate or buffer the negative effects of stress, and result in more positive behavioral and psychological outcomes in at-risk children than would have possible in their absence" (Masten \& Garmezy, 1985). Therefore, for similar levels of stress or risk, children with high protective factors as measured by the Protective Factor Scales of the DECA should have more positive behavioral outcomes as measured by the DECA Behavioral Concerns Scale. This study investigates whether the assessment instrument yields data that are consistent with predictions derived from the theory underlying the instrument.

\section{Method}

A commonly used approach to measuring stress and risk in children and families is to inventory the major life events that the child has experienced such as the death of a parent, homelessness, or major illness. An alternative approach to measuring stress and risk is to assess daily hassles, which are repetitive difficulties in daily living such as transportation problems, family conflict, or financial difficulties. As both approaches are valuable in determining a preschooler's exposure to risk, both were used in this study. No preexisting measures of risk were deemed appropriate for use with a preschool population, specifically for those preschoolers living in a state of poverty. For the purpose of this study, two risk assessments were developed and standardized. The Preschool Major Life Events Checklist is a survey of 30 episodic and traumatic events that may have occurred during the child's lifetime. This tool was adapted with permission from the Life Events Checklist (Work, Cowen, Parker, \& Wyman, 1990) and the Sources of Stress Inventory (Chandler, 1981). The Preschool Daily Hassles Checklist is survey of 30 recurring minor negative experiences that are viewed as harmful or threatening to the child's well being. These are items that may have occurred during the month preceding the rating, such as experiencing prejudice or having problems finding childcare. This tool was adapted with permission from the Daily Hassles Scale (Kanner, Coyne, Schaefer, \& Lazarus, 1981).

Parents or caregivers completed these two checklists for 392 preschool children, ages 2-5. Approximately one quarter $(n=94)$ of these children had already been identified as having significant social/emotional problems. The remaining $76 \%$ of the sample were non-identified children. This $3: 1$ ratio is consistent with many studies that have reported incidence rates of significant behavioral problems in preschool children ranging from 10 to 33\%. The sample was quite diverse with respect to race (e.g., 26\% black), ethnicity (e.g., $8 \%$ Hispanic) and socioeconomic status. Norms were generated separately for the two checklists using all 392 cases.

\section{Results}

Each individual checklist showed acceptable internal consistency (alpha $=.82$ for major events and .81 for daily hassles). Each scale was able to differentiate between identified and non-identified children. Independent sample $t$-tests indicated that identified children had significantly greater risk 
factors than non-identified children $(p<.001)$. In addition, the effect sizes were moderately small for daily hassles $(d$-ratio $=.40)$ but quite large for major life events $(d$-ratio $=.98)$. Classification accuracy was also assessed using a $+1 \mathrm{SD}$ decisions threshold. That is, children who received a $T$-score of 60 or higher were predicted to be from the identified sample. Children who received a $T$-score of 59 or lower were predicted to be the non-identified sample. The Preschool Major Life Events Checklist was superior (total classification accuracy of 79\%) to the Preschool Daily Hassles Checklist (total accuracy of $73 \%)$.

Raw scores from both risk assessment instruments were converted to $T$-scores. The two $T$-scores were then added together for each participant. The resulting sums were then converted to a "Total Risk Index" $T$-score. The Total Risk Index scores were then used to assign the 181 participants in the study to a High Risk Group (Total Risk Index score greater than or equal to 60) or a Low/Average Risk Group ( $T$-score less than 60). Similarly, participants were assigned to a Low Protective Factor Group (Total Protective Factor Scale Score $T$-score less than or equal to 40) or an Average/High Protective Factor Group ( $T$-score greater than 40).

Consistent with Resilience theory, the High Risk-Low Protective group had the highest mean score $(M=68.2)$. The High Risk-Average/High Protective group's mean score was $6 T$-score points lower $(M=62.3)$. The Low/Average Risk-High Protective group had the lowest mean score $(M=$ 53.8), a full one a half standard deviations lower than the High Risk-Low Protective group mean. These results were examined using a two-way ANOVA (Analysis of Variance). Main effects of both Total Risk, $F=19.3, d f=1,171, \mathrm{p}<.001 ;$ eta $=.101$, and Total Protective Factors, $F=33.7, d f=1,171$, $\mathrm{p}<.001 ;$ eta $=.165$, were found, and there was no interaction, $F=2.8, p>.05$. These findings indicate that protective factors, as measured by the $D E C A$, do indeed moderate risk. For children at both levels of risk, higher protective factors were associated with better outcomes than low protective factors. An alternative way of looking at these data is that all children with low protective factors, regardless of their risk status, tend to have elevated scores on a measure of behavior concerns. In contrast, children with Average/High protective factors tend to have elevated scores only if they are subject to high risk.

These findings provide evidence that the $D E C A$ does indeed measure protective factors related to resilience in young children. In addition, the higher $F$ and eta (a measure of the degree of relationship between two variables) values for protective factors indicate that it is somewhat more strongly associated with behavioral concerns than the Total Risk Index. This lends support to the idea that a strengthbased assessment may be more predictive of outcome than a comprehensive inventory of risk factors in the child's life.

\section{DISCUSSION}

The three studies presented in this paper indicate that measuring a child's strengths can provide psychometrically sound and useful information. These investigations demonstrate that the DECA discriminates between groups of preschoolers with and without emotional and behavior problems, that the DECA Total Protective Factor Scale predicts group membership as well as the DECA Behavioral Concerns Screener, and that the DECA assessment of protective factors is at least as good as a standardized assessment of risk in predicting behavioral concerns. Such findings imply that the $D E C A$, or another similarly grounded strength-based assessment, can guide intervention at least as well as assessments of risk, and that assessing a child's strengths is as effective as measuring a child's pathological behaviors in identifying children with significant emotional and behavioral problems. Since, all else being equal, focusing on strengths supports a more holistic and collaborative approach to working with children at risk, this should make a strength-based assessment the tool of choice for early intervention with preschoolers. 
The implications of this study must be taken in context of the strengths and weakness of the study methodology. One positive attribute of this study is the degree to which the sample groups matched. Another strength of the study is the medium to large effect sizes that were found, which indicate that the assessment tool is robust and has clinical utility for individual children. This study is limited by the absence of teacher ratings. Only parents were used as raters in this experiment due to their ability to reliably report on the child's exposure to risk. In future studies, additional matching variables that have been shown to influence school success should also be included. In addition, a longitudinal study to examine the predictive validity of low and high protective factors on subsequent achievement is a necessary next step.

Since the seminal studies of Emmy Werner, professionals have recognized that protective factors in early childhood have a crucial role in determining subsequent adjustment or maladjustment to life stresses. Werner's recommendation that both assessment and diagnosis in early intervention should focus on protective factors as well as risks (Werner, 1990) has been hampered by the lack of an economical, psychometrically sound, and clinically useful measure of within-child protective factors. The $D E C A$ has been developed to fill this gap and thereby provide early childhood professionals with an empirically sound tool for assessing the strength of protective factors in preschoolers.

As additional high caliber strength-based assessment tools come into existence, it is expected that policy will encourage their use. The Office of Juvenile Justice and Delinquency Prevention within the United States Department of Justice has recently proclaimed that, "Although focusing on risk factors that reduce the risk of delinquency is important, examining protective factors that reduce the risk of delinquency is as important for identifying interventions that are likely to work" (Wasserman et al., 2003). Based on the belief that the primary value of assessment is to guide effective services for children, the authors of this paper encourage additional research on the validity of strength-based assessments in order to direct policy and practice.

\section{REFERENCES}

Bracken, B. A. (1987). Limitations of preschool instruments and standards for minimal levels of technical adequacy. Journal of Psychoeducational Assessments, 5, 313-326.

Chandler, L. A. (1981). The source of stress inventory. Psychology in the Schools, 18(2), 164-168.

Cohen, J. (1988). Statistical power analysis for the behavioral sciences ( $2^{\text {nd }}$ ed.). San Diego, CA: Academic Press.

Epstein, M. H., \& Sharma, J. M. (1998). Behavioral and Emotional Rating Scale: A strength-based approach to assessment. Austin, TX: Pro-Ed.

Fraser, M. W., Richman, J. M., \& Galinsky, M. J. (1999). Risk, protection, and resilience: Toward a conceptual framework for social work practice. Social Work Research, 23(3), 131.

Joint Committee on Standards for Educational and Psychological Testing of the American Educational Research Association, the American Psychological Association, and the National Council on Measurement in Education. (1999). Standards for Educational and Psychological Testing. Washington, DC: American Educational Research Association.

Kanner, A. D., Coyne, J. C., Schaefer, C., \& Lazarus, R. S. (1981). Comparison of two modes of stress management: Daily hassles and uplifts versus major life events. Journal of Behavioral Medicine, 4(1), 1-37.

LeBuffe, P. A., \& Naglieri, J. A. (1999). The Devereux Early Childhood Assessment. Lewisville, NC: Kaplan Press Publishing.

Lyons, J. S. (1999). The Child and Adolescent Needs and Strengths for children and adolescents with mental health challenges (CANS-MH). Winnetka, IL: Buddin Praed Foundation.

Masten, A., \& Garmezy, N. (1985). Risk, vulnerability, and protective factors in developmental psychopathology. In B. Lahey \& A. Kazdin (Eds.), Advances in clinical child psychology. New York: Plenum Press.

U.S. Department of Commerce, Economics and Statistics Administration, Bureau of the Census. (1996). Statistical Abstract of the United States 1996: The National Data Book (116 ${ }^{\text {th }}$ ed.). Washington, DC: Author.

Walker, H. M, Horner, R. H, Sugai, G., Bullis, M., Sprague, J. R., Bricker, D., \& Kaufman, M. J. (1996). Integrated approaches and preventing antisocial behavior patterns among school-age children and youth. Journal of Emotional and Behavioral Disorders, 4(4), 194-209. 
Wasserman, G. A., Keenan, K., Tremblay, R. E., Coie, J. D., Herrenkohl, T. I., Loeber, R., \& Petechuk, D. (2003). Risk and protective factors of child delinquency. Child Delinquency Bulletin Series, U.S. Department of Justice, April, 1-14.

Werner, E. E. (1990). Protective factors and individual resilience. In S. J. Meisels \& M. Shonkoff (Eds.), Handbook of early intervention. New York: Cambridge University Press.

Werner, E. E., \& Smith, R. S. (1982). Vulnerable but invincible: A longitudinal study of resilient children and youth. New York: McGraw-Hill.

Work, W. C., Cowen, E. L., Parker, G. R., \& Wyman, P. A. (1990). Stress resilient children in an urban setting. Journal of Primary Prevention, 11(1), 3-17. 
Copyright 2004 California Association of School Psychologists

\title{
Personal Strengths and Assets Among Adolescents: A Comparison of Smokers and Nonsmokers
}

\author{
Oanh K. Tran \\ University of Oregon \\ Michael J. Furlong \\ University of California, Santa Barbara
}

\begin{abstract}
There is limited research on the relationship between adolescent smoking and related social and psychological factors, but it is known that adolescent tobacco users are at higher risk for behavioral disorders and substance abuse. Of great interest to those who work in youth tobacco prevention is expanding knowledge about those factors that lead to tobacco use as well as about those that may buffer against its use. This study examined protective factors and personal strengths in 386 adolescents as part of a high school Tobacco Use Prevention Education (TUPE) program funded by the California Department of Education. Multivariate analysis indicated a significant relationship between gender, smoking status, and personal strengths with smokers having lower levels of personal strengths. It is suggested that cessation programs consider smoking within the context of youths' personal assets and their social support networks. School support services professionals can contribute to youth tobacco prevention efforts by attending to smoking behavior and its correlates when they are involved in assessments, consultation, or direct counseling with students.
\end{abstract}

Keywords: Adolescent, Smoking, Tobacco, Cessation, Strength-Based Assessments

Adolescent tobacco use is a major concern for parents, youth-serving professionals, lawmakers, and public health officials. Cigarette smoking is "the most important source of preventable morbidity and premature mortality worldwide" (American Lung Association, 2002). Health concerns and other negative developmental outcomes associated with tobacco use among adolescents have been widely researched, but there has been limited research on the relationship between smoking and personal, social, and psychological factors. Tobacco (nicotine) is a "gateway drug" used by adolescents (Hallfors \& Van Dorn, 2002) because it is easily accessible, inexpensive, and introduces youths to substance use influences. In addition, adolescence is a period of experimentation, when tobacco use may be attractive due to the influences of peers, family, and the public media.

Youths experimenting with tobacco increase their chances of becoming regular users (Trinidad \& Johnson, 2002). Recent research shows that nicotine addiction for adolescents is different than for adults - adolescents can become addicted to nicotine in as little as 21 days from the onset of use (typically within six months; DiFranza et al., 2002). Given the prevalence of tobacco use among youths, school psychologists need to be knowledgeable of tobacco use trends and prevention efforts.

Of recent interest to those who work in youth tobacco prevention is to expand knowledge about those factors that lead to tobacco use as well as those that may buffer youths against its use. To expand knowledge in this area, this article presents information about (a) tobacco use patterns, (b) its correlates, and then (c) presents the results of a study that examines the personal strengths and assets of smokers and nonsmokers. This is an initial step to explore the potential of using personal strengths to individualize smoking prevention and intervention programs. It is hoped that the information gathered

Address correspondence to Michael Furlong; UCSB; Gevirtz Graduate School of Education; Santa Barbara, CA 93106. E-mail: mfurlong@education.ucsb.edu. 
from this study will assist school psychologists and educational professionals to be better understand the developmental complexities (i.e., internal and external factors) associated with adolescent tobacco use and how to intervene and prevent its use drawing on a strength-base perspective.

\section{Tobacco Use Patterns}

Tobacco smoke is dangerous at all ages, causing a variety of health risks, such as cardiovascular, carcinogenic, pulmonary, and teratogenic effects, regardless of the type of tobacco used. The earlier the onset of tobacco use, the more severe nicotine addiction becomes (Breslau \& Peterson, 1996; Taioli \& Wynder, 1991). There are two types of tobacco products: cigarettes or cigars and smokeless tobacco.

Cigarettes. Cigarettes and cigars are forms of tobacco that are widely advertised; these advertisements present smoking as sophisticated and stylish. In a longitudinal study, Pierce, Choi, Gilpin, Farkas, and Berry (1998) examined whether tobacco advertising and promotion increase the likelihood of smoking in 1,752 California youths. These adolescents were 12 to 17 years-old at baseline. Results indicated that more than half the sample named a favorite cigarette advertisement in 1993-Joe Camel advertisements were the most popular. At baseline, less than $5 \%$ possessed a personal tobacco promotional item, but an additional 10\% indicated that they were willing to use such an item. Although having a favorite advertisement in 1993 predicted which adolescents would progress toward smoking by 1996, possession or willingness to use a promotional item was even more strongly associated with future progression. The study estimated that $34 \%$ of all experimentation in California youths between 1993 and 1996 could be attributed to tobacco promotional activities.

Smokeless tobacco. Smokeless tobacco is another form of tobacco use that is not extensively discussed, although it is just as addictive and harmful as cigarette smoking. Unfortunately, a growing number of young people are using chewing or smokeless tobacco as an alternative to cigarettes. There are about three million people (under age 21) who use smokeless tobacco regularly (American Academy of Pediatrics, 2002). There are two major types of smokeless tobacco: snuff and chewing tobacco. Snuff is a finely ground or shredded form of tobacco. Users put a pinch of snuff between the lower lip or cheek and the gum. Chewing tobacco is more coarsely cut and also placed in the cheek pouch. Smokeless tobacco is absorbed into the blood through the oral mucosa and the gastrointestinal track. More chemicals enter the body through smokeless tobacco than smoking cigarettes because it is held in the mouth for minutes at a time. Like cigarettes, smokeless tobacco contains nicotine and can cause cancer and a number of non-cancerous oral conditions. Smokeless tobacco users are more likely than nonusers to become cigarette smokers. Studies have reported that nicotine levels in smokeless tobacco have been intentionally manipulated by manufacturers to lure underage users (Connolly, 1995; Djordjevic, Hoffman, Glynn, \& Connolly, 1995; Tomar, Giovino, \& Ericksen, 1995).

Prevalence of adolescent cigarette smoking. There is no single definitive source of information about adolescent cigarette smoking trends. The rates of tobacco use appear to vary as a function of the manner in which data are collected and the specific item used (it is common to ask in some form about life, 6-month, or 30-day smoking patterns). In addition, cigarette smoking has been found to vary by region of the country and by racial and ethnic background (Baezconde-Garbanati, 2002; Gardnier, 2002). Consequently, the global national adolescent cigarette smoking incidence rates have limited relevance across states. Despite this caution, several national databases provide information about youth tobacco use.

The American Lung Association (2002) reports that the most frequently used tobacco products by adolescents are cigarettes (28\%); cigars (14\%); kretecks or clove cigarettes (4\%; a cigarette made of fine tobaccos and clove spice); bidis (4\%; thin unfiltered cigarettes that are wrapped in brown leaves 
and tied with a short length of thread, and come in different flavors, including strawberry, chocolate, almond, and root beer); and tobacco in pipes (3\%). According to the national PRIDE Surveys (2002), in 2001 the rates of past year cigarette smoking were: $29 \%$ of ninth graders, $34 \%$ of tenth graders, $38 \%$ of eleventh graders, and $41 \%$ of the twelfth graders. Since 1996-1997, adolescent tobacco use across all age groups declined from $50 \%$ to $35 \%$ (PRIDE Surveys).

With the high priority given to tobacco prevention in California, there are several high-quality sources of information about tobacco use by adolescents. The California Attorney General's Office and the California Department of Education sponsor the biennial California Student Survey (CSS), which uses a random sample of students (Skager \& Austin, 2001). This survey reports that the incidence of any cigarette use in the past 30-days among California ninth graders is consistently lower than comparable national trends taken from the Centers for Disease Control's Youth Risk Behavior Surveillance Survey (YRBS). For example, in 1995, 28\% of California ninth graders used cigarettes vs. $31 \%$ of ninth graders nationally; in $1997,29 \%$ vs. $33 \%$, and most dramatically in $1999,12 \%$ vs. $27 \%$. In the 1999 CSS, current (30-day) cigarette use by eleventh (21\%) graders was also much lower than the rates found in comparable national surveys (YRBS and Monitoring the Future; see Skager \& Austin, 2001). Between 1991 and 1999, cigarette use among California secondary students showed sizable decreases $-61 \%$ for seventh graders, $50 \%$ for ninth graders, and $25 \%$ for eleventh graders (Skager \& Austin, 2001). The good news in tobacco prevention is that substantial progress is being made to reduce smoking among California's youth. Nonetheless, it remains the single most preventable source of long-term morbidity and its use is associated with various other unfavorable developmental outcomes. Thus, there is a need to be aware of various risk factors associated with adolescent smoking.

\section{Tobacco Use Correlates}

Adolescents experiment with tobacco for a variety of reasons; thus, it is important to understand the association between tobacco use and other harmful behaviors. Beyond curiosity and experimentation a number of risk factors predict adolescent tobacco use.

Psychosocial risk factors associated with adolescent smoking. Several studies have found differences in the psychosocial characteristics of nonsmokers and smokers (Ellickson, Tucker, \& Klein, 2001; Hallfors \& Van Dorn, 2002; Tomori, Zalar, Plesnicar, Ziherl, \& Sterger, 2001). Behavioral risks found to be more common among smokers include the use of alcohol and drugs and suicide attempts. Conduct disorders, school truancy, non-involvement in extracurricular activities, and poor academic performance are also more prevalent in smokers than nonsmokers. Students who report being truant and having low grades were five times more likely to be involved in tobacco and drug use. Smoking was found to be associated with eating disorders in girls only (Tomori et al., 2001) and as a means of weight control (Wagner \& Atkins, 1999). Also, compared to girls who do not smoke, girls who smoked were more likely to have experienced physical and sexual abuse. Early smokers are at greater risk for pregnancy and parenthood at a young age. Additionally, adolescent smoking is more frequent in families with high levels of conflict and inconsistent parental support and guidance (Hallfors \& Van Dorn, 2002). Smoking rates are highest among "white" adolescents and those whose parents are reported to abuse alcohol (Burns, Major, Vaughn, Anderson, \& Shanks, 2002; Hallfors \& Van Dorn). And, finally, the use of smokeless tobacco at school has been found to be the strongest predictor of school weapon possession in a study using the national Youth Risk Behavior Surveillance Survey (Furlong, Bates, Sharkey, \& Smith, 2004).

Social context of adolescent smoking. Alternatively, some youths smoke for social reasons (i.e., they are exposed to it at parties or informal social gatherings) and others because of social influences 
(Jessor, 1984; Lloyd-Richardson, Papandonatos, Kazura, Stanton, \& Niaura, 2002). For example, if a student feels alienated from school and hangs out off campus, this student is more likely to be exposed to smoking peers and consequently to experiment with tobacco. Also, adolescents may choose to smoke as a means of conveying an image of toughness to peers and to convey a social status associated with the transition to adulthood (Entwisle, Alexander, \& Olson, 2002).

Modeling behaviors are also an issue when discussing adolescent smoking. Youths may smoke because of the influence of their friends or family members. Lloyd-Richardson and colleagues (2002), in a national sample of 20,747 adolescents, found that peer smoking was the strongest predictor of smoking progression. The authors also found that students who had at least two smoking peers were about six times more likely to transition from experimentation to becoming regular smokers. Tomari and colleagues (2001) cite several studies showing that peer influence is a decisive factor in adolescent tobacco use. In one study, by late adolescence, chronic smokers report having essentially no nonsmoking close friends (Lloyd-Richardson et al., 2002).

Emotional disorders associated with adolescent smoking. More recently, researchers have examined smoking and short-term, immediate developmental and psychological risks such as depression and attention deficit hyperactivity disorder. These relationships emphasize the importance of school psychologists to attend to the presence and influences of smoking on adolescents.

Several studies have documented a relationship between depression and smoking (Brown, Lewinsohn, Seeley, \& Wagner, 1996; Escobedo, Reddy, \& Giovino, 1998), with smokers having higher levels of depressive symptoms than nonsmokers. Escobedo and colleagues postulated that initiation of smoking may occur more rapidly in adolescents who are depressed or are experiencing stressful situations. Byrne and Mazanov (2001) found that females experience more adolescent-related stress and showed lower levels of self-esteem than boys. However, Brown et al. (1996) did not find gender to influence the relationship between psychopathology and tobacco use in their epidemiological study of a community-based sample of 14 to 18 year-old adolescents. Despite some studies finding a depression-smoking link, it is unclear whether smoking precedes depression and/or exacerbates it, or if youth who are depressed are more likely to experiment with smoking and subsequently becomes addicted to nicotine. However, a recent prospective study by Wu and Anthony (1999) found that depression did not increase the risk of smoking, but that smoking exacerbated depressive symptoms.

Youths with ADHD have also been found to be at increased risk for smoking as they transition through adolescence into adulthood (Whalen, Jamner, Hender, Delfino, \& Lozano, 2002). It has been suggested that smoking is a form of "self-medication" for those with ADHD symptoms (Tercyak, Lerman, \& Audrain, 2002). Stimulation from nicotine, a central nervous stimulant, compensates for low levels of attention, arousal, and concentration in smokers with ADHD (Conners et al., 1996). Tercyak and colleagues examined the association of ADHD with cigarette smoking in a community sample of adolescents. Results suggest that adolescents with clinically significant inattention were three times more likely than "ever smokers" (even one cigarette over their lifetime) to experiment with smoking and be current smokers.

Milberger, Biederman, Faraone, Chen, and Jones (1997) in a four-year prospective study, found that ADHD predicted early onset of cigarette smoking, particularly co-morbid with other disorders (e.g., conduct disorder, major depression, and anxiety disorders). In a longitudinal study, Lambert and Hartsough (1998) examined the development of tobacco use among ADHD and non-ADHD participants. They found that ADHD is a contributing factor in adolescent and adult tobacco use. The association between ADHD and smoking suggests that prevention programs may need to be tailored to meet the needs of adolescents with ADHD. For example, utilizing one-on-one interventions rather than groups, or computerized cessation programs rather than printed materials (Tercyak et al., 2002). 


\section{Foundations of Strength-Based Assessments}

A shift in youth assessment is beginning to take place. Instead of focusing primarily on reducing risk factors for negative developmental outcomes such as smoking, increased attention is being given to building youth resilience. "Resiliency is the ability of youth to overcome obstacles, to meet the new social demands of adolescence, and to build the competencies necessary for success as adults" (California Adolescent Health Collaborative, 2001, p. 13). With appropriate school-based assessments and prevention programs, adolescents may benefit from relationships and opportunities enabling them to move successfully into adulthood (California Adolescent Health Collaborative, 2001).

Many traditional assessments and programs typically observe, label, and describe children and adolescents as having deficits, problems, and pathologies, while ignoring positive potentials (Epstein, Rudolph, \& Epstein, 2000). Positive traits (personal characteristics) that are overlooked in many assessments may be critical factors in overcoming problematic behaviors, such as nicotine addiction. In other words, youths' internal personal characteristics and access to positive social supports can influence their developmental outcomes. For example, if a youth believes that those in his or her social support network care for them, then they may be more motivated to choose appropriate behaviors. Contrary to youths' social network as a positive support system, smoking peers and family members may negatively influence youths to use tobacco. Lloyd-Richardson and colleagues (2002) found that parental smoking was positively correlated with the smoking frequency. However, social networks may also be positive influences in buffering youths from tobacco use. Lloyd-Richardson and colleagues (2002) also reported that school connectedness and family connectedness decreases the odds of smoking initiation and experimentation.

The use of strength-based assessments has recently received support in the fields of education, mental health, family services, and other social services (Epstein et al., 2000; Rhee, Furlong, Turner, \& Harari, 2001). Strength-based assessments measure emotional and behavioral skills, competencies, and characteristics that (a) create a sense of personal accomplishment; (b) contribute to satisfying relationships with family members, peers, and adults; (c) enhance one's ability to deal with adversity and stress; and (d) promote one's personal, social, and academic development (Epstein \& Sharma, 1998). Increased awareness of strength-based principles would seem to have the potential to improve psychoeducational assessments (Rhee et al., 2001), such as those supporting school-based, tobacco prevention-cessation programs.

\section{Purpose of the Current Study}

This study sought to expand knowledge about those factors that influence tobacco use as well as those that may buffer against its use. Information about multiple risks in combination with low assets would help school psychologists to better understand the complexities of working with youths who smoke and their need for specialized interventions. It was hypothesized that on a measure of personal strengths and assets (a) smokers would have fewer positive personal assets and strengths than nonsmokers would and (b) females would have more personal assets and strengths than males. Previous research did not provide a clear basis for making a hypothesis about a possible interaction between gender and smoking status; therefore, we elected to test the null hypothesis that there was no interaction.

\section{METHOD}

This study was part of the local evaluation of a district TUPE (Tobacco Use Prevention Education) program conducted in collaboration with University of California, Santa Barbara. These projects 
examined risk and health-related behaviors, including drug, alcohol, tobacco use, resilience, and perception of school violence.

\section{Participants}

The original sample included 419 students attending a comprehensive high school located in the central coast region of California. A total of 386 students provided useable data; that is, these students did not have an excessive amount of missing data and completed both surveys used in this study. The group included 194 males (50\%) and 192 females (49\%). Three hundred and fifty-nine were $9^{\text {th }}$ graders $(93 \%), 17$ were $10^{\text {th }}$ graders $(4 \%), 6$ were $11^{\text {th }}$ graders $(2 \%)$, and 4 were $12^{\text {th }}$ graders $(1 \%)$. Demographic information, such as ethnicity and age were not gathered, although the overall school demographic information is available from the California Department of Education Academic Performance Index (API) Base Report. According to the API (2001), students at this school were from a middleclass community. The school ranks 9 on a scale of 1 to 10 , where 1 is the lowest. The students are mainly of Caucasian descent (87\%) and other ethnic cultures (13\%).

\section{Measures}

Behavior and Emotional Rating Scale (BERS). The BERS was utilized to identify behaviors and emotional strengths. The BERS was developed by Epstein and Sharma (1998) and is composed of 52 items rated on a four-point scale ( $1=$ not at all like me; $2=$ not much like me; $3=$ like me; 4 = very much like me). It assesses five areas of children's personal strengths: (a) Interpersonal Strength (14 items, assesses a child's ability to control his or her behaviors and emotions in social situations); (b) Involvement with Family (10 items, measures a child's involvement and relationship with family members); (c) Intrapersonal Strength (11 items, assesses a child's perceptions of their abilities); (d) School Functioning (9 items, examines the consistency and competency of a child to complete school tasks); and (e) Affective Strength (7 items, assesses a child's abilities to accept affect from others and communicates feelings to others.

The coefficient alphas indicate strong internal consistency with all subscale coefficients above .80 and three above 90 . Content validity was examined using research literature on behavioral and emotional skills, strength-based assessment, developmental psychopathology, resilience, and protective factors. Discriminant validity data indicate that the BERS differentiates between children with differing known levels of strength (i.e., children without disabilities, children with learning disabilities, and children with emotional and behavioral problems). Inter-rater and retest reliability indicated moderate to high correlations across all subscales (.83 to .98 ). Additionally, when stability was examined over a six-month period, correlations were moderate to high across all subscales (above .80 and three were above .90; Epstein, Hertzog, \& Reid, 2001; Harniss, Epstein, Ryser, \& Pearson, 1999).

Tobacco Use Prevention Education Survey (TUPES). TUPES was modified from the California Student Survey (Skager \& Austin, 2001) and has been used as a local evaluation tool by district TUPE coordinators (Furlong \& Jimerson, 1999) in the central coast region of California. TUPES asks about health-related behaviors and attitudes relating to tobacco use among adolescents (e.g., student's motivation toward quitting). Included are items pertaining to programs available to students in the participating district. For the purposes of this study, tobacco use was assessed by an item that asked about the frequency of cigarette smoking within the past 30 days, following the smoking categories derived from Lloyd-Richardson et al. (2002). The TUPES item was: "In the past 30 days, how many cigarettes have you smoked?" The response options were: (a) I do not smoke, (b) one or a few, (c) 1-2 per day, (d) 7-19 per day, (e) 20 or more per days. Nonsmokers were defined as those youths who had smoked no 
cigarettes in the past 30 days; intermittent smokers were those students who indicated that they had smoked one or a few cigarettes in the past month; and regular smokers were those youths who smoked one or more cigarettes per day in the past month (i.e., daily smokers).

\section{Note on Definitions of Smokers and Nonsmokers}

As school psychologists attend to and assess the smoking behavior of the students with whom they work, they will need to consider the various ways to define this behavior. There is no single, universally accepted definition of when a student has become a "smoker." Brown et al. (1996) defined "smokers" as those who smoke cigarettes three or more times per week and "nonsmokers" were defined as those who smoked two or fewer times per week. Ellickson et al. (2001) defined smoking into three categories: "nonsmokers" (never smoked); "experimenters" (have tried cigarettes, but fewer than three times in the past year and not in the past 30 days); and "smokers" (smoked three or more times in the past year or any use in the past 30 days). Lloyd-Richardson et al. (2002) stringently defined smoking into five categories based on frequency and recency: "never smokers" (never tried a puff or two of cigarettes); "experimental smokers" (tried cigarettes, but denied smoking within the past 30 days or ever smoking regularly); "intermittent smokers" (smoking between 1 and 29 cigarettes in past 30 days); "regular smokers" (smoked regularly in past 30 days); and "ex-smokers" (have quit smoking, but have smoked regularly in the past and have not smoked in past 30 days).

Awareness of the differing smoking categories is important in order to assess research and program evaluation outcomes. Practically, it points to an interest among researchers in how adolescents move from having never smoked a cigarette to habitual use indicative of nicotine addiction. For school psychologists, this points to the need to be aware of smoking not as strictly a categorical behavior, but as a developmental process that occurs within social contexts, one that can accelerate rapidly once it begins. As efforts to reduce cigarette use by adolescents continue to realize gains, there is increased interest to better understand how to implement more powerful cessation programs for those youths who are at the early stages of experimentation as well as for those who are most addicted to nicotine.

\section{Procedure}

Classroom teachers under the direction of the school counselor (TUPE coordinator) administered surveys in Winter 2002. All students in the freshman health class who were in attendance at school on that particular day anonymously completed the surveys (non-ninth graders were taking the class to fulfill graduation requirements). The two measures used in this study were stapled together so that responses could be matched to the same participant while retaining anonymity. The questionnaires were developed in a machine-readable format using the Teleform software package. Prior to analysis, the responses were examined by research assistants for marking errors and ambiguities (i.e., bubbles that were not completely filled in were darkened or markings outside of the bubble were corrected). If an item had two marked responses it was considered missing data. After carefully examining the surveys, they were scanned and verified using the Teleform software package. The data were then automatically sent into an SPSS file.

In reviewing these data, extreme outliers were excluded, for example, participants who marked all 1's or 4's, an obvious invalidity indicator. Additionally, surveys were excluded if there was no way to match both the BERS and TUPES. Students who did not complete both surveys were excluded from the analysis. For surveys that had a minimal amount of missing data (no more than 3 items), these values were substituted with the overall sample mean (Switzer \& Roth, 2002). 


\section{RESULTS}

Frequencies were generated to describe the study population in terms of gender, smoking status, and the BERS subscales. Raw scores from the BERS measure were used in the statistical analysis. A multivariate analysis of variance was performed to test the relationships among gender, smoking status, and the BERS subscales.

\section{Smoking Status of Sample}

The final sample yielded 321 nonsmokers (83\%), 34 intermittent smokers (8\%), and 31 regular smokers (8\%). Table 1 shows the gender by smoking status. There were almost equal numbers of male and female nonsmokers and regular smokers; although, more females than males were intermittent smokers. In comparison to the most recent California tobacco use incidence data, there were more current smokers in this study's sample (16\%) than among ninth graders in California (12\%, Skager \& Austin, 2001).

\section{Multivariate Analysis}

A 2 (gender) by 3 (smoking status) by 5 (BERS subscales) multivariate analysis of variance (MANOVA) was conducted with repeated measures on the BERS subscales. Significant main effects were found for both gender, $F(5,376)=3.79, p=.002$, eta $=.048$, and for smoking status, $F(10,752)$ $=4.62, p=.000$, eta $=.058$. There was a nonsignificant multivariate interaction between smoking status and gender, $F(10,752)=1.12, p=.341$, eta $=.015$. consequently the discussion that follows focuses on the two significant main effects.

\section{Main Effect Findings}

The follow-up univariate analyses found significant differences for gender across all five BERS subscales (see Table 2). An examination of the group means showed that females obtained higher scores than males on all BERS subscales. It further showed that both males and females tended to rate their personal strengths in the positive direction; that is, the norm is for youths to have positive perceptions of their personal strengths.

Of particular interest in this study, the univariate ANOVAs revealed that the three smoking groups rated themselves differently on four of the five BERS subscales: Interpersonal Strength (InterS), $F(2$, $385)=8.68, p=.0001$, eta $=.044$; Family Involvement $(\mathrm{FI}), F(2,385)=14.55, p=.0001$, eta $=.071$;

Table 1.

Comparison of Nonsmokers, Intermittent smokers, and Regular Smokers by Gender

\begin{tabular}{|c|c|c|c|c|c|}
\hline & \multicolumn{2}{|c|}{ Females } & \multicolumn{2}{|c|}{ Males } & \multirow{2}{*}{$\begin{array}{l}\text { Total } \\
\quad N\end{array}$} \\
\hline & $n$ & $\%$ & $n$ & $\%$ & \\
\hline Nonsmokers & 154 & 80 & 167 & 86 & 321 \\
\hline Intermittent smokers & 23 & 12 & 11 & 5 & 34 \\
\hline Regular smokers & 15 & 7 & 16 & 8 & 31 \\
\hline Total & 192 & 49 & 194 & 50 & 386 \\
\hline
\end{tabular}


Intrapersonal Strength (IntraS), $F(2,385)=8.62, p=.0001$, eta $=.043$; and School Functioning (SF), $F(2,385)=13.94, p=.0001$, eta $=.068$ (see Table 3 ). There was no significant difference by smoking status for the Affective Strength (AS) subscale, $F(2,385)=1.52, p=.221$, eta $=.008$. An examination of the post-hoc comparisons (Tukey's HSD, see Table 3) showed that the regular smokers had significantly lower scores than the nonsmokers on all subscales except Affective Strength and the intermittent smokers had lower scores than the nonsmokers on FI and SF.

Post-hoc comparisons were performed to investigate group differences between the smoking groups in each BERS subscale. Group mean differences revealed that the nonsmokers rated themselves significantly different than the intermittent and regular smokers in social contexts (i.e., Family Involvement and School Functioning). Results may suggest that youths who smoke are less engaged and involved with family and school settings. Also, significant differences were revealed between non-

Table 2.

Univariate ANOVA for Gender-Subscale Comparison of Means, Standard Deviations, t-values, and Significance Values for Males and Females

\begin{tabular}{|c|c|c|c|c|c|c|}
\hline \multirow[b]{2}{*}{ BERS Subscale } & \multicolumn{2}{|c|}{ Male $(n=194)$} & \multicolumn{2}{|c|}{ Female $(n=192)$} & \multirow[b]{2}{*}{$t$} & \multirow[b]{2}{*}{$p$} \\
\hline & $M$ & $S D$ & $M$ & $S D$ & & \\
\hline Interpersonal Strength & 44.64 & 7.68 & 47.81 & 6.76 & -4.30 & .001 \\
\hline Family Involvement & 29.00 & 6.00 & 30.33 & 6.24 & -2.14 & .033 \\
\hline Intrapersonal Strength & 35.15 & 5.41 & 36.88 & 5.42 & -3.13 & .002 \\
\hline School Functioning & 26.79 & 5.19 & 28.48 & 4.58 & -3.40 & .001 \\
\hline Affective Strength & 21.25 & 4.13 & 23.83 & 3.36 & -6.75 & .001 \\
\hline
\end{tabular}

Note. Degrees of freedom (384).

Table 3.

Univariate ANOVAs for BERS Subscales by Smoking Status

\begin{tabular}{|c|c|c|c|c|c|c|c|c|c|}
\hline \multirow[b]{2}{*}{ BERS Subscale } & \multicolumn{2}{|c|}{ Nonsmokers } & \multicolumn{2}{|c|}{ Intermittent } & \multicolumn{2}{|c|}{ Regular } & \multirow[b]{2}{*}{$F$} & \multirow[b]{2}{*}{$p$} & \multirow[b]{2}{*}{ post-hoc } \\
\hline & $M$ & $S D$ & $M$ & $S D$ & $M$ & $S D$ & & & \\
\hline Interpersonal Strength & 46.89 & 7.01 & 44.00 & 7.00 & 41.77 & 9.65 & 8.73 & .0001 & $\mathrm{~N}>\mathrm{I}>\mathrm{R}$ \\
\hline Family Involvement & 30.36 & 5.79 & 27.56 & 6.00 & 24.71 & 7.27 & 15.14 & .0001 & $\mathrm{~N}>\mathrm{I}, \mathrm{R}$ \\
\hline Intrapersonal Strength & 36.48 & 5.31 & 34.74 & 4.62 & 32.61 & 6.76 & 8.34 & .0001 & $\mathrm{~N}>\mathrm{I}>\mathrm{R}$ \\
\hline School Functioning & 28.17 & 4.74 & 25.94 & 4.41 & 23.87 & 5.86 & 13.62 & .0001 & $\mathrm{~N}>\mathrm{I}, \mathrm{R}$ \\
\hline Affective Strength & 22.62 & 3.99 & 22.76 & 2.81 & 21.39 & 4.77 & 1.42 & .2420 & - \\
\hline
\end{tabular}

Note. Degrees of freedom $(2,385) ; \mathrm{N}=$ Nonsmoker, $\mathrm{I}=$ Intermittent smoker, and $\mathrm{R}=$ Regular smoker. 
smokers and regular smokers in social skills (i.e., Interpersonal Strength and Intrapersonal Strength). This may suggest that smokers view themselves as having lower social skills and as being more narrowly socially engaged:

1. Social Skills Comparisons

Interpersonal subscale: nonsmokers/regular smokers, $M \operatorname{diff} 5.10, p=.001$, Intrapersonal subscale: nonsmokers/regular smokers, $M \operatorname{diff} 3.86, p=.001$;

2. Social Context Comparisons

Family Involvement subscale, nonsmokers/intermittent smokers, $M$ diff 2.80, $p=.024$ ), and nonsmokers/regular-smokers, $M$ diff 5.65, $p=.001$;

School Functioning subscale, nonsmokers/intermittent smokers, $M$ diff 2.23, $p=.027$, and nonsmokers/regular smokers, $M \operatorname{diff}=4.30, p=.001$.

\section{DISCUSSION}

In this study to extend research on adolescent tobacco use, the goals were to explore factors associated with tobacco use as well as those that may potentially buffer against its use. Additionally, the information gathered was intended to help school psychologists and other educational professionals better understand the complexities of the combination of multiple risks and low assets when working with youths. The findings revealed that there were more female intermittent smokers than males in this sample, although there were about equal numbers of male and female regular smokers. This is consistent with other research with California adolescents showing that female smoking rates are now about the same or higher than those of males (Burns et al., 2002; Furlong, Bates, Casas, DeVera, \& Soliz, 2002). The multivariate analysis of variance indicated a main effect for smoking status and gender. Consistent with study hypotheses, it was found that (a) youths who smoked reported lower levels of positive personal assets and strengths on the BERS compared to the nonsmokers and (b) the most frequent smokers had the lowest BERS scores overall. Although not interacting with smoking status, females had higher positive personal assets and strength scores than males.

\section{Personal Assets and Tobacco Use}

Research has not intensively examined the role that personal assets play in tobacco use. For example, it is possible that personal strengths as assessed by the BERS, may act to prevent early experimentation (e.g., a child early on identifies as being a "nonsmoker") or buffer a youth against chronic use if she or he engages in early experimentation (e.g., a child tries a cigarette or two and decides that this is not a smart thing to do or those in her or his social context convey anti-tobacco messages to them). One possibility that may have the greatest implications for school-based cessation efforts is that personal strengths may be resources that can be used to support a youth's efforts to quit smoking. Such an approach is supported by other research (Atkins, Oman, Vesely, Aspy, \& McLeroy, 2002). Some protective factors that have been shown to decrease adolescent tobacco use are involvement in extracurricular activities (e.g., sports) and a general healthy lifestyle. Parental involvement is a crucial factor in a child's smoking behavior. For example, when parents communicate to their children about the negative effects of smoking and encourage them to participate in after-school activities, then they may be less likely to be exposed to social situations in which tobacco is available and used. These findings suggest that disengagement from family and school are associated with the early stages of smoking behavior and that efforts to support school and family connection may help to deflect longerterm cigarette smoking, a pattern found in a previous study (Topolski, Patrick, Edwards, Huebner, Connell, \& Mount, 2001). Such a pattern suggests that any efforts to support school engagement of students could indirectly alter their developmental course away from tobacco use circumstances. 
The regular smokers in this study were the most disengaged from family and school, but in addition, they reported having less positive interpersonal and intrapersonal skills. This is consistent with the findings of Griffin, Epstein, Botvin, and Spoth (2001) that social competence is a protective factor against smoking behavior. Future longitudinal research can help to clarify these findings, which suggest that youths who are socially disengaged are vulnerable to initiate smoking, and then may progress to nicotine addiction. Consequently, their relationship skills become relatively weak compared to nonsmokers. In addition, smokers then engage in more risk behaviors than nonsmokers (Furlong et al., 2002). Given such a developmental pattern, school-based smoking cessation efforts should target youths who are not only regular users, but also experimenters (i.e., tried in the past, but not currently smoking or occasionally smoking). Furthermore, efforts should continue to be made to educate all youths and their families, not waiting until and cessation intervention is required.

Finally, several studies have suggested that smoking can be interpreted as an attempt to manage psychosocial problems or as an escape route to self-medicate their problems (Brown et al., 1996; Escobedo et al., 1998; Tomari et al., 2001). This suggests that at least some of the students in this study who were disengaged from family and school and had low personal strength, smoke as a means of coping with life difficulties. In addition, smoking may increase the possibility of dysfunctional personal development, where stress factors reinforce negative behaviors (Brown et al., 1996; Escobedo et al., 1998). For example, smokers may be more defiant than nonsmokers, thus increasing family conflicts and educational problems. Interestingly, some youths who are at high risk for smoking do not smoke. Better understanding of this group may help researchers point to factors that buffer or protect them from habitual smoking. The results of the current study support a resilience model in which internal personal strengths and social supports that encourage nonuse have protective influences against smoking (Atkins et al., 2002). This suggests that school psychologist can consider youth smoking as evolving out of their limited school and family engagement, not just antisocial behavior. This can potentially shift the focus from treating smoking as a disciplinary infraction to efforts to improve student school engagement by drawing on their skills, strengths, interests, and social supports.

\section{Limitations and Future Directions}

The findings from this study must be considered in light of some limitations. As noted earlier, definitions of cigarette smoking is inconsistent in the research literature. Thus, these results generalize only to other studies that used a similar cigarettes use definition. However, the definition used is the current study is consistent with other research studies (e.g., Lloyd-Richardson et al., 2002) and is categorically defined according to frequency and intensity of use. In addition, since smokeless tobacco is also addictive and just as harmful, it would be relevant to examine this type of use concurrently with cigarette use or examined independently and compared to cigarette use. Future research should examine smokeless tobacco use because this type of tobacco use is rising among adolescents and the consequences are just as harmful.

It is also important to note that the present study relied on self-report measures by youths to assess smoking behaviors and personal attributes. Although questionnaires were anonymous, there is no guarantee that the responses provided were accurate and there is always a chance of youths minimizing perceived negative behaviors. In addition, some responses were found to have not been reliable (e.g., marking all extreme responses) and excluded from the analysis; this raises questions about the validity for other responses that may have had less obvious response sets. Caution must also be used in generalizing results from the present study to other populations and students from other communities. The sample population was predominantly white, middle-class students. Future studies could examine youth 
tobacco use from various populations and communities for comparison purposes, although tobacco use is higher among white youths.

Despite these qualifications, the results of this study are both noteworthy and relevant for school psychologists and other educational professionals in youth tobacco cessation efforts. This study extended research on youth smoking, particularly in identifying personal strengths and attributes of adolescent smokers as a factor contributing to the success of smoking prevention and intervention programs.

\section{Getting Involved in Tobacco Prevention Efforts}

With recent research pointing to rapid onset nicotine addiction among adolescents (DiFranza et al., 2002) and smoking's association with multiple negative developmental outcomes, school psychologist should attend closely to any smoking behavior among youth. Of particular interest to them will be assessments that help to evaluate behaviors associated with the degree of nicotine addiction (e.g., the time when the first cigarettes is smoked each day and the perceived need to smoke during school hours), not just the frequency of smoking, among adolescents (see O'Loughlin, Kishchuk, DiFranza, Tremblay, \& Paradis, 2002).

School-based cessation programs, as represented by the TUPE initiative in California, offer youths a convenient place to engage in tobacco use cessation interventions. The results of this study and others suggest, however, that these same youths typically leave school and immediately associate with peers who smoke and thereby expose them to second-hand smoke. Therefore, current cessation programs are not permanent solutions to youth smoking behaviors. It is necessary to assess the social context of smoking and personal assets of youths to improve the success rate of school-based smoking cessation programs. Knowing what a youth does well, is interested in, and how they see themselves in positive ways, may provide the context to explore alternative social outlets and strategies for how to cope with nicotine cravings. Such a focus offers school psychologists a way to increase their support of tobacco prevention and cessation efforts on their school campuses.

California provides various resources in the areas of tobacco use research and prevention that offer school psychologists the opportunity to support positive health promotion efforts; these include:

1. Proposition 99, which was approved by California voters in 1988, added an additional 25 cent tax to each pack of cigarettes, and has made an average of $\$ 74$ million available each year to California's Tobacco Control Program. This program implemented a major statewide antismoking media campaign beginning in the early 1990 s.

2. California's Tobacco Control Program allocates funding to the California Department of Education for school-based Tobacco-Use Prevention Education (TUPE) programs, locally designed for students in grades 4 through 12 (see the web site for the California Department of Education, www.cde.ca.gov).

3. In 1994, California's Tobacco Control Program developed the Operation Storefront campaign to stem the proliferation of tobacco advertising and promotion in communities.

4. The STAKE (Stop Tobacco Access to Kids Enforcement) Act prohibits the sale of or furnishing of tobacco to anyone under 18, requires retailers to check ID of anyone under 18 and post warning signs at sales counters, and authorizes $\$ 6,000$ fines for violations.

5. Title IV-Safe and Drug-free Schools (SADFS) and Communities provides funding for ageappropriate drug and violence prevention and education programs for all K-12 students through linkages between schools and communities (contact your district or county SADFS coordinator for additional information). 
6. The California Mentoring Initiative (CMI), through the California Department of Alcohol and Drug Programs (ADP) was initiated in 1995 in partnership with many community-based organizations to reduce four major problem areas: alcohol/drug use, teen pregnancy, educational failure, and gangs and violence.

7. The California Friday Night Live (FNL) Program, funded by ADP, was established in 1984 to promote a teenage lifestyle free of alcohol and other drugs. FNL's mission is to build partnerships for positive and healthy youth development, which engage youth as active leaders and resources in their communities.

8. Club Live is a prevention program aimed at middle school students in California and is an extension of the successful FNL program. It assists students in developing alternatives to using alcohol, tobacco, and other drugs.

9. TEENWORK, INC. is a private agency working to provide a forum for youth to share ideas and discuss solutions to the critical issues facing teens today. Since 1984, California high school students spend seven months planning a training institute that focuses on substance use prevention and includes broader issues such as pregnancy, gangs, suicide, HIV/AIDS, and recovery (California Adolescent Health Collaborative, 2001).

\section{Implications for School Psychologists}

The results of this study show that youth tobacco users' personal and social assets differ from those of non-smokers in ways that provide opportunities for school psychologists to become involved in prevention and intervention efforts. Knowing that youths who smoke are not as well engaged in school and may be overly involved in social contexts that support smoking, emphasize the importance of the interpersonal aspects of smoking behavior. School psychologist training standards clearly emphasize the roles of school psychologist in wellness promotion. The strong links between psychological well-being, the development of personal-social strengths, and the formation of positive health habits place tobacco education and cessation efforts squarely within school psychologists' service role. Tobacco use is an obvious student behavior with multiple known negative short- and long-term development consequences - any other behavior with such known association would be a prevention priority for educators. School psychologist can support tobacco prevention and cessation efforts by inquiring about tobacco use in their assessments and by supporting the availability of cessation options in the school and local community.

It is hoped that the results obtained from this study will assist school psychologist and educational professionals to better understand those factors that increase the risk of adolescent smoking and those that may buffer them from its use. The tobacco prevention efforts in California's schools are producing results. Addressing the influences of youth personal strengths on the process of the uptake and habitual use of cigarettes may contribute to a continued reduction in underage tobacco use. These possibilities will, of course, need to be enhanced by future longitudinal studies that assess the BERS and other strength-based instruments in developmental contexts juxtaposed with smoking behavior.

\section{REFERENCES}

American Academy of Pediatrics. (2002). Tobacco's toll: Implication for the pediatrician. Retrieved August 2, 2002, from http://www.aap.org/policy/re0041.html

American Lung Association. (2002). Trends in tobacco use. Retrieved August 6, 2002, from http:// www.lungusa.org/data/smoke/SMK1.pdf 
Atkins, L. A., Oman, R. F., Vesely, S. K., Aspy, C. B., \& McLeroy, K. (2002). Adolescent tobacco use: The protective effects of developmental assets. American Journal of Health Promotion, 16, 198-205.

Baezconde-Garbanati, L. (2002). Understanding tobacco-use research among Hispanic/Latino adolescents: A sociocultural perspective. In D. M. Burns, R. H. Amacher, \& W. Ruppert (Eds.), Smoking and tobacco change monographs-Monograph 14: Changing adolescent smoking prevalence (pp. 227-241). Washington, DC: U.S. Department of Health and Human Services; National Institutes of Health; National Cancer Institute.

Breslau, N., \& Peterson, E. (1996). Smoking cessation in young adults: Age at initiation of cigarette smoking and other suspected influences. American Journal of Public Health, 86, 214-220.

Brown, R. A., Lewinsohn, P. M., Seeley, J. R., \& Wagner, E. F. (1996). Cigarette smoking, major depression, and other psychiatric disorders among adolescents. Journal of the American Academy of Child and Adolescent Psychiatry, 35, 1602-1610.

Burns, D. M., Major, J. M., Vaughn, J. W., Anderson, C. M., \& Shanks, T. G. (2002). Cigarette smoking among adolescents in California, 1990-1996. In D. M. Burns, R. H. Amacher, \& W. Ruppert (Eds.), Smoking and tobacco change monographs-Monograph 14: Changing adolescent smoking prevalence (pp. 69-100). Washington, DC: U.S. Department of Health and Human Services; National Institutes of Health; National Cancer Institute.

Byrne, D. G., \& Mazanov, J. (2001). Self-esteem, stress, and cigarette smoking in adolescents. Stress and Health, 17, $105-110$.

California Adolescent Health Collaborative. (2001). Investing in adolescent health: A social imperative for California's future. Retrieved August 5, 2002, from http://youth.ucsf.edu/nahic/img/spfull.pdf

California Department of Education-Academic Performance Index (API) Base Report. (2002). Retrieved August 1, 2002, from www.api.cde.ca.gov

Conners, C. K., Levin, E. D., Sparrow, E., Hinton, S. C., Erhardt, D., Meck, W. H., et al. (1996). Nicotine and attention in adult attention deficit hyperactivity disorder (ADHD). Psychopharmacology Bulletin, 32, 67-73.

Connolly, G. N. (1995). The marketing of nicotine addiction by one oral snuff manufacturer. Tobacco Control, 4 , 73-79.

DiFranza, J. R., Savageau, J. A., Rigotti, N. A., Fletcher, K., Ockene, J. K., McNeill, J., Coleman, M., \& Wood, C. (2002). Development of symptoms of tobacco dependence in youths: 30-month follow-up data from the DANDY study. Tobacco Control, 11, 228-235.

Djordjevic, M. V., Hoffmann, D., Glynn, T., \& Connolly, G. N. (1995). U.S. commercial brands of moist snuff, 1994-assessment of nicotine, moisture, and PH. Tobacco Control, 4, 62-66.

Ellickson, P. L., Tucker, J. S., \& Klein, D. J. (2001). High-risk behaviors associated with early smoking: Results from a 5-year follow-up. Journal of Adolescent Health, 28, 465-473.

Entwisle, D. R., Alexander, K. L., \& Olson, L. S. (2002). Smoking and the adult transition among urban teenagers. Adolescent \& Family Health, 2, 108-122.

Epstein, M. H., Hertzog, M. A., \& Reid, R. (2001). The Behavioral and Emotional Rating Scale: Long term testretest reliability. Behavioral Disorders, 26, 314-320.

Epstein, M. H., Rudolph, S., \& Epstein, A. A. (2000). Strength-based assessment. Teaching Exceptional Children, $32,50-54$.

Epstein, M. H., \& Sharma, J. (1998). Behavioral and Emotional Rating Scale: A strength-based approach to assessment. Austin: TX: PRO-ED.

Escobedo, L. G., Reddy, M., \& Giovino, G. A. (1998). The relationship between depressive symptoms and cigarette smoking in U.S. adolescents. Addiction, 93, 433-440.

Furlong, M. J., Bates, M., Casas, J. M., DeVera, Z., \& Soliz, A. (2002). Santa Barbara County Children's Scorecard. Retrieved November 15, 2002, from University of California, Santa Barbara; Gevirtz Graduate School of Education-School Psychology Web site: www.education.ucsb/school-psychology

Furlong, M. J., Bates, M. P., Sharkey, J. D., \& Smith, D. C. (2004). The accuracy of school and nonschool risk behaviors to predict school weapon possession. In M. J. Furlong, M. P. Bates, D. C. Smith, \& P. E. Kingery (Eds.), Appraisal and prediction of school violence: Context, issues, and methods. Hauppauge, NY: Nova Science Publishers.

Furlong, M. J., \& Jimerson, S. R. (1999) Tobacco Use Prevention Education Survey (TUPES). Unpublished questionnaire. University of California, Santa Barbara, Gevirtz Graduate School of Education.

Gardiner, P. (2002). African American teen cigarette smoking: A review. In D. M. Burns, R. H. Amacher, \& W. Ruppert (Eds.), Smoking and tobacco change monographs-Monograph 14: Changing adolescent smoking prevalence (pp. 213-225). Washington, DC: U.S. Department of Health and Human Services; National Institutes of Health; National Cancer Institute.

Griffin, K. W., Epstein, J. A., Botvin, G. J., \& Spoth, R. L. (2001). Social competence and substance use among rural youth: Mediating role of social benefit expectancies of use. Journal of Youth \& Adolescence, 30, 485498. 
Hallfors, D., \& Van Dorn, R. A. (2002). Strengthening the role of two key institutions in prevention of adolescent substance abuse. Journal of Adolescent Health, 30, 17-28.

Harniss, M. K., Epstein, M. H., Ryser, G., \& Pearson, N. (1999). The Behavioral and Emotional Rating Scale: Convergent validity. Journal of Psychoeducational Assessment, 17, 4-14.

Jessor, R. (1984). Adolescent development and behavioral health. In J. D. Matarazzo, S. M. Weiss, J. A. Herd, N. E. Miller, \& S. M. Weiss (Eds.), Behavioral health, handbook of health enhancement and disease prevention (pp. 69-90). New York: Wiley.

Lambert, N. M., \& Hartsough, C. S. (1998). Prospective study of tobacco smoking and substance dependencies among samples of ADHD and non-ADHD participants. Journal of Learning Disabilities, 31, 533-544.

Lloyd-Richardson, G., Papandonatos, E., Kazura, A., Stanton, C., \& Niaura, R. (2002). Differentiating stages of smoking intensity among adolescents: Stage-specific psychological and social influences. Journal of Consulting and Clinical Psychology, 70, 998-1009.

Milberger, S., Biederman, J., Faraone, S., Chen, L., \& Jones, J. (1997). ADHD is associated with early initiation of cigarette smoking in children and adolescents. Journal of the American Academy of Child and Adolescent Psychiatry, 36, 37-44.

O'Loughlin, J., Kishchuk, N., DiFranza, J., Tremblay, M., \& Paradis, G. (2002). The hardest thing is the habit: A qualitative investigation of adolescent smokers' experience of nicotine dependence. Nicotine \& Tobacco Research, 4, 201-209.

Pierce, J. P., Choi, W. S., Gilpin, E. A., Farkas, A. J., \& Berry, C. C. (1998). Tobacco industry promotion of cigarettes and adolescent smoking. Journal of the American Medical Association, 279, 511-518.

PRIDE Surveys. (2002). PRIDE questionnaire report: 2001-2002 national summary, grades 6 through 12. Bowling Green, KY: Author. Retrieved August 30, 2002, from www.pride surveys.com

Rhee, S., Furlong, M. J., Turner, J. A., \& Harari, I. (2001). Integrating strength-based perspectives in psychoeducational evaluations. The California School Psychologist, 6, 5-17.

Skager, R., \& Austin, G., (2001). Preliminary findings: Results from the eighth biennial statewide California Student Survey, Alcohol and other drug use grades 7, 9, 11. Sacramento, CA: California Office of the Attorney General. Retrieved August 24, 2002, from http://caag.state.ca.us/cvpc/css.html

Switzer, F. S., \& Roth, P. (2002). Coping with missing data. In S. G. Rogelberg (Ed.), Handbook of research methods in industrial and organizational psychology (pp. 310-323). Malden, MA: Blackwell.

Taioli, E., \& Wynder, E. (1991). Effect of the age at which smoking begins on frequency of smoking in adulthood. New England Journal of Medicine, 325, 968-969.

Tercyak, K. P., Lerman, C., \& Audrain, J. (2002). Association of attention-deficit/hyperactivity disorder with levels of cigarette smoking in a community sample of adolescents. Journal of the American Academy of Child and Adolescent Psychiatry, 41, 799-805.

Tomar, S., Giovino, G., \& Ericksen, M. (1995). Smokeless tobacco brand preference and brand switching among US adolescents and young adults. Tobacco Control, 4, 67-72.

Tomori, M., Zalar, B. K., Plesnicar, B., Ziherl, S., \& Stergar, E. (2001). Smoking in relation to psychosocial risk factors in adolescents. European Child and Adolescent Psychiatry, 10, 143-150.

Topolski, T. D., Patrick, D. L., Edwards, T. C., Huebner, C. E., Connell, F. A., \& Mount, K. (2001). Quality of life and health-risk behaviors among adolescents. Journal of Adolescent Health, 29, 426-435.

Trinidad, D. R., \& Johnson, C. A. (2002). The association between emotional intelligence and early adolescent tobacco and alcohol use. Personality and Individual Differences, 32, 95-105.

Wagner, E. F., \& Atkins, J. H. (1999). Smoking among teenage girls. Journal of Child \& Adolescent Substance Abuse, 9, 93-110.

Whalen, C. K., Jamner, L. D., Henker, M., Delfino, R. J., \& Lozano, J. M. (2002). The ADHD spectrum and everyday life: Experience sampling of adolescent moods, activities, smoking, and drinking. Child Development, 73, 209-227.

Wu, L., \& Anthony, J. C. (1999). Tobacco smoking and depressed mood in late childhood and early adolescence. American Journal of Public Health, 89, 1837-1840. 
California School Psychologist, Vol. 9, pp. 79-87, 2004 Copyright 2004 California Association of School Psychologists

\title{
From Deficits to Development: A Case Study of the Journey of Friday Night Live
}

\author{
Margaret Libby, Maureen Sedonaen \\ Youth Leadership Institute \\ Jim Kooler \\ California Friday Night Live Partnership
}

\begin{abstract}
In 1996, the Youth Leadership Institute (a youth development institute) and California Friday Night Live Partnership (a statewide prevention program serving over 800,000 young people) undertook a major challenge: to come together as partners in an effort to bridge youth development research and practice. With guidance and strategic support from Youth Leadership Institute, California Friday Night Live Partnership set out to transform its statewide network of local prevention programs by shifting from a problem, or deficit, orientation to an approach that links effective and innovative prevention strategies with positive youth development research and "best practice." This article describes the research that informed the shift and the collaboration that brought it about. Additionally, it presents data regarding the youth participants' perceptions of the joint program. Results indicate that youth participants experience many of the supports and opportunities that research has linked to positive developmental outcomes.
\end{abstract}

Key Words: Evaluation, Youth Programs, Youth Development

Friday Night Live (FNL) was established in 1984 by the California Department of Alcohol and Drug Programs (ADP) and the Office of Traffic Safety. Created as a pilot program in a single county, FNL initially was designed to reduce deaths and injuries caused by teens driving under the influence of alcohol and other drugs. Based on the program's early success, in 1988 ADP began expanding FNL to additional counties throughout the state. ADP oversaw FNL until 1996, when the department outsourced statewide coordination of FNL programs to the Tulare County Office of Education. This led to the creation of the California Friday Night Live Partnership (CFNLP), which serves as an umbrella organization for the four FNL programs. CFNLP assists FNL county coordinators with program design, development, and management, and program evaluation.

Established in 1991, the Youth Leadership Institute (YLI) is a national organization that connects youth development theory, evaluation, research and practice and works with young people and adults to build communities that invest in youth. A leader in the field of youth development, YLI operates a national Training Institute and local Community-Based Programs, focusing on three disciplines: youth philanthropy, policy and civic engagement, and linking prevention with youth development.

At its inception in the early 1980s, FNL was singularly focused on preventing alcohol and drug use among youth. By the mid-1990s, staff became interested in expanding this vision. CFNLP already had a strong relationship with local FNL programs and experience in building and supporting a statewide system around prevention. Yet in order to expand the program, CFNLP sought guidance from Youth Leadership Institute, which had established itself as a pioneer in the field of youth development. Having been a coordinating organization for FNL programs in two (now three) counties over a decade, YLI was especially familiar not only with the emerging field of youth development, but also with the FNL history, and the strategies it had employed to transition its own FNL programs to a youth develop-

Address correspondence to Margaret Libby \& Maureen Sedonaen; Youth Leadership Institute; 246 First Street, Suite 400; San Francisco, CA 94105; or Jim Kooler; California Friday Night Live Partnership; 2637 West Burrel Ave.; Visalia, CA 93278. E-mail: jimk@ @tcoe.org. 
ment approach. Its first-hand knowledge of the FNL system and its expertise in youth development theory and practice, as well as training and evaluation, positioned YLI as a strong partner in helping the system transform.

\section{Review of Related Literature}

YLI and CFNLP turned to the research in an effort to determine which prevention approaches were most effective. This research suggested that prevention programs that focused solely on preventing the use of alcohol and drugs, such as the "Just Say No" approach, did not demonstrate effectiveness in several expected outcomes, particularly the important outcome of reducing use (Ennett et al., 1994; Kreft \& Brown, 1998) or influencing young people's decisions regarding whether to use substances (Brown et al., 1995). Further, a growing body of research indicated that programs with demonstrated effectiveness in both minimizing use and preventing other problems, as well as facilitating the development of important skills and social assets, used a positive youth development framework and approach. Such an approach focuses on promoting healthy development of young people, and providing support and opportunities to meet their developmental needs for love, belonging, respect, power, mastery, and meaning (Benard, 1991; Benson, 1997; Botvin at al., 1990; Eccles \& Gootman, 2002; Gambone et al., 2002; Hattie et al., 1997; McLaughlin et al., 1994; Pittman \& Cahill, 1992; Schweinhart \& Weikart, 1997; Tierney et al., 1995; Werner \& Smith, 1992).

Two recent and compelling studies make an especially strong case that providing youth with key supports and opportunities in a program setting leads to positive short- and long-term developmental outcomes (Eccles \& Gootman, 2002; Gambone et al., 2002). These longitudinal studies present scientific evidence that applying a youth development framework in a program setting is an effective strategy for both problem prevention and positive youth development. The Eccles and Gootman (2002) study indicates that "high-quality experimental and quasi-experimental evaluations show positive effects on a variety of outcomes, including both increases in psychological and social assets of youth and decreases in the incidence of such problem behaviors as early pregnancy, drug use, and delinquency" (p. 14). The Gambone and colleagues study establishes the strength of the relationship between good developmental outcomes in high school years and success in early adulthood, or longer-term outcomes.

Other key research findings regarding youth development programs lend relevant information to designing a program rooted in youth development. Involving youth as equal partners in program design and management increases positive developmental outcomes and can decrease young people's exposure to high-risk behaviors (Benard, 1991). Additionally, when young people are engaged as decision-makers in partnership with adults, the decision making that results is often more innovative than when solely adult driven. The process also provides youth with a critical opportunity for the acquisition of skills and an important sense of empowerment and productivity (Zeldin et al., 2002). Furthermore, experts point out that youth engagement not only has positive impacts on the youth and adults involved but can also strengthen the communities in which they live (Cahill, 1996). It has also been noted that programs focusing on the various developmental needs of young people (e.g., health/ physical; personal/social; creative/cognitive; vocational; and citizenship; Pittman \& Cahill, 1992) have been effective in reducing alcohol and other drug usage and other problem behaviors (American Youth Policy Forum, 1997). Finally, a meta-analysis of research on adolescent development identified key experiences necessary for healthy youth development: adequate nutrition, health, and shelter; supportive relationships with adults and peers; challenging and engaging activities and learning experiences; meaningful opportunities for involvement and membership; and physical and emotional safety (Connell, Gambone, \& Smith, 1998). 
Based on this review of the research, it was clear that the CFNLP system needed to adopt a positive youth development prevention approach if it wanted to ensure its relevance as a prevention program. YLI and CFNLP determined that the Friday Night Live programs statewide would move forward in a new and exciting direction in which problem-prevention would not be an end in itself, but would be situated in a more comprehensive youth development framework. With YLI's consultation, CFNLP committed itself to linking prevention programs that could be accountable to certain standards with a set of youth development outcomes that could be clearly defined and reliably evaluated. The knowledge gained thus led to transformative efforts to shift toward strategies that engaged youth in the design, planning, and implementation of the programs that served to train them in life skills; increase a focus in skills that would assist them academically (e.g., in writing and analytical thinking); and increase school bonding through positive associations of the Friday Night Live clubs on school campuses and their contributions to the schools in service learning and peer support.

\section{Program Implementation}

YLI began working closely with CFNLP, the Department of Alcohol and Drug Programs Prevention Division (ADP), and Bonnie Benard of Resiliency Associates to begin this ambitious effort to link effective and innovative science-based prevention strategies with positive youth development research. The goal was to firmly ground the mission, goals and strategies of the CFNLP system in positive youth development principles rather than problem reduction alone, reflecting the perspective shift from viewing "youth as problems" to "youth as resources." Thus, CFNLP adopted the following principles, stating that the Friday Night Live programs: (a) are youth driven and led; (b) help young people develop skills and resilient traits (e.g., foster a sense of power and autonomy); (c) build community partnerships to support youth; (d) provide meaningful and caring relationships among youth and with adults; (e) promote belief in youths' capacity to contribute; (f) provide safe, healthy, fun, and supportive places for youth to be; (g) demonstrate cultural competence; (h) have clearly defined and measurable goals, based on research and objective data; (i) support and train adults to work effectively with youth; and (j) evaluate programs periodically to assess progress and refine, improve, and strengthen the program's effectiveness.

A critical part of any shift to incorporate a youth development approach is to create meaningful roles for young people in the evaluation and assessment of those efforts. Mindful of this need, YLI ensured that young people sat on the committee that defined the standards of practice and another group of young people participated in the design of the youth development survey. Young people assisted with the administration of the survey at their local chapters and young people completed surveys, providing valuable feedback on their experiences in their FNL program. In many counties, young people participated in discussions about their survey results and the implications for program course correction.

In order to address the program evaluation principles by appropriately assessing outcomes across programs, which vary by setting (e.g., school-based or community-based) and geographical location (urban, suburban, and rural), CFNLP adopted a set of youth development standards of practice to serve as process outcomes. These outcomes represent critical supports, opportunities, and skills young people need to experience on a consistent and sustained basis in order to achieve longer-term developmental outcomes, and they include: a safe environment, opportunities for involvement and connection to community and school, opportunities for leadership and advocacy, opportunities to engage in skillbuilding activities, and caring and meaningful relationships with adults and other youth. These standards of practice closely mirror the features of positive youth development settings described by Eccles and Gootman (2002). 
Seven counties (Alameda, Butte, Orange, Riverside, Santa Cruz, Stanislaus, and Yolo) were selected to participate in the first year of the FNL Youth Development Pilot Initiative, which included focused Linking Youth Development and Prevention training with YLI. This initial pilot group provided CFNLP and YLI with an opportunity to test the curriculum and assess how implementation of the new approaches would unfold.

The training series for these counties was designed to present youth development theory, its application, and the research base that indicated the strength of the relationship between youth development and prevention. The training brought decision makers and youth from across a formerly disparate system together to ground them in common theory, dialogue and discuss cross-system collaboration and deepen their understanding of common outcomes for positive youth development. It was conducted over a ten-month period of time with each group spending 40-50 hours in the sessions. Experienced youth development and prevention experts conducted the trainings, with strong involvement from youth trainers and local community experts.

\section{Program Evaluation}

Using the standards of practice, YLI designed an evaluation process. The goal was to measure the extent to which FNL pilot counties were successfully applying their youth development training in their programs and measure the experiences that youth participants were having in the context of the standards of practice. While prevention programs have historically been held accountable for status outcomes (high school graduation rates and job attainment) and problem prevention outcomes (reducing alcohol-related problems or drug use), there has been recognition more recently that the set of outcomes has to be broader (Zeldin \& Charner, 1996). Two central drawbacks associated with measuring program effectiveness with problem prevention outcomes have been identified: (a) when program evaluation emphasizes these outcomes, the more positive set of developmental outcomes that programs are influencing, such as skill development and relationship development, are often ignored or overlooked; and (b) because there are numerous influences on a young person's life, including his or her community, family, school and peers, a single program cannot claim responsibility for those kinds of outcomes, nor is it reasonable to hold a single program accountable for such outcomes (Gambone \& Connell, 1998).

On the other hand, what a program can be reasonably held accountable for is the quality of the setting it provides (Gambone \& Connell, 1998). Therefore, rather than focusing on problem prevention outcomes, (i.e., whether FNL participants were reducing their alcohol intake as a result of their participation) Youth Leadership Institute's evaluation focuses on whether young people were experiencing quality program settings, or environments characterized by the standards of practice. The decision to design this type of evaluation in which process outcomes were examined was based in part on the body of research indicating that if young people experience support and opportunities, they are more likely to make positive and healthy decisions about their bodies and their lives and will gain the experience, skills and supportive relationships that will prepare them for their futures (Benard, 1991; Connell et al., 1998; Tierney, Grossman, \& Resch, 1995; Werner \& Smith, 1982). Thus, Youth Leadership Institute approach to program evaluation sought to determine the extent to which programs effectively and thoroughly integrated key supports and opportunities into their work with young people.

In the later part of year one, three additional counties outside of CFNLP supported trainings joined the process and engaged in the ground-building training and assessment. In year two all 10 counties participated in the assessment: Butte, Orange, Santa Cruz, Contra Costa, El Dorado, Sacramento, San Benito, San Diego, San Joaquin, and San Luis Obispo Counties. There were a total of 848 youth participants from 91 FNL and Club Live chapters throughout the state. Club Live is the junior high 
school component of FNL, following the same youth development standards of practice, implemented age appropriately. Approximately two-thirds of FNL participants who responded to the survey were female $(68.2 \%)$ and the age span of participants was 11 to 19. Approximately one-third of the FNL participants identified as Caucasian (32.3\%), close to one-third were Latino/Hispanic (30.7\%), 14.9\% were Asian/Pacific Islander, 7.1\% were African American, and 6\% indicated that they were biracial/ multiracial. The remaining participants identified as Native American (1.3\%), Middle Eastern (0.9\%) and other $(3.5 \%)$.

YLI developed a 43-item survey for youth participants designed to determine the range of opportunities available to youth participants and the range of supports they experienced through the program by assessing the standards of practice. Ten items addressed the standard of Safety by assessing emotional safety, physical safety, and cultural competence. Five items addressed Community Involvement standard through the evaluation of knowledge and contribution to the community. The Skill Building standard was addressed by nine items measuring challenging/interesting activities, and specific skills. Twelve items relate to the Relationship Building standard and measured guidance, practical support, emotional support, adult knowledge of youth, and sense of belonging. The Leadership and Advocacy standard was assessed by seven items measuring decision-making and governance. Each item was rated on a Likert scale ranging from 1 (strongly disagree) to 4 (strongly agree). There are six items related to the relationship building standard of practice that utilize a different scale ranging from 0 (no adults) to 3 (three adults). The alpha coefficients for the standards of practice were strong and ranged from .69 (safety) to .89 (skill development). Test-retest reliability studies were not conducted. The results were scored by dimension and by standard, with overall composite mean scores.

\section{RESULTS}

Results reveal some important information regarding the length of participation in the Friday Night Live program. Thirty-four percent of participants reported that they had been involved in the program for less than six months, whereas $32.0 \%$ reported six months to one year of involvement. The remaining 33.3\% reported being involved for longer than one year. Youth also reported varying levels of frequency of participation. Roughly a third reported that they participated in meetings, events or activities less than once a week $(33.6 \%)$, while $35.1 \%$ indicated that they participate weekly, and the remaining $31.3 \%$ reported that they attended more than once a week. Finally, youth responses also differed in terms of the length of time they stayed when attending a program event. Most youth respondents indicated that when they participated, they stayed for less than an hour (43.9\%). Another 35.6\% reported that they stayed between one and two hours, and the remaining $20.4 \%$, indicated staying more than two hours.

Results from the survey assessing the youths' perspective on their experience with each of the five standards of practice are presented below. As behavioral outcomes are not being measured here, there is no comparison data (with another type of prevention program), nor pre-implementation data. Thus, it is important to consider that the following results reflect the youths' opinions regarding their experience being in the program. Except where noted, all of the mean scores are based on the scale utilized in the survey, where 1 = strongly disagree, $2=$ disagree, $3=$ agree, and $4=$ strongly agree.

Youth overwhelmingly reported that they experience a safe environment in their FNL/CL program $(M=3.48, S D=.41)$. Responses to items related to safety were more consistent than those of any other standard; the scores reflect overall agreement, as well as the most positive reports on any of the five standards by FNL/CL youth. The Safe Environment mean score (across participating counties) was significantly higher than those of the other four standards, indicating that practices related to creating a safe environment appear to have been better implemented than practices related to the other 
areas across the counties. As was the case in most counties, physical safety had the strongest score, followed by emotional safety, and cultural competence. The range of safety means across the counties was 3.34 to 3.57 .

The overall mean score (across participating counties) for Community Involvement was 3.15 $(S D=.60)$ and its two dimensions: contribute to the community and knowledge of the community were 3.14 and 3.16, respectively. The range of county means was 2.86 to 3.33, indicating that there was variation across counties in terms of youth perceptions regarding whether the program offered such opportunities.

The overall mean score for Skill Building opportunities was $3.17(S D=.55)$, with the scores of the three dimensions ranging from 3.14 to 3.19. The range of county means for this standard was slightly wider than other standards: 2.83 to 3.38 . The mean score for Skill Building across participating counties was significantly higher than Relationship Building, indicating that practices related to Skill Building may have been more effectively implemented.

The overall mean for two of the dimensions assessing Relationship Building was 3.09 (SD=.64). There were differences by county, with a mean range of 2.87 to 3.27 for the Relationship Building standard. Three of the dimensions were measured on a different metric, such that the response indicated the number of adults the youth felt provided practical support, emotional support and guidance. The means for practical support, emotional support, and guidance indicate that, on average, young people reported that there were two adults that they felt they could go to: a strong statement about the relationships between youth participants and adult staff. Nearly all of the young people reported that there was at least one adult they felt they could rely on for practical support, emotional support and guidance. Research has consistently established a strong link between relationships with caring adults and positive youth development outcomes.

The overall mean response for leadership and advocacy was $3.11(S D=.62)$. The mean scores for the two dimensions differed, with stronger agreement that FNL provided opportunities for governance $(M=3.19)$, than for decision-making $(M=3.03)$. Interestingly, these scores suggest that while young people feel there are opportunities to facilitate meetings and provide input about decisions, for example, they are not as certain that these governance roles lead to opportunities to influence and participate in decision-making. The range of means across participating counties for leadership and advocacy was 2.83 to 3.29 .

\section{Summary of Data Analysis by Gender, Ethnicity and Participation Intensity}

Analysis by subgroup revealed some important differences across the standards of practice related to participation intensity, gender, and ethnicity. The findings are summarized below. Statistical tests were used to determine whether mean differences were significant among demographic subgroups and by rates of participation with a confidence interval of $95 \%(p<.05)$. Male and female mean comparisons were conducted with an independent samples $t$-test and the remaining mean comparisons were conducted with ANOVA tests. Any reported difference below was significant.

Gender. Female participant mean scores on all five standards of practice were significantly higher than those of males. This may be related to the fact that there are more female participants in the program, thus creating a more positive experience for them.

Ethnicity. There were no significant differences across ethnicity for the Relationship Building standard overall. This is an encouraging finding, as meaningful relationships with peers and adults provide a critical support for young people and address a key developmental need. However, some other differences by ethnicity became apparent. It was found that African American youth participant 
scores on Community Involvement were significantly lower than their Asian/Pacific Islander (API), Latino, and multiracial peers. Their scores on the Safety standard were significantly lower than those of Caucasian, multi-racial and API youth participants. Latino youth scores were significantly higher than Caucasian youth on Skill Building and Community Involvement, whereas their scores on the Safety and Leadership and Advocacy standards were significantly lower than those of Caucasian participants.

Level of participation. Results suggest that level of participation affects the youths' perspective on the standards of practice. There were significant differences across each length of participation increment ("less than six months," "six months to a year," and "more than one year"), for community involvement, skill development and leadership and advocacy. This indicates that as young people participate in the program over time, they may be more likely to report experiencing these supports and opportunities offered by the program. Interestingly, scores were significantly lower on Safety and Relationships for youth who were newer to the program, but there was not significant difference between these mean scores for the two groups of longer-term participants. This indicates that youth reports about their experience of Safety in program settings and support from adult staff increase significantly after six months and then plateau. Mean differences for frequency of participation reflect those seen with the length of participation analysis. However, for Community Involvement, Skill Building, Relationship Building and Leadership and Advocacy, it appears that weekly participation is ideal for addressing the developmental needs of young people through the program in these four areas. There were no differences across Safety, which could indicate that the program practices designed to create safe environments are effective regardless of frequency of participation. With the exception of Safety, mean differences increased significantly at each of the three levels of duration of participation. In other words, when youth participants stayed longer, their scores were higher.

In summary, it appears that young people's reports about their experiences in the program were often related to their level of participation, especially the duration of the activities, but also the frequency and length of their participation. Simply put, the more program participation, the stronger their endorsement that they were experiencing the supports and opportunities that define the standards of practice. Gender also appeared to be an influence, with females consistently reporting more positive experiences in the program. Ethnicity made a difference in some standards, with African Americans scores reflecting a less positive experience on the community involvement and safety standards.

\section{DISCUSSION}

Taking part in this program transformation and evaluation process has yielded a number of important lessons. First of all, it has become clear that prevention programs at a community level need science-based and research-driven data to not only identify expected and reasonable outcomes, but also to validate and confirm their practice, as well as discontinue and correct ineffective strategies and practice. Many programs within the system had still been engaged in targeting their resources toward goals and strategies that had not been proven through evaluation measures. For example, didactic classroom-based knowledge transfer via curricula about the dangers of drugs and drinking showed no correlation to the reduction of use (Ennett et al., 1994; Kreft \& Brown, 1998) nor to decisions about not to use (Brown et al., 1995). Learning about the importance of connections to community for example, promoted positive outreach and partnership for the program and served as a "win-win" situation for both the youth in FNL and another community coalition of groups working on substance abuse/tobacco prevention. 
Other key lessons learned consisted of an understanding that strong partnerships between research and assessment, and youth and adults in all elements of the program are critical. Furthermore, shared vision, values, and beliefs, regarding the roles of young people, the connection to the broader community, social justice, the need for effective program strategies, and the ways in which outcomes are measured is also essential for success. Along with an understanding of partnerships, has been an increased awareness on the part of staff about the necessity of engaging youth in the program and activities. By placing young people at the center of the CFNLP system, they are engaged at ALL levels of the program and are now often pulled into other initiatives locally, statewide and nationally as a model of youth-adult partnership and youth engagement.

Finally, important lessons were realized regarding the value of a thorough evaluation that is linked to the developmental needs and issues of the youth. Addressing the program elements over which staff has control is key to the success of a transition. The need to conduct ongoing evaluation to provide staff with a sense of what they are accomplishing and areas for improvement annually is critical to program accountability and improvement. Additionally, it is critical to provide staff and young people with opportunities to build their capacity in evaluation, through participation in the design, implementation and analysis of results. In examining the standards of practice outcomes for the first time we were able to look at youth participants in the context of their broader developmental needs and the issues that affect them. By examining supports and opportunities of CFNLP programs we were able to understand how the program is able to address important aspects of adolescent development, including: making community connections, meeting a diverse group of youth, and attaining skills and engaging in leadership efforts that also framed their peer and adult relationships.

Through this process we are now able to continue to make programmatic course correction through the lessons that were learned throughout this process and have a clear and compelling understanding of the need to apply those lessons to action-oriented policy recommendations to guide future actions. The system shift to embrace youth development is an ongoing process. Initiating pilots and building a learning network has created a pathway for the Friday Night Live system to adopt a number of different strategies. Rather than being focused solely on problem reduction, Friday Night Live has adopted a developmental framework that allows young people to be engaged as partners in the design and implementation of age-appropriate opportunities. Additionally, after experiencing the effects of the philosophy and framework on these particular programs, it was expanded to other components of Friday Night Live. One example of this philosophy expansion has been the successful transition of the cross-ageFNL Mentoring model. The Friday Night Live Mentoring program trains high school students to mentor middle school students, using a structured program that extends over a 16-week period.

The Friday Night Live Mentoring program followed the model of the youth development pilot programs. Grounded in the research base on the benefits of quality mentoring relationships, the Friday Night Live program joined the California Governor's Mentoring Partnership. Championed by Governor and Mrs. Wilson, and then by Governor and Mrs. Davis, the Governor's Mentoring Partnership helped raise the awareness and profile of the need for quality mentoring in California. The combination of research-based approaches and political will to support the success of children is powerful. In keeping with the commitment to engage youth, Friday Night Live looks to high school students to mentor middle school students. Adult allies work with the mentors and protégés to implement a 16week program, which incorporates the research based Project ALERT curriculum.

The Friday Night Live program has been able to bridge the gap between community- and schoolbased programs. Young people in the Friday Night Live program and the Friday Night Live Mentoring 
program are supported in their individuation and in taking appropriate risks. The Standards of Practice for youth development adopted by Friday Night Live provided the framework for a continuously improving system that is flexible to meet the continuous changing needs of youth. A shared understanding and belief that meeting the key developmental needs of adolescents, while approaching them in a holistic and engaged manner, is a critical promotion for both adolescent developmental science and youth development and prevention practitioners. School psychologists can utilize Friday Night Live as a partner in the school and community to provide additional supports and opportunities for young people.

\section{REFERENCES}

American Youth Policy Forum. (1997). Some things do make a difference for youth: A compendium of evaluations of youth programs and practices. Washington, DC: Institute for Educational Leadership.

Benard, B. (1991). Fostering resiliency in kids: Protective factors in the family, school, and community. San Francisco, CA: WestEd.

Benson, P. (1997). All kids are our kids: What communities must do to raise caring and responsible children and adolescents. San Francisco, CA: Jossey-Bass.

Botvin, G. J. et al. (1990). A Cognitive behavioral approach to substance abuse prevention: One year follow up. Addictive Behaviors, 15(1), 47-63.

Cahill, M. (1996). Youth development and community development: Promises and challenges of convergence. New York: Ford Foundation and International Youth Foundation.

Connell, J., Gambone, M. A., \& Smith, T. J. (1998). Youth development in community settings: Challenges to our field and our approach. Philadelphia, PA: Community Action for Youth Project.

Eccles, J., \& Gootman, J. A. (Eds.). (2002). Community programs to promote youth development. Washington, DC: National Academies Press.

Ennett, S., Tobler, N., Ringwalt, C., \& Flewelling, R. (1994). How effective is Drug Abuse Resistance Education? A meta-analysis of Project DARE outcome evaluations. American Journal of Public Health, 84, 1394-1401.

Gambone, M. A., Klem, A. M., \& Connell, J. P. (2002). Finding out what matters for youth: Testing key links in a community action framework for youth development. Philadelphia, PA:Youth Development Strategies, Inc., and Institute for Research and Reform in Education.

Hattie, J., Marsh, H., Neill, J., \& Richards, G. (1997). Adventure education and Outward Bound: Out-of-class experiences that make a lasting difference. Review of Educational Research, 67, 43-87.

Kreft, I., \& Brown, J. (Eds.), (1998). Special issue: Zero effects of drug prevention programs: Issues and solutions. Evaluation Review: A Journal of Applied Social Research, 22.

McLaughlin, M., Irby, M., \& Langman, J. (1994). Urban sanctuaries: Neighborhood organizations in the lives and futures of inner-city youth. San Francisco. CA: Jossey-Bass.

Morrow, K., \& Styles, M. (1995). Building relationships with youth in program settings. Philadelphia, PA: Public/ Private Ventures.

Pittman, K., \& Cahill, M. (1992). Youth and caring: The role of youth programs in the development of caring. Washington, DC: Center for Youth Development and Policy Research, Academy for Educational Development.

Schweinhart, L., \& Weikart, D. (1997). Lasting differences: The High/Scope Preschool Curriculum comparison study through age 23. Ypsilanti, MI: High/Scope Press.

Tierney, J., Grossman, J., \& Resch, N. (1995). Making a difference: An impact study of Big Brothers/Big Sisters. Philadelphia, PA: Public/Private Ventures.

Werner, E., \& Smith, R. (1982). Vulnerable but invincible: A longitudinal study of resilient children and youth. New York: Cornell University Press.

Werner, E., \& Smith, R. (1992). Overcoming the odds: High-risk children from birth to adulthood. New York: Cornell University Press.

Zeldin, S., McDaniel, A. K., Topitzes, D., \& Calvert, M. (2002). Youth in decision-making: A study on the impacts of youth on adults and organizations. Madison, WI: Innovation Center/Tides Center and University of Wisconsin Extension.

Zeldin, S., \& Charner, I. (1996). School-to-work opportunities through the lens of youth development. Washington, DC: Academy for Educational Development, National Institute for Work and Learning. 


\title{
Resilience: From Program to Process
}

\author{
Joel H. Brown \\ Center for Educational Research and Development (CERD), Berkeley \\ University of Oklahoma
}

\begin{abstract}
This article considers school engagement from a resilience perspective. Despite a 40-year research legacy, only recently have practitioners/researchers engaged in the explicit, prospective facilitation of resilience in school settings. Derived from the book Resilience Education (Brown, D'Emidio-Caston, \& Benard, 2000), based on supporting theory and evidence, a process-based model is advanced. As an ever-present part of school participant interaction, Resilience Education (ReSed) is conducted by balancing a global youth development orientation with the specificity of supporting protective factor development. Preliminary evidence suggests high satisfaction and internalization of the model by workshop participants. Discussion focuses on the potentially unique contribution ReSed offers, as well as some pragmatic ways to begin applying it in any school practice. While more research is needed, it is concluded that ReSed offers a promising model of how "resilience" occurs, not solely as an outcome, but as a moment-to-moment learning and development process.
\end{abstract}

Keywords: Resilience, School Engagement, Youth Development

\section{THE FOUNDATIONS OF RESILIENCE EDUCATION}

Resilience education is significant and unique as an interactive human and humane process that supports lifelong learning and development. In this process, a global and holistic view of such learning and development is balanced with the specificity of facilitating three research-based and affective protective factors: person-to-person connectedness, opportunities for participation and contribution, and high self expectations (Benard, 2003; Werner \& Smith, 2001). Resilience in Education represents a central part of how my colleagues and I view school engagement. Yet only recently has it been intentionally applied in educational settings. This model of applying resilience in Education (ReSed) was created with colleagues Bonnie Benard of WestEd and Marianne D'Emidio-Caston of Antioch University for the Center for Educational Research and Development (CERD) in Berkeley.

In a non-didactic yet directed way, ReSed facilitators develop the "hows" of building a community of support for identifying and working with people's strengths and interests in order to promote learning and development. This is achieved by strategically working with individuals, dyads, triads, small groups, and large groups. Such strategic inter- and intra-personal processes make visible to the facilitator and model opportunities for specific protective factor development and/or support. Moreover, the facilitation of ReSed serves as a model that young people can use to marshal their strengths for learning and development throughout the course of their own lives. This approach is described herein and more fully in the book Resilience Education (Brown et al., 2000). Because its focus is on a resilience building process, not a manualized program, ReSed is context acknowledging, yet context independent-participants can apply it in any school, counseling program, curricula, or human service program.

This article discusses the promise of resilience in school engagement not solely as an outcome, but as a moment-to-moment process orientation. In the following sections, its conceptual, definitional,

Address correspondence to Joel H. Brown. E-mail: jhb@ cerd.org. 
and applied grounding are described. The article closes with a discussion of the distinct and promising contribution that Resilience Education may offer, as well as recommendations to focus your work on resilience.

\section{Resilience Education Foundations: A Global Orientation Balanced with Protective Factor Facilitation}

CERD's view of resilience and its application in education balances a global and holistic view of development with the specific processes of facilitating three key protective factors. ReSed's research foundations are derived from the fields of Human Development, Psychology and Education. While a full literature review is provided in the book Resilience Education (Brown et al., 2000), its foundations are briefly described here.

Global resilience orientation. A global resilience orientation is seen as the likelihood that most young people, even those in the highest stress environments, will evolve into thriving adults (Garmezy, 1987, 1991; Rutter, 1985, 1987; Werner, 1989). For example, after following people from birth to adulthood for more than 40 years, Werner and Smith (2001) found that:

...most of the high-risk youths who did develop serious coping problems in adolescences had staged a recovery by the time they reach midlife... They were in stable marriages and jobs, were satisfied with their relationships with their spouses and teenage children, and were responsible citizens in their community. (p. 167)

In this and other longitudinal studies, approximately $70 \%$ of young people with multiple risk factors in youth thrive by midlife. Masten (2001) best captures this global resilience orientation:

Resilience does not come from rare and special qualities, but from the everyday magic of ordinary, normative human resources in the minds, brains, and bodies of children, in their families and relationships, and in their communities. (p. 238)

Theory and evidence suggests resilience can serve as a global orientation because its occurrence is a "normative" part of development in the vast majority of people's lives. When human beings are faced with life challenges, they often manage, adapt, and move on. A focus on resilient development as a powerful global orientation leads to reformulating the basic question from "Which people are resilient?" to "What are the resilient possibilities within each person?"

Specific protective factors. As noted earlier, the research literature suggests that three dimensions - connectedness, opportunities for participation and contribution, and high self expectationsserve as the primary protective factors predicting the fostering of resilience by midlife (Benard, 2003; Resnick et al., 1997). Psychobiologically, within each of these specific factors, socio-emotional or affective states may literally create development, learning and thriving (D'Arcangelo, 1998; Sylwester, 1995a). Emotions are not simply adjuncts to learning; they act as the glue between perception, learning, and development. Specifically, emotional arousal causes the movement of peptide chains to the brain, which in turn causes the formation of neural connections in the brain. This literally indicates learning and development (Parasuraman, 1998; Sylwester, 1995b; Vincent, 1990). Connecting this psychobiological evidence with the protective factor evidence, it is theorized that the affective dimensions inherent in these protective factors - a young person feeling connected with an adult, experiencing opportunities for participation and contribution as well as developing high self expectationscreate a variety of emotional states of readiness wherein learning and development can occur.

It is important to note that before the educational community began applying such human development evidence regarding protective factors to school and youth development, similar ideas could be drawn from Education and its foundational fields. Most notably, this is seen in the work of Berger and Luckmann (1967), Belenky et al. (1986), Thayer-Bacon (2000), Thayer-Bacon and Bacon (1998), as 
well as the applications of Dewey (1897, 1899, 1902), Montessori (1912), and Brown (1972, 1975). The thread binding these philosophers and practitioners is a constructivist and/or a socio-emotional perspective of learning. Within these perspectives, either originating from one's self or in concert with others, information or experiences become meaningful and learned in accord with each individual's emotional ties to that information or experience.

The most direct and significant evidence regarding application of resilience in Education emerges from a now-ended project of the Developmental Studies Center (DSC; Battistich \& Hom, 1997; Battistich, Schaps, Watson, Solomon, \& Lewis, 2000; Watson, Battistich, \& Solomon, 1997). DSC researchers/practitioners focused on the global view of creating a resilient school climate. An example of longitudinal findings from this research is summarized:

[Results revealed] higher test scores, higher grades in core academic subjects, more involvement in positive youth school and community activities and less misconduct at school than comparison students. (Brown, 2001, p. 50)

This evidence provides the strongest support to date establishing a reasonable basis for further exploration of the prospective role of resilience in education and related systems.

\section{A Process-Oriented Definition of Resilience}

The literature and evidence from Human Development, Psychology, and Education suggest the following: whether the context is counseling, math, science, history, or otherwise, a school engagement climate focused on learning and development includes both a global view of each person's developmental capacity along with the specificity of focusing on protective factors. Based on the theorized importance of this balance, a process-oriented definition of resilience is offered-A global orientation toward each individual's capacity for lifelong learning and development that is facilitated individually or interactively by cognitively, affectively, or behaviorally locating and/or supporting the protective factors of person-to-person connectedness, opportunities for participation and contribution, and high self expectations.

\section{Resilience Education: Translating Theory into Practice}

ReSed is designed to become a part of the evolving fabric of school engagement in learning and development activities. As such, the central dimension of ReSed's viability is how its theory and definition is translated into practice. This is to be achieved in two ways: (a) facilitating a caring learning community comprised of the day-to-day and moment-to-moment processes of locating and supporting the three protective factors and; (b) at the professional's discretion, offering subject-specific information - counseling feedback, math, science, history, or any form of subject content—during teachable moments. Teachable moments are those in which there is a perceived emotional state of readiness to receive subject-specific content, which may then become learned.

In CERD's training workshops designed for those working with young people, ReSed is not only discussed, it is experienced-often over a two-day period. The workshop's goal is to develop a resilience-oriented community. It is also to learn how to balance the global development view of resilience with the specificity of supporting the protective factors. By reinterpreting, adapting, and subsequently applying their own training experience from the training workshop to the unique needs of their professional setting, each workshop participant brings ReSed's principles to life. As participants go back into their professional settings, they then have an initial skill set to draw from for supporting the creation of a resilience community.

Within the training workshop itself, two types of facilitation exercises are used. The first is what is referred to in the Resilience Education (Brown et al., 2000) book as a "PORTable" approach. The 
second is embedded within the first-strategic and intentional regrouping or shuttling among workshop participants in individual, dyads, triads, small and large group configurations. More is said about each of these training categories.

\section{Two Categories of ReSed Exercises: PORTable and Group Configuration}

PORTable exercises. As noted above, we use an acronym for our resilience building approach$\mathrm{P}-\mathrm{O}-\mathrm{R}-\mathrm{T}$. It is named as such because it is literally portable-it can be applied in any learning environment. The model includes four distinct elements of the human experience believed integral to supporting resilient development: Participation, Observation, Reflection, and Transformation. Participation involves authentic, present-focused active engagement of self and with others involved in learning and development activities. Observation involves noting or describing rather than interpreting these experiences. Reflection involves interpreting such current experiences. Finally, transformation involves “...awareness of and responsibility for an act, process or instance of change" (Brown et al., 2001, p. $50)$.

In PORT-able exercises, facilitators work with participants to distinguish and differentiate these elements of human experience into the four distinct categories. An exemplar overview of a two-day workshop and its exercise and/or resilience-oriented goals is presented in Table 1. As a brief example here, I distinguish the Observation of an experience such as "you just spoke to me in a high pitched voice," with an interpretation of that experience or Reflection such as "from what you just said I am interpreting this as you being angry with me." PORT exercises are designed to highlight such distinctions cognitively as is noted here. Additionally, by actually participating in or experiencing skill-building PORT exercises, rather than simply talking about them, highlights distinctions affectively. For example, through workshop exercises, participants both sense and learn how to contribute to their own resilient development by experiencing the caring connected relationships inevitably developed during such exercises. Based on the combination of cognitive and affective dimensions of PORT exercises, participants learn how its elements serve distinct, essential purposes in supporting the protective factors of ReSed. This includes the development of ongoing awareness and personal responsibility for communication patterns, identifying resilient capacities, and strengths in how to facilitate resilience. Paradoxically, it appears that by differentiating the elements of the PORTable model, eventually participants reconnect them. Subsequently, an integrated and holistic view of resilience along with the initial skill set to support its facilitation, emerges.

Group shuttling exercises. Be it a counselor conducting group work, an educator with many students, or a school administrator facing competing time interests, using traditional means, one simply cannot meet all people's resilience learning needs. These concerns may be addressed by learning how to effectively shuttle or regroup participants as individuals, dyads, triads, small and large groups. Embedded within the PORTable exercises described above, the specific goals of configuration exercises are the following: (a) to make visible how different configurations affect one's ability to learn and develop, both individually and as part of a group; (b) to make visible multiple opportunities for support and/or facilitation of protective factors; and (c) to learn how to efficiently and effectively facilitate such shuttling as a means of protective factor support, learning, and development.

How do we know how and when to shuttle? There are numerous considerations. At its most basic level, such regrouping is necessitated by a combination of training experience, professional discretion learned through PORT, and ongoing participant feedback. Most importantly, reconfiguration or shuttling occurs when the facilitator perceives the resulting new configuration serves the development and/ or learning of the emerging resilient community.

More specifically, our facilitators always consider their audience. Exercise order, the level of detail, content, and sophistication will vary. Thus, different group configurations are needed. For ex- 
ample, during workshops such considerations may necessitate an orientation toward "reflection" rather than "observation." A reflective exercise may involve noting individual interpretation and reporting back to a larger participant group. On the other hand, an observational exercise may involve two participants working together to develop their skills at non-judgmental observation. By participating in different working configurations, participants can locate the configurations in which they feel most engaged. To the extent to which such shuttling is made explicit, participants also acquire a portion of the skill set needed to locate and meet his or her own learning and development needs. Shuttling then, to serve participants' needs is the epitome of being responsive to opportunities for protective factor development as they emerge.

\section{Resilience Education Workshop Summary}

Based on this model, ReSed workshops model and facilitate a resilience-oriented community through non-didactic yet directed learning. The non-didactic portion is that each person has a unique experience of discovering his or her own resilience and how that may support the principle of balancing the global orientation with specific protective factor work with their colleagues and/or young people with whom they work. The "directed learning" portion of the model is that there is usually a clear learning progression - that facilitators can direct efforts toward-as indicated by the typical order in the PORT-able model.

With professional discretion as to age appropriateness, opportunity, and skill level, ReSed principles are brought to life by using a variety of PORT-able and shuttling exercises. These include some of the exercises used during the training workshop. At the discretion of the professional, it may also include using new exercises she or he develops when working with young people. To the extent that the process and resilience-related principles are made explicit and used by the facilitator, the goal is one of self efficacy-young people or adults using them to develop skills in support of their own resilient oriented learning and development.

\section{Promising Pilot Findings: Positive Attitudes and High Levels of Internal Attribution}

Research regarding ReSed is in its earliest stages. In pilot research, participant satisfaction and implementation levels are now being examined. Qualitative and quantitative pilot results from workshops with counselors, educators and administrators suggest promise (Brown \& D'Emidio-Caston, 2003). For example, one educator typical of others, noted:

Personally I have begun to use the vocabulary and strategies in my day-to-day contacts. I've noticed that people are more open to hearing what I say if that "democratic community" is established. Even the brief respites of time to quiet myself and go inside allows me to be more open to what is being taught. With this openness I release judgments that might interfere with hearing what is being said. (Brown \& D'Emidio-Caston, 2003, p. 2)

Quantitatively, regarding overall perception of ReSed at a University of California, Berkeley cosponsored workshop, out of a potential rating of 4.0, participants rated the workshop on an average of 3.7, with 22 of 25 participants perceiving the workshop as "good" to "excellent." More importantly, it was found that by the end of the workshop, on psychological attribution outcome measures (Kelley, 1967; Raven, 1965), participants had taken on dimensions of ReSed as their own. These early results suggest that changes participants may make with respect to their ReSed practices were attributed significantly more to themselves (internal attribution) than to the group leaders (external attribution). Such attributions indicate an internal locus of control, perhaps as part of incorporating the protective 
factor of "high self expectations." Such internalized attributions predict long-term behavioral change (Ajzen \& Fishbein, 1980). These findings have been consistent across additional workshops.

While the preceding pilot evidence is interesting, further research is needed regarding (a) the developed skill and implementation level of ReSed in school environments and (b) the facilitator/ youth impact of ReSed. In addition to the measures noted above, outcomes being examined are similar to those of the DSC research as well as the developed level of "connectedness" described by Resnick et al. (1997).

\section{The Application of Resilience Education}

This article draws attention to the potential value of resilience as part of school engagement, learning and development by focusing on its daily opportunities. As the potential contributions are described below, there is an important matter to consider. For those interested in fully implementing the ReSed approach, more than two days of trainings are recommended. Among participating staff, approximately four workshop days spread over two months combined with two additional days in two subsequent years and/or ongoing whole-school change consultation support is recommended. Such additional work usually involves more in-depth variations of the training as described in Table 1.

\section{Table 1.}

General ReSed 1.5-Day Workshop Description

Exercise and Group Configuration Exercise and Resilience Goal
Day 1: Community Building and Introduction to Resilience Education

1. Dyads and then whole group: Partner Introductions

Each person interacts with another to first learn a bit about who the partner is, then later in the whole group, introduces the partner.

\section{Whole group: Develop Norms/Ground rules for workshop participation \\ Facilitator acts as prompter and note taker to develop participatory ground rules.}

\section{Individual: Brief guided imagery regarding individual that participant experiences as fostering an interpersonal life connection Followed by "quick write" to make immediate perceptions explicit.}

\section{Whole Group: Relationships, Messages, Opportunities}

Based on quick write above: Share relationships, opportunities and messages that you experienced in your life.

Experience is subsequently integrated with brief research presentation.
-Begin authentic present focus and building caring, connected interpersonal relationships

-Continue the above

-Helps build resilience oriented community by adding dimension of personal ownership and empowerment for the workshop

-Develops group participatory norms

-Continue building authentic present focus through low-risk exercise

-Helps make visible potential strengths for the protective factor of high self expectations

-Link affective experience, relationships and messages with cognitive information regarding resilience

-Concept attainment: Foster general understanding of research support for ReSed 
Table 1. Continued

\section{Individual and then dyads: Individual quick write to connect information above with learning about resilience in present moment Share noted learning with colleague.}

\section{Whole Group: Closure to first morning: Introduction to Processing}

Large group discussion of two dimensions to be made explicit: (a) content processing, e.g., what is being learned about resilience education; and (b) meta processing, what is being learned about how the participant learns, e.g., strength and interest identification.

\section{Be Here Now Exercise}

Identify participant focus in each moment as it occurs; partners face one another. One partner begins by stating "now I" and then the other partner responds with "now I." Continues back and forth for two or three minutes.

\section{Dyads or Triads: See, Imagine, Feel Exercise: Two people sit facing one another \\ If third is present, s/he observes the two. The first nonparticipant makes an "I see" statement, followed by an "I imagine" statement, concluded by an "I feel" statement. The partner responds with similar statements. They continue back and forth for approximately 3 minutes and then discuss their experience. If observer is present, $\mathrm{s} / \mathrm{he}$ provides and separates observational from reflective feedback. Observer then participates with a partner and new observer until each of the triad members have had an opportunity to participate and observe.}

\section{Whole Group; Mini-Lecture: Explicit Introduction to PORT approach and use of shuttling to facilitate resilient community}

10. Whole Group: Meta processing and end to day one
-Initiate reflective practice using present-focus and continue process of intrapersonal strength location

-Moving into dyads, using affective personal stories to begin tying personal experience into research-based dimensions of resilience -Further deepening of interpersonal connectedness

-Same as above -Deepen reflective practice -Make explicit types of learning strengths, individually noted optimal learning context(s)

-Explore desired opportunities for participation and contribution available to participants

-Make explicit authentic present focus -Continue deepening interpersonal connections

-Support development of protective factor of high self expectations through skills building exercise

-Learn how to explicitly distinguish between observation and reflection

-Learn how to give descriptive and evaluative feedback

-Continue deepening interpersonal connections; Supporting high self expectations through skills building exercises

-"PORT" concept attainment derived from above exercises and multiple configurations

-Same as similar exercise described above 
Table 1. Continued

\section{Day 2: PORT in Closer Detail and Application in Your Professional Setting}

11. Small Groups: View brief video; describe or note observations without evaluation

\section{Small Groups: Content and meta-reflection in present moment}

13. Triads: Transformation: Present and Future Applications: One case/situation in your professional environment where application of PORT may be possible

14. Whole Group: Closure; content and metaprocessing
-Reinforcing importance of separating observation and reflection

-Make explicit identification of intrapersonal observational strengths

-Deepen connectedness through small group configuration

-Reinforcing role of interpretation and distinction between content and metareflection

-Make explicit location of reflective strengths

-Deepen connectedness through small group configuration

-Concept attainment: Noting application in specific work environment

-Further develop high self expectations, by identifying realistic opportunities for change in work environment

-Preparation for application of strengths based focus outside workshop

-Make explicit final concept attainment -Learning about the process of ReSed, intrapersonal strengths and optimal learning configurations, a resilience-oriented caring connected community has been developed -Offer closing opportunities for deepening connectedness using participatory and contributory options, and how these can be continued outside this workshop

\section{The Potential Contribution(s) of Resilience Education to Learning and Development}

First, once learned, it appears that the ReSed process orientation may become commonplace. Our work is generally focused as a support to existing learning and development activities. As such, ReSed is not a stand-alone program, but rather can be integrated as part of nearly any school learning or development program. It is not an academic standard, but indications are that ReSed can lead to supporting the attainment of such standards.

Second, the psychobiological research suggests that the emotions developed when focused on protective factors create literal opportunities for learning and development. As people emotionally experience the protective factors, content specific information offered during that time can become learned through the creation of neural brain connections formed due to that emotional experience.

Third, ReSed may make a unique contribution because a most delightful aspect of the PORT-able 
approach is its mutuality. For example, the development of caring, connected relationship(s) for the purpose of learning and development by definition includes the building of relationship(s). Given the intended, recognized, and appreciated goal of mutuality, ReSed may also prevent facilitator burnout by supporting the professional development and health of the helper.

\section{Practical Steps for Promoting Resilient Development}

Overall, the supporting psychological, development and educational theory and evidence suggest that it is time to expand efforts to promote youth resilience. As a practical guide, in efforts to do soto bring about the "ordinary magic" to which Masten (2001) refers-several pragmatic steps may be taken.

In general, work to strike a balance between a global orientation toward resilience and the specificity of focusing on the protective factors through ongoing processes and professional assessment. Specifically, learn how to make these factors visible and supportable to the facilitator and with young people. This may be achieved by drawing dimensions from the PORT-able approach such as focusing on being presently engaged and becoming aware of verbal and non-verbal cues, and regularly providing descriptive rather than evaluative feedback. The goal of making explicit such observations is twofold: (a) to clearly note what is going on for you right now and (b) to clarify your thoughts or interpretations from those of others, or what is referred to in psychological terms as developing a clear boundary differentiation. In the service of modeling or facilitating development of a specific protective factor, share observations with those with whom you work as descriptions, not only determinations.

Another practical step involves adding regular and targeted opportunities for reflection as described above and in Table 1, item \#6, to your toolbox. This helps you make explicit for yourself and to hear from others their interpretation of the same thoughts or events. Additionally, the regular availability of non-judgmental processing may also help build the kinds of caring connected relationships known to support resilient development. Embedded in these practices is the importance of learning how to shuttle between individual and various group combinations.

Finally, one may want to use these process options before determining what resilience-supporting changes to make. This stepwise approach to resilience building allows the facilitator as well as those they serve to accomplish this goal-to support resilience-oriented change in real time, as part of an ongoing process. In so doing, decisions can be made by determination rather than by inertia or default.

\section{CONCLUSION}

As conceptualized, developed and implemented by CERD, ReSed draws from the best human development, psychobiological, and educational evidence to implement a development focus. The ReSed orientation has the potential to enhance school engagement. This change is toward a sophisticated, affective, and humanistic form of school engagement-one that is directed, yet youth supporting and focused. It does not replace other scholastic quality standards, but as learned through the ReSed process, can come to represent a higher level of quality_lifelong quality —in learning and development. ReSed offers a promising hope because those using it seek to strike a manageable balance between a global orientation toward resilience and a development process specifically connected with its protective factors. As a process and not just another program, ReSed provides counselors, educators, or administrators an opportunity to support a youth development approach. This is hu- 
manely managed school engagement.

\section{REFERENCES}

Ajzen, I., \& Fishbein, M. (1980). Understanding attitudes and predicting behavior. Englewood Cliffs, NJ: Prentice Hall.

Battistich, V., \& Hom, A. (1997). The relationships between students sense of their school as a community and their involvement in problem behaviors. American Journal of Public Health, 87(12), 1997-2001.

Battistich, V., Schaps, E., Watson, M., Solomon, D., \& Lewis, C. (2000). Effects of the Child Development Project on students drug use and other problem behaviors. Journal of Primary Prevention, 21(1), 75-99.

Belenky, M., Clinchy, B., Goldberger, N., \& Tarule, J. (1986). Women's ways of knowing. New York: Basic Books. Benard, B. (2003). Resiliency; What we have learned. San Francisco: WestEd.

Berger, P. L., \& Luckmann, T. (1967). The social construction of reality. Garden City, NY: Anchor Books.

Brown, G. I. (1972). Human teaching for human learning: An introduction to Confluent Education. Highland, NY: The Gestalt Journal.

Brown, G. I. (Ed.). (1975). The live classroom: Innovation through Confluent Education and Gestalt. New York: Viking Press.

Brown, J. H. (2001). Systemic reform concerning resilience in education. Association for Educational Communications and Technology, 45(4), 47-54.

Brown, J. H., \& D'Emidio-Caston, M. (2003, April). Resilience and Confluent Education: Pilot workshop results. Paper presented at the American Educational Research Association, Annual Meeting, Chicago, IL.

Brown, J. H., D'Emidio-Caston, M., \& Benard, B. (2000). Resilience education. Thousand Oaks, CA: Sage.

D'Arcangelo, M. (1998). The brains behind the brain. Educational Leadership, 56(3), 20-25.

Dewey, J. (1897). My pedagogic creed. The School Journal, LIV(3), 77-80.

Dewey, J. (1899). The school and society. Chicago: University of Chicago Press.

Dewey, J. (1902). The child and the curriculum. Chicago: University of Chicago Press.

Garmezy, N. (1983). Stressors of childhood. In N. Garmezy \& M. Rutter (Eds.), Stress, coping and development in children (pp. 43-84). New York: McGraw-Hill.

Garmezy, N. (1987). Stress, competence, and development: Continuities in the study of schizophrenic adults, children vulnerable to psychopathology, and the search for stress-resistant children. American Journal of Orthopsychiatry, 52(2), 159-175.

Garmezy, N. (1991). Resilience and vulnerability to adverse developmental outcomes associated with poverty. American Behavioral Scientist, 34, 416-430.

Kelley, H. H. (1967). Attribution theory in social psychology. In D. Levine (Ed.), Nebraska Symposium on Motivation (vol. 15, pp. 192-238). Lincoln, NE: University of Nebraska.

Masten, A. (2001). Ordinary magic: Resilience processes in development. American Psychologist, 56(3), 227238.

Montessori, M. (1912). The Montessori method. New York: Frederick Stokes.

Parasuraman, R. (Ed.). (1998). The attentive brain. Cambridge, MA: MIT Press.

Raven, B. H. (1965). Social influence and power. In M. Fishbein (Ed.), Current studies in social psychology (pp. 371-382). New York: Holt, Rinehart \& Winston.

Resnick, M., Bearman, P., Blum, R., Bauman, K., Harris, K., Jones, J., et al. (1997). Protecting adolescents from harm: Findings from the national longitudinal study on adolescent health. Journal of the American Medical Association, 278(10), 823-832.

Rutter, M. (1985, December). Resilience in the face of adversity: Protective factors and resistance to psychiatric disorder. British Journal of Psychiatry, 57, 598-611.

Rutter, M. (1987). Psychosocial resilience and protective mechanisms. American Journal of Orthopsychiatry, 57(3), 316-331.

Sylwester, R. (1995a). A celebration of neurons: An educator's guide to the human brain. Alexandria, VA: Association for Supervision and Curriculum Development (ASCD).

Sylwester, R. (1995b). How emotions affect learning. Educational Leadership, 52(2), 60-66.

Thayer-Bacon, B. J. (2000). Transforming critical thinking; Thinking constructively. New York \& London: Teachers College, Columbia University.

Thayer-Bacon, B. J., \& Bacon, C. S. (1998). Philosophy applied to Education: Nurturing a democratic community in the classroom. Upper Saddle River, NJ: Prentice Hall.

Vincent, J. D. (1990). The biology of emotions. Cambridge, MA: Basil Blackwell.

Watson, M., Battistich, V., \& Solomon, D. (1997). Enhancing students' social and ethical development in schools: An intervention program and its effects. International Journal of Educational Research, 27, 571-586.

Werner, E. E. (1989). High risk children in young adulthood: A longitudinal study from birth to 32 years. American Journal of Orthopsychiatry, 59(1), 72-81.

Werner, E. E., \& Smith, R. S. (2001). Journeys from childhood to midlife: risk, resilience, and recovery. Ithaca, NY: Cornell University Press. 
California School Psychologist, Vol. 9, pp. 99-113, 2004

Copyright 2004 California Association of School Psychologists

\title{
Using the Santa Barbara Assets and Risks Assessment to Examine the Ecology of Youths Experiencing Behavior Problems
}

\author{
Shane R. Jimerson, Jill D. Sharkey, Michael J. Furlong, Kathryn M. O’Brien \\ University of California, Santa Barbara
}

\begin{abstract}
Following a review of important factors and considerations among youths displaying behavior problems, this study examined the predictive validity of the Santa Barbara Assets and Risks Assessment (SB ARA) with a population of European American and Mexican American highrisk adolescents $(n=566)$. The results of this study provide evidence that the SB ARA has adequate predictive validity of recidivism. Notably, the SB ARA provided prediction of recidivism, 12 months following assessment, for both females and males. The analyses also revealed different sets of indicators that predicted recidivism for females and males, thus, providing evidence supporting the position that there are some unique and some common indicators predicting recidivism for females and males. It is proposed that the SB ARA provides an exemplar for assessing both assets and risks among many salient developmental dimensions, is appropriate to use with males and females, and provides a comprehensive understanding of youths displaying behavior problems. Implications for the provision of services are also discussed.
\end{abstract}

Key Words: Assets, Risks, Ecology, Context, Prediction, Recidivism

The number of students with emotional and behavioral disorders served by schools is approximately $2 \%$ of the student population; moreover, the number of students needing support for emotional and behavioral problems is estimated to be as high as 10\% (Sawka, McCurdy, \& Mannella, 2002). Students with behavioral difficulties are diverse, including those with traumatic brain injury, cognitive deficits, and psychiatric mental disorders with symptoms including hyperactivity, impulsivity, inattention, aggression, and low frustration tolerance (Gaoni, Black, \& Baldwin, 1998) with patterns of behavioral difficulty likely to emerge in preschool years and pervade home, school, peer, and community environments. Without appropriate intervention, behavior disorders tend to escalate throughout the elementary school years and children are at-risk for dropping out of school (Digest of Education Statistics, 2002), developing adult psychopathology, and leading antisocial lifestyles (Kauffman, 1989). There is a clear need to identify and intervene with children displaying behavioral difficulties at an early age in order to ensure that identification of needs leads appropriate services to children.

\section{ASSESSMENT OF STUDENTS DISPLAYING BEHAVIORAL PROBLEMS}

Though behavioral difficulties are one of the most common forms of referral to school psychologists, educational professionals remain uncertain of how to assess such problems. Forming a concise but comprehensive definition of behavior disorders is difficult due to the multitude and diversity of disorders that are involved. This may be due in part to a lack of common understanding in the diagnosis and treatment of behavioral disorders. The Individuals with Disabilities Education Act (IDEA) definition of emotional disturbance provides little guidance in the identification and treatment of this population of children. The definition is vague and contains controversial language (Rosenblatt \& Furlong, 1997) in addition to including children with a variety of internalizing, externalizing, and comorbid behavior problems (Stinnett, Bull, Koonce, \& Aldridge, 1999).

Address correspondence to Shane R. Jimerson; University of California, Santa Barbara; Gevirtz Graduate School of Education; Center for School-Based Youth Development; 2208 Phelps Hall; Santa Barbara, CA 93106-9490. E-mail: jimerson@education.ucsb.edu. 
Complicating an understanding of emotional and behavioral disorders is the difference in types of behaviors displayed by males and females. More males than females are diagnosed and treated for emotional and behavioral disorders, with ratios ranging from 3:1 to 25:1 (Callahan, 1994). Sex and gender differences in behavior disorders are caused by a multitude of factors including biological and social influences (Callahan, 1994). Girls tend to exhibit internalizing problems, whereas boys tend to exhibit externalizing problems (Keenan \& Shaw, 1997). In addition, girls and boys develop disorders along different developmental pathways. Whereas boys' problem behavior has been found to grow in a linear fashion, the development of girls' problem behavior is less consistent, being more dependent on females' unique biological, psychological, and social experiences during distinct developmental periods (e.g., adolescence; Keenan \& Shaw, 1997). The assessment of students displaying emotional and behavioral disorders should take into consideration differences between males and females.

Valid procedures to understand the ecology of youths displaying behavioral problems are essential for school psychologists to access. Screening procedures to identify students with emotional and behavior disorders are often used to make high-stakes decisions regarding supervision, treatment, and placement including referrals to mental health services and centers for therapeutic education and support. These measures tend to focus on individual child deficits, without attending to important family, community, and school influences affecting child behavior. The Santa Barbara Assets and Risks (SB ARA) assessment was designed to examine factors associated with developing behavioral disorders (risks) as well as those factors associated with preventing increasing behavioral difficulties (assets) through inclusion of indicators of youth risks and assets that address the unique developmental experiences of both males and females. In addition, the tool examines both strengths and weaknesses in order to provide a balanced and comprehensive understanding of the current context of the problem behaviors.

\section{Factors Associated with Behavior Problems}

Previous research reveals numerous factors that have been related to the adjustment and behaviors of adolescents. Many of these factors facilitate either positive or negative developmental trajectories, depending upon whether the youth experiences a relative asset or risk. The following provides a brief review of the most salient factors, including; parent-child relationships, family criminality, family substance abuse, family mental health, individual factors, individual criminality, individual substance use, community factors, peer factors, school factors, sexual activity, and history of trauma.

\section{Parent-Child Relationships}

Parent-child relationships are one of the most important factors guiding child outcomes. Variables such as antisocial behaviors among parents, difficult child temperament, and parent substance abuse are often mediated by poor family management skills, ineffective discipline, and lack of monitoring. Children in such environments are at greater risk for behavior problems because they are at greater risk for experiencing poor parenting practices (Patterson \& Stouthamer-Loeber, 1984). Similarly, positive family functioning variables, such as family cohesion, adaptability, and effective communication are predictive of fewer negative and more adaptive outcomes (Shields \& Clark, 1995).

\section{Family Criminality}

Studies have demonstrated a link between family criminality and future antisocial behavior (e.g., Farrington et al., 2001) with father criminality a stronger predictor than mother criminality. Juvenile offenders are also more likely to have siblings with criminal histories than the average adolescent 
(Fejes-Mendoza, Miller, \& Eppler, 1995). The risk of criminal family members may be particularly strong for females as evidence suggests that female offenders are significantly more likely to have criminally-involved parents than male offenders (Funk, 1999).

\section{Family Substance Use}

In their research, Kuperman, Schlosser, Lidral, and Reich (1999) found that boys in families with parental alcoholism had significantly higher rates of attention deficit hyperactivity disorder, oppositional defiant disorder, and conduct disorder than expected in the general population. Girls in such families evidenced increased rates of overanxious disorders. Luthar, Cushing, Merikangas, and Rounsaville (1998) examined the adjustment of 78 children and adolescents of opiate and cocaine abusing mothers. Of these children, $67 \%$ met criteria for at least one psychiatric disorder, with $46 \%$ qualifying for at least one affective/anxiety disorder, and $30 \%$ qualifying for at least one disruptive behavior disorder. Evidence supporting the impact of parental drug and alcohol abuse has been supported further by Rhodes and Fisher (1993), who found that females whose parents abused drugs or alcohol were significantly more likely to commit a greater number of delinquent offenses compared to delinquent females without such a risk.

\section{Familial Mental Health}

Familial mental health has also been significantly associated with delinquency (Ge et al., 1996; Renk, Phares, \& Epps, 1999). Some researchers have evidenced the genetic transmission of mental health problems among family members (Cadoret, Yates, Troughton, Woodworth, \& Stewart, 1995; Plomin \& McClearn, 1993), whereas others have established the impact that familial mental health problems may have on a child's environment (Bell \& Chapman, 1986). However, as found in an adoption study performed by Ge and colleagues (1996), familial mental health is likely to impact youths through both pathways. These researchers suggested that their findings support an interaction in which a child's genetic predisposition toward mental health problems may influence the childrearing practices of parents, which may subsequently reinforce problem behavior in children.

\section{Individual Factors}

A number of researchers have highlighted particularly salient individual characteristics that are associated with negative outcomes for youths. Using multiple measures of various dimensions of selfefficacy, Ludwig and Pittman (1999) found that high scores on the self-mastery and self-trustworthiness dimensions of self-efficacy were associated with lower levels of delinquent behavior, risky sex, and drug use. Hansen and Breivik (2001) examined the relationship between sensation seeking and risk-taking behavior among junior high school students in Norway and found high correlations between sensation seeking and risk behaviors. Longshore (1998) found that self-control was significantly correlated with juvenile criminal activity, suggesting either that crime was more frequent for individuals who endorsed lower self-control or that they were easier to catch. Taylor, Chadwick, Heptinstall, and Danckaerts (1996) found that hyperactivity predicted violence and defiant/disruptive behaviors as well as poor peer relationships, a lack of involvement in social activities, and poor academic achievement. Davis, Bean, Schumacher, and Stringer (1991), compared data regarding mental health functioning and social skills among youths involved in juvenile correctional institutions, youths in private psychiatric residential facilities, and a control sample of community youth. Findings indicated that juvenile offenders had similar mental health concerns as youths in mental health facilities but demonstrated significantly more acting-out behaviors. In comparison to the sample of community 
youth, juvenile offenders were found to have significantly more social skills deficits. In addition, prevalence rates of mental health disorders were significantly greater in youths involved in the juvenile justice system compared to controls.

\section{Individual Criminality}

Studies examining individual criminality have found that factors such as age at first offense and types of involvement in crime future behavior problems and recidivism (e.g., Hawkins et al., 1998). Findings from longitudinal studies demonstrate that children who become serious offenders later in life often have a history of disruptive behavior in childhood (Hawkins et al., 1998) and note that children with an early onset of delinquency were most likely to reach the most serious level within a pathway to disruptive behavior (Moffitt, 1993). The pattern of behavior leading to increasing behavioral difficulties may be different for females than males. For example, Chesney-Lind, Shelden, and Joe (1996) concluded that a notably high proportion of females first enter the juvenile justice system as runaways who seek to escape abuse and maltreatment in their home.

\section{Individual Substance Use}

Evidence of the relationship between substance use and negative outcomes has been well documented in the literature. According to their results, students reporting high alcohol use were two to six times more likely to exhibit delinquent and violent behaviors and almost four times more likely to intentionally break or damage objects in contrast to students reporting little to no alcohol use (Komro, Williams, Forster, Perry, Farbakhsh, \& Stigler, 1999). Taylor and Carey (1998) compared prevalence rates of conduct disorder, antisocial personality disorder, alcohol abuse, drug abuse, and somatization. They found significantly higher prevalence rates for all disorders among adolescent substance users and their families compared to adolescent controls and their families.

\section{Community Factors}

Community factors such as economic depravation and prevalence of community crime are associated with increased risk for behavior disorders (Preski \& Shelton, 2001), whereas factors such as participation in meaningful extracurricular activities and relationships with adults in the community have been associated with reduced externalizing behavior. The neighborhood context may exacerbate or buffer adolescent behavior problems.

\section{Peer Factors}

Lewin, Davis, and Hops (1999) found that boys who reported high levels of peer rejection were more likely to engage in delinquent behavior than boys reporting lower levels of rejection. For girls however, peer rejection was not significantly related to antisocial behavior. Mears, Ploeger, and Warr (1998) revealed that the presence of delinquent friends was a stronger predictor of male delinquency than female delinquency, suggesting that females may be less susceptible to negative peer influences than males. Similarly, Funk (1999) found that whereas a majority of male and female offenders experienced poor quality relationships, a significantly higher proportion of male offenders $(80 \%)$ reported relationships with peers to be poor in quality compared to females $(62 \%)$. When investigating the unique influence of gang membership on delinquent behavior, it has been found that among juvenile offenders, those who have been gang members had a significantly higher rate of delinquent behavior, were more committed to antisocial peers, were more tolerant of deviance, and were more likely to be viewed negatively by teachers than those who have not been involved in gangs (Jenson \& Howard, 1998). 


\section{School Factors}

LeBlanc, Vallieres, and McDuff (1993) found that academic performance during early adolescence was the most significant predictor of criminal offending in late adolescence and adulthood. In a study designed to examine the relationship between delinquency and school dropout, Thornberry, Moore, and Christenson (1985) found that dropping out of high school was significantly associated with high rates of crime, even after controlling for age, ethnicity, and post-school experiences. In another study, Rankin (1980) found that students who perceived themselves having poor academic achievement and low likelihood of graduating were significantly more likely to engage in delinquent behavior than students reporting more positive views, irrespective of sex or grade level. In addition, involvement in extracurricular activities was found to have a low but significant inverse correlation with delinquency but only for students in earlier grades. Finally, analyses by gender revealed that females with negative attitudes toward school were significantly more likely to commit delinquent acts than males with similar attitudes.

A number of researchers have attempted to determine whether positive school factors impact the likelihood of students engaging in delinquent activity. A study performed by Jenkins (1997) focused on four components of school social bonding and their relation to rates of school crime, misconduct, and non-attendance. Analyses revealed that three components of school bonding-school commitment, attachment to school, and belief in school rules-were inversely correlated with all three types of school delinquency. Of note, educational commitment was shown to have the strongest inverse relationship with all three forms of delinquency.

\section{Sexual Activity}

Research suggests that sexual activity usually occurs in sequence with delinquent behavior (Elliott \& Morse, 1989) and that adolescents engaging in early sexual activity are at increased risk for pregnancy and sexually transmitted diseases (Koyle, Jensen, Olsen, \& Cundick, 1989). Additional risk factors outlined by Reis and Herz (1989) include low rates of responsible contraception use observed in a sample of inner city adolescents.

\section{History of Trauma}

Previous findings have linked sexual and physical abuse to higher rates of sexual activity, risky sexual behavior, teenage pregnancy, drug and alcohol use, and delinquent activities (Luster \& Small, 1994). Whereas substantial evidence has highlighted the role of abuse as a major contributor to delinquency and other negative outcomes for both males and females, findings from a number of studies suggest that abuse may be particularly salient for females. Of those reporting previous sexual abuse in their study, Calhoun and colleagues (1993) found that females scored notably different on measures of suicidal risk, disordered eating, sexual risk taking, substance use, and delinquency compared to males. In addition, studies suggest that female survivors of sexual abuse are significantly more likely to be arrested, engage in property offenses, sell narcotics (Rhodes \& Fischer, 1993) and engage in runaway behaviors (McCormack, Janus, \& Burgess, 1996) compared to females who had not been sexually abused.

Jonson-Reid (1998) cited studies that support the link between witnessing violence and subsequent delinquent behavior. For example, a number of studies have found a significant and direct association between exposure to violence and violent behavior at home and at school. Exposure to violence at the community level has also been found to significantly predict aggression and antisocial behavior, as well as externalizing behavior problems in youths. 


\section{ASSESSMENT OF BEHAVIORAL DISORDERS}

The assessment of behavior disorders has focused on behavioral rating scales, which provides information to the assessor regarding the relative severity of behaviors when compared to same-aged peers in the general population. Though this information is important for diagnostic purposes, it is less useful in the allocation of treatment and supervision resources. In addition, rating scales are more useful for identifying youths already displaying clinical levels of problems rather than those youths atrisk for developing problems in the future. Gaoni and colleagues (1998) recommended examining the risk and protective factors associated with the development of behavior problems in addition to focusing more on primary prevention. Assessments that provide information regarding intervention needs before problems escalate are crucial to maximizing resources for prevention.

In terms of meeting the needs of males and females, rating scales attempt this by differentiating normative comparisons by gender. Though such norms do acknowledge that males and females display different levels of certain behaviors, they do not take into account different patterns of behavior that may occur for males versus females.

\section{The Current Study}

Further research is essential in order to examine the utility of various assessments. Among youth with behavior problems, it is particularly important to examine high-risk youth involved with the juvenile justice system. In addition, it is crucial to further investigate important factors that are unique and those that are common across females and males. The current study examines the predictive validity of the SB ARA among a group of high-risk youths with behavior problems. Of particular interest is predictive validity among male and female youths.

\section{METHOD}

\section{Participants}

This study included a sample of 566 first-time juvenile offenders (age 10-18 years, average 14.94). Participants were 370 male (65\%) and 196 female (35\%) adolescents of whom 55\% were Mexican American, $40 \%$ European American, and 5\% other ethnicities. Participants were drawn from a county in Southern California and are a subset of a larger investigation funded through the Juvenile Justice Crime Prevention Act (Jimerson, Furlong, Kaufman, DeVera, Jai, \& Turner, 2002). This subsample was created to ensure that all participants were first-time offenders, thus, exhibiting serious behavior problems that warranted involvement with the juvenile justice system.

\footnotetext{
Measures

Santa Barbara Assets and Risks Assessment. The SB ARA (Jimerson, Sharkey, O'Brien, \& Furlong, 2003; O’Brien, Jimerson, Saxton, \& Furlong, 2001) is a semi-structured interview conducted with youths and their family members. The development of the SB ARA was informed by the transactional-ecological model of development, which recognizes that a child's current functioning is a product of previous experiences as well as various influences (e.g., individual, family, school, and community) within a child's current environment (Bronfenbrenner, 1986; Sameroff, 1975, 1989, 1993, 1995, 2000). Indicators were derived through several steps designed to capture those variables related to trajectories of increasing behavioral difficulties such as impulsivity, conduct disorder, and delinquency. Reviewing extant theories and empirical investigations related to developmental pathways toward increasing levels of delinquency, with particular attention to gender differences, was a specific focus
} 

manager provided each youth's offense history for the 12-month period post-intake for each youth. This information is collected regularly as part of probation department standard procedures.

\section{Analyses}

Logistic regression was used to determine which indicators were significantly associated with recidivism for males and females. Logistic regression is a special case of regression for predicting a dichotomous outcome and allows for nominal, ordinal, or continuous independent variables (Fan \& Wang, 1999). Model chi-square provides the significance test for a logistic model, examining the null hypothesis that none of the independent variables are linearly associated with the logged odds of the dependent variable. Thus, it does not test whether every independent variable is significant (Garson, 2003). Nagelkerke's $R^{2}$, which varies from 0 to 1 , is an estimate of multiple $R^{2}$ that attempts to estimate the degree of variance in the dependent variable explained by the independent variables (Garson, 2003). ROC curve graphs were plotted in order to provide a visual representation of the overall prediction of the SB ARA.

\section{RESULTS}

Predictive validity was assessed through a logistic regression analysis to examine the association between the items on the SB ARA and recidivism. The combination of all items from the SB ARA significantly predicted recidivism for females, $\chi^{2}=139.18, \mathrm{df}=55, p<.000$. As indicated by Nagelkerke's $R^{2}, 100 \%$ of the variance in recidivism scores was explained by the SB ARA items for females, with an overall correct classification of $100 \%$. In addition, the combination of all items from the SB ARA significantly predicted recidivism for males, $\chi^{2}=112.62, \mathrm{df}=55, p<.000$. As indicated by Nagelkerke's $R^{2}, 56 \%$ of the variance in recidivism scores was explained by this combination of indicators for males, with an overall correct classification of $83 \%$. Additional logistical analyses using only those items yielding significant Spearman's Rank Order correlations were completed separately in order to delineate the most powerful individual indicators for females (Table 1) and males (Table 2).

Table 1.

Twenty-one Significant Predictors of Recidivism at 12 Months among Females $(n=162)$

\begin{tabular}{lrrr}
\hline Variable & $b$ & $S E$ & $e^{b}$ \\
\hline Communication & .509 & .254 & 1.664 \\
Emotional Support & -.156 & .334 & .855 \\
Monitoring & .160 & .239 & 1.174 \\
Discipline & -.251 & .279 & .778 \\
Boundaries/Roles & .021 & .310 & 1.021 \\
Mother Arrests & .476 & .231 & 1.609 \\
Father Mental Health & .321 & .361 & 1.378 \\
Self-Effectiveness & -.320 & .258 & .726 \\
Anger Management & .030 & .251 & 1.030 \\
Self-Control & .007 & .249 & 1.007 \\
Types of Crime & .630 & .313 & 1.877 \\
Running Away & -.088 & .364 & .916 \\
Youth's Alcohol Use & .343 & .340 & 1.410
\end{tabular}


Table 1 continued.

Twenty-one Significant Predictors of Recidivism at 12 Months Among Females ( $n=162)$

\begin{tabular}{lccr}
\hline Variable & $b$ & $S E$ & $e^{b}$ \\
\hline Youth's Drug Use & -.090 & .296 & .913 \\
Peer Influence & .306 & .213 & 1.358 \\
Friendships & -.059 & .238 & .943 \\
Peers' Substance Use & .616 & .264 & 1.851 \\
Current Attendance & .061 & .219 & 1.063 \\
Sexual Activity & -.301 & .302 & .740 \\
Witnessed Violence in the Home & .537 & .387 & 1.710 \\
Physical Abuse & .093 & .430 & 1.097 \\
Constant & -10.1661 & 2.499 & \\
\end{tabular}

$R^{2}=.430, \chi^{2}=55.355, d f=21, p<.001$

Table 2.

Twenty-eight Significant Predictors of Recidivism at 12 Months among Males (n=300)

\begin{tabular}{lccc}
\hline Variable & $b$ & $S E$ & $e^{b}$ \\
\hline Communication & -.175 & .132 & .840 \\
Monitoring & .168 & .160 & 1.183 \\
Discipline & -.121 & .193 & .886 \\
Boundaries/Roles & -.019 & .184 & .981 \\
Father Mental Health & .898 & .316 & 2.455 \\
Hyperactivity & .075 & .127 & 1.078 \\
Self-Effectiveness & .264 & .168 & 1.302 \\
Anger Management & .245 & .136 & 1.278 \\
Self-Control & .068 & .168 & 1.070 \\
Mental Health & -.019 & .227 & .981 \\
Number of Prior Referrals & .129 & .204 & 1.137 \\
Running Away & .597 & .283 & 1.817 \\
Age at First Referral & .266 & .244 & 1.304 \\
Youth's Alcohol Use & -.034 & .214 & .966 \\
Youth's Drug Use & .033 & .180 & 1.034 \\
Use of Free Time & -.042 & .133 & .959 \\
Peer Influence & -.088 & .147 & .916 \\
Friendships & -.090 & .202 & .914 \\
Peer Communication & .249 & .194 & 1.283 \\
Gang Membership & .169 & .223 & 1.184 \\
Special Education & .079 & .178 & 1.082 \\
Relationship with Adult at School & .177 & .128 & 1.194 \\
Educational Goals & -.011 & .189 & .989 \\
& & & \\
& & & \\
& & & \\
& & &
\end{tabular}


Table 2 continued.

Twenty-eight Significant Predictors of Recidivism at 12 Months among Males $(n=300)$

\begin{tabular}{lrcc}
\hline Variable & $b$ & $S E$ & $e^{b}$ \\
\hline Progress Toward Graduation & -.251 & .160 & .778 \\
Current Attendance & .327 & .137 & 1.387 \\
Grades & .219 & .167 & 1.244 \\
Suspensions & .032 & .131 & 1.033 \\
Expulsions & .416 & .229 & 1.517 \\
Constant & -10.829 & 1.783 & \\
\end{tabular}

$R^{2}=.303, \chi^{2}=72.607, d f=28, p<.001$

ROC curve graphs were plotted in order to provide a visual representation between the truepositive rate (sensitivity) and the false-positive rate (100\% minus specificity; specificity is the true negative rate) when using a combination of SB ARA indicators to predict recidivism for males and females (Sharkey et al., 2003). For the ROC curve analysis, SB ARA indicators significantly associated with recidivism, as appropriate by gender, were summed to derive the test variable. Thus, the higher the computed SB ARA total score, the more risks versus assets were present.

The ROC curve for the model predicting female recidivism is plotted in Figure 1. The area under the curve for the female sample is .792 (95\% confidence interval $=.714$ to $\left..870, S_{x}=.040\right)$, which indicates that a randomly selected individual from the group of females who reoffended had a higher score on this combination of research-based indicators than a randomly selected individual from the group of females who did not reoffend $79.2 \%$ of the time. As the confidence interval indicates, using this set of SB ARA indicators to predict recidivism was valuable for the female adolescents.

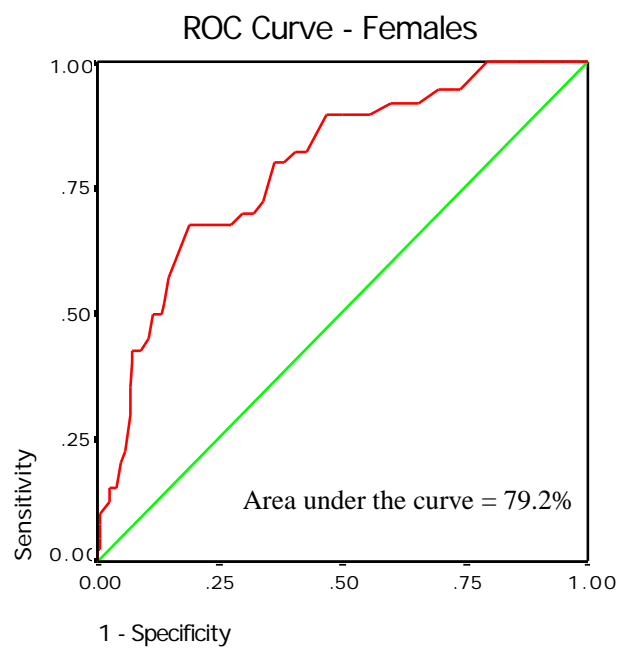

Figure 1.

ROC Curve for Female Sample: Sensitivity and 1.00-Specificity for Each Criterion 

cially important in this study included; communication with family, emotional support from family, parental monitoring, discipline strategies in the home, boundaries and roles in the family, witnessing violence in the home, whether the mother had ever been arrested, father's mental health, the youth's sense of self-effectiveness, individual anger management skills, self control skills, the type of crime, the experience of running away, whether the youth used alcohol or drugs, peer influences, friendships, school attendance, sexual activity, and whether the youth experienced physical abuse.

The Santa Barbara Assets and Risks Assessment has emerged as a valuable tool for professionals to identify the needs of high-risk youths. Through conducting a semi-structured interview with the youth and family, school psychologists and other professionals systematically explore salient factors associated with youth adjustment and behaviors. For each of the factors, exploring the relative positive (assets) or negative (risks) features provides important information to professionals regarding what particular strengths the youth/family may incorporate in an effort to facilitate healthy and pro-social behaviors. Because the SB ARA factors include individual, family, peers, school, and neighborhood elements, professionals gain insights regarding relative assets and risks that may be influencing the behaviors of the youth. Likewise, better understanding the relative assets and risks in the life of a youth is important in determining appropriate services or interventions to simultaneously address problems and promote strengths for a comprehensive treatment. For example, understanding that a student who abuses drugs and alcohol, has been diagnosed with Attention Deficit/Hyperactivity Disorder, and has difficulty with self-control also has open communication with parents, an adult role model in the community, and goals of attending college allows for a far more appropriate and targeted intervention by utilizing a student's resources within a treatment program.

The variables included in the SB ARA were designed to be appropriate for understanding the ecology of youths in multiple settings (e.g., school, community, mental health, and juvenile justice). The SB ARA has particular promise in aiding school psychologists to better understand the nature of the family, peer, and community variables impacting youths with behavioral difficulties, areas that are neglected in currently available assessments. It is also particularly notable how many of the significant indicators among males were related to behaviors in the school context (e.g., attendance, grades, educational goals).

Additional studies should focus on the utility of the SB ARA with children before their behavioral problems escalate to delinquent activities. In addition, future research should examine the influence of ethnicity on results. Finally, recidivism is a very specific outcome to measure. Though recidivism is a primary outcome of interest in the juvenile justice system, it represents a narrow view of the potential consequences of intervention and ignores positive youth development. Additional outcomes, such as mental health, school completion, and job satisfaction should be examined as well. Though this study selected out several indicators that predict recidivism, it is likely that each different outcome is predicted by a diverse set of indicators.

\section{CONCLUSION}

This study represents a positive step forward with respect to understanding numerous factors associated with behavior problems among males and females. As demonstrated in this study through the investigation of the SB ARA, the systematic application of findings derived from empirical research examining risk factors and resiliency has the potential to enhance the assessment of adolescents involved in delinquent activities. It is proposed that the SB ARA provides a promising assessment of both assets and risks among many salient developmental dimensions that is also gender sensitive and aims to provide a more comprehensive understanding of youths displaying behavior problems than norm-referenced surveys. 


\section{REFERENCES}

Bell, R. Q., \& Chapman, M. (1986). Child effects in studies using experimental or brief longitudinal approaches to socialization. Developmental Psychology, 22, 595-603.

Bronfenbrenner, U. (1986). Ecology of the family as a context for human development: Research perspectives. Developmental Psychology, 22(6), 723-742.

Cadoret, R. J., Yates, W. R., Troughton, E., Woodworth, G., \& Stewart, M. A. (1995). Adoption study demonstrating two genetic pathways to drug abuse. Archives of General Psychiatry, 46, 1131-1136.

Calhoun, G., Jurgens, J., \& Chen, F. (1993). The neophyte female delinquent: A review of the literature.Adolescence, $28,461-471$.

Callahan, K. (1994). Wherefore art thou, Juliet? Causes and implications of the male dominated sex ratio in programs for students with emotional and behavioral disorders. Education and Treatment of Children, 17(3), 228-243.

Carran, D. T., Nemerofsky, A., Rock, E. E., \& Kerins, M. (1996). Risk of unsuccessful program completion for students with serious emotional/behavioral disorders: An epidemiologic risk analysis. Behavioral Disorders, 21(2), 172-189.

Chesney-Lind, M. (2001). Girls, violence, and delinquency: Popular myths and persistent problems. In S. White (Ed.), Handbook of youth and justice: The Plenum series in crime and justice (pp. 135-158). New York: Kluwer Academic/Plenum Publishers.

Chesney-Lind, M., \& Brown, M. (1999). Girls and violence: An overview. In D. J. Flannery \& C. R. Huff (Eds.), Youth violence: Prevention, intervention, and social policy (pp. 171-199). Washington, DC: American Psychiatric Press.

Chesney-Lind, M. Shelden, R. G., \& Joe, K. A. (1996). Girls, delinquency, and gang membership. In R. C. Huff (Ed.), Gangs in America ( $2^{\text {nd }}$ Ed.) (pp. 185-204). Thousand Oaks, CA: Sage.

Davis, D. L., Bean, G. J., Schumacher, M. A., \& Stringer, T. L. (1991). Prevalence of emotional disorders in a juvenile justice institutional population. American Journal of Forensic Psychology, 9(1), 5-17.

Digest of Educational Statistics. (2002). http://nces.ed.gov/pubs/digest97/d97t052.html.

Elliott, D. S., \& Morse, B. J. (1989). Delinquency and drug use as risk factors in teenage sexual activity. Youth and Society, 21, 32-57.

Epstein, M. H., \& Sharma, J. M. (1998). Behavioral and Emotional Rating Scale: A strength-based approach to assessment. Examiner's manual. Austin, TX: Pro-Ed.

Fejes-Mendoza, K., Miller, D., \& Eppler, R. (1995). Portraits of dysfunction: Criminal, education, and family profiles of juvenile female offenders. Education and Treatment of Children, 18, 309-321.

Funk, S. J. (1999). Risk assessment for juveniles on probation: A focus on gender. Criminal Justice \& Behavior, 26, 44-68.

Gaoni, L., Black, C. P., \& Baldwin, S. (1998). Defining adolescent behaviour disorder: An overview. Journal of Adolescence, 21, 1-13.

Ge, X., Conger, R. D., Cadoret, R. J., Neiderhiser, J. M., Yates, W., Troughton, E., \& Stewart, M. A. (1996). The developmental interface between nature and nurture: A mutual influence model of child antisocial behavior and parent behaviors. Developmental Psychology, 32, 574-589.

Hansen, E. B., \& Breivik, G. (2001). Sensation seeking as a predictor of positive and negative risk behavior among adolescents. Personality and Individual Differences, 30(4), 627-640.

Hawkins, J. D., Herrenkohl, T., Farrington, D. P., Brewer, D., Catalano, R. F., \& Harachi, T. W. (1998). A review of predictors of youth violence. In R. Loeber \& D. P. Farrington (Eds.), Serious and violent juvenile offenders (pp. 106-146). Thousand Oaks, CA: Sage.

Jenson, J. M., \& Howard, M. O. (1998). Correlates of gang involvement among juvenile probationers. Journal of Gang Research, 5(2), 7-15.

Jimerson, S. R., Furlong, M. J., Kaufman, A. M., DeVera, Z., Jai, L., \& Turner, J. (2002). Juvenile Justice Crime Prevention Act-2002: A preliminary report of the implementation of the Comprehensive Initial Assessment (Santa Barbara Assets and Risks Assessment-SB ARA). Santa Barbara, CA: University of California, Santa Barbara.

Jimerson, S. R., Sharkey, J. D., O’Brien, K. M., \& Furlong, M. J. (2003). The Santa Barbara Assets and Risks Assessment: Technical manual. Santa Barbara, CA: University of California, Santa Barbara.

Jimerson, S. R., Sharkey, J. D., O'Brien, K. M., \& Furlong, M. J. (2004). The Santa Barbara Assets and Risks Assessment to predict recidivism among male and female juveniles: An investigation of inter-rater reliability and predictive validity. Manuscript submitted for publication.

Jonson-Reid, M. (1998). Youth violence and exposure to violence in childhood: An ecological review. Aggression and Violent Behavior, 3, 159-179.

Kauffman, J. M. (1989). Characteristics of behavior disorders of children and youth. Columbus, OH: Merrill. 
Keenan, K., \& Shaw, D. (1997). Developmental and social influences on young girls' early problem behavior. Psychological Bulletin, 121(1), 95-113.

Komro, K. A., Williams, C. L., Forster, J. L., Perry, C. L., Farbakhsh, K., \& Stigler, M. H. (1999). The relationship between adolescent alcohol use and delinquent and violent behaviors. Journal of Child \& Adolescent Substance Abuse, 9, 13-28.

Koyle, P., Jensen, L., Olsen, J., \& Cundick, B. (1989). Comparison of sexual behaviors among adolescents having an early, middle, and late first intercourse experience. Youth and Society, 20, 461-475.

Kuperman, S., Schlosser, S. S., Lidral, J., \& Reich, W. (1999). Relationship of child psychopathology to parental alcoholism and antisocial personality disorder. Journal of the American Academy of Child and Adolescent Psychiatry, 38, 686-692.

LeBlanc, M., Vallieres, E., \& McDuff, P. (1993). The prediction on males' adolescent and adult offending from school experience. Canadian Journal of Criminology, 23, 459-478.

Farrington, D. P., Jolliffe, D., Loeber, R. Stouthamer-Loeber, M., \& Kalb, L. M. (2001). The concentration of offenders in families, and family criminality in the prediction of boys' delinquency. Journal of Adolescence, 24, 579-596.

Funk, S. J. (1999). Risk assessment for juveniles on probation. Criminal Justice and Behavior, 26(1), 44-68.

Jenkins, P. H. (1997). School delinquency and the school social bond. Journal of Research in Crime and Delinquency, 34, 337-367.

Lewin, L., Davis, B., \& Hops, H. (1999). Childhood social predictors of adolescent antisocial behavior: Gender differences in predictive accuracy and efficacy. Journal of Abnormal Child Psychology, 42, 517-536.

Longshore, D. (1998). Self-control and criminal opportunity: A prospective test of the general theory of crime. Social Problems, 45(1), 102-113.

Ludwig, K. B., \& Pittman, J. F. (1999). Adolescent prosocial values and self-efficacy in relation to delinquency, risky sexual behavior, and drug use. Youth \& Society, 30(4), 461-482.

Luster, T., \& Small, S. A. (1994). Factors associated with sexual risk-taking behaviors among adolescents. Journal of Marriage and the Family, 56, 622-632.

Luthar, S. S., Cushing, G., Merikangas, K. R., \& Rounsaville, B. J. (1988). Multiple jeopardy: Risk and protective factors among addicted mothers' offspring. Development and Psychopathology, 10, 117-136.

McCormack, A., Janus, M., \& Burgess, A. (1996). Runaway youths and sexual victimization: Gender differences in an adolescent runaway population. Child Abuse and Neglect, 10, 387-395.

Mears, D. P., Ploeger, M., \& Warr, M. (1998). Explaining the gender gap in delinquency: Peer influence and moral evaluations of behavior. Journal of Research in Crime \& Delinquency, 35, 251-266.

Moffitt, T. E. (1993). Adolescence-limited and life-course persistent antisocial behavior: A developmental taxonomy. Psychological Review, 100, 674-701.

O’Brien, K. M., Jimerson, S. R., Sharkey, J. D., \& Furlong, M. J. (2001). The Santa Barbara Assets and Risks Assessment. University of California, Santa Barbara: Authors.

O'Brien, K. M., Jimerson, S. R., Sia, A. B., Sharkey, J. D., \& Furlong, M. J. (2002, March). Development of the Santa Barbara Assets and Risks Assessment. Poster presented at the California Association of School Psychologists Conference, Sacramento, CA.

Offord, D. R., Abrams, N., Allen, N., \& Poushinsky, B. A. (1979). Broken homes, parental psychiatric illness, and female delinquency. American Journal of Orthopsychiatry, 49, 252-264.

Ogles, B. M., Melendez, G., Davis, D. C., \& Lunnen, K. M. (2001). The Ohio Scales: Practical outcome assessment. Journal of Child \& Family Services, 10(2), 199-212.

Orange County Probation Department. (1988). Orange County California Probation Department Juvenile Risk/ Needs Assessment instruments. Unpublished manuscript.

Patterson, G. R., \& Stouthamer-Loeber, M. (1984). The correlation of family management practices and delinquency. Child Development, 4, 1299-1307.

Plomin, R., \& McClearn, G. (1993). Nature, nurture, and psychology. Washington, DC: American Psychological Association.

Preski, S., \& Shelton, D. (2001). The role of contextual, child and parent factors in predicting criminal outcomes in adolescence. Issues in Mental Health Nursing, 22, 197-205.

Rankin, J. H. (1980). School factors and delinquency: Interactions by age and sex. Sociology and Social Research, 64, 420-434.

Reis, J., \& Herz, E. (1989). An examination of young adolescents' knowledge of an attitude toward sexuality according to perceived contraceptive responsibility. Journal of Applied Social Psychology, 19, 231-250.

Renk, K., Phares, V., \& Epps, J. (1999). The relationship between parental anger and behavior problems in children and adolescents. Journal of Family Psychology, 13, 209-227.

Rhodes, J., \& Fischer, K. (1993). Spanning the gender gap: Gender differences in delinquency among inner-city adolescents. Adolescence, 28, 879-889. 
Rosenblatt, J. A., \& Furlong, M. J. (1997). Serious emotional disturbance and social maladjustment: A critical examination of four schools of thought. California School Psychologist, 2, 5-30.

Sameroff, A. (1975). Transactional models in early social relations. Human Development, 18, 65-79.

Sameroff, A. J. (1989). Models of developmental regulations: The environtype. In D. Cicchetti (Ed.), Development and psychopathology (pp. 41-68). Hillsdale, NJ: Lawrence Earlbaum.

Sameroff, A. J. (1993). Models of development and developmental risk. In C. H. Zeanah Jr. (Ed.), Handbook of infant mental health (pp. 3-19). New York: Guilford.

Sameroff, A. J. (1995). General systems theories and developmental psychopathology. In D. Cicchetti \& D. Cohen (Eds.), Manual of developmental psychopathology, Volume 1 (pp. 659-695). New York: Wiley.

Sameroff, A. J. (2000). Developmental systems and psychopathology. Development and Psychopathology, 12, 297-312.

Sawka, K. D., McCurdy, B. L., \& Mannella, M. C. (2002). Strengthening emotional support services: An empirically based model for training teachers of students with behavior disorders. Journal of Emotional and Behavioral Disorders, 10(4), 223-232.

Shields, G., \& Clark, R. D. (1995). Family correlates of delinquency: Cohesion and adaptability. Journal of Sociology and Social Welfare, 22, 93-106.

Stinnett, T. A., Bull, K. S., Koonce, D. A., \& Alderidge, J. O. (1999). Effects of diagnostic label, race, gender, educational placement, and definitional information on prognostic outlook for children with behavior problems. Psychology in the Schools, 36(1), 51-59.

Taylor, J., \& Carey, G. (1998). Antisocial behavior, substance use, and somatization in families of adolescent drug abusers and adolescent controls. American Journal of Drug and Alcohol Abuse, 24, 635-646.

Taylor, E., Chadwick, O., Heptinstall, E., \& Danckaerts, M. (1996). Hyperactivity and conduct problems as risk factors for adolescent development. Journal of the American Academy of Child \& Adolescent Psychiatry, 35(9), 1213-1226.

Thornberry, T. P., Moore, M., \& Christenson, R. L. (1985). Dropping out of high school on subsequent criminal behavior. Criminology, 23, 3-18. 

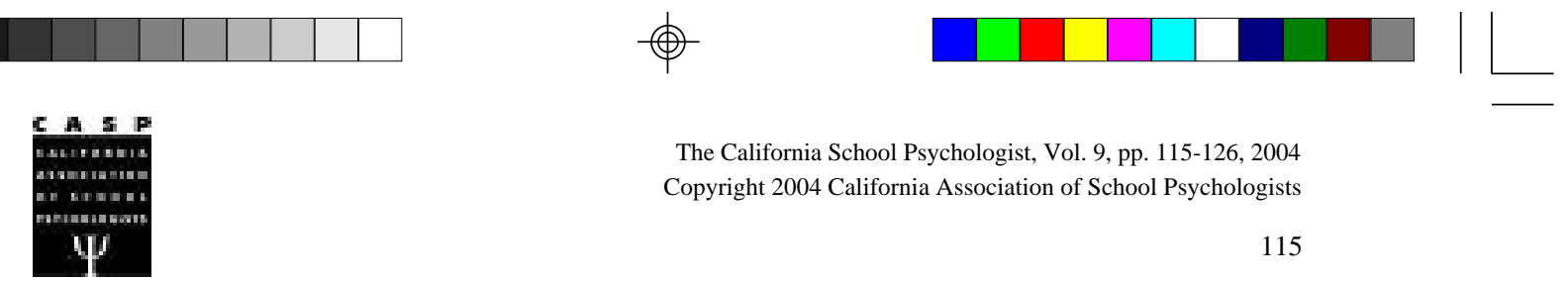

The California School Psychologist, Vol. 9, pp. 115-126, 2004

Copyright 2004 California Association of School Psychologists

\title{
Strength-Based Assessment of Adolescents Who Abuse Drugs: Implications for Helping High-Risk Youth
}

\author{
Merith Cosden, Frances Panteleakos, Lisa Gutierrez, Sivan Barazani \\ University of California, Santa Barbara
}

\author{
Elisa Gottheil \\ Santa Barbara County Mental Health Care Services
}

\begin{abstract}
Strength-based assessments were designed to assess more completely the outcomes for youth having academic and behavioral problems in the schools. This approach has gained appeal among those working with adolescents who have serious behavior problems, such as those involved in drug use and related delinquent behavior. Traditional assessment procedures provide an overwhelmingly negative picture of these youths and the delineation of these deficits do not contribute to effective treatment planning. This paper describes the use of two strength-based assessment procedures with adolescents who have serious drug problems. The adolescents in this study were participants in a drug treatment court, part of a growing national trend to serve adolescents with non-violent, drug-related problems in their least restrictive environment, allowing them to remain at home and to attend their neighborhood schools. Different methods of using strengthbased assessments are examined. In Study 1, assessments are used to identify students' competencies and determine which of these factors were related to youth outcomes. In Study 2, a case study is presented in which strength-based assessments are used at the individual level to develop specific treatment plans. The current state of the field, and future challenges for effective utilization of the strength-based approach to assessment and intervention, are discussed.
\end{abstract}

Key Words: Strength-Based Assessment, Adolescents, Drug Problems, Treatment Plans

Strength-based assessment has been promoted as a means to obtain a more accurate, well-rounded picture of youth experiencing academic or behavioral problems in the schools (Rhee, Furlong, Turner, \& Harari, 2001). This form of assessment is part of a larger strength-based approach for working with children and families (e.g., Dunst, Trivette, \& Mott, 1994). This approach has been advocated for school psychologists in order to increase the engagement of children and families in their own interventions, and, in so doing, to increase the likelihood of school success (Powell, Batsche, Ferro, Fox, \& Dunlap, 1997).

While the concept of identifying a youth's assets as well as deficits has strong face validity, the practical value for school psychologists will depend on whether or not the knowledge obtained from these assessments results in practices that improve student outcomes. Different ways of using strengthbased assessments have been proposed in the literature. For example, it has been suggested that the information obtained through strength-based assessment can be used to increase positive expectations for the child; to empower the child and his or her family to take more responsibility for the child's treatment; to improve parent-professional relationships; to establish treatment goals; and to track student progress (Epstein, Dakan, Oswald, \& Yoe, 2001; Rhee et al., 2001). The strength-based approach to assessment also encourages the establishment of non-traditional goals, including increased independence from service providers (including school psychologists) and a higher quality of life (Powell et al., 1997).

Address correspondence to: Merith Cosden; Counseling, Clinical, School Psychology; Gevirtz Graduate School of Education; University of California; Santa Barbara, CA 93106. Email: cosden@education.ucsb.edu. 
Initially, strength-based assessment emerged as an alternative approach to the traditional, deficitbased assessment used to identify students' weaknesses and qualify them for special education. While these traditional assessments identified students' academic needs, they presented limited information on the child's "assets," knowledge of which could also contribute to their educational plans (Reid, Epstein, Pastor, \& Ryser, 2000). Although strength-based assessments were initially developed to supplement the educational information available for students in special education, more recently the principles of strength-based assessment have been applied to adolescents at risk for school failure, including those with substance abuse problems (MacKinnon-Lewis, Kaufman, \& Frabutt, 2002). Identification of strengths in youths who are beginning to use drugs and engage in other delinquent behaviors may serve as a preventive measure, interrupting the need for more intensive interventions and out of school placements. This article will consider the application of strength-based assessment to youths with substance abuse problems. Different methods for determining strengths, and alternative means for using this information, will be discussed.

\section{What is Strength-Based Assessment?}

Epstein and Sharma (1998, p. 3) provide a commonly cited definition of strength-based assessment, as the "measurement of emotional and behavioral skills, competencies and characteristics that create a sense of personal accomplishment, contribute to satisfying relationships with family members, peers and adults, enhance one's ability to deal with adversity and stress, and promote one's personal, social and academic development." The authors used this definition in their development of the Behavioral and Emotional Rating Scale (BERS), a strength-based assessment that covers intrapersonal strengths, family involvement, intrapersonal strengths, school functioning and affective strengths. While the BERS is intended to be comprehensive with regard to covering the range of potential youth strengths, it is still left to empirical studies to define how specific student strengths are related to desired student outcomes.

Researchers have identified several general, intra-personal factors that support resilience in children and adolescents under a variety of adverse circumstances. These factors include intellectual ability, positive temperament, self-efficacy, achievement orientation, high expectations, and engagement in productive activities (Doll \& Lyon, 1998). In addition, resources external to the child can serve as protective factors, including relationships with supportive adults, high expectations from others, and opportunities to engage in meaningful activities. The research on risk and resilience suggests areas in which to start to examine individual youth assets.

One of the assumptions of strength-based assessment is that every child and family has strengths (Epstein et al., 2001). For youths engaged in drug use and other criminal activity, however, identification of personal strengths, as well as supports in their natural communities, may present particular challenges.

\section{Application of Strength-Based Assessment to Students Engaged in Drug Abuse and Related Delinquent Behaviors}

The deficiencies of youth involved in drug abuse have been well delineated in the literature (RoundsBryant, Kristiansen, \& Hubbard, 1999). While many adolescents come to the attention of adults (e.g., educators, treatment providers, or the juvenile justice system) because of their drug abuse, these youths typically present with a myriad of psychosocial problems, including educational failure, poor selfesteem, depression, and few social supports (Neighbors, Kempton, \& Forehand, 1992). It is clear that there are significant differences among adolescents who engage in drug use. Nevertheless, little is known about the strengths of these youths or the ability of practitioners to assess and utilize these assets. 

used to monitor and evaluate specific interventions, while informal strength-based assessments may have greater clinical utility for the individual child. The following group study and case study demonstrate the use of both formal and informal strength-based assessment procedures. The first study focuses on the use of strength-based assessment to evaluate a program, whereas the second case study demonstrates the utility of informal strength-based assessments for treatment planning.

\title{
STUDY 1 \\ USING STRENGTH-BASED ASSESSMENT FOR PROGRAM EVALUATION OF A JUVENILE DRUG COURT
}

\author{
Method Study 1
}

\section{Participants}

Data are presented on 215 adolescent participants in a Juvenile Drug Court (JDC) treatment program. Participation in the JDC was voluntary. Adolescents were eligible for the program if they had a drug-related offense and a history of moderate to severe substance abuse. Juveniles charged with a violent offense, or those with prior convictions for violent offenses, were excluded. All adolescents entering the JDC during its first 18 months of operation were included in this study.

In terms of demographic characteristics, $70 \%$ of the sample was male, while ethnicity was largely Latino (57\%) and European American (36\%), with 3\% each from African American and Asian American groups, and $1 \%$ from other ethnic groups. The age range was $13-17-32 \%$ were $17,34 \%$ were 16 , $22 \%$ were $15,11 \%$ were 14 , and $1 \%$ were 13 years of age. Adolescents averaged four years of prior drug use, with most reporting the use of marijuana and alcohol. A majority (58\%) had two or more criminal offenses prior to entering the JDC.

\section{Program}

Juvenile drug treatment courts were developed to respond to the growing national problem of adolescent substance abuse. Currently, there are over 200 juvenile drug courts in the United States (Cooper, 2002). These programs involve the collaboration of multiple service agencies, including the schools, probation, treatment providers, and the juvenile court system. The purpose of these courts is to reduce recidivism by providing outpatient treatment and court supervision for youths charged with drug-related, non-violent criminal activities. Efforts are made to serve the youth in their least restrictive environment, allowing them, whenever possible, to remain at home and in their communities. These programs emphasize interventions that go beyond drug and alcohol treatment to include the development of personal and educational skills. This requires a multi-disciplinary approach, and multiagency involvement, with school performance a key component of most treatment plans. Thus, while organized outside of the school system, these programs have significant implications for school psychologists. This process also increases the number of students with substance abuse and related behavior problems requiring services in their community schools.

The JDC in this study had a five-phase outpatient treatment program, lasting 12-15 months. In addition to court appearances and supervision, treatment included drug testing, attendance at relapse prevention groups and individual counseling, home visitations by trained caseworkers, school attendance, and participation in sober group activities. Graduation was based on meeting treatment goals including 90 days of continuous sobriety, regular attendance of program meetings and school, and behavior changes that reflect their ability to remain in the community. 

sion are categorized into four domains: "enmeshed," "connected," "separated," and "disengaged." Scores for family adaptability are also categorized into four domains: "very flexible," "flexible," "structured," and "rigid." For both subscales, the middle two categorizations are considered to reflect healthier family interactions. Internal reliability for the FACES - II is reported at 0.91 for the cohesion scale and 0.80 for the adaptability scale (Olsen, Sprenkle, \& Russell, 1979).

\section{Procedure}

Mental health practitioners administered the AASI, CBCL, FACES-II, and YSR after the court approved a youth's participation in the program. The unscored protocols were sent to the University of California evaluators, who scored them and prepared a report clarifying the client's areas of clinical strengths and weaknesses that was sent to the treatment providers. The same assessments were readministered after the youths were in treatment for 12 months. In addition, probation officers reviewed school records, and provided records of the clients' criminal activities, including new bookings, convictions and jail days, during the program.

\section{RESULTS STUDY 1}

First, descriptive statistics were used to develop an understanding of the range of students' strengths and weaknesses. Changes in behaviors were noted through the use of paired $t$-tests on the re-assessment data 12 months into treatment. Finally, analysis of variance statistical tests were used to determine which of these factors were associated with program graduation.

Table 1 reflects the academic background of participants. As noted, approximately half of the youths were attending regular public schools. While a majority of youths had some types of behavioral problems at school, as demonstrated by their suspensions, there was a range in academic performance. Further, only one-third of students reported problems requiring special education. From a strengthbased perspective, the data suggest that many of the students had academic strengths that could be utilized.

Table 1

Educational Functioning of Adolescents in JDC

\begin{tabular}{crr}
\hline & $N$ & $\%$ \\
Type of school $^{1}$ & & \\
Special School & 90 & 47 \\
Public School $^{\text {Not Attending }}$ & 91 & 48 \\
Academic Performance $^{1}$ & 9 & 5 \\
Above Average & 10 & 5 \\
Average $^{\text {Below Average }}$ & 70 & 37 \\
Suspended $^{2}$ & 108 & 57 \\
Failed Classes & 77 & \\
Special Education & 67 & 30 \\
Difficulty Reading & 47 & 34 \\
Difficulty Writing & 35 & 18 \\
\hline
\end{tabular}

${ }^{1}$ Data obtained from school records (teacher reports)

${ }^{2}$ Data obtained from the AASI (self-reports) 
Figure 1 notes some of the other competencies for the youths as self-reported and reported by their parents. While the adolescents reported higher levels of competence for themselves than did their parents, both groups were aware of the youths' competencies. As shown in Figure 2, many of the adolescents and their parents reported that the youths had hobbies, including music, riding bikes, reading, computers, skateboards, and videogames; that they engaged in sports, such as basketball, football, swimming, and cheerleading; and that they did chores, ranging from babysitting, to washing dishes, cleaning the house, and taking out the trash. It was also the case that a majority of the parents $(67 \%)$ reported that their children had serious externalizing behavior problems. However, reporting only the deficit portion of the assessment, as is sometimes the case, would have limited awareness of the youths' assets, and prohibited their consideration in the development of interventions.

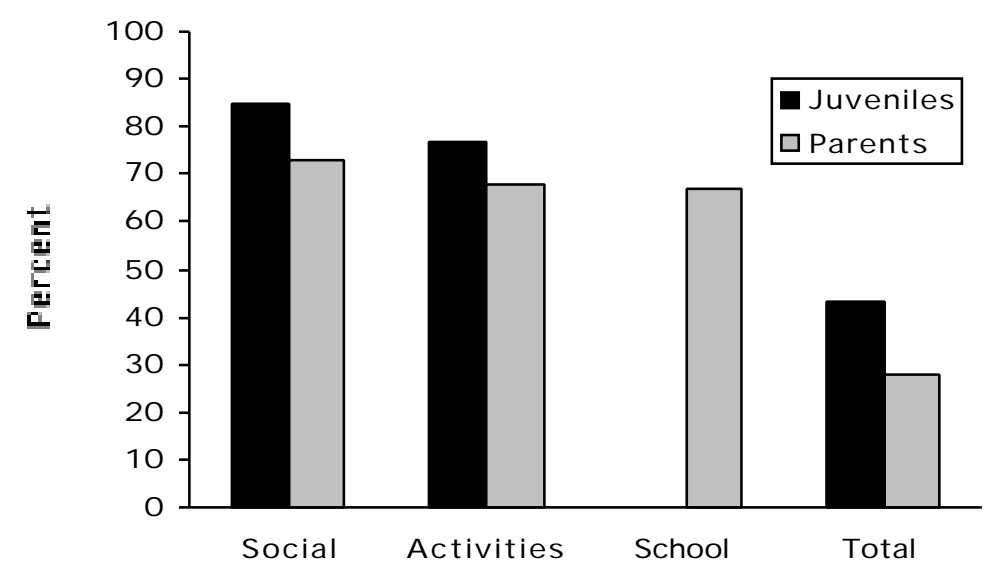

Figure 1.

Youth Competencies as Indicated by the Youths and Their Parents on the YSR and CBCL

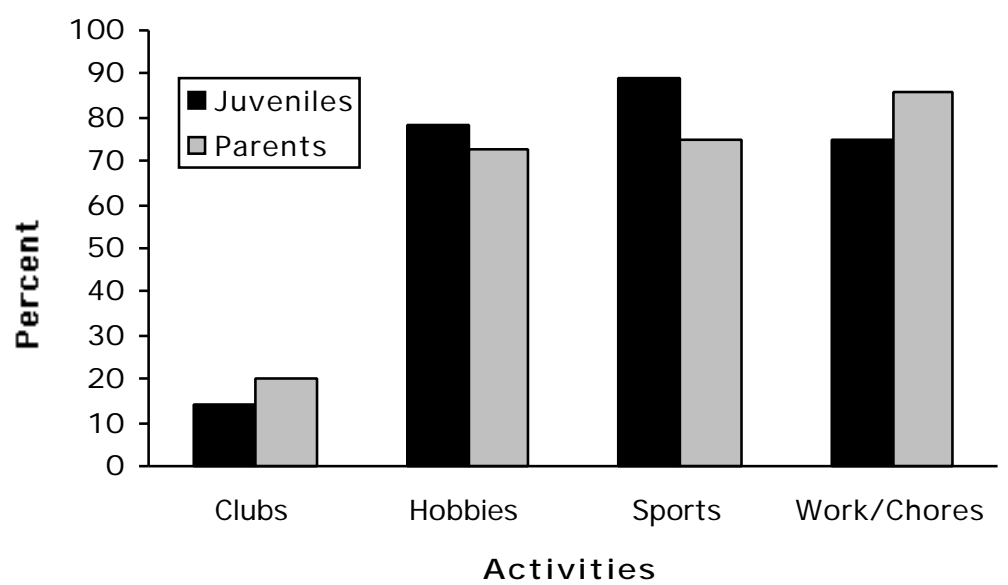

Figure 2.

Extracurricular Activities Noted by the Youths and Their Parents on the YSR and CBCL 
Of the 119 juveniles who had exited the program at the time this report, $27 \%$ graduated, having met all treatment goals. At the end of 12 months in the program, both the parents of the graduates, and the graduates themselves, saw increased strengths in different aspects of their lives. Graduates were reported by their parents as showing significantly higher school competencies, $t(16)=2.8, p<.05$, and total competencies, $t(13)=2.5, p<.05$, than they had at intake. Adolescents who graduated perceived their families as more cohesive at the end of 12 months in treatment than they had been at intake, $t(24)$ $=2.18, p<.05$.

Using graduation status as an independent variable, analysis of variance statistics were conducted to determine which strengths and weaknesses were associated with this outcome. Graduation status was associated with the absence of serious problems and the presence of specific strengths. For example, relative to unsuccessful adolescents, graduates had fewer externalizing behavior problems at intake as assessed on the CBCL, $F(1,117)=6.19, p<.05$, and had fewer prior criminal detentions and arrests with less time spent in detention than had nongraduates, $F(1,117)=7.41, p<.01$. On the positive side, graduates reported more family and social support than did nongraduates at intake as assessed by family composite scores on the AASI, $F(1,117)=4.0, p<.05$.

In terms of school factors, adolescents who were doing better in school were also more likely to finish the program. Over $61 \%$ of graduates were attending regular public school at the time they entered treatment, compared to only $39 \%$ of nongraduates $\chi^{2}(N=119)=6.1, p<.05$. More nongraduates reported difficulties with reading $(25 \%)$ than did graduates $(7 \%), \chi^{2}(N=119)=5.82, p<.05$. Nongraduates were also more likely to have a diagnosed learning disability $(21 \%)$ than were graduates (13\%), although this difference was not statistically significant.

\section{DISCUSSION STUDY 1}

These analyses found that family support, personal strengths, and school functioning, were associated with the successful completion of treatment. Students who had family, behavioral and schoolbased strengths were more likely to succeed and graduates were likely to show improvements in these areas. This information was used to refocus program efforts to increase family involvement and school engagement overall. However, there are many ways in which families can support or hinder their children; further, school engagement can be affected in a number of different ways, depending on the strengths and interests of the students. Thus, assessments were added to the protocol to provide a more specific picture of students' strengths in these areas, for the purposes of individualized treatment planning in these areas.

\section{STUDY 2 \\ A CASE STUDY ON THE USE OF STRENGTH-BASED ASSESSMENT TO DEVELOP INTERVENTIONS}

The initial assessment procedures were revisited after the first year of the program. While the original procedures were used to identify factors associated with program success, such as family support and school functioning, the measures themselves were too broad to provide specific direction on how to improve outcomes for specific adolescents in the program. For example, while many of the youths were not experiencing school success, it was unclear from the earlier assessments how to help them become more engaged in the schools. In an effort to increase the rate of success, specific measures of the youths' strengths were added, with the goal of using this information to improve interventions and outcomes. 
Additional formal (standardized) and informal strength-based assessments were administered by an intake worker. At the outset, two "facilitated assessment" meetings were scheduled with each minor. The first meeting focused on values clarification with the goal of helping the minor elicit his or her own values, personal qualities, and future plans. The second meeting revolved around motivation for change, and involved asking the minor to state what he or she was willing to do to move from the present situation to his or her ideal future image (elicited at a values clarification meeting). This procedure was designed to help the youth develop a collaborative relationship with the staff and adopt more of a solution-oriented focus to their program.

Following these meetings there was a lengthy (1 $1 / 2$ to 2 -hour) individual interview with the minor. The questions in this semi-structured interview were designed to assess the presence of the 40 Developmental Assets identified by the Search Institute as related to positive youth outcomes (Search Institute, 2003). These assets fall into eight domains: positive identity (e.g., "What are the most important things in your life?"); constructive use of time (e.g., "How do you spend your free time?"); family support (e.g., "Who do you have the strongest connection with among adults?"); commitment to learning (e.g., "How involved are you in school?"); empowerment (e.g., "How would you like to get involved in your community?"); social competencies (e.g., "How easy is it for you to make decisions?"); boundaries and expectations (e.g., "How are rules enforced in your house?"); and positive values (e.g., "What are the equalities you look for in a friend?"). While the Institute has developed its own surveys, the questions used here were created by the program staff, and designed to be integrated within a broader intake assessment. This aspect of the assessment was used to identify the presence of the student's assets, which was then added to the clinical report on each client.

In addition, the How I Think questionnaire (HIT, Barriga \& Gibbs, 1996) was administered. The HIT identifies the presence or absence of distorted cognitions. The adolescent records his or her level of agreement with 54 statements (including "It's OK to tell a lie if someone is dumb enough to fall for it"), with his or her responses categorized as "self-centered," "blaming others," "minimizing/ mislabeling," and "assuming the worst." These types of distortions have been associated with delinquent behavior. It has also been suggested that altering these cognitions may affect delinquent behavior (Liau, Barriga, \& Gibbs, 1998).

Finally, the Strengths and Difficulties Questionnaire (SDQ; Goodman, 1997) was administered to the youths. The SDQ is similar in concept to the YSR and CBCL, but much shorter, containing only 25 items and fewer subscales. Of the five scales, four measure problem areas (e.g., emotional symptoms, conduct problems, hyperactivity, peer problems) and one measures prosocial behavior.

An interview was also conducted with the minor's parental figures in which they were asked to describe the strengths of the minor, as well as their family strengths.

At the end of this assessment process, a clinical report was developed that integrated the findings from these strength-based assessments. This report was able to speak to the client's motivation for change (from the Facilitated Assessment); their personal, social and family assets (from questions regarding the Developmental Assets); their presence or absence of cognitive distortions (from the HIT); and their capacity to identify areas of personal strength and weakness (on the SDQ). In addition, the process itself was viewed as therapeutic in that the clients and the assessor discussed the youth's strengths, setting a positive framework for treatment.

\section{CASE SUMMARY STUDY 2}

A brief case study of J.S. ${ }^{1}$, a 17-year-old European American male who entered the JDC after five years of drug use, is presented. J.S. had five years of serious drug use and related behaviors before he

${ }^{1}$ Identifying information was altered to protect the youth's confidentiality. 
came to the JDC. The minor's low sense of self-esteem prevented him from identifying any personal strengths on the Assets interview. The How I Think questionnaire revealed no distorted or antisocial cognitions on the part of the minor. The assessment of his motivation to change revealed that he was ambivalent about stopping his drug use. However, he was performing adequately at school and had a future aspiration to attend college. Finally, although his single father had not been successful in controlling his son's behavior to date, this was the one affective relationship that J.S. trusted. Thus, the importance of this relationship to J.S. could be drawn on in treatment efforts.

The information gathered at intake was used to identify J.S.'s strengths, although he had been unable to identify these strengths on his own. From information obtained during the facilitated assessment meetings, it was clear that he was not ready to stop using substances, although he wanted to decrease his use. This assessment also found that his future goals included high school graduation and attendance at college. The questions based on the Developmental Assets indicated that he did not identify with his drug-using friends, and that he had a strong connection with his father. The HIT showed J.S. to have an absence of cognitive distortions. His clarity of thinking, the connection of trust with his father, and his desire to achieve his future goals led the case manager to think that this minor could benefit from a structure that taught him self-regulation and enhanced his self-esteem while offering a new possibility for sobriety.

Within this framework, recommendations were made to the treatment team, which included specific goals for the school psychologist. The school psychologist was encouraged to increase involvement with the father and to use this connection to monitor the adolescent's academic progress, as well as to assist the father in maintaining supervision over the youth's activities. This involvement could be tied to the minor's goal of attending college. Further, the school was made aware of the youth's leadership among his peers, as he had a talent for procuring free drugs and alcohol for himself from his friends. Providing the youth with supervised leadership activities could, potentially, redirect some of the energy that was going into drug related activities.

These recommendations were partially utilized. J.S. and his father continued to meet in therapy and began to work together more effectively. The knowledge that J.S. wanted to graduate high school and attend college was used as motivation both for him and for the school personnel working with him. J.S. remains in treatment, with occasional relapses.

\section{GENERAL CONCLUSIONS}

Strength-based assessments can be used to identify assets in youths who present with a myriad of drug and alcohol related psychosocial problems. As exemplified in this paper, a wide range of formal and informal assessments can be used to assess individual strengths, as well as to identify strengths associated with important school and community outcomes. Traditional, standardized assessments like the CBCL can be used in a strength-based manner to identify student assets associated with successful outcomes. Identification of these assets, in turn, can be used to develop global treatment strategies, for example, to increase parent involvement or improve school performance. The more detailed strength-based assessments, such as the interview items on the Developmental Assets and the facilitated assessments of student motivation conducted here, can promote shared goals and provide greater specificity with regard to the youth's needs. In tandem, these approaches can facilitate both general and specific goals in treatment.

There are several caveats to the use of these strength-based assessments, however. The utility of strength-based assessments can be restricted by the willingness of personnel to use the information they receive to develop individual interventions. Educators are required to implement individualized 
treatment plans for children in special education; they are also encouraged to modify classroom activities based on the needs and learning styles of all students. Nevertheless, it is common practice for teachers to favor particular methods for delivering instruction and maintaining behavior in their classes. This is an area in which school psychologists can be of assistance, by helping educators to use the information obtained through strength-based assessments to inform classroom and other school-based activities. Addressing the needs of students who have serious behavioral problems may require particular creativity, as these students are likely to benefit from "out of the box" thinking (Rhee et al., 2001). Clark (1996) notes that we have few evidenced-based practices for working with high-risk youth. The group study, and case study, presented here suggest areas for potential interventions, which could include using future goals as incentives to promote school involvement, encouraging family involvement in school activities, and developing areas in which students could demonstrate their leadership potential.

Further, there are likely to be other positive consequences associated with the use of strengthbased assessment. It is hypothesized that the process of identifying the adolescents' strengths itself will have an impact both on the school psychologists who are working with the adolescents and on the adolescents themselves. School psychologists will hold greater hope for adolescents when they are aware of their assets as well as their deficits. Similarly, adolescents are more likely to form a working relationship with the school psychologist if they believe that the school psychologist has hope and higher expectations for them. In sum, strength-based assessment is a promising practice with this population, but one that requires additional study.

\section{REFERENCES}

Achenbach, T. M. (1991). Manual for the Child Behavior Checklist. Burlington, VT: University of Vermont, Department of Psychiatry.

Achenbach T. M. (1991b). Manual for the Youth Self-Report and 1991 Profiles. Burlington, VT: University of Vermont Department of Psychiatry.

Adolescent Addiction Severity Index. (2000). [Computer assessment and description]. Retrieved January 10, 2004, from com/forms.htm" http://www.accurateassessments.com/forms.htm

Barriga, A. Q., Landau, J. R., Stinson, B. L., Liau, A. K., \& Gibbs, J. C. (2000). Cognitive distortion and problem behaviors in adolescents. Criminal Justice \& Behavior, 27, 36-56.

Benson, P. L., Roehlkepartain, E. C., \& Sesma, A., (2004). Tapping the power of community: The potential of asset building to strengthen substance abuse prevention efforts. Search Institute Insights \& Evidence, 2, 1-14.

Cacciola, J. S., Koppenhaver, J. M., McKay, J. R., \& Alterman, A. I. (1999). Test-retest reliability of the lifetime items on the Addiction Severity Index. Psychological Assessment, 11, 86-93.

Clark, M. D. (1996). Brief solution-focused work: A strength-based method for juvenile practice. Juvenile \& Family Court Journal, 47, 57-65.

Cooper, C. S. (2002). Juvenile drug treatment courts $\mathrm{n}$ the United States: Initial lessons learned and issues being addressed. Substance Abuse \& Misuse, 37, 1689-1722.

Cosden, M., Macias, S., Panteleakos, F., \& Gutierrez, L. (2003). Evaluation of the Santa Barbara County Juvenile Drug Court. Gevirtz Graduate School of Education, University of California, Santa Barbara.

Dobkin, P. L., Chabot, L., Maliantovitch, K., \& Craig, W. (1998). Predictors of outcome in drug treatment to adolescent inpatients. Psychological Reports, 83, 175-186.

Doll, B., \& Lyon, M. A. (1998). Risk and resilience: Implications for the delivery of educational and mental health services in schools. School Psychology Review, 27, 348-363.

Dunst, C. J., Trivette, C. M., \& Mott, D. W. (1994) Strengths-based family-centered intervention practices. In C. J. Dunst, C. M. Trivette, \& A. G. Deal (Eds.), Supporting and strengthening families, Vol.1: Methods, strategies and practices (pp. 115-131). Cambridge, MA: Brookline.

Epstein, M. H., Dakan, E., Oswald, D. P., \& Yoe, J. T. (2001). Using strengths-based data to evaluate children's mental health programs. In M. Hernandez \& S. Hodges (Eds.), Developing outcome strategies in children's mental health (pp. 153-166). Baltimore, MD: Paul H. Brookes.

Epstein, M. H., \& Sharma, J. M. (1998). Behavioral and Emotional Rating Scale (BERS). Austin, TX: PRO-ED.

Friedman, A. S., Terras, A., \& Kreisher, C. (1995). Family and client characteristics as predictors of outpatient treatment outcome for adolescent drug abusers. Journal of Substance Abuse, 7, 345-356. 
Goodman, R. (1997). The Strengths and Difficulties Questionnaire: A research note. Journal of Child Psychiatry, $38,581-586$.

Hodgins, D. C., \& El-Guebaly, N. (1992). More data on the Addiction Severity Index. Reliability and validity with the mentally ill substance abuser. The Journal of Nervous and Mental Disease, 180, 197-201.

Latimer, W. W., Newcomb, M., Winters, K. C., \& Stinchfield, R. D. (2000). Adolescent substance abuse treatment outcomes: The role of substance abuse problem severity, psychosocial, and treatment factors. Journal of Counseling, Consulting, and Clinical Psychology, 68, 684-696.

Leonhard, C., Mulvey, K., Gastfriend, D. R., \& Shwartz, M. (2000). The Addiction Severity Index: A field study of internal consistency and validity. Journal of Substance Abuse Treatment, 18, 129-135.

Liau, A. K., Barriga, A. Q., \& Gibbs, J. C. (1998). Relations between self-serving cognitive distortions and overt vs. covert antisocial behavior in adolescents. Aggressive Behavior, 24, 335-346.

MacKinnon-Lewis, C., Kaufman, M. C., \& Frabutt, J. M. (2002). Juvenile justice and mental health: Youth and families in the middle. Aggression and Violent Behavior, 7, 353-363.

McLellan, A., Kushner, H., Metzger, D., Peters, P., Smith, I., Grissom, G., Pettinati, J., \& Argeriou, M. (1992). The fifth edition of the Addiction Severity Index. Journal of Substance Abuse Treatment, 9, 199-213.

Neighbors, B., Kempton, T., \& Forehand, R. (1992). Co-occurrence of substance abuse disorder with conduct, anxiety, and depression disorders in juvenile delinquents. Addictive Behaviors, 17, 379-386.

Nissen, L. (1999). Building assets in youth and families served by the juvenile justice system: A working guide. Institute for Strengths in Juvenile Justice.

Olson, D. H., Sprenkle, D. H., \& Russell, C. S. (1979). Circumplex model of marital and family systems: I. Cohesion and adaptability dimensions, family types, and clinical applications. Family Process, 18, 3-28.

Powell, D., Batsche, C. J., Ferro, J., Fox, L., \& Dunlap, G. (1997). A strength-based approach in support of multirisk families: Principles and issues. Topics in Early Childhood Special Education, 17, 1-26.

Rhee, S., Furlong, M. J., Turner, J. A., \& Harari, I. (2001). Integrating strength-based perspectives in psychoeducational evaluations. The California School Psychologist, 6, 5-17.

Rounds-Bryant, J. L., Kristiansen, P. L., \& Hubbard, R. L. (1999). Drug abuse treatment outcome study of adolescents: A comparison of client characteristics and pretreatment behaviors in three treatment modalities. American Journal of Drug and Alcohol Abuse, 25(4), 573-591.

Search Institute. (2003). 40 Developmental assets for adolescents. Retrieved January 9, 2004, from http:// www.search-institute.org/assets/forty.html

Stoffelmayer, B. E., Mavis, B. E., \& Kasim, R. M. (1993). The longitudinal stability of the Addiction Severity Index. Journal of Substance Abuse Treatment, 11, 373-378.

Williams, R. J., \& Chang, S. Y. (2002). A comprehensive and comparative review of adolescent substance abuse treatment outcome. Clinical Psychology: Science and Practice, 7, 138-166. 
The California School Psychologist, Vol. 9, pp. 127-134, 2004

Copyright 2004 California Association of School Psychologists

\title{
Perceived Quality of Life: A Neglected Component of Assessments and Intervention Plans for Students in School Settings
}

\author{
E. Scott Huebner \\ University of South Carolina \\ Rich Gilman \\ University of Kentucky
}

\begin{abstract}
The relevance and contribution of the construct of quality of life to assessments and intervention plans for children and youth in school settings are discussed. Theory, measurement, and research related to perceived quality of life (PQOL) are reviewed leading to the contention that PQOL information contributes incremental validity above and beyond traditional deficit-based information. The use of PQOL in assessments, treatment planning, and monitoring of the well-being of students in school settings warrants further consideration to provide more comprehensive assessment-intervention activities.
\end{abstract}

Key Words: Quality of Life, Assessment, School

Traditional assessment, intervention planning, and monitoring services for children and youth in school settings have emphasized the measurement and "repair" of behavior and learning problems. Although such information is fundamental to understanding the needs of school-age youth, the deficitoriented approach focuses attention on circumscribed aspects of their adaptation, ignoring important intrapersonal, and environmental assets (Epstein et al., 2003; Lopez, Snyder, \& Rasmussen, 2003; Rhee, Furlong, Turner, \& Harari, 2001). In an effort to develop a more comprehensive perspective of a child's development, psychologists and educators associated with the "positive psychology" movement (Seligman \& Csikzentmihalyi, 2000) have called for increased attention to positive indicators of well-being to complement the focus on negative indicators. As early as 1991, Cowen argued that definitions of psychological wellness should be expanded to include positive elements such as "a basic satisfaction with oneself and one's existence ...or life satisfaction" (p. 404). Although early work in positive psychology targeted adults, recent research attention is being directed to children and youth (Gilman \& Huebner, 2003).

The distinction between positive and negative indicators of mental health is illustrated in research by Greenspoon and Saklofske (2001). In one study of children in grades 3-6, they demonstrated that psychopathology (PTH) and subjective well-being (SWB) (measured by life satisfaction) were not simply opposite poles of a continuum. Their results identified four distinguishable groups of students: high PTH-high SWB, high PTH-low SWB; low PTH-high SWB; and low PTH-low SWB, the latter of which particularly challenges one-dimensional models of mental health. Using only pathology-based measures (i.e., measures of the presence of psychopathological symptoms), the low PTH-low SWB students would appear "healthy" even though their SWB is low at baseline and/or declining. Thus, the use of positively-focused SWB measures would appear to offer the opportunity to develop more comprehensive portraits of the adaptation of youth to their life circumstances.

Address correspondence to: Scott Huebner; Department of Psychology; University of South Carolina; Columbia, SC 29208. E-mail: huebner@sc.edu. 
Quality of life is a broad concept that provides one expanded framework for considering factors that relate to positive and negative behavior and emotions of children and adults (Cummins, 1997a; Huebner, 1994). Quality of life studies with persons with and without disabilities have investigated both objective and subjective indicators of persons and their environments. Examples of objective indicators include functional living skills, physician ratings of physical health, and access to recreational services. Examples of subjective indicators include perceived life satisfaction, positive emotions, and self-rated health. Increased interest has been demonstrated in the study of subjective indicators given the weak relationships between objective indicators and subjective perceptions. For example, the association between objective health indices and persons' health-related quality of life perceptions is quite modest (cf. Diener, Suh, Lucas, \& Smith, 1999).

Perceived quality of life (PQOL) or life satisfaction is considered to be a key indicator of subjective well-being (Diener \& Diener, 1995; Diener, Scollon, \& Lucas, in press). PQOL is defined as a cognitive evaluation of the positivity of one's overall life or in specific life domains (e.g., school experiences, family life, and living environment; Campbell, Converse, \& Rodgers, 1976). The use of PQOL measures in assessment and intervention planning and evaluation has been advocated in medical (Fallowfield, 1990), community (Cowen, 1991), and school settings (Gilman \& Huebner, 2003) to address theoretical, practical, and ethical concerns. With respect to the former, children and youth wish first and foremost to be happy and content (Hales, 1996; Kazdin, 1993). Because an important goal of all interventions is to enhance the recipients' quality of life (Jenkins, 1992), PQOL measures have the potential to serve as crucial outcome indicators for monitoring intervention efficacy (Frisch, 1999), including children and youth in school settings. Practically, the use of PQOL measures is emphasized because of their sensitivity to changes in life circumstances, including psychosocial interventions (Farrell et al., 2003; Frisch, 1999). Although professionals view PQOL in divergent ways, ethical considerations necessitate the development and implementation of educational programs (e.g., placement in remedial/special education programs or specialized groupings), which, at the least, do not result in decreases in long-term PQOL. Similarly, related services, such as medical and psychosocial interventions associated with learning and behavior problems (e.g., medical treatments, specific curricular modifications, or individualized behavioral intervention plans) should also not negatively impact the long-term PQOL of the students. Professionals who work with students with and without disabilities in schools would likely agree with such a perspective. However, formal efforts to safeguard the PQOL of children and youth have not been undertaken routinely. The primary purpose of this paper is thus to advocate for consideration of PQOL in assessments and intervention planning and evaluation with students in school settings.

Promising measures of PQOL have been developed for children and youth, generally for grades 3-12, depending upon the instrument. As with adults, the measures are self-report in nature, given that the instruments are designed to assess student perceptions of the quality of their lives. Scales that measure the overallPQOL of children and youth include the Perceived Life Satisfaction Scale (Adelman, Taylor, \& Nelson, 1989), the Quality of Life Profile-Adolescent Version (Raphael, Rukholm, Brown, Hill-Bailey, \& Donato, 1996), and the Students' Life Satisfaction Scale (Huebner, 1991). More comprehensive, multidimensional measures include ratings of specific life domains (e.g., family, peers, and school). Such measures include the Comprehensive Quality of School Life Scale-School Version (Cummins, 1997b), Multidimensional Students' Life Satisfaction Scale (MSLSS; Huebner, 1994), and the Quality of Student Life Questionnaire (Keith \& Schalock, 1995).

Reviews of PQOL scales can be found in Bender (1997) and Gilman and Huebner (2000). The multidimensional scale that has received the most empirical support is the MSLSS. The MSLSS con- 

and youth well-being. By including ratings ranging from "very low" through "neutral" and "very high," PQOL measures meet this requirement because they can differentiate among subtle changes in subjective well-being (e.g., clients who move from "very low" to "moderately low" PQOL).

Furthermore, the use of domain-based PQOL measures provides multicontextual measurements of needs and assets, including both personal and environmental factors. For example, a child who reports low PQOL in the areas of family experiences and self-satisfaction necessitates different intervention considerations relative to a child who reports positive family experiences and self-satisfaction along with unsatisfactory school experiences. Such "profiles" of PQOL assessments suggest differentiated information related to a student's perceptions of individual and environmental strengths and weaknesses that may inform prevention and intervention planning.

\section{PQOL Draws Attention to Environments in Children's Development}

Multicontextual PQOL reports affirm the role of the environment in the development of children and youth. PQOL reports provide indexes of students' perceptions of key life contexts, such as the family, peers, school experiences, and community environment. Understanding the contributions of such environmental factors to a child's academic and behavioral functioning is facilitated by inclusion of assessments of environmental factors, however, few such measures exist that are psychometrically sound (Hoge, 1999). Most professionals working with students in schools recognize the importance of person-environment interactions in the development of problem behavior. Nevertheless, systematic efforts are rarely undertaken to assess aspects of students' environments that may be crucial to understanding and changing their behavior. PQOL measures can aid in assessment-intervention planning by revealing the differential impact of various contexts in a child's life, particularly from the perspective of the child him or herself (Brantley et al., 2002; Huebner et al., 1998). Such subjective assessments provide an estimate of the "goodness of fit" between a child and the objective conditions of her or his life (Schalock, Keith, Hoffman, \& Karan, 1989).

The inclusion of PQOL ratings in assessments may also relate to intervention compliance and positive prognosis, although research in this area has focused exclusively on adults to date. For example, studies by Holcomb and colleagues (Holcomb, Parker, \& Leong, 1997; Holcomb, Parker, Leong, et al., 1998) found that psychiatric inpatients reporting high PQOL within their immediate treatment environment also demonstrated greater adaptive functioning and decreased psychiatric symptoms. Further, Carlson and Gabriel (2001) reported that clients in a residential drug treatment program who were more satisfied with their services also were more likely to abstain from alcohol and/or illicit drugs one year after starting treatment (see also Chan \& Sorenson, 1997). These findings suggest that a complex, reciprocal relationship exists between changes in life quality and client perceptions, further underscoring the notion that specific PQOL assessments (e.g., satisfaction with interventions per se) can be useful in outcome evaluations (Frisch, 1999).

\section{PQOL Serves as a Determinant of Youth Behavior}

That PQOL is related to important youth behavior is supported by a variety of cross-sectional studies of child and youth PQOL and measures of behavioral, physical, and emotional functioning. For example, low PQOL has been related to aggressive behavior, internalizing behavior, loneliness, suicide ideation, maladaptive eating and physical exercise behavior, and drug and alcohol use (see Huebner et al., 2004 for a review). Furthermore, some studies suggest a mediational role for global PQOL in the

relationship between parenting behavior and externalizing and internalizing behavior in adolescence (Suldo \& Huebner, 2004a) as well as between stressful life events and adolescents' internalizing be- 

with their weaknesses), rather than merely focusing on developing a specific diagnosis and providing a related "treatment." This information could then be specifically designed to increase PQOL (e.g., through a greater emphasis on building upon existing strengths). Such intervention strategies have resulted in positive outcomes in response to stress (Frederickson, 2001) and poor physical health (Seeman, 1989). Specifically, educators operating from a strengths-based perspective would work toward the development of educational programs that incorporate goals and activities based on important strengths. Goals and objectives that ensure that student strengths and environmental assets are capitalized upon in educational program may facilitate student progress and more positive parentschool and child-school partnerships (Epstein et al., 2003). Given such benefits, the use of strengthsbased information, such as high scores on PQOL domains, should be viewed as a crucial component of a comprehensive evaluation process, in which the students can provide valuable insights into their treatment plans, effectiveness, and resources.

\section{CONCLUSION}

PQOL measures can potentially contribute positive student/environment information that is readily understandable to educators of all students. Such contributions can extend to students with special needs, even those with behavior problems who are often "swimming in a sea of negativity" (Jensen et al., 2004, p. 69). PQOL measures often contain items corresponding to multiple domains in a student's life, such as satisfaction with various subsystems in an educational environment (e.g., peers, school, and community; Gilman \& Handwerk, 2001). Thus, individual and program evaluation results can be more specific and more understandable across professional groups, parents, and students; all of whom are concerned that the services benefit the students. For example, administrators can utilize the information in their reports to various accreditation bodies and funding sources-information that would increase the array of outcomes considered in evaluating the efficacy and impact of educational services. As noted previously, reliance on deficit-focused measures can obscure positive outcomes. With the inclusion of positive measures, such as PQOL reports, evaluators are afforded more comprehensive means to determine program effects. Teachers, school psychologists, and other support personnel can interpret specific information in PQOL reports as indicators of the quality of day-to-day experiences in relation to students' important environmental contexts.

Developmental issues are likely critical in the incorporation of PQOL considerations in schoolbased assessment and intervention. Nevertheless, little research attention has been devoted to such concerns. One exception is a study by Suldo and Huebner (2004a) that demonstrated that parenting behaviors assumed differential levels of importance to PQOL reports for adolescents of differing ages. Also, Dew (1995) found that older adolescents can differentiate more life satisfaction domains than younger adolescents. Such findings point to the need for further study of developmental differences in the nature and determinants of PQOL reports in children and youth.

In summary, the inclusion of PQOL ratings as a part of a comprehensive school program evaluations offers unique information that may benefit "consumers" of school-related services, ranging from individual students to entire school systems (e.g., school district). We agree, "what gets measured, gets done" (Moore, Brown, \& Scarupa, 2003). Although monitoring the traditional indicators of student progress remains important, the use of PQOL measures should be considered to increase the opportunity to more comprehensively assess potential positive and negative outcomes associated with school experiences, particularly as perceived by the students themselves. In this manner, schools will be best prepared to achieve a fundamental purpose, that is, to enhance students' overall quality of life. 


\section{REFERENCES}

Adelman, H., Taylor, L., \& Nelson, P. (1989). Minors' dissatisfaction with their life circumstances. Child Psychiatry and Human Development, 20, 135-147.

Bender, T. A. (1997). Assessment of subjective well-being during childhood and adolescence. In G. Phye (Ed.), Handbook of classroom assessment: Learning, achievement, and adjustment (pp. 129-225). San Diego, CA: Academic Press.

Bearsley, C., \& Cummins, R. A. (1999). No place called home: Life quality and purpose of homeless youths. Journal of Social Distress and the Homeless, 8, 207-226.

Brantley, A., Huebner, E. S., \& Nagle, R. J. (2002). Multidimensional life satisfaction reports of adolescents with mild mental disabilities. Mental Retardation, 40, 321-329.

Campbell, D., Converse, P., \& Rodgers, W. (1976). The quality of American life. New York: Russell Sage Foundation.

Carlson, M. J., \& Gabriel, R. M. (2001). Patient satisfaction, use of services, and one-year outcomes in publicly funded substance abuse treatment. Psychiatric Services, 52, 1230-1236.

Chan, M., \& Sorenson, J. L. (1997). Client satisfaction with drug abuse day treatment versus residential care. Journal of Drug Issues, 27, 367-377.

Cowen, E. L. (1991). In pursuit of wellness. American Psychologist, 46, 404-408.

Cummins, R. A., (1997a). Assessing quality of life. In R . I. Brown (Ed.), Quality of life for people with disabilities $\left(2^{\text {nd }}\right.$ ed., pp. 116-150). London: Stanley Thornes.

Cummins, R. A. (1997b). Manual for the Comprehensive Quality of Life Scale-Student (Grades 7-12): ComQol S5 (5 $5^{\text {th }}$ ed.). Melbourne, Australia: Deakin University, School of Psychology.

Dew, T. (1995). The development and validation of a life satisfaction scale for adolescents. Unpublished doctoral dissertation, University of South Carolina, Columbia.

Diener, E., \& Diener, M. (1995). Cross-cultural correlates of life satisfaction and self-esteem. Journal of Personality and Social Psychology, 68, 653-663.

Diener, E., Scollon, C. N., \& Lucas, R. E. (in press). The evolving concept of subjective well-being: The multifaceted nature of happiness. In P. T. Costa \& I. L. Siegler (Eds.), The psychology of aging. London: Elsevier.

Diener, E., Suh, E. M., Lucas, R. E., \& Smith, H. L. (1999). Subjective well-being: Three decades of progress. Psychological Bulletin, 125, 276-302.

Epstein, M. H., Harniss, M. K., Robbins, V., Wheeler, L., Cyrulik, S., Kriz, M., \& Nelson, J. R. (2003). Strengthsbased approaches to assessment in schools. In M. D. Weist, S. W. Evans, \& N. A. Lever (Eds.), Handbook of school mental health: Advancing practice and research (pp. 285-299). New York: Kluwer Academic Press.

Fallowfield, L. (1990). The quality of life: The missing measurement in health care. London: Souvenir Press.

Farrell, A. D., Valois, R. F., Meyer, A. L., \& Tidwell, R. P. (2003). Impact of the RIPP prevention program on rural middle school students. The Journal of Primary Prevention, 24, 143-167.

Frederickson, B. L. (2001). The role of positive emotions in positive psychology: The broaden-and-build theory of positive emotions. American Psychologist, 56, 218-226.

Frisch, M. B. (1999). Quality of life assessment/intervention and the Quality of Life Inventory (QOLI). In M. R. Maruish (Ed.), The use of psychological testing for treatment planning and outcome assessment (2nd ed., pp. 1227-1331). Hillsdale, NJ: Lawrence Erlbaum.

Frisch, M. B., Cornell, J., Villenueva, M., \& Retzlaff, P. J. (1992). Clinical validation of the Quality of Life Inventory: A measure of life satisfaction for use in treatment and planning outcome assessment. Psychological Assessment, 4, 92-101.

Furr, R. M., \& Funder, D. (1998). A multimodal analysis of personal negativity. Journal of Personality and Social Psychology, 74, 1580-1591.

Gilman, R., \& Barry, J. (2003). Life satisfaction and social desirability among adolescents in a residential treatment setting: Changes across time. Residential Treatment for Children and Youth, 21, 19-41.

Gilman, R., \& Handwerk, M. L. (2001). Changes in life satisfaction as a function of stay in a residential setting. Residential Treatment for Children and Youth, 18, 47-65.

Gilman, R., \& Huebner, E. S. (2000). Review of life satisfaction measures for adolescents. Behaviour Change, 17, 178-195.

Gilman, R., \& Huebner, E. S. (2003). A review of life satisfaction research with children and adolescents. School Psychology Quarterly, 18, 192-205.

Greenspoon, P. J., \& Saklofske, D. H. (1998). Confirmatory factor analysis of the Mulitidmensional Students' Life Satisfaction Scale. Personality and Individual Differences, 25, 965-971.

Greenspoon, P. J., \& Saklofske, D. H. (2001). Toward an integration of subjective well-being and psychopathology. Social Indicators Research, 54, 81-108.

Hales, D. (1996, August 18). How teenagers see things. Parade Magazine, pp. 4-5.

Hoge, R. (1999). Assessing adolescents in educational, counseling, and other settings. Mahwah, NJ: Lawrence Erlbaum. 
Holcomb, W. R., Parker, J. C., \& Leong, G. B. (1997). Outcomes of inpatients treated on a VA psychiatric unit and a substance abuse treatment unit. Psychiatric Services, 48, 699-704.

Holcomb, W. R., Parker, J. C., Leong, G. B., Thiele, J., \& Higdon, J. (1998). Customer satisfaction and selfreported treatment outcomes among psychiatric inpatients. Psychiatric Services, 49, 929-934.

Huebner, E. S. (1991). Initial development of the Students' Life Satisfaction Scale. School Psychology International, $12,231-240$

Huebner, E. S. (1994). Preliminary development and validation of a multidimensional life satisfaction scale for children. Psychological Assessment, 6, 149-158.

Huebner, E. S., \& Alderman, G. L. (1993). Convergent and discriminant validation of a children's life satisfaction scale: Its relationship to self- and teacher-reported psychological problems and school functioning. Social Indicators Research, 30, 71-82.

Huebner, E. S., Brantley, A., Nagle, R. J., \& Valois, R. F. (2002). Correspondence between parent and adolescent ratings of life satisfaction for adolescents with and without mental disabilities. Journal of Psychoeducational Assessment, 20, 20-29.

Huebner, E. S., Laughlin, J. E., Ash, C., \& Gilman, R. (1998). Further validation of the Multidimensional Students' Life Satisfaction Scale. Journal of Psychoeducational Assessment, 16, 118-134.

Huebner, E. S., Suldo, S. M., Smith, L. C., \& McKnight, C. (2004). Life satisfaction in children and youth: Empirical foundations and implications for school psychologists. Psychology in the Schools, 41, 81-93.

Jenkins, C. D. (1992). Assessment of outcomes in health intervention. Social Science and Medicine, 35, 367-375.

Jenson, W. R., Olympia, D., Farley, M., \& Clark, E. (2004). Positive psychology and externalizing students in a sea of negativity. Psychology in the Schools, 41, 67-80.

Kazdin, A. E. (1993). Treatment of conduct disorder: Progress and directions in psychotherapy research. Development and Psychopathology, 5, 277-310.

Keith, K. D., \& Schalock, R. L. (1995). Quality of Student Life Questionnaire. Worthington, OH: IDS.

Lopez, S. J., Snyder, C. R., \& Rasmussen, H. N. (2003). Striking a vital balance: Developing a complementary focus on human weakness and strength through positive psychological assessment. In S. J. Lopez \& C. R. Snyder (Eds.), Positive psychological assessment: A handbook of models and methods (pp. 3-20). Washington, DC: American Psychological Association.

McKnight, C. G., Huebner, E. S., \& Suldo, S. M. (2002). Relationships among stressful life events, temperament, problem behavior, and global life satisfaction in adolescents. Psychology in the Schools, 39, 677-687.

Moore, K. A., Brown, B. V., \& Scarupa, M. S. (2003). The uses (and misuses) of social indicators: Implications for public policy. Child Trends Research Brief, Publication \#2003-01. Washington, DC: Child Trends.

Raphael, D., Brown, I., Renwick, R., \& Rootman, I. (1997). Quality of life: What are the implications for health promotion? American Journal of Health Behavior, 21, 118-128.

Raphael, D., Rukholm, E., Brown, I., Hill-Bailey, P., \& Donato, E. (1996). The Quality of Life Profile-Adolescent Version: Background, description, and initial validation. Journal of Adolescent Health, 19, 366-375.

Rhee, S., Furlong, M. J., Turner, J. A., \& Harari, I. (2001). Integrating strengths-based assessment perspectives in psychoeducational evaluations. The California School Psychologist, 6, 5-17.

Schalock, R. L., Keith, K. D., Hoffman, K., \& Karan, O. C. (1989). Quality of life, its measurement, and use in human service programs. Mental Retardation, 27, 25-31.

Seeman, J. (1989). Towards a model of positive health. American Psychologist, 44, 1099-1109.

Seligman, M. E. P., \& Csikszentmihalyi, M. (2000). Positive psychology: An introduction. American Psychologist, $55,5-14$.

Seligson, J., Huebner, E. S., \& Valois, R. F. (2003). Preliminary validation of the Brief Multidimensional Students' Life Satisfaction Scale. Social Indicators Research, 61, 121-145.

Suldo, S. M., \& Huebner, E. S. (2004a). The role of life satisfaction in the relationship between parenting styles and adolescent problem behavior. Social Indicators Research, 66, 3-33.

Suldo, S. M, \& Huebner, E. S. (2004b). Does life satisfaction moderate the effects of stressful life events on psychopathological behavior in adolescence? School Psychology Quarterly, 19, 93-105.

Watson, S. M., \& Keith, K. D. (2002). Comparing the quality of life of school-age children with and without disabilities. Mental Retardation, 40, 304-312. 
The California School Psychologist, Vol. 9, pp. 135-144, 2004 Copyright 2004 California Association of School Psychologists

\title{
Dropout and Violence Needs Assessment: A Follow-up Study
}

\author{
Aimee P. Miltich, Mary Helen Hunt, Joel Meyers \\ Georgia State University
}

\begin{abstract}
The current study investigated a needs assessment survey designed to measure perceptions of causes of dropout and school violence and related interventions. The needs assessment was conceptualized as a first step to be taken by schools to facilitate program planning, school-based implementation and acceptability of programs designed to prevent school violence and dropout. The research reported in this paper is a follow-up to a recently published comprehensive needs assessment regarding the prevention of school dropout and violence. Results compare survey administration in Michigan with the original sample in Georgia. The revised instrument was administered to a school district in Michigan, and the results supported the five-factor model proposed in the initial research. Those factors include: School Connectedness, Causes of Disruptive of Violent Behavior, Causes of School Disengagement/Dropout, Interventions for Violence and Interventions for Dropout. This article considers implications for future use of adapted versions of this needs assessment surveys in developing effective preventive interventions.
\end{abstract}

Keywords: Needs Assessment, Consultation, School Violence, Dropout

School violence and dropout are critical issues in today's schools. National attention has focused on violence prevention, as well as on school success (No Child Left Behind Act, 2001). School personnel are increasingly being called upon to prevent problems by arranging, implementing and evaluating preventive activities in the schools (Meyers \& Nastasi, 1999). Ecological models and prior research show that violence and dropout are long-term processes involving multiple levels of influence (Bronfenbrenner, 1989; Coie, Lochman, Terry, \& Hyman, 1992; Finn, 1993; Grannis, 1991; Tolan \& Guerra, 1994). The literature on violence and dropout prevention indicates considerable overlap regarding the factors contributing to these problems and recommendations for interventions (Frick et al., 1991; Hinshaw, 1992). Hunt, Meyers, Davies, Meyers, and Grogg (2002) thoroughly reviewed factors related to both dropout and school violence. Analysis of the factors cited in the literature, as well as results from the comprehensive needs assessment survey provided support for conceptualizing these factors together in research and practice. According to these authors, the following factors appear to be risk factors for both school violence and school dropout: lack of school connectedness or interest, withdrawal from social networks, academic difficulties, poor peer relations, behavior problems, and low SES (Hunt et al., 2002). Therefore, schools need to develop interventions that address these issues simultaneously.

An essential component of program planning for violence prevention in schools is conducting a needs assessment to obtain perceptions from students, parents, and employees (e.g., Furlong, Morrison, Chung, Bates, \& Morrison, 1997; Meyers \& Nastasi, 1999). Preventive interventions that include input from participants are likely to have higher treatment acceptability (Elliott, Witt, \& Kratochwill, 1991; Truscott, Cosgrove, Meyers, \& Eidle-Barkman, 2000). Collecting information from participants is key to forecasting an intervention's acceptability, integrity and longevity (Fullan, 1991). Therefore, the present study investigates a needs assessment survey focused on school violence and dropout that

Address correspondence to Aimee P. Miltich; 1656 Emory Place Drive; Atlanta, GA 30329.

E-mail: miltich@mindspring.com. 
builds on a previously developed needs assessment survey (Hunt et al., 2002). The survey gathers information about school staff perceptions regarding causes and interventions for school dropout and violence.

The original survey was constructed based on qualitative interviews. Interview questions were derived from the literature on school violence (Patterson, DeBaryshe, \& Ramsey, 1989; Tolan \& Guerra, 1994), literature on dropout (Sinclair, Christenson, Evelo, \& Hurley, 1998) and input from key informants from the school district. Survey questions were created based on themes derived from the interview data. This survey was administered to school staff in the district where the interviews took place. This survey consisted of 84 Likert-type items on a 5-point scale. Data gathered from returned surveys (59\% return rate) were analyzed quantitatively. Results of a principal component analysis indicated a 5-factor structure. The five factors were: school connectedness/positive school climate, causes of violence, causes of school dropout, interventions for dropout, and interventions for violence. The survey was then revised based on the principal component analysis. Items that did not load significantly on any factor were eliminated. This resulted in a proposed survey with 54 items. Four additional items were demographic in nature. The results of this survey indicated that there was high agreement among the participants across the items. Findings showed that the perceptions of the school personnel generally reflected the risk factors cited in the literature (Hunt et al., 2002).

\section{The Current Study}

Using the original survey as a basis, the current survey was further developed through collaborative action research methods (Greenwood, Whyte, \& Harkavy, 1993; Nastasi et al., 2000). According to collaborative action research methodologies, the use of key stakeholders (i.e., school personnel) throughout the process of intervention development leads to interventions that have increased cultural specificity and potential for longevity (Nastasi, Varjas, Schensul et al., 2000). Similarly, participatory action research methods utilize key stakeholders to bridge the gap between suggested research and acceptable applied practices (Ho, 2002). Thus, recent research highlights the importance of including participant input in the design and implementation of interventions.

This follow-up study is designed to contribute to the literature by addressing three basic questions:

1. How do school employees in this sample view the importance of the items reflecting the following areas of drop out and violence research: school connectedness, causes of disruptive or violent behavior, causes of school disengagement/dropout, interventions for violence and interventions for dropout?

2. How do responses to this revised survey administered in Michigan compare to district responses on the original survey that was administered in Georgia?

3. What are the practical implications and uses of this needs assessment survey?

\section{METHOD}

\section{Participants}

Data were gathered district-wide in a small city school system in Michigan. The district has approximately 750 employees housed in two elementary schools grades K-6, two elementary schools grades K-3, two elementary schools grades 4-6, one middle school grades 7-8, and one high school grades 9-12. The district also has central administration, transportation, maintenance and Head Start 
buildings. The district superintendent and central administrative staff agreed to work collaboratively with the researcher to collect survey data. Data were collected from all school personnel. Both the original survey sample (from Georgia) and the Michigan sample included certified and non-certified school employees. The districts were also similar in student enrollment (approximately 4000 in the Georgia sample, and 6,500 in Michigan). The districts differed in student ethnic demographics. The Georgia student population was approximately one-third Hispanic, one-third African American and one-third European American. Student demographics of the Michigan sample included approximately 50\% African American, 45\% European American and 5\% Hispanic American.

\section{Procedure}

The current needs assessment survey was also conducted using collaborative action research methods. The superintendent met with the researcher to review the original survey and to negotiate survey administration. In additional meetings, the superintendent met with principals and central administrative staff to review the survey and make recommendations for adaptation of items. Finally, the researcher met with the superintendent and central administrative staff to finalize the survey based on their feedback. This collaboration is in line with participatory action research and helps to increase cultural specificity and acceptability (Ho, 2002; Nastasi et al., 2000). The final survey had 60 items, four of which were demographic in nature.

Surveys were distributed district-wide to all employees. All employees were included at the request of district administration in order to obtain perceptions that accurately reflected employee opinions. A total of 385 surveys were completed for a return rate of $51 \%$. The employees participating in the survey included school personnel such as teachers, teacher assistants, counselors, school specialists, administrative staff, clerical staff, cafeteria employees, and bus drivers. Reminders to complete and return surveys were left to the discretion of the building administrator. An administrator for each building served as the contact person for the research project. Surveys were collected in boxes beside staff mailboxes.

\section{Analyses}

Survey data were analyzed by assigning each response a point value from 1 to $5(1=$ not at all important, 2 = slightly important, $3=$ moderately important, $4=$ important, $5=$ very important $)$. The breakdown of respondents by school was as follows: $57 \%$ of the respondents were from the elementary schools, $15 \%$ from the middle school, $16 \%$ from the high school, and $11 \%$ from the administrative, transportation, maintenance and Head Start buildings or from personnel serving more than one school. Approximately $77 \%$ of the respondents were female, and $18 \%$ male (18 respondents omitted this question). Approximately $79 \%$ of the respondents were Caucasian, 5\% African American, 3\% Hispanic, 1\% Asian American, and 6\% Other (22 respondents omitted this question).

\section{RESULTS}

The results are presented in three sections. First, Michigan survey results are reported in five areas: school connectedness, causes of disruptive or violent behavior, causes of school disengagement/ dropout, interventions for violence and interventions for dropout. These five areas correspond to the five factors derived from the original survey. Second, current survey results are compared to the original sample from Georgia. The third section presents the principal components analysis from the Michigan survey results to provide more information about the factor structure of the scale. 


\section{Survey Factor Results}

A complete list of mean scores for all items is included in Table 1. There was generally high agreement among participants that the survey items were viewed as important (see Table 1). The most highly rated items are discussed for each factor, as well any items whose overall mean was less than 3.5. This cut-off was selected because it reflects any items that were rated by participants as less than "important" (i.e., moderately important $=3$, important $=4$, and very important $=5$ ). This cut-off was also selected because it was used in the previous study (Hunt et al., 2002) and allowed for comparison of results across studies.

Table 1.

Comparison of District-Wide Means of Individual Items for Each Scale

\begin{tabular}{|c|c|c|c|c|}
\hline & \multicolumn{2}{|c|}{$\underline{\text { GA }}$} & \multicolumn{2}{|c|}{ MI } \\
\hline & $M$ & $S D$ & $M$ & $S D$ \\
\hline \multicolumn{5}{|l|}{ Factor I-School Connectedness/Positive School Climate } \\
\hline Student feels that someone really cares for them & 4.79 & .50 & 4.74 & .51 \\
\hline Student had an adult at school they can go to with a problem & 4.66 & .61 & 4.52 & .67 \\
\hline Strong positive relationships with an educator & 4.47 & .72 & 4.50 & .65 \\
\hline Caring teacher attitude & 4.80 & .50 & 4.74 & .49 \\
\hline Friendly, positive school climate & 4.60 & .64 & 4.55 & .61 \\
\hline Teach conflict resolution & 4.36 & .84 & 4.12 & .83 \\
\hline Emotional support & 4.41 & .77 & 4.37 & .73 \\
\hline Teach problem solving skills & 4.36 & .76 & 4.12 & .85 \\
\hline Student has someone they can look up to & 4.52 & .73 & 4.36 & .73 \\
\hline Student feels safe at school & 4.69 & .57 & 4.52 & 67 \\
\hline Teacher shows interest in students' activities outside of school & 3.87 & .95 & 3.87 & .88 \\
\hline Individual teacher/student time & 4.23 & .86 & 4.14 & .84 \\
\hline Increase motivation & 4.69 & .56 & 4.43 & .69 \\
\hline Rewarding positive behavior & 4.23 & .93 & 3.95 & .98 \\
\hline Teacher contact with parents & 4.48 & 69 & 4.33 & .75 \\
\hline \multicolumn{5}{|l|}{ Factor II - Causes of Disruptive or Violent Behavior } \\
\hline Disrespect for peers & 4.23 & .85 & 4.10 & .92 \\
\hline Disrespect for authority & 4.60 & .72 & 4.49 & .75 \\
\hline Lack of involvement in school activities & 3.65 & 1.07 & 3.67 & 1.03 \\
\hline Poor anger management skills & 4.31 & .85 & 4.40 & .81 \\
\hline Emotional immaturity & 4.08 & .91 & 3.90 & .97 \\
\hline Gangs & 3.90 & 1.32 & 3.20 & 1.38 \\
\hline Children with behavior disorders & 4.00 & 1.07 & 4.01 & .94 \\
\hline Lack of role models in the community & 3.69 & 1.07 & 3.70 & 1.16 \\
\hline Drug use & 3.74 & 1.44 & 3.38 & 1.39 \\
\hline Cliques or groups of children & 3.71 & 1.05 & 3.67 & .98 \\
\hline Racial or ethnic differences & 3.36 & 1.23 & 2.72 & 1.08 \\
\hline Lack of academic interest & 4.18 & .89 & 4.15 & .90 \\
\hline Peer pressure & 4.06 & 1.01 & 3.91 & .99 \\
\hline
\end{tabular}


Table 1 continued.

Comparison of District-Wide Means of Individual Items for Each Scale

\begin{tabular}{lrrrr}
\hline & & & & \\
Parent support/involvement & 4.38 & .93 & 4.50 & .80 \\
Media (radio, TV, news, movies, sports) & 3.85 & 1.14 & 3.61 & 1.08 \\
& & & & \\
Factor III - Causes of School Disengagement/Drop Out & & & & \\
Student is an ethnic minority & 2.65 & 1.28 & 2.36 & 1.09 \\
Student has been retained & 3.22 & 1.16 & 3.16 & 1.15 \\
Socioeconomic status & 2.88 & 1.12 & 3.10 & 1.00 \\
Academic success & 4.36 & .65 & 4.53 & .64 \\
English language proficiency & 3.89 & .95 & 3.97 & .91 \\
Student with a disability & 2.92 & 1.15 & 2.96 & 1.12 \\
Lack of support for slow learners & 3.50 & 1.29 & 3.99 & 1.00 \\
Early reading achievement & 4.32 & .77 & 4.51 & .73 \\
Lack of self-esteem or confidence & 4.09 & .98 & 4.36 & .89 \\
& & & & \\
Factor IV - Interventions for Disruptive or Violent Behavior & & & & \\
In or out of school suspension & 4.15 & 1.02 & 2.98 & 1.09 \\
Juvenile court & 3.79 & 1.21 & 2.90 & 1.16 \\
Utilizing district support personnel (i.e., social worker, school & 4.06 & 1.07 & 3.70 & .93 \\
psychologist, etc.) & & & & \\
Punishment or consequences & 4.49 & 1.05 & 3.60 & 1.05 \\
School working with law enforcement & 4.19 & .96 & 3.71 & 1.02 \\
Opportunity/time-out room & 4.00 & 1.13 & 3.49 & 1.14 \\
Parent contact, phone calls or conferences & 4.55 & .78 & 3.79 & .89 \\
Behavior contracts & 3.68 & 1.07 & 3.13 & 1.02 \\
& & & & \\
Items added to MI survey & & & & \\
Lunchtime recess alternatives & na & na & 3.29 & 1.10 \\
Connecting students with community services & na & na & 3.59 & .94 \\
Peer mediation & na & na & 3.16 & 1.03 \\
Use of behavior intervention specialist & na & na & 3.52 & 1.01 \\
Child Study Teams & na & na & 3.15 & 1.03 \\
& & & & \\
Factor V - Interventions for Dropout & & & & \\
A mentoring program & 4.14 & .91 & 3.97 & .88 \\
After school academic help & 4.25 & .88 & 3.60 & .98 \\
Role models & 4.61 & .62 & 4.29 & .83 \\
A parent resource center/family education & 3.91 & 1.01 & 3.76 & .99 \\
Parent support groups & 3.88 & .99 & 3.61 & 1.01 \\
Expand vocational training programs & 4.22 & .83 & 4.06 & .88 \\
After school programs, sports or clubs & 4.29 & .78 & 3.96 & .96 \\
\hline & & & &
\end{tabular}


School connectedness. Educators were asked to rate ways that help students feel connected to school and to teachers. The two items that were rated as most important included: caring teacher attitude $(M=4.74, S D=.49)$ and student feels someone really cares for them $(M=4.74, S D=.49)$. None of the items from this area of the survey were rated below 3.5.

Causes of disruptive or violent behavior. Participants were asked to rate the importance of certain items as they contribute to disruptive or violent behavior in school. The two items that were rated as most important included: lack of parent support/involvement $(M=4.50, S D=.80)$ and disrespect for authority $(M=4.49, S D=.75)$. Three items from this area of the survey were rated as relatively less important (i.e., 3.5 or below). These items were: racial and ethnic differences $(M=2.72, S D=1.08)$, drug use $(M=3.38, S D=1.39)$, and gangs $(M=3.20, S D=1.38)$.

Causes of school disengagement/dropout. Participants were asked to rate the importance of items as they contribute to school disengagement/school dropout. Academic success $(M=4.53, S D=.64)$ and early reading achievement $(M=4.51, S D=.73)$ were the items rated as most important. Three items in this factor were rated as less than important (i.e., $M<3.5)$ : student is an ethnic minority $(M=$ $2.36, S D=1.09)$, socioeconomic status $(M=3.10, S D=1.00)$, and student has been retained $(M=3.16$, $S D=1.15)$.

Interventions for violence. The two interventions rated as most important for reducing disruptive and violent behavior included: parent contact, phone calls or conferences $(M=3.79, S D=.89)$, and schools working with law enforcement $(M=3.71, S D=1.02)$. Three items in this factor were rated as less than important: in or out of school suspension $(M=2.98, S D=1.09)$, juvenile court $(M=2.90, S D$ $=1.16)$, and behavioral contracts $(M=3.13, S D=1.02)$.

Interventions for dropout. The following items were viewed as particularly important issue with an influence on whether children dropout of school: role models $(M=4.29, S D=.83)$ and expanded vocational programs $(M=4.06, S D=.88)$. No items in the factor had a mean rating below 3.5 .

\section{Comparison of Michigan Survey Results to Georgia Survey Results}

The return rate for the survey in Michigan (51\%) was comparable to the return rate for the Georgia sample (59\%). Response ratings of the current survey were very similar when means and standard deviations were compared with the original sample (see Table 1). In fact, only one item differed by more than a standard deviation between the two samples. This item was listed in factor four, interventions for disruptive or violent behavior, in or out of school suspension (GA $M=4.15$ vs. MI $M=2.98$ ).

\section{Principal Components Analysis of the Michigan Survey}

Data were analyzed using a principal components analysis to learn more about the factor structure and item loadings of this revision of the needs assessment survey. Initially all items were included in a principal components analysis using a varimax rotation. A scree test supported a 5-factor solution, which was similar to the factor solution of the previously proposed survey. An additional principal components analysis was conducted forcing the items into a 5-factor solution. Five items that did not load on any of the factors at .40 or above were eliminated. The principal components analysis was conducted again using the remaining items. Results of this analysis resulted in $46 \%$ of the total variance accounted for by the remaining 51 items. This is consistent with the previously proposed survey's total variance accounted (44\%) for by the 5 -factor solution. Table 2 provides a comparison of factors, items in each factor and factor loadings for the items for both the Michigan and Georgia samples. An analysis of factor content revealed the same items on both administrations. Exceptions were items that were added by the Michigan district as a result of consultation prior to the survey administration. Items within the factors showed equally strong factor loadings between the two samples. The School Connectedness factor accounted for the most variance on both administrations. 
Table 2.

Comparison of Needs Assessment Surveys by Administration and Factor Loadings

GA Loading MI Loading

Factor I-School Connectedness/Positive School Climate

$\begin{array}{lll}\text { Student feels that someone really cares for them } & .80 & .74\end{array}$

$\begin{array}{lll}\text { Student had an adult at school they can go to with a problem } & .79 & .74\end{array}$

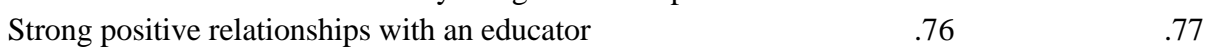

$\begin{array}{lll}\text { Caring teacher attitude } & .69 & .65\end{array}$

Friendly, positive school climate $\quad .67 \quad .66$

$\begin{array}{lll}\text { Teach conflict resolution } & .62 & .52\end{array}$

$\begin{array}{lll}\text { Emotional support } & .61 & .68\end{array}$

$\begin{array}{lll}\text { Teach problem solving skills } & .54 & .55\end{array}$

Student has someone they can look up to $\quad .58 \quad .75$

Student feels safe at school $\quad .54 \quad .55$

Teacher shows interest in students' activities outside of school $\quad .54 \quad .61$

Individual teacher/student time $\quad .49 \quad .56$

Increase motivation $\quad .46 \quad .51$

Rewarding positive behavior $\quad .45 \quad .40$

$\begin{array}{lll}\text { Teacher contact with parents } & .43\end{array}$

Factor II - Causes of Disruptive or Violent Behavior

Disrespect for peers $\quad .72$

.73

$\begin{array}{lll}\text { Disrespect for authority } & .65 & .64\end{array}$

$\begin{array}{lll}\text { Lack of involvement in school activities } & .59\end{array}$

Poor anger management skills $\quad .58 \quad .61$

Emotional immaturity $\quad .57 \quad .62$

Gangs $\quad .54 \quad .57$

Children with behavior disorders $\quad .54<.40$

Lack of role models in the community $\quad .53 \quad .52$

$\begin{array}{lll}\text { Drug use } & .51 & .54\end{array}$

Cliques or groups of children $\quad .50 \quad .63$

Racial or ethnic differences $\quad .50<.40$

$\begin{array}{lll}\text { Lack of academic interest } & .50 & .71\end{array}$

$\begin{array}{lll}\text { Peer pressure } & .46 & .51\end{array}$

$\begin{array}{lll}\text { Parent support/involvement } & .45\end{array}$

Media (radio, TV, news, movies, sports) $\quad .42 \quad .57$

Factor III - Causes of School Disengagement/Dropout

Student is an ethnic minority $\quad .69 \quad 67$

$\begin{array}{lll}\text { Student has been retained } & .65 & .68\end{array}$

$\begin{array}{lll}\text { Socioeconomic status } & .55\end{array}$

Academic success $\quad .53 \quad<.40$

$\begin{array}{lll}\text { English language proficiency } & .52 & .48\end{array}$

$\begin{array}{lll}\text { Student with a disability } & .52 & .67\end{array}$ 
Table 2 continued.

\begin{tabular}{|c|c|c|}
\hline Lack of support for slow learners & .48 & $<.40$ \\
\hline Early reading achievement & .48 & $<.40$ \\
\hline Lack of self-esteem or confidence & .41 & $<.40$ \\
\hline \multicolumn{3}{|l|}{ Factor IV - Interventions for Disruptive or Violent Behavior } \\
\hline In or out of school suspension & .71 & .42 \\
\hline Juvenile court & .61 & .58 \\
\hline $\begin{array}{l}\text { Utilizing district support personnel (i.e., social worker, school } \\
\text { psychologist, etc.) }\end{array}$ & .60 & .60 \\
\hline Punishment or consequences & .59 & $<.40$ \\
\hline School working with law enforcement & .59 & .59 \\
\hline Opportunity/time-out room & .56 & .52 \\
\hline Parent contact, phone calls or conferences & .54 & .50 \\
\hline Behavior contracts & .47 & .66 \\
\hline \multicolumn{3}{|l|}{ Items added to MI survey } \\
\hline Lunchtime recess alternatives & na & .54 \\
\hline Connecting students with community services & na & .58 \\
\hline Peer mediation & na & .58 \\
\hline Use of behavior intervention specialist & na & .60 \\
\hline Child Study Teams & na & .66 \\
\hline \multicolumn{3}{|l|}{ Factor V-Interventions for Drop out } \\
\hline A mentoring program & .57 & .75 \\
\hline After school academic help & .51 & .69 \\
\hline Role models & .51 & .60 \\
\hline A parent resource center/family education & .48 & .68 \\
\hline Parent support groups & .47 & .64 \\
\hline Expand vocational training programs & .47 & $<.40$ \\
\hline After school programs, sports or clubs & .35 & .58 \\
\hline
\end{tabular}

\section{DISCUSSION}

Results of the current needs assessment survey indicated that school staff in this Michigan school district generally agree about causes and interventions for school dropout, causes and interventions for school violence, and ways to promote school connectedness. Similar to findings from the original study (Hunt et al., 2002), most items on the survey were rated as "important" or "very important." Further analysis of the survey using principal components analysis supported the use of a model for conceptualizing school dropout and violence that includes a mediating factor of school connectedness.

Future consultation and intervention development for dropout and violence prevention may be enhanced by the use of an adapted version of this needs assessment survey as a tool for planning intervention and promoting treatment acceptability. The survey could be adapted through participatory action research methods. That is, the survey items could be modified based on input from participants so that the data collected is most useful and meaningful. The inclusion of key stakeholders, as outlined in participatory action research methodology, may enhance treatment implementation and sustainability. 
For example, this survey could be administered to school personnel after obtaining information from key stakeholders within the district. Further, the survey could also be revised in order to collect data from other members of the school community (i.e., parents and students) as well as the local community.

The 5-factor structure has been supported and appears to be a reasonable way of conceptualizing prevention and intervention in this area. However, the recommended use of this survey is as a consultation tool. In keeping within the collaborative nature of consultation, it is at the discretion of the consultant and consultee to determine what items and factors are included.

A potentially important use of the revised needs assessment survey may be its utilization to stimulate intervention research based on input from participants. School psychologists have the training and knowledge to use this survey as a data collection step in participatory action research model as proposed by Ho (2002). In addition to data provided by the survey, results could be used as a basis for designing in-depth focus groups and member checking meetings. In this manner, the survey is a tool in the recursive process of intervention development and relationship building between the researchers and school personnel. Previous research highlights the importance of participant input in designing interventions with high treatment acceptability (Ho, 2002; Truscott et al., 2000). Interventions with high treatment acceptability are more likely to be sustained (Kazdin, 1980). Thus, the process of participatory action research model allows the school psychologist to make a best fit between school district culture and available interventions. Consideration of empirically validated interventions and their subsequent acceptability by educators is an important aspect of effective consultation. Consultation is an important role for school psychologists and one way for role expansion (Gutkin \& Curtis, 1999).

A limitation in this study is that it does not include perceptions from parents and students. Eliciting perceptions from these groups would enrich future data collection in this area. Obtaining perceptions from multiple sources allows for the triangulation of data and may supply researchers with more support that the collected data is valid and applicable across groups (Lincoln \& Guba, 1985). Inclusion of parent, teacher and student perceptions have important implications for developing effective intervention programs because these groups may have differing viewpoints. Considering the needs and opinions of these groups may increase the acceptability and sustainability of system-wide interventions. In addition, replication of the survey in different areas of the country, including California, would provide information and opportunity for comparison of perceptions across geographical regions.

Another limitation of the current study is that the responses were combined across levels (elementary, secondary, administrative, and non-classified) due to the small sample size. In the future, analysis of potential differences between these groups could provide useful information for intervention planning.

Results indicated that sometimes there is a discrepancy between educator perceptions of factors related to dropout and school violence and empirical data. For example, school staff in this sample did not perceive grade retention and low socioeconomic status as significant risk factors for school dropout. However, literature suggests these factors are related to school dropout (Kortering, Hess, \& Braziel, 1997). This suggests the need for staff training on these topics. Educators with a solid understanding of risk factors for dropout and violence are in a better position to help design and implement interventions in these areas.

The measurement of staff perceptions of factors related to school dropout and violence is an important component of designing interventions with high treatment acceptability. However, this does not suggest that interventions should be based solely on staff perceptions. Ultimately, researchers should consider staff perceptions in combination with empirically validated interventions for dropout 
and violence prevention when developing interventions. Use of data generated by the survey in combination with knowledge of validated intervention programs allows for the development of interventions with high treatment acceptability and efficacy.

\section{REFERENCES}

Bronfenbrenner, U. (1989). Ecological systems theory. In R. Vasta (Ed.), Annals of child development (Vol. 6, pp. 187-249). Greenwich, CT: JAI Press.

Coie, J. D. Lochman, J. E., Terry, R., \& Hyman, C. (1992). Predicting early adolescent disorder from childhood aggression and peer rejection. Journal of Consulting and Clinical Psychology, 60, 783-792.

Elliott, S. N., Witt, J. C., \& Kratochwill, T. R. (1991). Selecting, implementing, and evaluating classroom interventions. In G. Stoner, M. R. Shinn, \& H. M. Walker (Eds.), Interventions for achievement and behavior problems (pp. 99-136). Silver Spring, MD: National Association of School Psychologists.

Finn, J. D. (1993). School engagement and students at risk. Buffalo, NY: State University, U.S. Department of Education, National Center for Educational Statistics. (ERIC Document Reproduction Service No. ED 362 322).

Frick, P., Kamphaus, R. W., Lahey, B. B., Loeber-Christ, M. G., Hart, E., \& Tannenbaum, L. E. (1991). Academic underachievement and the disruptive behavior disorders. Journal of Consulting and Clinical Psychology, 59, 289-294.

Fullan, M. G. (1991). The new meaning of educational change (2 ${ }^{\text {nd }}$ ed.). New York: Teachers College Press.

Furlong, M., Morrison, G. M., Chung, A., Bates, M., \& Morrison, R. (1997). School violence. In G. G. Bear, K. M. Minke, \& A. Thomas (Eds.) Children's needs II: Development, problems and alternatives. Bethesda, MD: National Association of School Psychologists.

Grannis, J. C. (1991). Meeting the goals of school completion. New York: ERIC Clearinghouse on Urban Education (ERIC Document Reproduction Service No. ED 334 309).

Greenwood, D. J., Whyte, W. F., \& Harkavy, I. (1993). Participatory action research as a process and as a goal. Human Relations, 46, 175-192.

Gutkin, T. B., \& Curtis, M. J. (1999). School-based consultation theory and practice: The art and science of indirect service delivery. In C. R. Reynolds \& T. B. Gutkin (Eds.), The handbook of school psychology (pp. 598-637). New York: Wiley.

Hinshaw, S. (1992). Externalizing behavior problems and academic underachievement in childhood and adolescence: Causal relationships and underlying mechanisms. Psychological Bulletin, 111, 127-155.

Ho, B. S. (2002). Application of participatory action research to family-school interventions. School Psychology Review, 31, 106-121.

Hunt, M. H., Meyers, J., Davies, G., Meyers, B., \& Grogg, K. (2002). A comprehensive needs assessment to facilitate implementation of a dropout and violence prevention program. Psychology in the Schools, 39, 399416.

Kazdin, A. E. (1980). Acceptability of alternative treatments for deviant child behavior. Journal of Applied Behavioral Analysis, 13, 259-273.

Kortering, L. J., Hess, R. S., \& Braziel, P. M. (1997). School drop out. In G. G. Bear, K. M. Minke, \& A. Thomas (Eds.). Children's needs II: Development, problems, and alternatives (pp. 511-521). Bethesda, MD: National Association of School Psychologists.

Lincoln, Y. S., \& Guba, E. G. (1985). Naturalistic inquiry. Beverly Hills, CA: Sage.

Meyers, J., \& Nastasi, B. (1999). Primary prevention in school settings. In C. Reynolds \& T. Gutkin (Eds.), The handbook of school psychology (pp. 764-799). New York: Wiley.

Nastasi, B. K., Varjas, K., Berstein, R., \& Jayasena, A. (2000). Conducting participatory culture-specific consultation: A global perspective on multicultural consultation. School Psychology Review, 29, 401-413.

Nastasti, B. K., Varjas, K., Schensul, S. L., Silva, K. T., Schensul, J. J., \& Ratnayake, P. (2000). The participatory intervention model: A framework for conceptualizing and promoting intervention acceptability. School Psychology Quarterly, 15, 207-232.

No Child Left Behind Act 2001, Pub. L. 107-110 (2001).

Patterson, G. R., DeBaryshe, B. D., \& Ramsey, E. (1989). A developmental perspective on antisocial behavior. American Psychologist, 44, 329-335.

Sinclair, M. F., Christenson, S. L., Evelo, D., \& Hurley, C. (1998). Dropout prevention for high-risk youth with disabilities: Efficacy of a sustained school engagement procedure. Exceptional Children, 65, 7-21.

Tolan, P. H., \& Guerra, N. G. (1994). What works in reducing adolescent violence: An empirical review of the field. Boulder, CO: Center for the Study and Prevention of Violence, University of Colorado.

Truscott, S. D., Cosgrove, G., Meyers, J., \& Eidle-Barkman, K. A. (2000). The acceptability of organizational consultation with prereferral intervention teams. School Psychology Quarterly, 15, 172-206. 


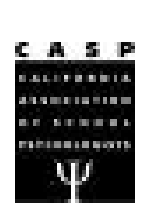

\title{
Twenty-five Years after Larry $P$.: The California Response to Overrepresentation of African Americans in Special Education
}

\author{
Kristin M. Powers, Kristi S. Hagans-Murillo \\ California State University, Long Beach \\ Alberto F. Restori \\ California State University, Northridge
}

\begin{abstract}
In this article, major laws, regulations, court cases, policies and practices related to intelligence testing of African American students in California are reviewed. A California Department of Education (CDE) ban on intelligence testing of African American students for the purpose of determining special education eligibility is in effect and enforced by Special Education Hearing Officers (SEHO) and Coordinated Compliance Reviewers (CCR). Although the CDE bases its restrictions on the results of the Larry $P$. case, we found that (a) the CDE policy runs counter to the ruling and intent of the Larry P. case; (b) overrepresentation of African Americans in special education programs continues despite the use of alternative assessment methods to measure intelligence; and (c) overrepresentation of African Americans in special education is not the result of intelligence test bias, rather, more endemic socio-political inequalities are to blame. We conclude with a discussion of three critical questions to be considered in future responses to the Larry P. court case.
\end{abstract}

Key Words: Larry P., Special Education, Intelligence Testing, Minority Overrepresentation

Intelligence testing ${ }^{1}$ of African American students for the purpose of determining special education eligibility is a politically and legally charged issue in California. While bias in intelligence testing is discussed at a national level from time to time (for example, the 1994 publication of Hernstein and Murray's The Bell Curve sparked considerable debate), only in California is administration of an intelligence test to an African American student explicitly banned by public policy. The California Department of Education (CDE) ban is based in large part on the well-known Larry P. court case. This and other related case law, state and federal laws and regulations, the state hearing officers' rulings and coordinated compliance reviews, state and district policies, and current practices in intelligence testing of African Americans in California are reviewed, followed by a summary of the literature on test bias. In this review we found that many of the policies and practices surrounding intelligence testing of African Americans in California have not achieved their purpose as evidenced by the fact that 25 years after Larry $P$. and the introduction of alternative assessment methods for determining special education eligibility, African Americans remain significantly over-represented in special education (U.S.

${ }^{1}$ Intelligence testing is a generic term used in this paper to refer to any commercially developed, widely used, and publicly scrutinized test of intelligence, cognition or aptitude. These tests include, but are not limited to, the Wechsler Intelligence Tests, Woodcock-Johnson Tests of Cognitive Abilities, and Stanford-Binet Intelligence Scale.

Address correspondence to Kristin Powers; School Psychology Program Coordinator; CSULB; Educational Psychology, Administration, and Counseling; 1250 Bellflower Blvd.; Long Beach, CA 90840-2201.

E-mail: kpowers@csulb.edu. The authors thank Thomas Kampwirth for the resources and guidance he offered in assisting with the preparation of this manuscript. We also wish to thank those who reviewed this manuscript for The California School Psychologist for providing thoughtful comments and suggestions. 
Department of Education, 2002). While the intent of these efforts is laudable, more work remains to be done to address the systemic issues surrounding overrepresentation of African American students in special education programs.

\section{LAWS, REGULATIONS, AND LITIGATION}

\section{Federal and State Laws and Regulations}

IDEA'97. The 1997 re-authorization of the Individuals with Disabilities Education Act (IDEA), like its predecessors, enumerates standards for conducting evaluations. The first standard is that tests "are selected and administered so as not to be discriminatory on a racial or cultural basis" (300.532(a)(1)(i)). Another standard requires that eligibility decisions not be based on a single test or procedure (300.532(f)). IDEA ' 97 does not ban the use of intelligence tests for determining special education eligibility of African American students.

California codes and regulations. Like IDEA, California codes and regulations require that assessments conducted for the purposes of determining eligibility be nondiscriminatory (56320(a)); based on more than one procedure or test (56320(e); 5 CCR 3030(j)(4)); and the influence of the student's culture, environment and economic status be considered (30 EC 56327(g)). California Regulations further note, "When standardized tests are considered to be invalid for a specific pupil, the discrepancy shall be measured by alternative means as specified on the assessment plan" (3030(j)(4)(B)). While this regulation specifically applies to diagnosing Learning Disabilities (LD), it illustrates best practices in assessment regardless of the suspected disability. While Larry P. was ostensibly about assessing students for placement in Educable Mental Retardation (EMR) programs, current state education code focuses on bias in testing for identifying LD. This likely reflects the shift over the past 20 years in identifying fewer students for the category of mental retardation (MR) and greater numbers for the category of LD (National Research Council, 2002).

\section{Case Law}

Larry P. v. Riles. The 1979 Larry P. decision declared that intelligence tests should not be used to qualify African American students for EMR classes or their substantial equivalent. While this finding has become almost legendary, less attention has been devoted to Judge Peckham's other findings, which include EMR programs are primarily "dead-end" programs and the State Board of Education should conduct a review process for approving intelligence tests for use in determining special education eligibility. The State Board of Education review was never conducted, thus, there are no CDE approved assessments of African American students' intelligence (Lopez, 2001). In 1986, the court expanded the injunction on intelligence tests from banning their use in placing African American students in EMR programs to determining eligibility of African American students for all special education programs. Thus, Larry $P$. was extended to:

the complete prohibition against using intelligence tests for identifying or placing Black pupils in special education....and IQ tests may not be given to a Black pupil even with parental consent. Moreover, when a school district receives records containing test protocols from other agencies...IQ scores contained in the records shall not become a part of the pupil's current school record. There are no special education related purposes for which IQ tests shall be administered to Black students (Larry P., 1986, p. 4, as cited in Reschly, 1997).

Crawford v. Honig. This suit brought by a group of African American students in 1992 challenged the 1986 expansion of the Larry P. injunction on intelligence testing to all special education eligibility decisions. The plaintiffs requested that intelligence tests be allowed for determining the eligibility of 

2003; Student v. Lemon Grove Elementary School District, 1998; Student v. Los Angeles Unified School District, 2002; Student v. Manteca Unified School District, 2001); one exception is Student v. Temecula Valley Unified School District (2001) in which the African American plaintiff requested compensatory education due to an inappropriate diagnosis of MR. Though an exhaustive review of all of the relevant SEHO cases was not conducted, the randomly selected cases we examined suggest that contrary to Larry P. v. Riles, African Americans are currently fighting to get their children into rather than out of special education programs.

Meanwhile, California school psychologists struggle to determine legally permitted assessment practices in the face of Hearing Officers' inconsistent decisions. For example, the Hearing Officer in Student v. South Pasadena Unified School District (2003) prohibited the NVIT because the Larry P. Task Force had recommended that the NVIT be banned but approved the other tests the district planned to administer including the Matrix Analogies Test (MAT). Yet, in Student v. Temecula Valley Unified School District (2001) the hearing officer found "that the MAT is a standardized test of intelligence within the scope of Larry P." (p. 15) and the district's assessment was inappropriate because the MAT was a racially discriminatory test. In short, the MAT was determined to be acceptable in the South Pasadena case but not in the Temecula Valley case.

\section{Summary of the Legal Standing of Larry P. v. Riles}

Case law prohibits administration of an IQ test to African Americans to determine eligibility for EMR or the substantial equivalent of an EMR program. Since EMR programs are now obsolete and the definition of "substantial equivalent" has not been established, the application of the 1979 ruling to determining eligibility for current special education programs is questionable. In 1992, the CDE issued a legal advisory that defined "substantially equivalent" programs to include those in which (a) students typically do not receive the regular curriculum and fall further and further behind students in regular classes, (b) fewer than $20 \%$ of students are returned to the regular classroom, and (c) African Americans are disproportionately represented (Zolotar, 1992). This CDE interpretation of Crawford $v$. Honig would define many special education programs in California as "substantially equivalent" or "dead-end." The California Association of School Psychologists (CASP) vehemently opposed the CDE interpretation arguing that it ran "counter to both Judge Peckham's decision and its intent," (p. 1) noting that since the courts had not established a definition for "substantial equivalent" programs the CDE's legal advisory was inaccurate and misleading (Henry, 1992). Despite the concerns raised by CASP, the CDE proceeded to ban intelligence testing of African Americans referred for special education though the legal basis for this action is questionable.

\section{PUBLIC POLICY}

\section{California Department of Education Policy}

The most current CDE policy on intelligence testing of African American students was articulated in a 1997 memo crafted by Leo Sandoval who was the Assistant Superintendent of Public Instruction, Director of Special Education Division at that time. In this memorandum, Mr. Sandoval acknowledged that the review process for the approval of standardized intelligence tests with African American students had not yet been conducted and attempted to "clear-up the confusion regarding implementation of the court rulings prohibiting the administration of standardized intelligence tests to African American students for special education eligibility"(p. 1). However, his memorandum contributes to the confusion rather than elucidates the issues. In one paragraph he stated, "I am instructing consultants who will be conducting Coordinated Compliance Reviews (CCR) to limit non-compliance findings to 
those tests specifically listed as prohibited in the 1979 court decision or the 1989 Task Force report " (p. 1). Yet he concluded with "Please keep in mind that no tests or measures of standardized intelligence or IQ should be used for the purpose of assessing African American students' eligibility for special education even if it does not appear on any of the lists provided in the attachment"(p. 2). These two contradictory statements leave the reader with little guidance on identifying the CDE sanctioned method for assessing African American students for special education eligibility.

State policy has been enforced primarily through CCRs conducted by state consultants. Lopez (2001) reported that, both before and after the release of the1997 CDE memorandum, CCR consultants were offering idiosyncratic "on-the-spot" opinions about the adequacy of administering a specific test to an African American student. Thus, districts are vulnerable to being found non-compliant in their assessment of African American students regardless of their best intentions. This vulnerability to being capriciously penalized for assessment practices is not surprising given a State policy that is explicit, albeit contradictory, on what not to do but offers little in terms of approved practices. Further research is needed to determine the scope and variability of the non-compliance penalties applied to California districts for their assessment of African American students.

\section{District Policy}

Districts have responded to federal and state laws and regulations, case law, SEHO rulings, and CDE policies on intellectual assessment of African American students for special education eligibility in a variety of ways. Some have developed lists of "alternative assessments." These alternative assessments often comprise a battery of processing tests and achievement subtests that are not designed to provide a general intelligence score. For example, Totton's (2000) recommended "alternative assessment" battery contains four processing tests, subtests from two achievement tests, an adaptive test, and the Southern California Ordinal Scales, though how the results of these varied tests are to be combined to create an estimate of general intelligence required for determining eligibility under LD or MR criteria is unclear. Significant limitations to using this and similar batteries of tests include the administration of tests psychometrically inferior to standardized tests of intelligence and a non-theoretical, hodgepodge assessment of intelligence. Furthermore, the diagnosis for LD requires a discrepancy between intelligence and achievement caused by one or more of the basic psychological processes (California Education Regulations, Title 5, Section 3030 5CCR (j)a). Therefore, the use of processing tests or subtests of achievement batteries to derive cognitive ability obfuscates the assumed distinction between intelligence, achievement, and processing.

Some districts, such as Long Beach Unified School District, avoid the practice of replacing standardized tests of intelligence with standardized tests of processing or achievement by using interview, observation, and classroom work samples to estimate cognitive abilities (Long Beach Unified School District, 2002). Under this model, a psychologist would rule out developmental delays if the data suggested average abilities, and deduce that the disability causing academic failure must therefore be LD. In fact, there is support for this logic in California Education Regulations, Title 5, Section 3030 5CCR (j)c that allows the IEP team to determine a student eligible for special education services under the diagnosis of LD even if a discrepancy between achievement and cognition is not found through formal testing. A recent SEHO case involving an African American student referred for LD upheld a cognitive assessment based solely on review of record, interview, and observation (Student v. Los Angeles Unified School District, 2002).

Additional models for determining eligibility for special education are being piloted by nine California districts. While a review of those studies is beyond the scope of this article, some of the studies promote the traditional discrepancy model with greater refinement in conceptualization and measure- 
ment of intelligence, processing and achievement, and others are more curriculum-based and emphasize intervention responsiveness and progress monitoring. Hopefully, each model will be evaluated on the basis of curbing over- and under-representation of minority youth in special education, as well as demonstrating positive educational outcomes for all students.

\section{School Psychologists' Practices}

Currently, many school psychologists have adapted to the CDE ban and their own district's policies on intelligence testing by administering "alternative assessments." There is considerable variation in what psychologists consider alternative assessment. Some school psychologists avoid any test that refers to general intelligence in the manual or title (Lopez, 2001). Others will not report a general IQ or composite score, relying exclusively on less reliable subtest scores. Totten (2000) advised that best practice in alternative assessment of African Americans is to avoid intelligence testing altogether. Totten wrote "No standardized cognitive assessment instrument should ever [emphasis original] be given to this type of referred student"(p. 4). Lopez (2001) reported that some interpret the current CDE policy to prohibit the use of all standardized tests, including tests of achievement, for determining the eligibility of an African American student.

School psychologists may spend considerable time attempting to discern which standardized test of cognition or processing abilities remains legally sanctioned, yet the criteria used for selecting an acceptable test is unclear and often based on mythology rather than research or case law. For example, a school psychologist was reported to have declined an African American mother's request for traditional intellectual assessment of her child based on the rationale that, "the courts stated that public institutions can not administer an IQ test to an African American student due to the norms being inadequate for African Americans as decided by the Larry P. case" (M. S. Flores, personal communication, March 4, 2002). This quote highlights both the legal and psychometric confusion held by some psychologists. Current case law does not prohibit intellectual assessments of African American students for the purpose of determining special education eligibility (unless the student is being placed in an EMR program) and, as will be discussed next, intellectual assessments are not technically biased against African American students.

\section{TEST BIAS AND OTHER MEASUREMENT ISSUES}

The rationale for prohibiting intelligence testing of African American students is commonly based on test bias. Test bias is assumed to exist because African American students' average performance on standardized tests of intelligence is lower than that of European American students' average performance (Brown et al., 1999; Jensen, 1980). Although this mean difference is often attributed to test bias, empirical research consistently indicates that standardized cognitive tests are not biased against native-born, English-speaking ethnic/racial subgroups (Brown et al., 1999). Those who erroneously admonish intelligence tests on the basis of racial bias typically offer one or more of the following criticisms: (a) inadequate representation of African American children in the standardization sample; (b) bias in content, predictive and/or construct validity; and (c) situational bias in administering intelligence tests. Although these positions are intuitively compelling they have not been supported empirically.

\section{Representation in the Standardization Group}

Since intelligence tests are largely developed and standardized on European American middle class children, it is sensible to posit that intelligence tests may be culturally biased against African 
American children. Yet most published, standardized tests of intelligence that have withstood public scrutiny are based on a carefully selected standardization group that represents the nation. Any test that fails to offer a standardization sample proportionate to recent census data should be viewed as suspect. When using a quality test, African Americans will be represented in the norms used to calculate an individual's derived scores in the same proportions to which they populate the United States. Furthermore, a study conducted by Fan, Willson, and Kapes (1996) that systematically manipulated the representation of four ethnic groups in the test development sample found no evidence to support systematic bias against those with small or no representation in the test construction sample. Conversely, ethnic groups with larger representation in the test construction sample had no systematic advantage in test performance compared to those who are more sparsely represented (Fan et al., 1996).

\section{Test Validity}

The criticisms regarding the validity of intelligence tests are directed specifically at the content, predictive, and construct validity of such tests. Content bias exists when items or subscales are relatively more difficult for members of one group than another when general ability levels are held constant. Subjective judgments by "experts" who identify specific items as biased have failed to provide compelling evidence of item bias (Brown et al., 1999). Empirical studies of item difficulty have found little evidence of bias (Jensen, 1980). For example, Ross-Reynolds and Reschly (1983) found very little or no evidence of item bias, in terms of internal consistency estimates, rank order of item difficulty, outlier analyses and point biserial correlations, among the performance of European American, African American and Hispanic students on six subtests of the WISC-R.

With respect to predictive validity, a test is said to be a biased predictor if its scores are poorer predictors of performance on a criterion (e.g., educational setting or job performance) for some groups than for others. A statistically significant difference between groups in the slope, intercept, or standard error of estimates of the separate regression lines for those groups suggests bias in predictive validity (Jensen, 1980). When comparing European Americans with African Americans, different regression intercepts do emerge, however, regression slopes are comparable (Jensen, 1980). These results indicate that although mean differences exist between European Americans and African Americans, intelligence tests predict equally well for each group. The majority of research on predictive validity has not found intelligence tests to yield differential predictive validity for European Americans and African Americans (Brown et al., 1999; Reynolds, Lowe, \& Saenz, 1999).

Although criticism regarding the construct validity of intelligence tests has been raised with respect to their use with African Americans, empirical studies of the construct validity of intelligence tests provides consistent results for both European Americans and African Americans. For example, Kush et al. (2001) conducted exploratory and confirmatory factor analyses on WISC-III results gathered from European American and African American students included in the standardization sample and African American students referred for psychological evaluations in order to investigate the validity of using this instrument with African American students. The authors found substantial factorial similarity between the three groups of students, which supports the construct validity of the WISC-III. Kush et al. concluded that the WISC-III Verbal and Performance indices are "relatively robust indicators of intelligence for both White and Black children" (p. 80). A multi-sample confirmatory factor analysis study by Keith et al. (1995) failed to find evidence of construct bias in the K-ABC for a sample of European American and African American test takers. In short, researchers have not found consistent evidence of bias in construct validity of intelligence tests (Brown et al., 1999; Reynolds et al., 1999). 


\section{Situational Bias}

Another important criticism levied against the use of intelligence tests with minority students addresses situational bias. Situational bias includes contextual factors such as student motivation, examiner/examinee interaction effects, and antagonistic test session behaviors and thus, is not a psychometric property of the test per se. Though there have been few studies of situational bias in the school psychology literature (Brown et al., 1999), several studies have reported that the performance of ethnic minority students is unaffected by situational test-session behaviors or interactions between the examiner and examinee (Frisby, 1999; Mishra, 1982). In a recent study looking at the relation between culture and student test behavior, examiners rated African Americans test takers higher on test session behaviors (e.g., follows directions, shows interest in test activities) than would be expected based on their test scores (Frisby, 1999). These results are in direct opposition to the theory that situational bias is present and responsible for diminished test performance among African Americans.

\section{Score-Based Inferences}

Research on the psychometric qualities of a test, such as validity, is based on and applies to groups of students not individuals. Studies such as those cited above provide evidence that cognitive tests do not produce biased results. However, an important and often overlooked subtlety of measurement stipulates that a test in isolation is neither valid nor invalid; validity is not a characteristic that is inherent to one test or another. Rather, a score based inference about a student's performance on a test is either valid or invalid (Popham, 1995). As Messick (1989) wrote “... what is to be validated is not the test or observation device as such but the inferences derived from the test scores" (p. 13). This is an important distinction to make in discussing intelligence testing of African American students because it rephrases the question from "Are intelligence tests valid for African Americans?" to "Did the student's performance on this intelligence test produce scores that accurately reflect this African American student's intelligence?" In order to answer this question, school psychologists must scrutinize the test's manual and render a clinical judgment based on the psychometric attributes of the test (including validity estimates), the testing conditions, the child's apparent effort, and the individual child's unique life experiences.

\section{Consequential Validity}

Consequential validity is also not a psychometric property of a test or a group of tests per se. Rather consequential validity refers to the social consequences of test results. Though traditional standardized intelligence tests are not technically biased against African American students, their central role in special education identification may contribute to over- or even under-identification of African American students in special education programs. Messick (1994) wrote:

...it is not sufficient to provide evidence that the assessments are measuring the intended constructs. Evidence is also needed that the uses and interpretations are contributing to enhanced student achievement and, at the same time, not producing unintended negative outcomes. (p. 8)

Thus, the end results of an assessment in terms of the educational outcomes the student achieves are more important than which assessment tool is selected. This is especially important when considering the social consequences of over-identifying minority students as disabled.

African Americans on average score below European Americans on standardized tests of cognition (Brown et al., 1999) and African Americans as a group are over-represented in special education programs (U.S. Department of Education, 2002). While it is tempting to blame cognitive tests for these 
outcomes, this assumption is spurious when one considers that lower cognitive scores actually $d e$ crease the likelihood of meeting the criteria for $\mathrm{LD}$, the most prevalent disability. Sternberg and Grigorenko (2002) observed that students with poor reading skills from a low-socioeconomic African American community were disadvantaged because their lower IQ scores made it difficult for them to qualify for special education services under the IQ/achievement discrepancy criteria for LD. Accordingly, relatively lower IQ scores can not account for disproportionate representation of African Americans in any special education category, save MR. Hosp and Reschly (2003) determined that academic achievement along with demographic and economic variables predicted overrepresentation of African American student in ED, LD, and MR. Factors such as achievement and economic conditions that impact African American representation within each of the various special education categories and the outcomes of the programs that serve these students must be considered in order to understand the consequences of the current system of qualifying African American students for special education. As Cleary (1980) suggested "The problem is the special education classes. There would be no controversy about testing if kids blossomed when they were put into special education classes” (p. 7).

\section{Current Status of Over-Representation in California Special Education Programs}

Special education enrollment by ethnicity and disability suggests that replacing cognitive tests with alternate assessment methods has not resolved the problem of over-identification of African American students for special education programs. In California, 12\% of African American students

Table 1.

California and National Percentages of Children Served in Three Special Education Categories by Race/Ethnicity

\begin{tabular}{|c|c|c|c|c|c|c|}
\hline \multirow[t]{2}{*}{ Ethnicity } & \multicolumn{2}{|c|}{ Learning Disabilities } & \multicolumn{2}{|c|}{ Mental Retardation } & \multicolumn{2}{|c|}{ Emotional Disturbance } \\
\hline & $\begin{array}{c}\text { California } \\
(\%)\end{array}$ & $\begin{array}{c}\text { National } \\
(\%)\end{array}$ & $\begin{array}{c}\text { California } \\
(\%)\end{array}$ & $\begin{array}{c}\text { National } \\
(\%)\end{array}$ & $\begin{array}{l}\text { California } \\
(\%)\end{array}$ & $\begin{array}{c}\text { National } \\
(\%)\end{array}$ \\
\hline $\begin{array}{l}\text { American Indian/ } \\
\text { Alaskan Native }\end{array}$ & 6.37 & 6.15 & 0.55 & 0.98 & 0.44 & 0.82 \\
\hline $\begin{array}{l}\text { Asian/Pacific } \\
\text { Islander }\end{array}$ & 1.43 & 1.68 & 0.33 & 0.40 & 0.06 & 0.21 \\
\hline Black & 7.88 & 4.92 & 0.69 & 2.06 & 0.87 & 1.17 \\
\hline Hispanic & 4.48 & 4.14 & 0.46 & 0.51 & 0.13 & 0.32 \\
\hline White & 3.96 & 3.94 & 0.38 & 0.75 & 0.37 & 0.65 \\
\hline Total & 4.21 & 4.36 & 0.43 & 0.93 & 0.27 & 0.72 \\
\hline
\end{tabular}

Note. Based on the 2000 census population and children ages 6-12 served under IDEA during the 2000-2001 school year as reported in the $24^{\text {th }}$ Annual Report to Congress on the Implementation of the Individuals with Disabilities Act (U.S. Department of Education, 2002). 
are identified as disabled, whereas only $7.4 \%$ of European American students and 3.5\% of Asian American students are classified as disabled (U.S. Department of Education, 2002). Data reported in the $24^{\text {th }}$ Annual Report to Congress on the Implementation of the Individuals with Disabilities Act (see Table 1) indicate African American students are almost twice as likely as European American students to be identified as having a LD, MR or ED in California. Compared to national statistics, however, Californians appear to have had some success in reducing over-representation in the MR disability category. Two percent of African Americans nation-wide are identified as meeting the criteria for MR, as compared to less than one percent in California. However, African Americans are identified for LD in California at nearly twice the rate of African Americans nationwide.

African American students in California are more than twice as likely as European American students and six times as likely as Hispanic students to be identified for the category of ED (U.S. Department of Education, 2002). A comparison between the enrollment rates of African American students in EMR programs just prior to Larry P. to current identification rates for LD and ED among African American students suggests the problem of over-representation has not been rectified; rather over identification has simply shifted disability categories (i.e., from MR to ED or LD). In 1969, less than $10 \%$ of the school population was African American, yet $25 \%$ of EMR students were African American (Elliott, 1987). In 2002, African American students constituted less than $9 \%$ of the public school population (California Department of Education, 2002a), while 23\% of students identified as ED were African American (California Department of Education, 2002b). The over-representation of African American students in ED is alarming considering that nationwide students with ED are disproportionately served in restrictive settings such as separate public facilities and have the highest dropout rate $(51 \%)$ compared to students served under other disability categories (U.S. Department of Education, 2002).

\section{CRITICAL QUESTIONS}

The outcomes of Larry $P$. raise the following three critical questions related to future policy making, educational processes, and school psychologists' role in curbing overrepresentation in special education.

1. What lessons have been learned in the 25 years since Larry P. v. Riles that can be applied to future policies? The Larry $P$. case raised very important issues about how competence and intelligence is defined and increased school psychologists' and other IEP team members' attention to issues of racial inequality. However, public policy applied to one race and not another, such as banning intelligence testing of African American students, suggests that members of that race unilaterally share one or more characteristics that are absent among members of other races. This reasoning fails to recognize the incredible diversity within a racial group and minimizes the experiences and characteristics that are shared across groups. Helms (1997) warned "selection according to group membership must not be misconstrued as constituting measurement of cultural criteria because a person's group designation may not reveal the person's cultural, social class, or racial socialization" (p. 529). Public policy applied to a single race raises difficult questions about who (the individual or the state) determines and how ("one-drop" rule, physical features, last name, etc.) to determine racial membership. The current CDE policy raises questions such as "Are intelligence tests not to be used with a student who is $1 \%$ African American and 99\% European American?" or "Are intelligence tests prohibited for an African American student who is being raised by a European American family?" Considering that one in four Californian children are of mixed-race (Lopez, 2003) and other race-based policies in the history of America include Jim Crow laws and Japanese internment, the CDE ban on testing African American students is neither socially nor historically justified and constitutes a misstep that should not be re- 
peated in future policymaking. Rather, future state and district policies should target underperforming students of all races and should stress evidence-based solutions rather than myopic solutions such as prohibiting a type of test.

2. If current alternative assessment practices for identifying African American students eligible to receive special education services are psychometrically flawed, not lawfully required by the state department, and have failed to decrease overrepresentation of African Americans in special education in California, what component of the educational process should be altered to redress disproportional representation in special education? Although attention has focused primarily on assessment tools and methodology as the step in the sequence responsible for overrepresentation in special education, understanding who is assessed and ultimately classified is a much larger socio-political issue. Contrary to State Department of Education conclusions, disproportionate referral and placement in special education may be a result of poor quality schools serving minority populations and a wait-to-fail model of special education. Changes to the education system that address these areas may have a larger effect on decreasing overrepresentation than finding the correct tools to document aptitude-achievement discrepancies in struggling African American learners in need of remedial instruction.

To determine why African American children are overrepresented in special education it is necessary to understand the factors that may have led to African American children being disproportionately referred for special education services. Although bias in teacher referrals has been identified as a possible factor, convergent research is not available to strongly advocate this position. A recent metaanalysis conducted by Hosp and Reschly (2002) concluded that students referred for special education eligibility, regardless of race or ethnicity, had low achievement or a combination of low achievement and behavior problems. Indeed, no African American students were referred who did not have low achievement. The incidence of disparate achievement among minority populations across grade levels is well documented (U.S. Department of Education, 2001). Research has strongly concluded that general education programs fail to provide quality instruction delivered by skilled and experienced teachers in schools that predominately serve minority and disadvantaged children (Betts, Rueben, \& Dannenberg, 2000; Lee \& Loeb, 1995; U.S. Department of Education 2001). The National Research Council (1999) documented inequities in school resources by race and income that directly relate to student achievement (e.g., class-size reduction and qualified staff). For example, Strickland (2001) reported that African American students are twice as likely to be assigned to teachers with less experience and expertise. In turn, African American children are more likely to need additional instruction and remediation and thus, are more likely to be referred for special education eligibility (Hosp \& Reschly, 2002). These inadequacies in the public school system directly impact minority student achievement and may explain why African American students are referred and placed in special education programs disproportionately. While the CDE policy misguidedly focuses on prohibiting specific assessment tools to decrease overrepresentation, poor quality general education programs have been overlooked as a critical link in the chain of disproportionate minority placement in special education.

With the reauthorization IDEA, general educators will be expected to take greater responsibility for ensuring the provision of quality academic interventions at the earliest signs of academic difficulty. Thus, a child would not have to first fail in order to receive assistance. Researchers have concluded that the effectiveness of early intervention is considerably greater than the effectiveness of later, postfailure intervention (Juel, 1988; McGill-Franzen \& Goatley, 2001 ). This change could reduce inappropriately identifying students as disabled when in fact their underachievement is the result of poor instruction. Since African American students are disproportionately exposed to poor instruction, requiring quality general education interventions may decrease overrepresentation of African American students in special education programs, particularly if those interventions are evidence-based and data- 
driven. Marston, Muyskens, Lau, and Canter (2003) have, in fact, found a decrease in over-representation of African American students referred, assessed and found eligible for special education with the implementation of a problem-solving model that focused on data-based pre-referral interventions.

3. What are the implications of Larry $P$. in the $21^{\text {st }}$ century for school psychologists? School psychologists may have persisted in using processing tests and other standardized, norm-referenced tests for determining eligibility because it is simpler to replace one test with another than to learn an entirely new method of assessment. Yet, as a professional group, psychologists have demonstrated great agility in their collective ability to make major adjustments to their assessment practices. For example, significant professional development occurred among psychologists in response to IDEA '97 and California education law and regulations (i.e., the Hughes Bill) requiring functional assessments of student behaviors. This suggests that psychologists will likely commit to significant re-training if the proper support and legal mandates were in place. Thus, an entirely new approach to determining special education eligibility, one based on interventions rather than tests, is a tenable option for improving the practices of California school psychologists and reducing overrepresentation of African American students in special education. The reauthorization of IDEA will likely include a resistance to intervention (RTI) criteria for classifying students as LD. This is a promising beginning, yet overrepresentation of African American students is more problematic in ED than LD. California has very thorough requirements for conducting functional analysis assessments for students with disabilities who exhibit behavioral difficulties (5CCR 3052[b][1]); adopting similar standards in determining eligibility for ED, such an identifying the conditions that maintain maladaptive behaviors, conducting an ecological assessment, and systematic observance of the target behavior(s) may reduce disproportional representation within the ED classification. A cogent agenda from the CDE and professional organizations that prioritizes assessments linked to intervention, progress monitoring, program evaluation, and community-home-school partnerships would not only serve to expand the role of many school psychologists so that their skills may be better utilized, it would better fulfill the promise of Larry P. v. Riles.

\section{CONCLUSION}

The Larry P. Task Force (1989), which was established to guide CDE policy, sought to address four identified needs in public education (a) the amelioration of overrepresentation of African American students in special education, (b) the identification of nondiscriminatory alternative assessment processes, (c) equity and access by all pupils to quality instruction and a relevant core curriculum, and (c) continual cultural awareness and sensitivity within the entire education community. The Task Force concluded that solutions reside in more culturally relevant curricula, greater collaboration between general and special education, and problem solving teams - suggestions that are just as pertinent today. Unfortunately, more attention seems to have been paid to which tests the Task Force prohibited than to the complex issues about educational equity they raised. It is time to move beyond Larry $P$. and the controversy over IQ testing and refocus those efforts on identifying practices that improve the educational outcomes of all students.

\section{REFERENCES}

Betts, J. R., Rueben, K. S., \& Dannenberg, A. (2000, February). Equal resources, equal outcomes? The distribution of school resources and student achievement in California. Public Policy Institute of California. Retrieved December 10, 2003, from http://www.ppic.org/main/publication.asp?i=64. 
Brown, R. T., Reynolds, C. R., \& Whitaker, J. S. (1999). Bias in mental testing since "Bias in mental testing." School Psychology Review, 14(1), 208-230.

California Department of Education. (2002a). Statewide enrollment in California public schools by ethnic group, 2000-01. Retrieved April 1, 2002, from http://www.cde.ca.gov/dataquest/

California Department of Education, Special Education Division. (2002b) Special education enrollment by ethnicity and disability statewide report. Retrieved April 1, 2002, from http://www.cde.ca.gov/dataquest/

Cleary, A. (1980, November). APA Monitor, 11 (1), 7.

Elliott, R. (1987). Litigating intelligence: IQ tests, special education, and social science in the courtroom. Dover, MA: Auburn House.

Fan, X., Willson, V. L., \& Kapes, J. T. (1996). Ethnic group representation in test construction samples and test bias: The standardization fallacy revisited. Educational and Psychological Measurement, 65(3), 365-381.

Frisby, C. L. (1999). Culture and test session behavior: Part I. School Psychology Quarterly, 14, 263-280.

Helms, J. E. (1997). The triple quandary of race, culture, and social class in standardized cognitive ability testing. In D. P. Flanagan, J. L. Genshaft, \& P. L. Harrison (Eds.), Contemporary intellectual assessments: Theories, tests and issues (pp. 517-532). New York: Guilford.

Henry, B. (1992). Letter to special education administrators concerning: Reaction to the legal advisory issued by the CDE in the Larry P. v. Riles and Crawford v. Honig decision. Sacramento, CA: California Association of School Psychologists.

Hernstein, R. J., \& Murray, C. (1994) The bell curve: Intelligence and class structure in American life. New York: Free Press.

Hosp, J. L., \& Reschly, D. J. (2002). Predictors of restrictiveness of placement for African-American and Caucasian students. Exceptional Children, 68, 225-238.

Hosp, J. L., \& Reschly, D. J. (2003). Disproportionate representation of minority students in special education: Academic, demographic, and economic predictors. Exceptional Children, 70, 185-200.

Individuals with Disabilities Education Act Amendments of 1997(PL 105-17). 20 USC,§ 12453-12459.

Jensen, A. R. (1980). Bias in mental testing. New York: Free Press.

Juel, C. (1988). Learning to read and write: A longitudinal study of 54 children from first through fourth grades. Journal of Educational Psychology, 80, 437-447.

Keith, T. Z., Fugate, M. H., DeGraff, M., Diamond, C. M., Shadrach, E. A., \& Stevens, M. L. (1995). Using multisample confirmatory factor analysis to test for construct bias: An example using the K-ABC. Journal of Psychoeducational Assessment, 13, 347-364.

Kush, J. C., Watkins, M. W., Ward, T. J., Ward, S. B., Canivez, G. L., \& Worrell, F. C. (2001). Construct validity of the WISC-III for White and Black students from the WISC-III standardization sample and for Black students referred for psychological evaluation. School Psychology Review, 30(1), 70-88.

Larry P. Task Force. (1989). The Larry P. Task Force report: Policy and alternative assessment guideline recommendations. Sacramento, CA: California Department of Education.

Lee, V., \& Loeb, S. (1995). Where do Head Start attendees end up? One reason why preschool effects fade out. Educational Evaluation and Policy Analysis, 17, 62-82.

Long Beach Unified School District. (2002). School psychology handbook. Author.

Lopez, A. M. (2003). Mixed-race school-age children: A summary of census 2000 data. Educational Researcher, 32(6), 25-37.

Lopez, R. (Winter, 2001). Response to frequently asked questions, CASP Today, 13-14.

Marston, D., Muyskens, P., Lau, M., \& Canter, A. (2003). Problem-solving model for decision making with highincidence disabilities: The Minneapolis experience. Learning Disabilities Research and Practice, 18(3), 187200.

McGill-Franzen, A., \& Goatley, V. (2001). Title I and Special Education: Support for children who struggle to learn to read. In S. B. Neuman \& D. D. Dickinson (Eds.), Handbook of early literacy research (pp. 471-483). New York: Guilford.

Messick, S. (1989). Validity. In R. L. Linn (Ed.), Educational measurement (3rd ed., pp.13-33). New York: Macmillan.

Messick, S. (1994). The interplay of evidence and consequences in the validation of performance assessments. Educational Researcher, 23(2), 8-23.

Mishra, S. P. (1982). The WISC-R and evidence of item bias for Native-American Navajos. Psychology in the Schools, 19, 458-464.

National Research Council Committee on Education Finance. (1999). Making money matter: Financing America's schools. H. F. Ladd \& J. S. Hansen (Eds.). Washington, DC: National Academy Press.

National Research Council Committee on Minority Representation in Special Education. (2002). Minority students in special education, M. S. Donovan \& C. T. Cross (Eds.). Washington, DC: National Academy of Sciences. 
Popham, W. J. (1995). Classroom assessment: What teachers need to know. Boston: Allyn \& Bacon.

Reschly, D. J. (April, 1997). Disproportionate minority participation in general and special education programs: Patterns, analyses, and solutions. Paper presented at the meeting of the National Association of School Psychologist, Atlanta, GA.

Ross-Reynolds, J., \& Reschly, D. J. (1983). An investigation of item bias on the WISC-R with four sociocultural groups. Journal of Consulting and Clinical Psychology, 51(1), 147-148.

Reynolds, C. R., Lowe, P. A., \& Saenz, A. L. (1999). The problem of bias in psychological assessment. In C. R. Reynolds \& T. B. Gutkin (Eds.), The handbook of school psychology (3rd., pp. 549-595). New York: Wiley.

Sandoval, L. (August 20, 1997). Letter to California special education directors concerning clarification and the use of intelligence tests with African American students for special education assessment. Sacramento, CA: California Department of Education.

Sternberg, R. J., \& Grigorenko, E. L. (2002). Difference scores in the identification of children with learning disabilities: It's time to use a different method. Journal of School Psychology, 4O(1), 65-83.

Strickland, D. S. (2001). Early intervention for African American children considered to be at risk. In S. B. Neuman \& D. D. Dickinson (Eds.), Handbook of early literacy research (pp. 322-332). New York: Guilford.

Student v. Compton Unified School District, No. SN99-01478 (CA SEHO, 2002).

Student v. Culver City Unified School District, No.1262 (CA SEHO, 1995)

Student v. Elk Grove Unified School District, No. 729 (CA SEHO, 2003).

Student v. Lemon Grove Elementary School District, No. 1107 (CA SEHO, 1998).

Student v. Los Angeles Unified School District, No. 1056 (CA SEHO, 2002).

Student v. Manteca Unified School District, No. 2051. (CA SEHO, 2001).

Student v. Ravenswood Elementary School District and Sequoia Union High School District, No. 988. (CA SEHO, 1997).

Student v. South Pasadena Unified School District, No. 371 (CA SEHO, 2003).

Student v. Temecula Valley Unified School District, No. 2415 (CA SEHO, 2001).

Totton, C. (2000). Best practices in psycho-educational assessment for school psychologists: A guide to test selection. Burbank, CA: Author.

U.S. Department of Education. (2002). Twenty-fourth annual report to congress on the implementation of the Individuals with Disabilities Act. Retrieved October 30, 2003, from http://www.ed.gov/about/reports/annual/ osep/2002/index.html

U.S. Department of Education, National Center for Educational Statistics. (2001, March). NAEP 2000 reading assessments. [Online]. Available: http://nces.ed.gov

Zolotar, B. (1992). Letter to special education administrators concerning “Analysis of Judge Peckham's August 31, 1992 Decision in Larry P. v. Riles and Crawford v. Honig." Sacramento, CA: California Department of Education. 


\section{The California School Psychologist Guidelines for Authors}

Current abstracts and previous volumes are available on-line: www.education.ucsb.edu/school-psychology

The California School Psychologist is a refereed journal published annually by the California Association of School Psychologists (CASP). The California School Psychologist is devoted to contemporary issues in school psychology. The goal of the journal is to gather high quality articles concerning research, assessment, consultation, collaboration, training, service delivery, and other relevant topics that have implications for the profession of school psychology. It is also the intent of the journal to highlight the diversity of the profession and of the students, parents, and communities served by school psychologists in California.

Selection of articles to be published is determined on the basis of blind peer review. Reviewers examine the importance of the topics addressed, accuracy and validity of the contents, contribution to the profession, implications for the practice of school psychology in California, originality, and quality of writing. Professionals across the country are encouraged to submit manuscripts.

Contents of The California School Psychologist are available on international electronic literature databases, including ERIC, developed by the US Department of Education, and PsycINFO, developed by the American Psychological Association. Thus, it is essential to include up to five keywords following the abstract of each manuscript. In preparing your manuscript, please consider the review elements described above. In addition, authors must attend to the specific guidelines of the American Psychological Association Publication Manual, including the abstract, headings, citations, tables, and references. Manuscripts that are not prepared according to the APA format will be returned to the authors for revision prior to distribution to reviewers.

Manuscripts should be between 15-20 pages in length (including references and tables). The entire manuscript must be double spaced with at least 1-inch margins. Authors must include a cover letter stating the title of the manuscript submitted, and provide a mailing address, phone number, and e-mail for further correspondence. The cover letter must also specify that the manuscript has not been previously published and is not currently being considered for publication elsewhere.

\section{Submissions should be mailed electronically to: Jimerson@education.ucsb.edu \\ Shane R. Jimerson, Ph.D. - Editor, The California School Psychologist \\ University of California, Santa Barbara - Gevirtz Graduate School of Education \\ Center for School-Based Youth Development - Santa Barbara, California 93106}

\section{The Center for School-Based Youth Development}

The Center for School-Based Youth Development at the University of California, Santa Barbara is the sponsor of the special topic section of The California School Psychologist on "Strength-Based Assessment, Youth Development, and School Success." Resources for this effort were made possible through a Gevirtz Graduate School of Education - Funds for Excellence Grant from Don and Marilyn Gevirtz. The Center addresses contemporary challenges for educating youth such as school violence, school discipline, substance abuse, child abuse, and learning disabilities. The Center assists students, schools, and educators through applied research, consultation services, training of professionals, and disseminating scholarly publications. UCSB scholars collaborate with local schools, community-based agencies, and scholars and professionals across the state of California and the nation. It is the mission of the UCSB Center for School-Based Youth Development to enhance school engagement for all students through strength-based assessment and targeted interventions designed to promote social and cognitive competence. This mission will be facilitated through research and development and by increasing the cadre of educators who are knowledgeable about and support a comprehensive and coordinated approach to student support services. For additional information about the Center, you may visit its website at www.education.ucsb.edu/school-psychology. 


\section{The California School Psychologist 2004 Volume 9}

Shane R. Jimerson

Jill D. Sharkey

Vanessa Nyborg

Michael J. Furlong

Jacquelyn A. Buckley

Michael H. Epstein

\section{Carien Lubbe}

Irma Eloff

Amanda B. Nickerson

Amy M. Brosof

Valerie B. Shapiro

Paul A. LeBuffe

Valerie B. Shapiro

Oanh K. Tran

Michael J. Furlong

Margaret Libby

Maureen Sedonaen

Jim Kooler

\section{Joel H. Brown}

Shane R. Jimerson

Jill D. Sharkey

Michael J. Furlong

Kathryn M. O'Brien

Merith Cosden

Frances Panteleakos

Lisa Gutierrez

Sivan Barazan

Elisa Gottheil

\section{E. Scott Huebner}

Rich Gilman

Aimee P. Miltich

Mary Helen Hunt

Joel Meyers

\section{Kristin M. Powers}

Kristi S. Hagans-Murillo

Alberto F. Restori

: CASP

$1400 \mathrm{~K}$ Street

Suite 311

Sacramento

California 95814

916.444 .1595 tel

916.444.1597 fax

www.casponline.org
Strength-Based Assessment and School Psychology:

A Summary and Synthesis

The Behavioral and Emotional Rating Scale -2 (BERS-2):

Providing a Comprehensive Approach to Strength-Based Assessment

Asset-Based Assessment in Educational Psychology:

Capturing Perceptions During a Paradigm Shift

Predicting Positive Outcomes for Students With Emotional Disturbance

Lending "Strength" to the Assessment of Preschool Social-Emotional Health

Personal Strengths and Assets Among Adolescents:

A Comparison of Smokers and Nonsmokers

From Deficits to Development:

A Case Study of the Journey of Friday Night Live

Resilience: From Program to Process

Using the Santa Barbara Assets and Risks Assessment

to Examine the Ecology

Strength-Based Assessment of Adolescents Who Abuse Drugs:

Implications for Helping High-Risk Youth

Perceived Quality of Life: A Neglected Component of Assessments and Intervention Plans for Students in School Settings

Dropout and Violence Needs Assessment: A Follow-up Study

Twenty-five Years after Larry P.: The California Response to Overrepresentation of African Americans in Special Education 